Universidade de Brasília

Instituto de Biologia

Departamento de Botânica

Programa de Pós-Graduação em Botânica

CHESTERTON ULYSSES ORLANDO EUGÊNIO

INFLUÊNCIA DO TEMPO, ESPAÇO, FOGO E FERTILIZAÇÃO NA COMUNIDADE HERBÁCEO-ARBUSTIVA NO CERRADO 


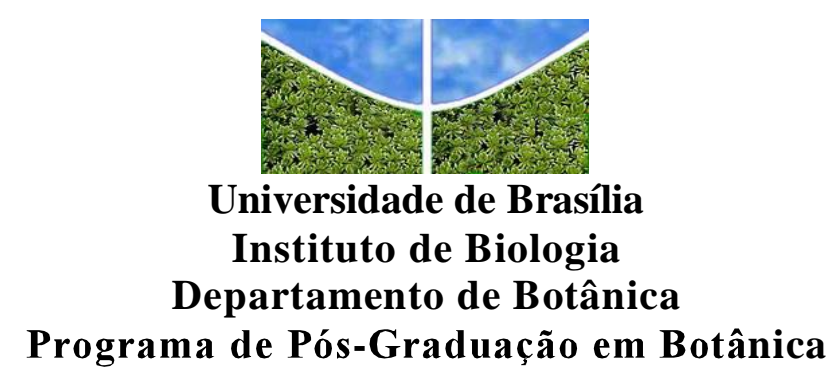

CHESTERTON ULYSSES ORLANDO EUGÊNIO

\section{INFLUÊNCIA DO TEMPO, ESPAÇO, FOGO E FERTILIZAÇÃO NA COMUNIDADE HERBÁCEO-ARBUSTIVA NO CERRADO}

Tese apresentada ao Programa de PósGraduação em Botânica do Instituto de Ciências Biológicas da Universidade de Brasília, como parte dos requisitos necessários à obtenção do título de Doutor em Botânica.

Aluno: Chesterton Ulysses Orlando Eugênio Orientador: Dr. Augusto César Franco 
Influência do tempo, espaço, fogo e fertilização na comunidade herbáceo-arbustiva no Cerrado

\section{Chesterton Ulysses Orlando Eugênio}

Esta Tese foi julgada adequada para obtenção do Título de Doutor e aprovada em sua forma final pelo Programa de Pós-graduação em Botânica do Instituto de Ciências Biológicas da Universidade de Brasília

Banca Examinadora:

Dr. Augusto Cesar Franco

Orientador e Presidente da Banca Examinadora

Dra. Heloisa Sinatora Miranda

Membro da Banca Examinadora

Dr. Lúcio Flávio de Alencar Figueiredo

Membro da Banca Examinadora

Dr. José Roberto Rodrigues Pinto

Membro da Banca Examinadora

Dr. Marcelo Fragomeni Simon

Membro da Banca Examinadora

Dr. Eduardo Rogério Moribe Barbosa

Membro da Banca Examinadora 
À minha nova família, a qual venho cultivando... 


\section{Agradecimentos}

A Deus, por sempre me acompanhar em minhas vitórias.

À Ani Cátia Giotto, meu anjo, que me acompanha nesses últimos anos. Esta tese é uma conquista em conjunto. Obrigado por ter fé em mim.

À minha mãe, Úrsula, e ao meu pai, Ornelino, que me mostram que as coisas aparentemente simples - como família, educação e respeito ao próximo - são a base para grandes conquistas.

Assim como aos meus irmãos, Ornelino e Uilon, que me acompanham e ajudam nas nossas conquistas.

À Cássia Beatriz Rodrigues Munhoz, que me acompanhou em mais esta etapa da minha vida. A eterna gratidão de um aluno de graduação que, apesar de conquistar titulações, sempre terá você como orientadora e ainda espera aprender com você.

Ao Augusto César Franco, pelas orientações, conversas e conselhos durantes esses anos de doutorado, sempre me mostrando a melhor forma de fazer ciência.

A todos os amigos, colegas de campo e de curso que me ajudaram nas coletas de dados e contribuíram nos aprendizados acadêmicos, de modo especial: Thiago, Tassiana, Frederico, Priscila, Raphael, Aldení, Meghan, Menic, Reynaldo, Isadora, Klécia, André, Eric, Izabelly, Willian, Isa, Reneida, Paulo Henrique, Andrea, Vitória, Maura, Anne Priscila, Evandro e André.

Aos professores Heloisa S. Miranda, Lúcio Flávio A. Figueiredo, José Roberto R. Pinto, Marcelo F. Simon e Eduardo R. M. Barbosa, por participarem da banca examinadora e por suas contribuições e considerações a este trabalho.

À Universidade de Brasília, em especial aos professores e funcionários dos Departamentos de Botânica, Ecologia, Geociência e Engenharia Florestal, pelo apoio técnico e pelas informações que ajudaram na construção deste aprendizado. 
À Universidade Católica de Brasília, em especial aos professores e funcionários dos Cursos de Ciências Biológicas, Engenharia Ambiental e Gestão Ambiental, pelo apoio técnico, estrutura física e pelas trocas de experiências que tive como aluno de graduação e, agora, como professor da instituição.

Aos funcionários do Herbário da UnB, da Reserva Ecológica do IBGE, do Jardim Botânico e da Embrapa, em especial à Marina Fonseca, Cássia Munhoz, Carolyn Proença, Regina Oliveira e Christopher Fagg, pelo grande apoio na identificação botânica.

Às Unidades de Conservação, Parque Nacional de Brasília, Floresta Nacional de Brasília, Jardim Botânico de Brasília, Reserva Ecológica do IBGE e Estação Ecológica Águas Emendadas, pelas autorizações para realização da pesquisa nas Unidades de Conservação.

Ao Laboratório de Genética Vegetal da Embrapa, em especial ao Professor Doutor Dario Grattapaglia.

Ao Conselho Nacional de Desenvolvimento Científico e Tecnológico - CNPq (Processo

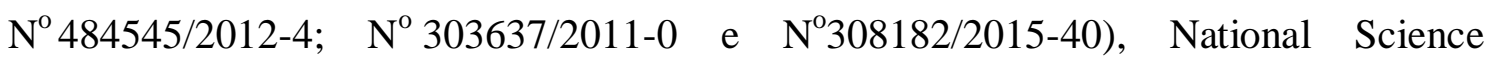
Foundation (DEB-0542912), A. W. MellonFoudatione ao Programa de Pesquisa Ecológica de Longa Duração - PELD (Processo N N $^{\circ} 403845 / 2012-2$ ) pelo apoio financeiro. 


\section{RESUMO GERAL}

O estrato herbáceo-arbustivo representa plantas com diversos hábitos de crescimento que vão desde ervas, gramíneas, subarbustos, lianas a palmeiras, que apresentam diferentes estratégias fenológicas e ciclos de vidas de anual a perenes. Esse estrato muitas vezes é negligenciado em estudos de dinâmica temporal e espacial para o Cerrado devido à carência de taxonomistas em algumas famílias botânicas, o que dificulta a identificação das espécies, e a padronização de métodos de amostragem que consigam mensurar a complexidade morfológica e fenológica desse grupo. Entretanto, nas últimas décadas tem se aumentado os esforços para conhecer melhor a composição florística e a estrutura desse estrato principalmente porque para o Cerrado a importância em nível de número de táxons aumenta de ambientes florestais a ambientes campestres, onde representa mais de $90 \%$ das espécies. Outro ponto importante é que devido à variação nos ciclos de vida e na morfologia o estrato herbáceo-arbustivo responde mais rapidamente a perturbações nos ambientes que o componente arbóreo. O objetivo da tese foi avaliar a dinâmica da comunidade herbáceo-arbustiva ao longo do tempo e do espaço. Além disso, para áreas de Veredas, foi possível observar o efeito da passagem do fogo no processo de recuperação da comunidade vegetal. Enquanto para uma área de ecótono savana-floresta inclui-se o efeito da fertilização. Desta forma, a presente tese é apresentada em três capítulos. No primeiro capítulo, comparou-se a composição e estrutura de quatro Veredas no Distrito Federal antes do incêndio de setembro de 2011; posteriormente, acompanhou-se a recuperação dessas áreas até dois anos após a perturbação. Em intervalo temporal pequeno ( 3 a 4 meses), as comunidades chegaram a reduzir a riqueza de espécies em até $15 \%$ e a cobertura vegetal sobre o solo em $49 \%$. Entretanto, intervalos temporais maiores que um ano após a perturbação foram suficientes para a recobertura do solo e reestabelecer a riqueza de espécies nas Veredas estudadas. As Veredas apresentaram composição florística distintas entre si no primeiro levantamento, demostrando a peculiaridade de cada local independente de pertencer à mesma fitofisionomia. $\mathrm{O}$ aumento da similaridade ocorreu após a perturbação devido ao reestabelecimento das espécies menos sensíveis ao fogo. As variáveis ambientais e o espaço explicaram apenas $26 \%$ da variação das comunidades herbáceo-arbustivas das Veredas estudadas ao longo do tempo e do espaço. No segundo capítulo, acompanhouse, por três anos e cinco meses, a recuperação da composição e estrutura da comunidade 
herbáceo-arbustiva em um ecótono savana-floresta após um incêndio em setembro de 2011, comparando o efeito da fertilização sobre o processo de recobertura do solo e na composição das espécies. A fertilização acelerou o processo de recobertura do solo, porém com a redução de cerca de $50 \%$ da riqueza de espécies. Com intervalo de dois anos e cinco meses da passagem do fogo, a cobertura vegetal acima do solo nas parcelas controle foi retomada por quase completo e os parâmetros de diversidade apresentaramse superiores às parcelas com fertilização. Ao longo do período de estudo, ficou evidente que a composição e a estrutura do estrato herbáceo-arbustivo em fitofisionomia florestal são inferiores ao observado em fitofisionomia savânica, assim como o processo de recuperação apresenta-se mais lento. No último capítulo, buscou-se averiguar se existe diferença entre as curvas espectrais foliares e nas concentrações de carbono, nitrogênio e enxofre nas folhas de espécies comuns em áreas de Vereda, assim como se essas características se mantêm em diferentes localidades do Distrito Federal. Dessa forma, amostrou-se indivíduos de Trembleya parviflora (D.Don) Cogn. e Lavoisiera imbricata (Thunb.) DC., espécies arbustivas que se encontram em expansão em áreas úmidas no Distrito Federal e indivíduos de Paspalum lineare Trin., Andropogon bicornis L. e A. leucostachyus Kunth, espécies de gramíneas comuns e abundantes encontrando-se entre as dez espécies com maior cobertura em áreas úmidas nessa região. As curvas espectrais geradas por cada espécie demonstraram menor variação dentro da espécie do que entre as áreas de amostragem, reforçando que cada espécie poderia ser representada pela sua curva espectral. A diversidade espectral pode servir como subsídio fundamental para compreensão e determinação da diversidade química, abrindo novas portas para o uso de dados hiperespectrais, permitindo futuramente o uso de métodos de modelagens de diversidade e ciclos biogeoquímicos por sensoriamento remoto. De modo geral, as perturbações ambientais, como fogo e fertilização, promovem redução na composição e estrutura da comunidade herbáceo-arbustiva; entretanto, com a supressão do fogo, a comunidade consegue se reestabelecer em curta escala de tempo e as curvas espectrais apresentam potencial para auxiliar para identificação de espécies herbáceo-arbustivas.

Palavras-chave: Vereda, cerrado sensu stricto, Mata de galeria, infravermelho, curva espectral. 


\begin{abstract}
The herbaceo-shrubby layer is composed of species with different growth habits: herbs, graminoids, sub-shrubs, vines and palms, each habit can also have distinct phenological strategies and life cycles (anual or perennial). This layer is neglected in the majority of studies dealing with temporal and spatial dynamics in the Cerrado Biome, as there is a general lack of specialists on some families, what greatly hampers species identification. Also, there is a lack of standard methodological sampling procedures able to measure the phenological and morphological diversity in the group. However, in the last decades there have been a growing interest and effort to attain a better knowledge about this layer's composition and structure, as its richness grows progressively from forests to grasslands (where about $90 \%$ of the species belong to the herbaceo-shrubby layer). Another important point to consider is that, being composed by species with distinct life cycles and morphologies, the herbaceo-shrubby layer has a faster response to environmental perturbation, both in time and space, compared to the tree layer. This thesis aimed to evaluate the herbaceo-shrubby layer's temporal and spatial dynamics. Besides, it was possible to observe the effects of a wildfire in a palm swamp (Vereda) community and the effects of nutrients addition on a forest-savanna ecotone. The thesis is structured in three chapters: In the first one, the structure and composition of four palm swamps (Vereda) located in the Distrito Federal were assessed. These palm swamps were hit by a wildfire on September 2011 and its regeneration were monitored until 2013. Its composition and structure before and after the fire were compared. In a short time interval (from 3 to 4 months), the communities' richness was reduced in $15 \%$ and its plant cover, in $49 \%$. However, a time interval of more than 1 year was sufficient for the community to recover its richness and soil cover levels. Before the wildfire, the palm swamps were floristically distinct, even if beloinging to the same phytophysiognomy, showing the diversity of the herbaceo-shrubby layer. The similarity between the palm swamps increased after the fire, when the fire resilient species reestablished themselves. Environmental and spatial variables accounted for only $26 \%$ of the temporal and spatial variation found in the palm swamp communities. In the second chapter, the structure and composition of the herbaceo-shrubby layer of a savanna-forest ecotone was accompained for three years and five months after the
\end{abstract}


September 2011 wildfire, comparing the effects of different nutrient additions on the recovery of the herbaceo-shrubby layer and the process of soil revegetation. Nutrient additions accelerated the recovery of the soil cover but also reduced plant species richness in $50 \%$. After two years and five months, the soil covering levels were almost the same as before the fire in the control plots and the plant diversity in these plots were higher than in the fertilized plots. Along the study, it became clear that the composition and structure of the herbaceo-shrubby layer in forests are lower than in savannas and the recovery process, slower. The last chapter aimed at assessing if there are differences between leaf spectral curves and in the Carbon, Nitrogen and Sulphur contents in species occurring commonly in palm swamps, as well as if the foliar characteristics of each species are maintained in different palm sawamps. Five species were selected: Two shrubby species, Trembleya parviflora (D.Don) Cogn. and Lavoisiera imbricata (Thunb.) both showing a population expansion in moist areas along the Federal District, and three graminoid species, Paspalum lineare Trin., Andropogon bicornis L. and A. leucostachyus Kunth, the three being very abundant and among the ten most important in moist areas in the Federal District. The spectral curves for each species showed less variation for individuals from the same palm swamp than for individuals from different palm swamps, suggesting that it would be possible to represent each species by its spectral curve. The diversity of spectral curves can be fundamental in determining and comprehending the chemical diversity of an area, opening new opportunities to use spectral data and allowing, in the future, modelling of biogeochemical cycles and diversity through remote sensing. In general, environmental disturbances such as fire and nutrient additions promote a reduction of composition and structure in the herbaceo-shrubby layer, however, fire suppression allows the community to reestablish in a short time span. Also the use of spectral curves is a promising tool to help us identify different species in the herbaceo-shrubby layer.

Keywords: Palm swamp (Vereda), woody savanna (cerrado sensu stricto), gallery forest (Mata de galeria), infra-red, spectral curve. 


\section{SUMÁRIO}

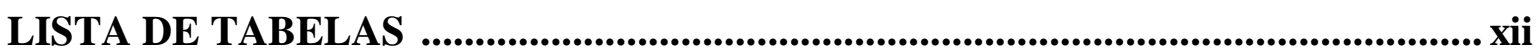

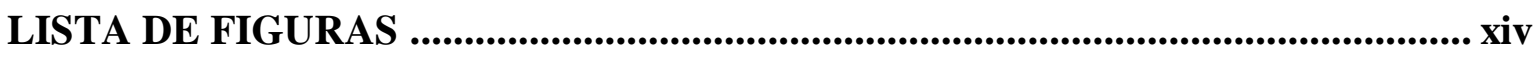

INTRODUÇÃO GERAL ............................................................................................... 19

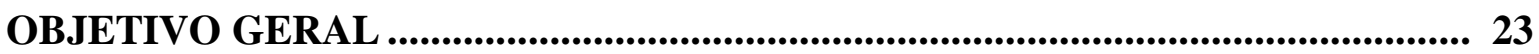

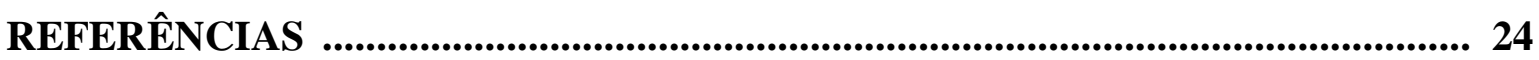

CAPÍTULO 1- DINÂMICA ESPACIAL E TEMPORAL DO ESTRATO HERBÁCEO-ARBUSTIVO EM VEREDAS .............................................................. 40

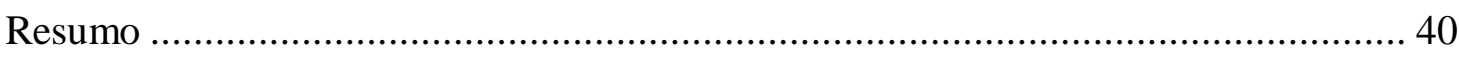

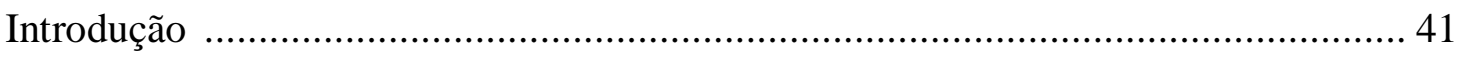

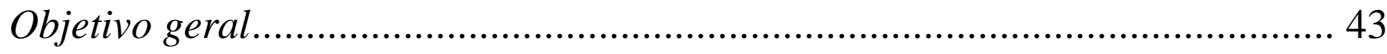

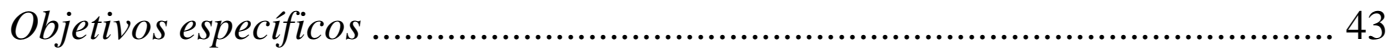

Material e Métodos ........................................................................................ 43

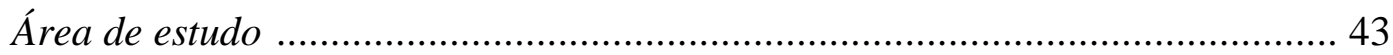

Amostragem da vegetação ...................................................................... 46

Dinâmica da comunidade .................................................................... 48

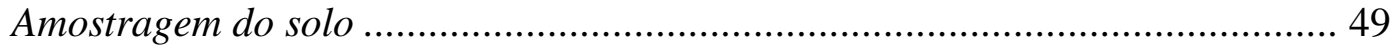

Correlações das espécies e as variáveis ambientais ...................................... 50

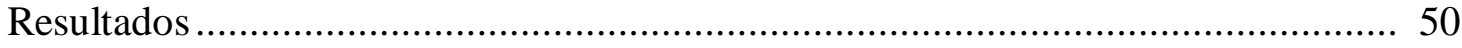

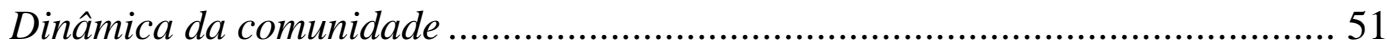

Correlações das espécies e variáveis ambientais ........................................ 57

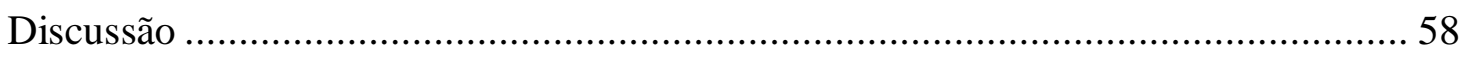

Dinâmica temporal da comunidade ............................................................ 59

Correlações das espécies e variáveis ambientais ............................................ 61

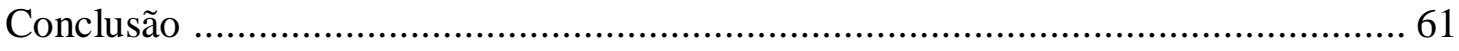



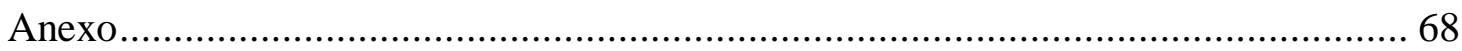


CAPÍtULO 2 - EFEITO DA FERTILIZAÇÃO NA COBERTURA E COMPOSIÇÃO FLORÍSTICA DO ESTRATO HERBÁCEO-ARBUSTIVO EM ECÓTONO SAVANA-FLORESTA, NO DISTRITO FEDERAL, BRASIL............... 73



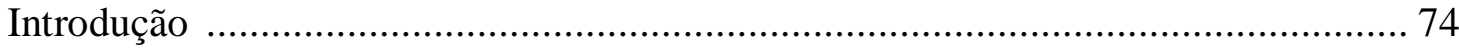

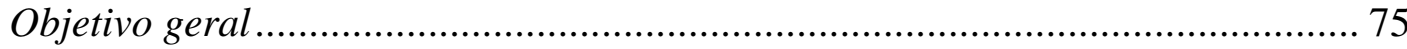

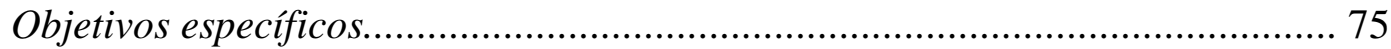

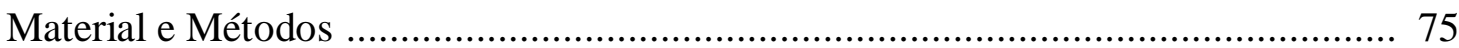

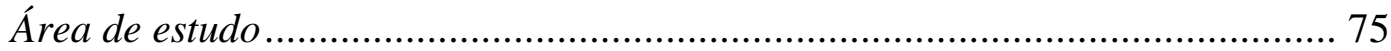

Amostragem da vegetação ............................................................................. 76

Amostragem do solo ................................................................................. 78

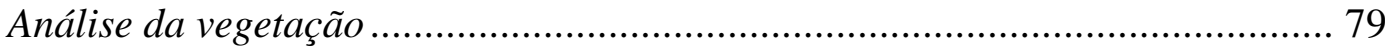



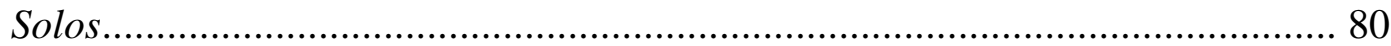

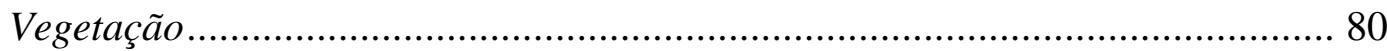

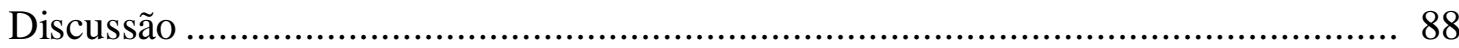

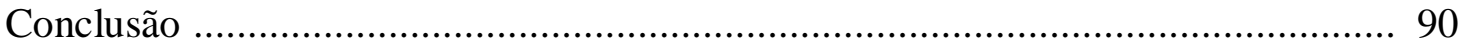

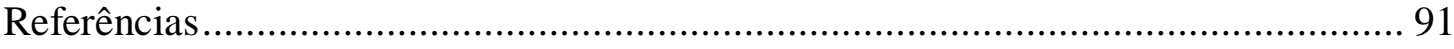

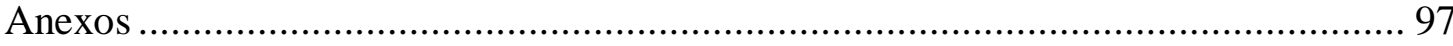

CAPÍTULO 3 - UTILIZAÇÃO DE ESPECTROSCOPIA DE REFLECTÂNCIA

NO INFRAVERMELHO PRÓXIMO NA DISCRIMINAÇÃO DE ESPÉCIES HERBÁCEO-ARBUSTIVAS E A RELAÇÃO COM A CONCENTRAÇÃO FOLIAR DE CARBONO, NITROGÊNIO E ENXOFRE. ......................................... 107

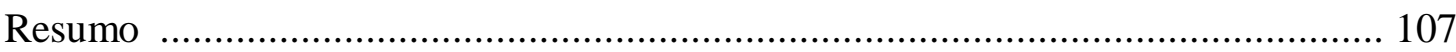

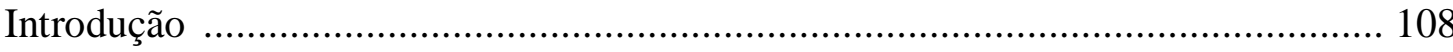

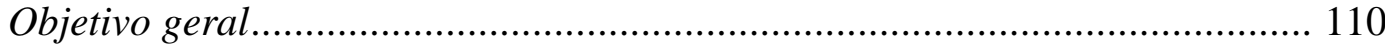

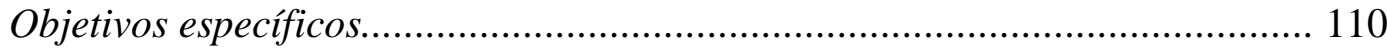

Material e Métodos .................................................................................................. 111

Seleção de espécies e das áreas de estudo........................................................ 111

Coletas e processamento de amostras de folhas .............................................. 111

Medições da reflectância na faixa do infravermelho próximo (NIRS -

NearInfraredReflectanceSpectroscopy)..................................................... 112 
Concentração de Carbono Nitrogênio e Enxofre.............................................. 112

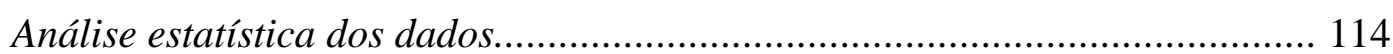

Avaliação de desempenho do modelo PLSR e análise de incerteza................... 115

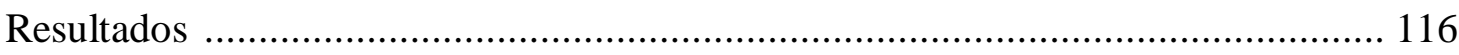

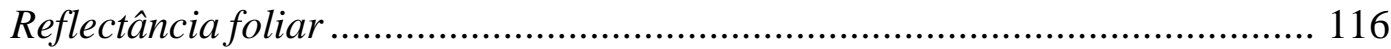

Concentração de Carbono, Nitrogênio e Enxofre........................................... 121

Relação entre reflectância foliare o teor de carbono nitrogênio e enxofre........ 124

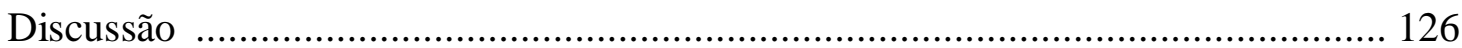

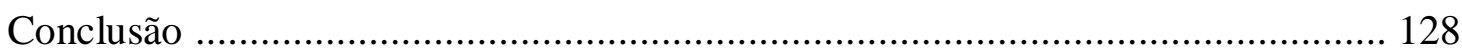

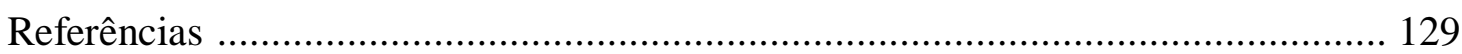




\section{LISTA DE TABELAS}

\section{Capítulo 1}

Tabela 1 - Localização das áreas de estudo de Vereda com os anos em que foram realizados os levantamentos. Estes foram realizados no auge do período chuvoso (janeiro a março)

Tabela 2 - Valores do Índice de Similaridade de Chao-Sørensen \pm desvio padrão para cada Vereda (JBB - Jardim Botânico de Brasília, IBGE - Reserva Ecológica do IBGE, PNB - Parque Nacional de Brasília e FLONA - Floresta Nacional de Brasília) amostradas nos três períodos (1-levantamento antes do fogo, 2-três a quatro meses após o fogo e 3-pelo menos um anoapós a da passagem do fogo)

Tabela 3 - Características edáficas (médias \pm desvio padrão) da Vereda do Parque Nacional de Brasília (PNB), da Floresta Nacional de Brasília (FLONA), da Estação Ecológica do Jardim Botânico (JBB) e da Reserva Ecológica do Instituto Brasileiro Geografia e Estatística (IBGE). Letras diferentes após os números indicam médias diferentes $(p<0,05)$, pelo teste de Tukey. CTC $=$ Capacidade de Troca Catiônica, M.O.= Matéria Orgânica, S.B.= Saturação de Bases, S.Al= Saturação por Alumínio. *Váriveis utilizadas na pRDA

\section{Capítulo 2}

Tabela 1 - Índice de similaridade de Chao-Sørensen \pm intervalo de confiança, entre os inventários e tratamentos com e sem fertilização em uma área de transição Savana-Floresta na Reserva Ecológica do IBGE, Brasília, Distrito Federal, Brasil. ..... 82

\section{Capítulo 3}

Tabela 1 - Matriz de confusão gerada pelos valores de reflectância das curvas espectrais para todas as amostras coletadas para as cinco espécies do estrato herbáceo-arbustivo em cinco Veredas no Distrito Federal, Brasil.

Tabela 2 - Teor de carbono (C), nitrogênio (N) e enxofre (S) foliar para cinco espécies herbáceo-arbustivas amostradas em cinco Veredas no Distrito Federal, Brasil. Média \pm desvio padrão 
Tabela 3 - Resultados da modelagem e cross-validation PLSR para os teores de carbono (Cmass\%), nitrogênio (Nmass\%) e enxofre (Smass\%) foliar para cinco espécies herbáceo-arbustivas amostradas em cinco Veredas no Distrito Federal, Brasil. Calibração (Cal). Validação (Val). Coeficiente de Determinação $\left(\mathrm{R}^{2}\right)$, Root

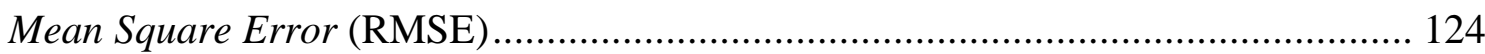




\section{LISTA DE FIGURAS}

\section{Capítulo 1}

Figura 1 - Localização das quatro Unidades de Conservação em que se realizou levantamento do estrato herbáceo-arbustivo, em Veredas no Distrito Federal, Brasi.... 44

Figura 2 - Registro dos locais de estudo, Reserva Ecológica do IBGE (IBGE) e Jardim Botânico de Brasília (JBB), antes e um mês após a passagem do fogo que ocorreu em setembro de 2011, onde se encontram instaladas linhas para o levantamento fitossociológicos.

Figura 3 - Ilustração do método de interseção na linha, perspectiva frontal (a) e aérea (b- visão da tomada da projeção das espécies), na subunidade de amostragem de um metro (fonte: Munhoz e Araújo 2011)

Figura 4 - Análise de Escalonamento Multidimensional Não Métrico das relações florísticas e da cobertura entre as áreas (FLONA - Floresta Nacional de Brasília, IBGE - Reserva Ecológica do IBGE, JBB - Jardim Botânico de Brasília e PNB Parque Nacional de Brasília) e os períodos (1-levantamento antes do fogo, 2-três a quatro meses após o fogo e 3-amostragem superior um ano da passagem do fogo). Stress $=0,13 ; \mathrm{R}^{2}=0,50-$ eixo 1 e $\mathrm{R}^{2}=0,14-$ eixo 2 .

Figura 5 - Rarefação e extrapolação estimadas pelo número de Hill adaptado por Chao et al (2014), para as ordens de $\mathrm{q}=0$ (riqueza), $\mathrm{q}=1$ (exponencial do índice de Shannon) e q=2 (o inverso do índice de Simpson). Áreas sombreadas correspondem aos intervalos de confiança de $95 \%$. Trinagulo ( $\Delta$ ) primeiro levantamento, círculo $(\bullet)$ segundo levantamento e quadrado ( $\square$ ) terceiro levantamento. (JBB - Jardim Botânico de Brasília, IBGE - Reserva Ecológica do IBGE, PNB - Parque Nacional de Brasília e FLONA - Floresta Nacional de Brasília.

Figura 6 - Valor de Importância \% (soma da cobertura relativa e frequência relativa) das dez principais espécies nos quatro levantamentos realizados no Jardim Botânico de Brasília (JBB), Reserva Ecológica do IBGE (IBGE), Parque Nacional de Brasília 
(PNB) e Floresta Nacional de Brasília (FLONA). ( $\square$ ) primeiro, ( $\square$ ) segundo e

(घ) terceiro levantamento

Figura 7 - Partição da variância explicada pelos dados de variáveis ambientais e espaciais na estruturação da comunidade herbáceo-arbustiva do JBB - Jardim Botânico de Brasília, IBGE - Reserva Ecológica do IBGE, PNB - Parque Nacional de Brasília e FLONA - Floresta Nacional de Brasília.

\section{Capítulo 2}

Figura 1 - Registro do local de estudo, ecótono Cerrado sentido restrito (A)-Mata de Galeria (B), em 12 de outubro de 2011 (um mês após a passagem do fogo), dentro da Reserva Ecológica do Instituto Brasileiro de Geografia e Estatística.

Figura 2 - Croqui do arranjo amostral do estudo do ecótono Mata de Galeria Cerrado sentido restrito na RECOR-IBGE no Distrito Federal, adaptado de Geiger et al., (2011). Doze parcelas de 70m instaladas perpendicularmente à fronteira da Mata de Galeria e subdivididas em subparcelas de $10 \mathrm{~m}$. A parcela central de $10 \mathrm{mx} 10 \mathrm{~m}$ foi considerada transição Mata de Galeria - Cerrado sentido restrito em função da mudança na estrutura do componente arbóreo e herbáceo. A amostragem do estrato herbáceo-arbustivo foi realizada em transecto de $70 \mathrm{~m}$ localizado no centro de cada parcela (-----), sendo seis transectos em parcelas com fertilização (F) e seis sem fertilização (C). Ponto de coleta de solo $0-15 \mathrm{~cm}(\bullet)$.

Figura 3 - Variação do pH e na concentração de nutrientes do solo em transectos 10x70m ao longo de uma transição entre o Cerrado sentido restrito e a Mata de Galeria na RECOR-IBGE. Médias após sete anos de fertilização (- $\left.{ }^{-}-\right)$e médias das parcelas controle sem fertilização (--- $\square---)$

Figura 4 - Cobertura relativa das dez principais espécies nos quatro levantamentos sob tratamentos com e sem fertilização em uma área de transição Savana-Floresta na Reserva Ecológica do IBGE, Brasília, Distrito Federal, Brasil. ( $\square$ ) Cerrado, ( $\square$ ) Ecótono e (匹) Mata 
Figura 5 - Rarefação e extrapolação estimado pelo número de Hill adaptado por Chao et al., (2014), para as ordens de $q=0$ (riqueza), $q=1$ (exponencial do índice de Shannon) e q=2 (o inverso do índice de Simpson). Áreas sombreadas correspondem

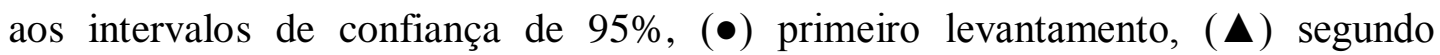
levantamento, $(\mathbf{\square})$ terceiro levantamento e $(+)$ quarto levantamento para as parcelas sobre efeito da fertilização.

Figura 6 - Rarefação e extrapolação estimado pelo número de Hill adaptado por Chao et al., (2014), para as ordens de $q=0$ (riqueza), $q=1$ (exponencial do índice de Shannon) e q=2 (o inverso do índice de Simpson). Áreas sombreadas correspondem aos intervalos de confiança de $95 \%,(\bullet)$ primeiro levantamento, ( $\mathbf{\Delta})$ segundo levantamento, ( $\mathbf{\square})$ terceiro levantamento e $(+)$ quarto levantamento para as parcelas sem fertilização.

Figura 7 - Ordenações quantitativas da composição de espécies herbáceo-arbustivas entre ecótono Mata de galeria - Cerrado sentido restrito em áreas sobre fertilização e áreas sem fertilização na Reserva Ecológica do IBGE, Distrito Federal, Brasil.

Figura 8 - Variação da cobertura absoluta média (m) do estrato herbáceo-arbustivo entre os anos de 2012, 2013 e 2014 em uma transição Mata de Galeria - Cerrado sentido restrito $(-30 \mathrm{~m}$ a $30 \mathrm{~m})$ na Reserva Ecológica do IBGE, Distrito Federal, Brasil. Fertilizada 2012 ( $\Delta-$ ), Fertilizada 2013 (○-), Fertilizada 2014 (口-),

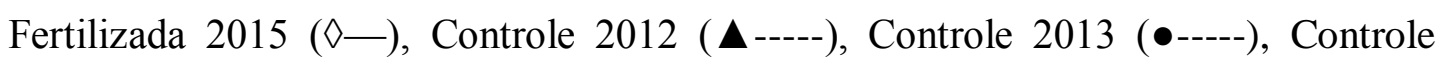
2014 (ロ-----) e Controle 2015 ( 


\section{Capítulo 3}

Figura 1 - Localização das cinco Unidades de Conservação (áreas de amostragem) em que se realizou a coleta das espécies herbáceo-arbustivas comuns às Veredas no Distrito Federal, Brasil.

Figura 2 - Curvas espectrais das reflectâncias de folhas (a) de Andropogon bicornis, (b) de A. leucostachyus, (c) de Paspalum lineare, (d) de Lavoisiera imbricata, (e) de Trembleya parviflora e (f) do total de 106 folhas das cinco as espécies estudadas

Figura 3 - Separação de cinco espécies do estrato herbáceo-arbustivo (A) pelo primeiro e segundo componente principal (PC) explicando $84 \%$ da variância e (B) pelo primeiro, segundo e terceiro componente principal explicando $88 \%$ da variância, gerados pelos valores de reflectância da curva espectral $(1100-2500 \mathrm{~nm})$ das espécies amostradas em cinco Veredas no Distrito Federal, Brasil. andropogon bicornis, - A. leucostachyus, $\gg$ Paspalum lineare, $\Delta$ Lavoisiera imbricata, $\nabla$ Trembleya parviflora.

Figura 4 - Separação de cinco espécies do estrato herbáceo-arbustivo pelos componentes principais (PC) gerados pelos valores de reflectância da curva espectral $(1100-2500 \mathrm{~nm})$ das espécies amostradas em cinco Veredas no Distrito Federal, Brasil. • ESECAE - Estação Ecológica de Águas Emendadas; • FLONA - Floresta Nacional de Brasília; $\triangle$ IBGE - Reserva Ecológica do IBGE; JBB - Jardim Botânico de Brasília, $\nabla$ PNB - Parque Nacional de Brasília.

Figura 5 - Análise discriminante linear (LDA) de cinco espécies herbáceoarbustivas pelo teor de Carbono (Cmass\%), Nitrogenio (Nmass\%) e Enxofre (Smass\%) coletadas em cinco Veredas no Distrito Federal, Brasil. andropogon bicornis, • A. leucostachyus, • Paspalum lineare, $\Delta$ Lavoisiera imbricata, $\nabla$ Trembleya parviflora. JBB - Jardim Botânico de Brasília, FLONA - Floresta Nacional de Brasília, PNB - Parque Nacional de Brasília, ESECAE - Estação Ecológica de Águas Emendadas e IBGE - Reserva Ecológica do IBGE 
Figura 6 - Resultados da validação de dados independente para a modelagem PLSR (Partial Least-Squares Regression); teor de nitrogênio $\left(\mathrm{N}_{\text {massa }}\right)$, teor de carbono $\left(\mathrm{C}_{\text {massa }}\right)$ e teor de enxofre $\left(\mathrm{S}_{\text {massa }}\right)$. As barras de erro indicam os intervalos de confiança de $95 \%$ para cada valor previsto, enquanto que as linhas pretas denotam os intervalos de predição com $95 \%$ de confiança e linhas cinzentas mostram o intervalo de confiança de $95 \%$ dos modelos. As linhas tracejadas mostram a 1:1, com a linha de regressão mostrado a cinzento claro. PRESS - Prediction Residual Sum of Squares; RMSE - Root Mean Square Error e Coeficiente de Determinação $\left(\mathrm{R}^{2}\right)$...... 125 


\section{INTRODUÇÃO GERAL}

O estrato herbáceo-arbustivo apresenta espécies com diversas estratégias fenológicas, com ciclos de vidas de anual a perenes (Tannus et al., 2006; Munhoz e Felfili, 2007) e diferentes hábitos de crescimento (Rowe e Speck, 2005) que vão desde ervas cespitosas delicadas, gramíneas, subarbustos, lianas a palmeiras. $\mathrm{Na}$ savana brasileira, o Cerrado, estima-se que a relação de espécies do estrato rasteiro para espécies do estrato lenhoso seja na proporção de 5,6:1, sendo que essa relação aumenta para áreas mais abertas (Mendonça et al., 2008). O que demonstra a importância florística desse componente para as comunidades vegetais nesse bioma.

Em áreas com manejos que diminuem a incidência de distúrbios antrópicos e até mesmo incêndios tem se observado o aumento expressivo de espécies lenhosas em ambientes campestres e savânicos, o que altera a paisagem para ambientes florestais (Briggs et al., 2005; Brook e Bowman, 2006; Pinheiro e Durigan, 2009; Bowman et al., 2010; Wigley et al., 2010) ou apenas o aumento gradual sem grandes alterações na paisagem savânica (Roques et al., 2001; Goslee et al., 2003; Asner et al., 2004). As consequências desse adensamento são alterações nos processos ecossistêmicos, como aumento da biomassa (Knapp et al., 2008), e mudanças na diversidade, tanto da flora (Ratajczak et al., 2012; Santos e Munhoz, 2012), como da fauna (Blaum et al., 2009; Sirami et al., 2009), seja por perda da riqueza ou pela alteração da composição de espécies. Estudos têm apontado como fatores reguladores desse aumento na abundância de espécies lenhosas a redução do regime de frequência de fogo (Higgins et al., 2000; Pinheiro e Durigan, 2009; Geiger et al., 2011), o aumento do gás carbônico na atmosfera (Buitenwerf et al., 2012), a diminuição nas taxas de herbivoria (Prins e van der Jeugd, 1993) e as interações dessas variáveis (Scholes e Archer, 1997; Bond, 2008; Sankaran et al., 2008; Staver et al., 2011).

O fogo promove efeitos diretos e indiretos nos processos ecológicos das savanas (Miranda et al., 2002; Bond et al., 2005), influenciando na disponibilidade de nutrientes (Nardoto et al., 2006), de luz (Ludwig et al., 2011), da temperatura do solo e do ar (Miranda et al., 1993) e na quantidade de biomassa seca acumulada pela vegetação (Moreira, 2000). Portanto, trata-se de um fator que pode modelar a dinâmica de comunidades vegetais com diferentes variações devido às distintas características 
morfológicas, fisiológicas e de estratégias fenológicas que foram adquiridas pelas espécies ao longo da história evolutiva das savanas (Coutinho, 1990). Observa-se que na ausência dessa perturbação espécies estimuladas pelo fogo reduzem a frequência na comunidade devido à redução da fenofase reprodutiva (Araújo et al., 2013), ou seja, ocorre redução no número de flores, frutos e sementes ou rebrotas e isso leva a uma menor probabilidade de inclusão de novos indivíduos na comunidade, assim como maior probabilidade de exclusão dessas espécies ao longo do tempo (Munhoz e Felfili, 2006) o que leva a uma progressiva simplificação florística (Líbano e Felfili, 2006) . A redução do regime de queima também pode acelerar a evolução estrutural de fisionomias abertas para outras mais fechadas, com maior fitomassa (Durigan e Ratter, 2006; Líbano e Felfili, 2006; Pinheiro e Durigan, 2009). Por outro lado, a alta frequência de queimadas resulta na redução da biomassa e na diversidade das comunidades vegetais (Ramos-Neto e Pivello, 2000; Ribeiro et al., 2012), principalmente do componente arbóreo devido a alteração da taxa de regeneração (Hoffmann, 2000; Medeiros e Miranda, 2005), da mortalidade de plântulas pela queima (Hoffmann, 1998) e do aumentado entouceiramento no estrato herbáceo que dificulta o crescimento do componente arbóreo (Fiedler et al., 2004).

Para o Cerrado, observa-se também que a entrada alóctone conjunta de fontes de nitrogênio e fósforo resulta na redução da riqueza e da diversidade em áreas savânicas (Jacobson et. al., 2011; Mello et al., 2014). Associa-se essa perda de riqueza pela entrada e expansão de espécies invasoras, devido a alteração na razão N e P (Lannes et al., 2012), com consequente aumento da biomassa destas espécies (Villela e Haridasan, 1994; Haridasan et al., 1997) e diminuição da luminosidadepelo sombreamento que causam ao estrato rasteiro (Hoffmann et al., 2004; Freitas e Lima, 2010).

Uma maneira de observar essas mudanças de forma mais rápida e ampla de modo espaço-temporal seria por sensoriamento remoto, visto que atualmente existe uma variedade de imagens de sensoriamento remoto disponível para o mapeamento da vegetação utilizando sensores multi-espectrais e hiperespectrais(Adam et al., 2010). As imagens hiperespectrais ou dados obtidos por espectroscopia podem ser utilizados para discriminar e mapear a vegetação em nível de espécie (Rossoet al., 2005; Vaiphasa et al., 2005; Belluco et al., 2006; Pengra et al., 2007). Além disso, dentro da espectroscopia é possível obter simultaneamente dados de propriedades biofísicas e 
bioquímicas, tais como índice de área foliar, biomassa, concentrações de nutrientes e teor de água da vegetação (Rendong e Jiyuan, 2004; Kovacs et al., 2005; Proisy et al., 2007). Pode-se gerar também por meio da espectroscopia estimativas de nutrientes foliares na escala da folha e do dossel, o que foi obtido para diversos ecossistemas (Asner e Martin, 2008; Asner et al., 2012). Além disso, bancos de dados podem ser gerados e assim permitir a detecção de mudanças propriedades biofísicas e bioquímicas ao nível de espécies ou de ecossistemas ao longo do tempo (Shaikh et al., 2001; Ozesmi e Bauer, 2002). Entretanto, ainda são incipientes trabalhos para as fitofisionomias savânicas e campestres do Cerrado (Silva-França e Sano, 2011; Amaral et al., 2015).

Para auxiliar na obtenção de informações da dinâmica espacial, temporal com relação à perturbação pelo fogo e pela adição de nutrientes no estrato herbáceoarbustivo, assim como avaliar o uso da espectroscopia para estudos da composição nutricional do estrato herbáceo-arbustivo, esta tese foi dividida nos seguintes capítulos:

- Capítulo 1 - DINÂMICA ESPACIAL E TEMPORAL DO ESTRATO HERBÁCEO-ARBUSTIVO EM VEREDAS.

- Objetivo geral

- Avaliar a dinâmica temporal e espacial da flora herbáceoarbustiva em áreas de Veredas no Distrito Federal.

- Objetivos específicos

- Averiguar se os parâmetros de diversidade do componente herbáceo-arbustivo se diferenciam entre diferentes Veredas e ao longo do tempo;

- Verificar se houve alternância na dominância das espécies.

- Avaliar a persistência da comunidade herbáceo-arbustiva após a passagem de um incêndio.

- Correlacionar variáveis edáficas e espaciais com a composição e a estrutura da comunidade vegetal

○ Hipótese

- Assumiu-se que a heterogenidade ambiental observada dentro das Veredas e a interação dos fatores edáficos, climáticos e bióticos resultem em variação espacial e temporal nas comunidades de Vereda mesmo após estabilidade na composição florística. 
- Capítulo 2 - EFEITO DA FERTILIZAÇÃO NA COBERTURA E COMPOSIÇÃO FLORÍSTICA DO ESTRATO HERBÁCEO-ARBUSTIVO EM ECÓTONO SAVANA-FLORESTA, NO DISTRITO FEDERAL, BRASIL

- Objetivo geral

- Descrever a reabilitação da cobertura vegetal do estrato herbáceoarbustivo em ecótono savana-floresta após um incêndio, assim como avaliar a influência da adição de nutrientes na dinâmica estrutural e temporal da comunidade.

- Objetivos específicos

- Acompanhar a reabilitação da cobertura vegetal do estrato herbáceo-arbustivo após fogo ao longo de três anos e cinco meses (2012-2015) em ecótono savana-floresta;

- Avaliar o efeito da fertilização na dinâmica temporal da composição florística e estrutural do estrato herbáceo-arbustivo em ecótono savana-floresta;

○ Hipótese

- Partiu do princípio de que a diversidade de espécies tende a ser menor em áreas sobre efeito de fertilização, assim como se tende a reduzir a riqueza de espécies ao longo do gradiente savanafloresta. Para tanto, utilizou-se uma área de transição savanafloresta sobre o efeito da fertilização controlada após incêndio acidental.

- Capítulo 3 - UTILIZAÇÃo DE ESPECTROSCOPIA DE REFLECTÂNCIA NO INFRAVERMELHO PRÓXIMO NA DISCRIMINAÇÃO DE ESPÉCIES HERBÁCEO-ARBUSTIVAS E A RELAÇÃO COM A CONCENTRAÇÃO FOLIAR DE CARBONO, NITROGÊNIO E ENXOFRE. 
- Objetivo geral

- Averiguar se existe diferença nas curvas espectrais das folhas entre as espécies frequentes em áreas de Vereda, assim como se o espectro se mantém em diferentes localidades e se são relacionadas às concentrações foliares de carbono, nitrogênio e enxofre.

- Objetivos específicos:

- Diferenciar a curva espectral de espécies herbáceo-arbustivas comuns em áreas de Vereda, assim como se essa curva se mantém constante em diferentes localidades;

- Associar as refletâncias descritas nas curvas espectrais com as concentrações foliares de carbono, nitrogênio e enxofre.

- Quantificar o teor de carbono, nitrogênio e enxofre foliar das espécies herbáceo-arbustivas comuns em áreas de Vereda, assim como se esses teores se mantêm constante em diferentes localidades;

\section{○ Hipótese}

- Espécies comuns em comunidades de Vereda do Distrito Federal apresentam curvas espectrais distintas e independentes do local de ocorrência, e que estas podem ser utilizadas para estimar a concentração foliar de carbono, nitrogênio e enxofre.

\section{OBJETIVO GERAL}

Investigar a dinâmica da comunidade herbáceo-arbustiva ao longo do tempo e do espaço. Além disso, para áreas de Veredas, observar o efeito da passagem do fogo no processo de recuperação da comunidade vegetal. Enquanto que para uma área de ecótono savana-floresta incluiu-se o efeito da fertilização. Assim como estimar e modelar o comportamento espectral de espécies herbáceo-arbustivas comuns em Vereda do Distrito Federal. 


\section{REFERÊNCIAS}

Adam, E.,Mutanga, O., \& Rugege, D. (2010). Multispectral and hyperspectral remote sensing for identification and mapping of wetland vegetation: a review. Wetlands Ecology and Management, 18, 281-296.

Amaral, C. H., Roberts, D. A., Almeida, T. I., \& Souza Filho, C. R. (2015). Mapping invasive species and spectral mixture relationships with neotropical woody formations in southeastern Brazil. ISPRS Journal of Photogrammetry and Remote Sensing, 108, 80-93.

Araújo, G. M., Amaral, A. F., Bruna, E. M., \&Vasconcelos, H. L. (2013). Fire drives the reproductive responses of herbaceous plants in a Neotropical swamp. Plant Ecology, 214, 1479-1484.

Asner, G. P., Elmore, A. J., Olander, L. P., Martin, R. E., \& Harris, A. T. (2004). Grazing systems, ecosystem responses, and global change. Annual Review of Environment and Resources, 29, 261-299.

Asner, G. P., \& Martin, R. E. (2008). Airborne spectranomics: mapping canopy chemical and taxonomic diversity in tropical forests. Frontiers in Ecology and the Environment, 7, 269-276.

Asner, G. P., Mascaro, J., Muller-Landau, H. C., Vieilledent, G., Vaudry, R., Rasamoelina, M., Hall, J. S., \& van Breugel, M. (2012).A universal airborne LiDAR approach for tropical forest carbon mapping. Oecologia, 168, 1147-1160.

Belluco, E., Camuffo, M., Ferrari, S., Modenese, L., Silvestri, S., Marani, A., \& Marani, M. (2006). Mapping salt-marsh vegetation by multispectral and hyperspectral remote sensing. Remote Sensing of Environment, 105, 54-67.

Blaum, N., Seymour, C., Rossmanith, E., Schwager, M., \& Jeltsch, F. (2009). Changes in arthropod diversity along a land use driven gradient of shrub cover in savanna 
rangelands: identification of suitable indicators. Biodiversity and Conservation, 18, 1187-1199.

Bond, W. J., Woodward, F. I., \& Midgley, G. F. (2005). The global distribution of ecosystems in a world without fire. New Phytologist, 165, 525-538.

Bond, W. J. (2008). What Limits Trees in $\mathrm{C}_{4}$ Grasslands and Savannas? Annual Review of Ecology, Evolution, and Systematics, 39, 641-659.

Bowman, D. M., Murphy, B. P., \& Banfai, D. S. (2010). Has global environmental change caused monsoon rainforests to expand in the Australian monsoon tropics? Landscape ecology, 25, 1247-1260.

Briggs, J. M., Knapp, A. K., Blair, J. M., Heisler, J. L., Hoch, G. A., Lett, M. S., \& McCarron, J. K. (2005). An ecosystem in transition: causes and consequences of the conversion of mesic grassland to shrubland. BioScience, 55, 243-254.

Brook, B. W., \& Bowman, D. M. (2006). Postcards from the past: charting the landscape-scale conversion of tropical Australian savanna to closed forest during the 20th century. Landscape Ecology, 21, 1253-1266.

Buitenwerf, R., Bond, W. J., Stevens, N., \& Trollope, W. S. W. (2012). Increased tree densities in South African savannas: $>50$ years of data suggests $\mathrm{CO}_{2}$ as a driver. Global Change Biology, 18, 675-684.

Coutinho, L. M. (1990). Fire in the ecology of the Brazilian cerrado. 82-105. In: J. G. Goldammer (ed.). Fire in the Tropical Biota.Ecological Studies, 84. Berlin, Springer Verlag.

Durigan, G., \& Ratter, J. A. (2006). Successional changes in cerrado and cerrado/forest ecotonal vegetation in western Sao Paulo State, Brazil, 1962-2000. Edinburgh Journal of Botany, 63, 119-130. 
Fiedler, N.C.; Azevedo, I.N.C.; Resende, A.V.; Medeiros, M.B. \& Venturoli, F. (2004). Efeito de incêndios florestais na estrutura e composição florística de uma área de cerrado sensu stricto na Fazenda Água Limpa - DF. Revista Árvore, 28, 129-138.

Freitas, J. R., \& Lima, M. I. S. (2010). Desenvolvimento de Copaifera langsdorffii em uma área de Cerrado em regeneração sob a influência de Melinis minutiflora. Floresta, 40, 327-334.

Geiger, E. L., Gotsch, S. G., Damasco, G., Haridasan, M., Franco, A. C., \& Hoffmann, W. A. (2011). Distinct roles of savanna and forest tree species in regeneration under fire suppression in a Brazilian savanna. Journal of Vegetation Science, 22, 312-321.

Goslee, S. C., Havstad, K. M., Peters, D. P. C., Rango, A., \& Schlesinger, W. H. (2003). High-resolution images reveal rate and pattern of shrub encroachment over six decades in New Mexico, USA. Journal of Arid Environments, 54, 755-767.

Haridasan, M., Pinheiro, A. A. M. C., \& Torres, F. R. R. (1997). Resposta de algumas espécies do estrato rasteiro de um cerrado à calagem e à adubação. 87-91. In: Leite, L. L. e Saito, C. H. (Eds). Contribuição ao conhecimento ecológico do cerrado. Brasília, Universidade de Brasília.

Higgins, S. I., Bond, W. J., \& Trollope, W. S. (2000). Fire, resprouting and variability: a recipe for grass-tree coexistence in savanna. Journal of Ecology, 88, 213-229.

Hoffmann, W. A. (1998). Post-burn reproduction of woody plants in a neotropical savanna: the relative importance of sexual and vegetative reproduction. Journal of Applied Ecology, 35, 422-433.

Hoffmann, W. A. (2000). Post-Establishment Seedling Success in the Brazilian Cerrado: A Comparison of Savanna and Forest Species. Biotropica, 32, 62-69.

Hoffmann, W. A., Lucatelli, V. M., Silva, F. J., Azeuedo, I. N., Marinho, M. D. S., Albuquerque, A. M. S., Lopes, A.O., \& Moreira, S. P. (2004). Impact of the 
invasive alien grass Melinis minutiflora at the savanna-forest ecotone in the Brazilian Cerrado. Diversity and Distributions, 10, 99-103.

Jacobson, T. K. B., Bustamante, M. M. C., \& Kozovits, A. R. (2011). Diversity of shrub tree layer, leaf litter decomposition and $\mathrm{N}$ release in a Brazilian Cerrado under $\mathrm{N}, \mathrm{P}$ and N plus P additions. Environmental Pollution, 159, 2236-2242.

Knapp, A. K., Briggs, J. M., Collins, S. L., Archer, S. R., Bret-Harte, M. S., Ewers, B. E., Peters, D. P., Young, D.R., Shaver, G. R., Pendall, E., \& Cleary, M. B. (2008). Shrub encroachment in North American grasslands: shifts in growth form dominance rapidly alters control of ecosystem carbon inputs. Global Change Biology, 14, 615-623.

Kovacs, J. M., Wang, J., \& Flores-Verdugo, F. (2005). Mapping mangrove leaf area index at the species level using IKONOS and LAI-2000 sensors for the Agua Brava Lagoon, Mexican Pacific. Estuarine, Coastal and Shelf Science, 62, 377384.

Lannes, L. S., Bustamante, M. M. C., Edwards, P. J., \& Venterink, H. O. (2012). Alien and endangered plants in the Brazilian Cerrado exhibit contrasting relationships with vegetation biomass and N: P stoichiometry. New Phytologist, 196, 816-823.

Líbano, A. M., \& Felfili, M. J. (2006). Mudanças temporais na composição florística e na diversidade de um cerrado sensu stricto do Brasil Central em um período de 18 anos. Acta Botanica Brasilica, 20, 927-936.

Ludwig, F., Kroon, H., Prins, H. H., \& Berendse, F. (2001). Effects of nutrients and shade on tree-grass interactions in an East African savanna. Journal of Vegetation Science, 12, 579-588.

Medeiros, M. D., \& Miranda, H. S. (2005). Mortalidade pós-fogo em espécies lenhosas de campo sujo submetido a três queimadas prescritas anuais. Acta Botanica Brasilica, 19, 493-500. 
Mello, T. R., Munhoz, C. B., \& Bustamante, M. M. C. (2014). Effects of Nutrient Additions on the Diversity of the Herbaceous-Subshrub Layer of a Brazilian Savanna (Cerrado). 147-154. In: Sutton, M. A., Mason, K. E., Sheppard, L. J., Sverdrup, H. Haeuber, R., Hicks, W. K. (eds.). Nitrogen Deposition, Critical Loads and Biodiversity. Springer Netherlands.

Mendonça, R. C., Felfili, J. M., Walter, B. M. T., Silva Júnior, M. C., Rezende, A. V., Filgueiras, T. S., Nogueira, P. E. N., \&Fagg, C. W. (2008). Flora vascular do Cerrado. Checklist com 12.356 espécies. In: Sano, S. M., Almeida, S. P. e Ribeiro, J. F. (eds.). Cerrado: Ambiente e Flora. Embrapa Cerrados, Brasília.

Miranda, A. C., Miranda, H. S., Dias, I. F. O., \& Dias, B. F S. (1993). Soil and air temperatures during prescribed cerated fires in Central Brazil. Journalof Tropical Ecology, 9, 313-320.

Miranda, H. S., Bustamante, M. M. C., Miranda, A. C., Oliveira, P., \&Marquis, R. (2002). The fire factor.The Cerrados of Brazil. Ecology and Natural History of a Neotropical Savanna, 51-68.

Moreira, A. G. (2000). Effects of fire protection on savanna structure in Central Brazil. Journal of Biogeography, 27, 1021-1029.

Munhoz, C. B. R., \& Felfili, J. M. (2006). Fitossociologia do estrato herbáceosubarbustivo de uma área de campo sujo no Distrito Federal, Brasil. Acta Botanica Brasilica, 20(3), 671-685.

Munhoz, C. B. R., \& Felfili, J. M. (2007). Reproductive phenology of an herbaceoussubshrub layer of a Savannah (Campo Sujo) in the Cerrado Biosphere Reserve I, Brazil. Brazilian Journal of Biology, 67, 299-307.

Nardoto, G. B., Bustamante, M. M. C., Pinto, A. S., \& Klink, C. A. (2006). Nutrient use efficiency at ecosystem and species level in savanna areas of Central Brazil and impacts of fire. Journal of Tropical Ecology, 22, 191-201. 
Ozesmi, S. L., \& Bauer, M. E. (2002). Satellite remote sensing of wetlands. Wetlands Ecology and Management, 10, 381-402.

Pengra, B. W., Johnston, C. A., \& Loveland, T. R. (2007). Mapping an invasive plant, Phragmitesaustralis, in coastal wetlands using the EO-1 Hyperion hyperspectral sensor.Remote Sensing of Environment, 108, 74-81.

Pinheiro, E. D. S., \& Durigan, G. (2009). Dinâmica espaço-temporal (1962-2006) das fitofisionomias em unidade de conservação do Cerrado no sudeste do Brasil. Revista Brasileira de Botânica, 32, 441-454.

Prins, H. H., \& van der Jeugd, H. P. (1993). Herbivore population crashes and woodland structure in East Africa. Journal of Ecology, 81, 305-314.

Proisy, C., Couteron, P., \&Fromard, F. (2007). Predicting and mapping mangrove biomass from canopy grain analysis using Fourier-based textural ordination of IKONOS images. Remote Sensing of Environment, 109, 379-392.

Ramos-Neto, M. B., \& Pivello, V. R. (2000). Lightning fires in a Brazilian savanna National Park: rethinking management strategies. Environmental Management, 26, 675-684.

Ratajczak, Z., Nippert, J. B., \& Collins, S. L. (2012). Woody encroachment decreases diversity across North American grasslands and savannas. Ecology, 93, 697-703.

Rendong, L., \& Jiyuan, L. (2004).Estimating wetland vegetation biomass in the Poyang Lake of central China from Landsat ETM data.IEEE TransGeosci Remote Sen, 4, 4590-4593.

Ribeiro, M. N., Sanchez, M., Pedroni, F., \& Peixoto, K. S. (2012). Fogo e dinâmica da comunidade lenhosa em cerrado sentido restrito, Barra do Garças, Mato Grosso. Acta Botanica Brasilica, 26, 203-217. 
Roques, K. G., O'connor, T. G., \& Watkinson, A. R. (2001). Dynamics of shrub encroachment in an African savanna: relative influences of fire, herbivory, rainfall and density dependence. Journal of Applied Ecology, 38, 268-280.

Rosso, P. H., Ustin, S. L., \& Hastings, A. (2005). Mapping marshland vegetation of San Francisco Bay, California, using hyperspectral data. International Journal of Remote Sensing, 26, 5169-5191.

Rowe, N., \& Speck, T. (2005) Plant growth forms: an ecological and evolutionary perspective. New Phytologist 166, 61-72

Sankaran, M., Ratnam, J., \& Hanan, N. (2008). Woody cover in African savannas: the role of resources, fire and herbivory. Global Ecologyand Biogeography, 17, 236245.

Santos, F. F. M., \& Munhoz, C. B. R. (2012). Diversidade de espécies herbáceoarbustivas e zonação florística em uma Vereda no Distrito Federal. Heringeriana, 6, 21-27.

Scholes, R. J., \& Archer, S. R. (1997).Tree-grass interactions in savannas. Annual Review of Ecology and Systematics, 28, 517-544.

Shaikh, M., Green, D., \& Cross, H. (2001). A remote sensing approach to determine environmental flows for wetlands of the Lower Darling River, New South Wales, Australia. International Journalof Remote Sensing, 22, 1737-1751.

Silva-França, A. M., \& Sano, E. E. (2011). Mapeamento de áreas de campo limpo úmido no Distrito Federal a partir de fusão de imagens multiespectrais. Sociedade \& Natureza, 23, 197-209.

Sirami, C., Seymour, C., Midgley, G., \& Barnard, P. (2009). The impact of shrub encroachment on savanna bird diversity from local to regional scale. Diversity and Distributions, 15, 948-957. 
Staver, A. C., Archibald, S., \& Levin, S. (2011). Tree cover in sub-Saharan Africa: rainfall and fire constrain forest and savanna as alternative stable states. Ecology, 92, 1063-1072.

Tannus, J. L., Assis, M. A., \& Morellato, L. P. C. (2006). Fenologia reprodutiva em campo sujo e campo úmido numa área de cerrado no sudeste do Brasil, ItirapinaSP. Biota Neotropica, 6, 1-27.

Wigley, B. J., Bond, W. J., \& Hoffman, M. (2010). Thicket expansion in a South African savanna under divergent land use: local vs. global drivers? Global Change Biology, 16, 964-976.

Vaiphasa, C., Ongsomwang, S., Vaiphasa, T., \& Skidmore, A. K. (2005). Tropical mangrove species discrimination using hyperspectral data: A laboratory study. Estuarine, Coastal and Shelf Science, 65, 371-379.

Villela, D. M., \& Haridasan, M. (1994). Response of the ground layer community of a cerrado vegetation in central Brazil to liming and irrigation. Plant and Soil, 163, 25-31. 


\section{CAPÍTULO 1 - DINÂMICA ESPACIAL E TEMPORAL DO ESTRATO HERBÁCEO-ARBUSTIVO EM VEREDAS}

\section{RESUMO}

A Vereda é um tipo de fitofisionomia do Cerrado com similaridades na composição de espécies, porém com variações locais na flora em resposta aos gradientes de umidade e das características edáficas do ambiente. A presença de incêndios também pode modelar a dinâmica dessas comunidades promovendo efeitos diretos e indiretos nos processos ecológicos. O objetivo deste estudo foi averiguar se os parâmetros de diversidade do componente herbáceo-arbustivo em áreas de Veredas se diferenciam ao longo do tempo, assim como se são correlacionados com as variáveis edáficas, espaciais e influenciados pela passagem de incêndio. O estudo foi realizado em quatro Veredas, onde foram instaladas permanentemente linhas de amostragem para levantamentos fitossociológicos; ao longo de quatro anos, em três dessas áreas no ano de 2011 ocorreu a passagem de incêndio. Em cada amostragem foram determinadas a frequência e a cobertura linear das espécies através do método de interseção na linha e estimados os parâmetros de diversidade pelo método de rarefação e extrapolação pelo número de Hill. Avaliou-se a relação da estrutura da comunidade com as variáveis ambientais e espaciais por meio da Análise de Redundância Parcial. A perturbação por incêndios alterou a comunidade herbáceo-arbustiva de Vereda em intervalo menor que um ano, tendo como principais efeitos a redução temporária da riqueza e a evidência de espécies que aumentam a reprodução sexuada e/ou assexuada. Apesar das quatro Veredas apresentarem características físico-químicas distintas, as variáveis edáficas mensuradas, em nível de escala regional explicaram pouco na distribuição das espécies. Após um ano da passagem do incêndio, a estrutura e a composição florística da comunidade retornaram. As Veredas apresentam estrato herbáceo-arbustivo com estabilidade nos parâmetros de diversidade mesmo com a perturbação do fogo sendo, portanto, consideradas comunidades persistentes.

Palavras-chave: área úmida, regeneração, incêndio. 


\section{INTRODUÇÃO}

O entendimento dos fatores mantenedores da biodiversidade vem crescendo no âmbito científico global, por meio de programas de pesquisas ecológicas de longa duração, os quais permitem tanto as descrições da dinâmica da vegetação, como estudos experimentais enfocando os fatores que regulam a diversidade de espécies (Bakker et al., 1996). Recentemente, é crescente o esforço na amostragem e no monitoramento de comunidades de Vereda no Cerrado (Araújo et al., 2002; Guimarães et al., 2002, Resende et al., 2013), com evidência de carências em informações quanto às características florísticas (Resende et al., 2013, Moreira et al., 2015), edáficas (Guimarães et al., 2002; Ramos et al., 2006; Ramos et al., 2014) e, principalmente, nos processos de dinâmica temporal e espacial de comunidades herbáceo-arbustivas.

A Vereda é um tipo de fitofisionomia do Cerrado que ocorre normalmente próxima à nascente, em área com lençol freático superficial, entre as Matas de Galeria e o Cerrado sensu stricto, sendo frequentemente área de transição entre essas fitofisionomias (Araújo et al., 2002; Ribeiro e Walter, 2008). Ocorrem sobre solos Hidromórficos pertencentes às classes Organossolos, Gleissolos Melânicos e Gleissolos Háplicos (Guimarães et al., 2002; Ramos et al., 2006; Ramos et al., 2014), com predominância dos Organossolos nas regiões mais úmidas e os Gleissolos nas áreas mais bem drenadas próximas de Cerrado sensu stricto (Ramos et al., 2014). Em termos de vegetação predominam as espécies herbáceo-arbustivas, com representantes característicos de ambientes com flutuação de excedente hídrico subsuperficial (Resende et al., 2013), e riqueza chegando a 130 espécies (Resende et. al, 2013; Moreira et al., 2015), além de machas do componente arbóreo associado a palmeiras, principalmente por Mauritia flexuosa L.

Levantamentos florísticos demonstram similaridades na composição de espécies entre Veredas, porém com variações locais na flora em resposta aos gradientes de umidade típicos desse ecossistema (Resende et al., 2013; Moreira et al., 2015). Em áreas úmidas, a variação na composição e a presença de espécies exclusivas está associada à sazonalidade no alagamento dos solos (Sarmiento et al., 2004; Cianciaruso e Batalha, 2008; Munhoz e Felfili, 2008; Moreira et al., 2015) e nas características edáficas do ambiente (Guimarães et al., 2002; Resende et al., 2013, Ramos et al., 2014). 
A sazonalidade climática dentro do intervalo de um ano (Cianciaruso e Batalha, 2008; Munhoz e Felfili, 2008) ou os eventos climáticos, como El Niño, com intervalos maiores que um ano (Eugênio et al., 2011) promovem flutuação na composição e na abundância da comunidade.

A avalição dessas variáveis abióticas deve ser realizada com o controle das escalas espaciais (Legendre, 1993; Dormann, 2007), pois a presença de estrutura espacial nos parâmetros das comunidades leva a maior probabilidade de semelhança entre comunidades espacialmente mais próximas (Lichstein et al., 2002). Dessa forma, a estrutura espacial do conjunto de dados viola o pressuposto da independência estatística nas análises, o que pode provocar interpretações errôneas dos padrões de distribuição das espécies (Peres-Neto et al., 2006; Diniz-Filho et al., 2012). Portanto, torna-se importante averiguar a variação dos fatores ambientais ao longo do espaço e sua relação com a distribuição de espécies nessa fitofisionomia.

Outro fator que pode modelar a dinâmica dessas comunidades é a frequência de incêndios. O fogo promove efeitos diretos e indiretos nos processos ecológicos das savanas (Miranda et al., 2002; Bond et al., 2005), influenciando na disponibilidade de nutrientes (Nardoto et al., 2006), luz, temperatura do solo e do ar (Miranda et al., 1993) e na quantidade de biomassa seca acumulada pela vegetação (San José e Farinas, 1991; Moreira, 2000). A alteração no regime de queima resulta em efeitos importantes sobre a biomassa e a diversidade das comunidades vegetais (San José e Farinas, 1991; RamosNeto e Pivello, 2000), em função das diferentes características morfológicas, fisiológicas e de estratégias fenológicas, adquiridas ao longo da história evolutiva das savanas (Coutinho, 1990). Por outro lado, a ausência de queimadas superior a três anos em comunidades savânicas altera o processo dinâmico influenciando diretamente na mudança de cobertura de algumas espécies (Fidelis et al., 2007), ou até mesmo provocando grandes alterações na estrutura da vegetação de fisionomias abertas para outras mais fechadas, com maior fitomassa (San José e Farinas, 1991; Durigan e Ratter, 2006; Pinheiro e Durigan, 2009). Como a frequência e época de incêndios mudaram em resultado do aumento da atividade humana no Cerrado (Pivello 2011), torna-se importante avaliar os efeitos do fogo sobre espécies vegetais nos ecossistemas, incluindo Vereda, exclusiva de regiões neotropicais e altamente ameaçada pelos efeitos antrópicos (Araújo et al., 2013). 
Os padrões de regeneração em comunidades vegetais após a passagem do fogo são determinados pela combinação de fatores bióticos e abióticos, tais como condições climáticas, fatores edáficos, dinâmica da comunidade, estrutura das populações e pelas estratégias reprodutivas das espécies que as compõem. Com isso, espera-se que a heterogenidade ambiental observada dentro das Veredas e a interação dos fatores edáficos, climáticos e bióticos resultem em variação espacial e temporal nas comunidades de Vereda mesmo após estabilidade na composição florística. Para tanto, realizou-se a amostragem da composição de espécies em quatro Veredas no Distrito Federal, monitoradas em parcelas permanentes que passaram por incêndio.

\section{Objetivo geral}

Avaliar a dinâmica temporal e espacial da flora herbáceo-arbustiva em áreas de Veredas no Distrito Federal.

\section{Objetivos específicos}

- Averiguar se os parâmetros de diversidade do componente herbáceo-arbustivo se diferenciam entre diferentes Veredas e ao longo do tempo;

- Verificar se houve alternância na dominância das espécies.

- Avaliar a persistência da comunidade herbáceo-arbustiva após a passagem de um incêndio.

- Correlacionar variáveis edáficas e espaciais com a composição e a estrutura da comunidade vegetal

\section{MATERIAL E MÉTODOS}

Área de estudo

O estudo foi realizado em quatro localidades (Figura 1) dentro de Unidades de Conservação situadas no Distrito Federal (Tabela 1) em fitofisionomia de Vereda. As Veredas encontram-se sobre solo hidromórfico, englobando áreas permanentemente alagadas, próximas à Mata de Galeria que as ladeiam, assim como áreas que apresentam alagamento somente no período chuvoso, nas regiões mais próximas de fitofisionomias 
savânicas. O clima da região é do tipo Aw, segundo a classificação de Koppen, com dois períodos definidos; um seco, de maio a setembro e outro úmido, de outubro a abril.



Figura 1 - Localização das quatro Unidades de Conservação em que se realizou levantamento do estrato herbáceo-arbustivo, em Veredas no Distrito Federal, Brasil. 
Tabela 1 - Localização das áreas de estudo de Vereda com os anos em que foram realizados os levantamentos. Estes foram realizados no auge do período chuvoso (janeiro a março).

\begin{tabular}{|c|c|c|c|c|}
\hline Áreas & $\begin{array}{l}\text { Latitude } \\
\text { (Sul) }\end{array}$ & $\begin{array}{c}\text { Longitude } \\
\text { (Oeste) }\end{array}$ & UA & $\begin{array}{c}\text { Ano das } \\
\text { Amostragens }\end{array}$ \\
\hline $\begin{array}{c}\text { Floresta Nacional de } \\
\text { Brasília - FLONA }\end{array}$ & $15^{\circ} 45^{\prime} 40^{\prime \prime}$ & $48^{\circ} 04^{\prime} 13^{\prime \prime}$ & 15 & $2009,2012 *$ e 2013 \\
\hline $\begin{array}{c}\text { Reserva Ecológica do } \\
\text { IBGE - IBGE }\end{array}$ & $15^{\circ} 55^{\prime} 53^{\prime \prime}$ & $47^{\circ} 53^{\prime} 57^{\prime \prime}$ & 21 & $2010,2012 *$ e 2014 \\
\hline $\begin{array}{l}\text { Jardim Botânico de } \\
\text { Brasília - JBB }\end{array}$ & $15^{\circ} 53^{\prime} 30^{\prime \prime}$ & $47^{\circ} 51^{\prime} 25^{\prime \prime}$ & 17 & $2010,2012 *$ e 2014 \\
\hline $\begin{array}{l}\text { Parque Nacional de } \\
\text { Brasília - PNB }\end{array}$ & $15^{\circ} 46^{\prime} 48^{\prime \prime}$ & $47^{\circ} 58^{\prime} 37^{\prime \prime}$ & 15 & 2009,2012 e 2013 \\
\hline
\end{tabular}

*Amostragem 3 a 4 meses após a passagem de fogo nas áreas. UA (Unidade amostral) linhas de $10 \mathrm{~m}$

Na Vereda do Parque Nacional de Brasília (PNB), não consta registro de incêndio desde 2008 (SISFOGO, 2016). A partir de 2008, as demais localidades sofreram um incêndio em setembro de 2011, que queimou toda a matéria seca, assim como todo o estrato herbáceo-subarbustivo acima do solo (Figura 02). Os levantamentos fitossociológicos foram realizados antes do fogo (2009 - PNB e FLONA; 2010 - JBB e IBGE), três a quatro meses após a passagem do fogo (todas em 2012) e a última amostragem foi realizada com um ano após o fogo (2013) para o PNB e FLONA, e dois anos após o incêndio (2014) para o JBB e IBGE. As amostragens em todos os anos sempre foram realizadas no auge do período chuvoso (janeiro a março), por apresentar maior cobertura viva do estrato herbáceo-arbustivo e quando a maior parte das espécies desse componente encontra-se em estágio reprodutivo (Tannus et al., 2006; Munhoz \& Felfili, 2007). Para os levantamentos, utilizou-se de transecções permanentemente instaladas distribuídas de forma estratificada a captar toda a heterogeneidade presente na fitofisionomia. 

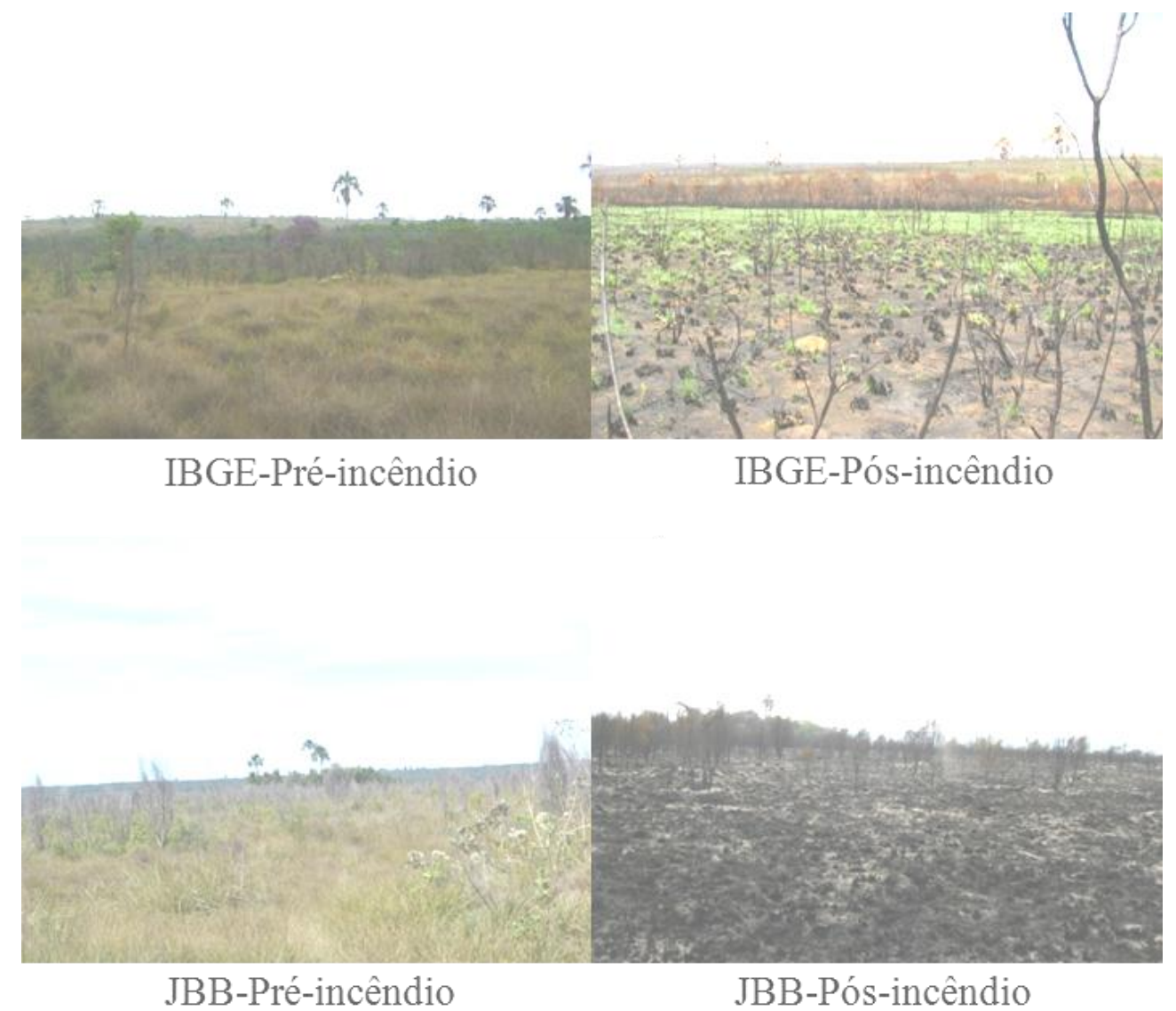

Figura 2 - Registro dos locais de estudo, Reserva Ecológica do IBGE (IBGE) e Jardim Botânico de Brasília (JBB), antes e um mês após a passagem do fogo que ocorreu em setembro de 2011, onde se encontram instaladas linhas para o levantamento fitossociológicos.

\section{Amostragem da vegetação}

Em cada área selecionada, foram instaladas permanentemente de 15 a 21 linhas de 10m (unidade amostral - UA), perfazendo toda a heterogeneidade de umidade do solo da área. Foram determinadas a frequência e a cobertura linear das espécies através do método de inventário de interseção na linha (Canfield, 1941; 1950, Figura 3). Os cálculos de cobertura e frequência, absolutas e relativas, para o estrato herbáceoarbustivo das áreas foram realizados pelas fórmulas de Kent e Coker (1992). O valor de importância (VI) da espécie foi determinado pela soma da frequência relativa e da cobertura relativa, pois espécies entouceiradas podem apresentar baixa frequência e alta cobertura, enquanto plantas cespitosas podem apresentar alta frequência, porém baixa cobertura. As seguintes fórmulas foram utilizadas para o cálculo desses parâmetros: 
- Frequência absoluta: $F A_{i}=\left(\frac{n_{i}}{n}\right) \times 100$

- Frequência relativa: $F R_{i}=\left(\frac{F A_{i}}{\sum_{i=1}^{n} F A_{i}}\right) \times 100$

- Cobertura Absoluta: $C A_{i}=\sum_{i=1}^{n} P_{i} A$

- Cobertura Relativa: $C R_{i}=\left(\frac{C A_{i}}{\sum_{i=1}^{n} C A_{i}}\right) \times 100$

- Valor de Importância: $V I_{i}=\mathbf{C} R_{i}+F R_{i}^{-}$

Onde: $n_{i}$ é número de UAs onde a espécie ( $i$ ) ocorreu; o $n$ é número total de unidades amostrais (UAs); $\sum_{i=1}^{n} F A_{i}$ é o somatório da frequência absoluta de todas as espécies; $\sum_{i=1}^{n} P_{i} A$ é a soma da projeção da espécie $(i)$ em todas as UAs; $\sum_{i=1}^{n} C A_{i}$ é o somatório da cobertura de todas as espécies em todas as UAs. 


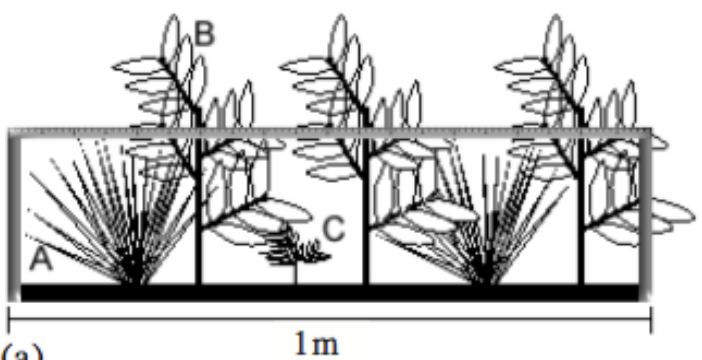

(a)

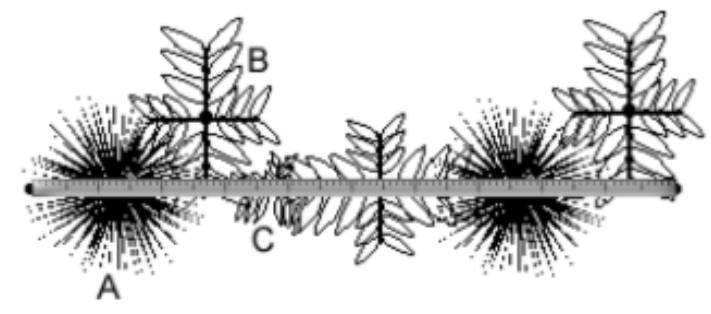

(b)

Figura 3 - Ilustração do método de interseção na linha, perspectiva frontal (a) e aérea (b- visão da tomada da projeção das espécies), na subunidade de amostragem de um metro (fonte: Munhoz e Araújo 2011).

Os materiais botânicos coletados nos inventários foram identificados por meio de comparação com exemplares herborizados depositados no Herbário da Universidade de Brasília (UB) e no Herbário da Reserva Ecológica do Instituto Brasileiro de Geografia e Estatística (IBGE), com auxílio de materiais literários e consulta a especialistas. Os materiais férteis foram herborizados e depositados nos Herbários UB e IBGE. As espécies foram classificadas em famílias de acordo com sistema do Angiosperm Phylogeny Group IV (APG IV, 2016) e a grafia dos nomes foi confirmada no banco de dados eletrônicos da Flora do Brasil (< http://floradobrasil.jbrj.gov.br/ >) através do pacote flora 0.2.7 (Carvalho, 2016) realizadas no programa R 3.2.3 (R Core Team 2015).

\section{Dinâmica da comunidade}

A similaridade da composição florística entre as áreas e os períodos amostrados foi avaliada pelo índice de similaridade de Chao-Sørensen (Chao et al., 2005; 2006). Para tanto, utilizou-se uma matriz com a cobertura absoluta como medida de abundância, para melhor aferir a semelhança entre os levantamentos, pois dessa forma são corrigidos os desvios de estimativa que poderiam ser produzidos em análises de similaridade que utilizam somente presença ou ausência de espécies (Chao et al., 2005; 2006). Os índices Chao-Sørensen e os desvios padrões foram obtidos pelo programa EstimateS 9.1.0 (Colwell, 2013). Para a comparação dos índices de similaridades entre 
os inventários, utilizou-se Análise de Variância de Similaridade de dois fatores (tempo e local) (ANOSIM) (Clarke, 1993).

As relações florísticas e a cobertura vegetal, entre as áreas e entre os períodos, foram visualizadas pela Análise de Escalonamento Multidimensional Não Métrico (NMDS - Non-Metric Multidimensional Scaling) (Clarke, 1993). Foram calculadas as diferenças entre todos os pares de amostras usando a medida de dissimilaridade de Bray-Curtis, por ser uma medida robusta para ordenação de dados ecológicos (Anderson e Willis, 2003).

Para a comparação da riqueza e diversidade de espécies entre os períodos e as localidades, utilizou-se o método de rarefação e extrapolação pelo número de Hill (Chao et al., 2014). Este procedimento permite estimar as ordens de $q=0$ (riqueza), $\mathrm{q}=1$ (exponencial do índice de Shannon) e $\mathrm{q}=2$ (o inverso do índice de Simpson), e possibilitando a caracterização das comunidades, assim como futuras comparações. Com base nas medidas de variâncias estimadas durante a aleatorização por Bootstrap, foram gerados intervalos de confianças de 95\%, para inferir diferenças na riqueza e diversidade entre as veredas. O número total de espécies estimado para cada comunidade foi calculado pelo estimador de riqueza Chao 2 (Chao, 1987). A extrapolação e a rarefação do número de Hill foram realizadas no programa R 3.2.3 (R Core Team 2015) com o uso dos pacotes iNEXT 2.0.5 (Hsieh et al., 2015) e devtools 1.8.0 (Wickham et al., 2015).

\section{Amostragem do solo}

$\mathrm{Na}$ ocasião do primeiro levantamento da vegetação em cada área realizou-se a coleta de solo a 0-20 cm de profundidade na porção central de cada unidade amostral (transeção de 10m), com o objetivo de avaliar a relação das variáveis edáficas com a estrutura da comunidade. As variáveis de solo analisadas foram: $\mathrm{pH}$, teores de $\mathrm{Ca}+\mathrm{Mg}$, $\mathrm{Ca}, \mathrm{Mg}, \mathrm{Al}, \mathrm{H}+\mathrm{Al}, \mathrm{K}, \mathrm{P}, \mathrm{S}, \mathrm{Na}, \mathrm{Co}, \mathrm{Zn}, \mathrm{B}, \mathrm{Cu}, \mathrm{Fe}, \mathrm{Mn}$, e Mo, saturação de bases (V), saturação de $\mathrm{Al}$ (\% Al), material orgânica, capacidade de troca catiônica (CTC) e teores de argila, silte e areia que foram mensuradas conforme o protocolo da Embrapa (1997) pelo Solocria Laboratório Agropecuário LTDA. Por meio da Análise de Variância Multivariada (MANOVA - Multivariate Analysis of Variance) avaliou-se se as variáveis edáficas mensuradas diferem entre as áreas de estudo. Para tanto, testou-se as premissas 
de normalidade e homocedasticidade e, quando necessário, realizou-se a transformação dos dados (Zar, 2009).

\section{Correlações das espécies e as variáveis ambientais}

A relação da estrutura da comunidade com as variáveis ambientais e espaciais foi avaliada por meio da Análise de Redundância Parcial (partial Redundancy Analysis - $p R D A$ ), o que permite remover possíveis erros relacionados à estruturação espacial das variáveis e interpretações equivocadas em relação às influências do meio sobre a comunidade (Peres-Neto et al., 2006), pois a presença de autocorrelação espacial nas variáveis preditoras e respostas inflam o valor de $\alpha$ levando ao erro tipo I nos testes de hipóteses (Lennon, 2000).

A análise pRDA exige três matrizes: uma matriz contendo as coberturas das espécies observadas em cada inventário, onde os dados são transformados pela distribuição de Hellinger para atender aos pressupostos da pRDA (Legendre e Gallagher, 2001); uma matriz com as variáveis ambientais (variáveis edáficas), sendo selecionadas somente as variáveis edáficas sem multicolinearidade - para tanto, testouse a correlação entre as variáveis e excluiu-se aquelas que apresentaram alta correlação significativa $(\mathrm{r} \geq 0,85, p<0,05)$. A última matriz contém variáveis espaciais que foram representadas pelas coordenadas binárias da região inicial de cada unidade amostral (transecção de 10m); posteriormente, utilizou-se o método de Moran's Eigenvector Maps (MEM) e a técnica de Moran (Dray et al., 2006) para avaliar a estruturação espacial. As análises foram realizadas no programa R 3.2.3 (R Core Team 2015) com o uso dos pacotes vegan 2.0-10 (Oksanen et al., 2007), spacemakeR 0.0-5 (Dray, 2013) e venneuler 1.1-0 (Wilkinson, 2011).

\section{RESULTADOS}

Em conjunto, as quatro Veredas apresentaram total de 228 táxons (Anexo1), sendo que na amostragem realizada antes da passagem do fogo, o maior número de espécies observado foi 109 na Vereda do IBGE e o menor foi 53 na Vereda do JBB. Os maiores valores de cobertura e riqueza foram de representantes da família Poaceae, Asteraceae, Cyperaceae, Melastomataceae e Xyridaceae, no total de 40, 30, 24, 23 e 15 
espécies por família, respectivamente, que representaram 58\% da composição florística. Cada Vereda apresentou parte da flora exclusiva do local de coleta, como por exemplo, a presença de Abolboda pulchella Humb. (Xyridaceae) e Syngonanthus densiflorus (Körn.) Ruhland (Eriocaulaceae) somente na FLONA, Ferdinandusa speciosa (Pohl) Pohl (Rubiaceae) somente no IBGE, Laplacea fructicosa (Schrad.) Kobuski (Theaceae) e Xyris seubertiana A.Nils. (Xyridaceae) somente no JBB e Xyris asperula Mart. (Xyridaceae) e Syngonanthus fischerianus (Bong.) Ruhland (Eriocaulaceae) somente no PNB. As três primeiras espécies ocorreram com baixa frequência e cobertura nos levantamentos, consequentemente, baixo valor de importância (VI - menor que 1,5\%), porémS. fischerianus e X. seubertiana apresentaram valores de VI altos (maior que $3,5 \%)$ e S. fischerianus encontra-se entre as dez espécies de maior VI para o PNB.

$\mathrm{Na}$ amostragem após três a quatro meses da passagem do incêndio na FLONA, IBGE e JBB as comunidades apresentaram redução na riqueza de espécies em até 15\% e a cobertura vegetal sobre o solo em $49 \%$. Nesse período, o maior número de espécies continuou sendo observado na Vereda do IBGE (109 espécies) e o menor na Vereda do JBB (45 espécies). Somente nesse período, observou-se o registro do gênero Ctenium sp. (Poaceae) nas três Veredas que passaram pelo incêndio, o qual não foi observado nos demais levantamentos e inclusive no $\mathrm{PNB}$, onde não ocorreu incêndio. Entre as espécies comuns às Veredas onde incêndios ocorreram, a espécie Mikania officinalis Mart. (Asteraceae) manteve-se em todas as amostragens, porém com maior VI após o fogo, ao ponto de ter ocupado a terceira posição de importância para a Vereda do IBGE em 2012.

\section{Dinâmica da comunidade}

A similaridade florística foi maior dentro dos locais (ANOSIM $\mathrm{R}=0,09 ; p<0,01$ ), observando-se índice de similaridade de Chao-Sørensen superior a 0,89 para a mesma localidade e quando se comparou localidades diferentes o índice mostrou-se menor, chegando a valores de 0,49 (Tabela 2). Ou seja, as Veredas apresentaram composição florística distintas entre si desde o primeiro levantamento, o que demostra a peculiaridade de cada local independente de pertencer à mesma fitofisionomia. Entre os períodos de amostragem, observou-se diferença (ANOSIM $\mathrm{R}=0,39 ; p<0,01$ ), onde o segundo levantamento (amostragem realizada de três a quatro meses após a passagem 
de fogo) diferiu do primeiro (antes da passagem do fogo) e do último (um ano da passagem do fogo), enquanto o primeiro e o último levantamento não diferiram entre si. Padrão expresso na NMDS (Figura 4) onde se observa maior aproximação dos inventários pelo local de coleta, assim como entre o primeiro e último levantamento.



Eixo 1

Figura 4 - Análise de Escalonamento Multidimensional Não Métrico das relações florísticas e da cobertura entre as áreas (FLONA - Floresta Nacional de Brasília, IBGE - Reserva Ecológica do IBGE, JBB - Jardim Botânico de Brasília e PNB - Parque Nacional de Brasília) e os períodos (1-levantamento antes do fogo, 2-três a quatro meses após o fogo e 3-amostragem superior um ano da passagem do fogo). Stress = 0,$13 ; \mathrm{R}^{2}=0,50$ - eixo 1 e $\mathrm{R}^{2}=0,14-$ eixo 2 . 


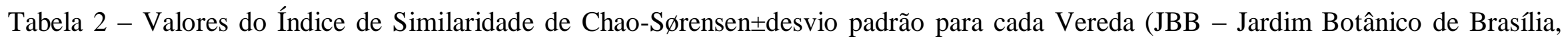
IBGE - Reserva Ecológica do IBGE, PNB - Parque Nacional de Brasília e FLONA - Floresta Nacional de Brasília) amostradas nos três períodos (1-levantamento antes do fogo, 2-três a quatro meses após o fogo e 3-pelo menos um anoapós a da passagem do fogo).

\begin{tabular}{|c|c|c|c|c|c|c|c|c|c|c|c|}
\hline & FLONA_1 & FLONA_2 & FLONA_3 & IBGE_1 & IBGE_2 & IBGE_3 & JBB_1 & JBB_2 & JBB_3 & PNB_1 & PNB_2 \\
\hline FLONA_2 & $0,95 \pm 0,03$ & & & & & & & & & & \\
\hline FLONA_3 & $0,98 \pm 0,01$ & $0,95 \pm 0,03$ & & & & & & & & & \\
\hline IBGE_1 & $0,69 \pm 0,08$ & $0,70 \pm 0,20$ & $0,71 \pm 0,13$ & & & & & & & & \\
\hline IBGE_2 & $0,69 \pm 0,07$ & $0,74 \pm 0,07$ & $0,67 \pm 0,11$ & $0,90 \pm 0,04$ & & & & & & & \\
\hline IBGE_3 & $0,72 \pm 0,12$ & $0,74 \pm 0,10$ & $0,73 \pm 0,05$ & $0,96 \pm 0,02$ & $0,93 \pm 0,03$ & & & & & & \\
\hline JBB_1 & $0,66 \pm 0,10$ & $0,68 \pm 0,12$ & $0,82 \pm 0,07$ & $0,50 \pm 0,16$ & $0,49 \pm 0,11$ & $0,53 \pm 0,09$ & & & & & \\
\hline JBB_2 & $0,69 \pm 0,08$ & $0,71 \pm 0,12$ & $0,83 \pm 0,08$ & $0,49 \pm 0,07$ & $0,53 \pm 0,06$ & $0,53 \pm 0,11$ & $0,94 \pm 0,03$ & & & & \\
\hline JBB_3 & $0,76 \pm 0,07$ & $0,76 \pm 0,15$ & $0,87 \pm 0,04$ & $0,62 \pm 0,06$ & $0,52 \pm 0,09$ & $0,65 \pm 0,10$ & $0,93 \pm 0,04$ & $0,89 \pm 0,08$ & & & \\
\hline PNB_1 & $0,74 \pm 0,06$ & $0,80 \pm 0,06$ & $0,79 \pm 0,08$ & $0,68 \pm 0,13$ & $0,71 \pm 0,07$ & $0,77 \pm 0,06$ & $0,65 \pm 0,13$ & $0,63 \pm 0,09$ & $0,74 \pm 0,08$ & & \\
\hline PNB_2 & $0,77 \pm 0,08$ & $0,81 \pm 0,08$ & $0,80 \pm 0,12$ & $0,73 \pm 0,08$ & $0,74 \pm 0,04$ & $0,77 \pm 0,09$ & $0,68 \pm 0,11$ & $0,65 \pm 0,08$ & $0,74 \pm 0,08$ & $0,99 \pm 0,01$ & \\
\hline PNB_3 & $0,71 \pm 0,08$ & $0,76 \pm 0,11$ & $0,74 \pm 0,12$ & $0,68 \pm 0,09$ & $0,68 \pm 0,06$ & $0,74 \pm 0,12$ & $0,58 \pm 0,09$ & $0,59 \pm 0,14$ & $0,66 \pm 0,13$ & $0,94 \pm 0,05$ & $0,95 \pm 0,04$ \\
\hline
\end{tabular}


Observa-se também que a passagem do fogo nas áreas reduziu todos os parâmetros de diversidade medidos pelas ordens de q (Figura 5), entretanto, cada área apresentou respostas diferentes, devido não somente ao número de táxons, mas também relacionadas à composição do conjunto de espécies. Por exemplo, na Vereda do JBB houve menor variação na distribuição dos valores de VI, além da presença de espécies arbustivas como Trembleya parviflora (D.Don) Cogn.e T. phlogiformis DC. Enquanto nas demais áreas ocorreram maiores valores de importância para espécies do estrato graminoso e com maior variação, ou seja, a primeira e a segunda espécies apresentaram valores de VI duas a três vezes maiores que as demais gerando distribuição de frequência do tipo exponencial negativa (Figura 6). Dentre as espécies comuns às quatro Veredas, observa-se que dentro da família Poaceae as espécies Paspalum lineare Trin., Andropogon leucostachyus Kunth, A. virgatus Desv. e A. lateralis Nees, assim como as dentro da família Cyperaceae as espécies Rhynchospora tenuis Link e R. globosa (Kunth) Roem. \& Schult.com frequencia constante desses táxons com apenas oscilações no VI entre os locais e os períodos estudados (Anexo 1). 

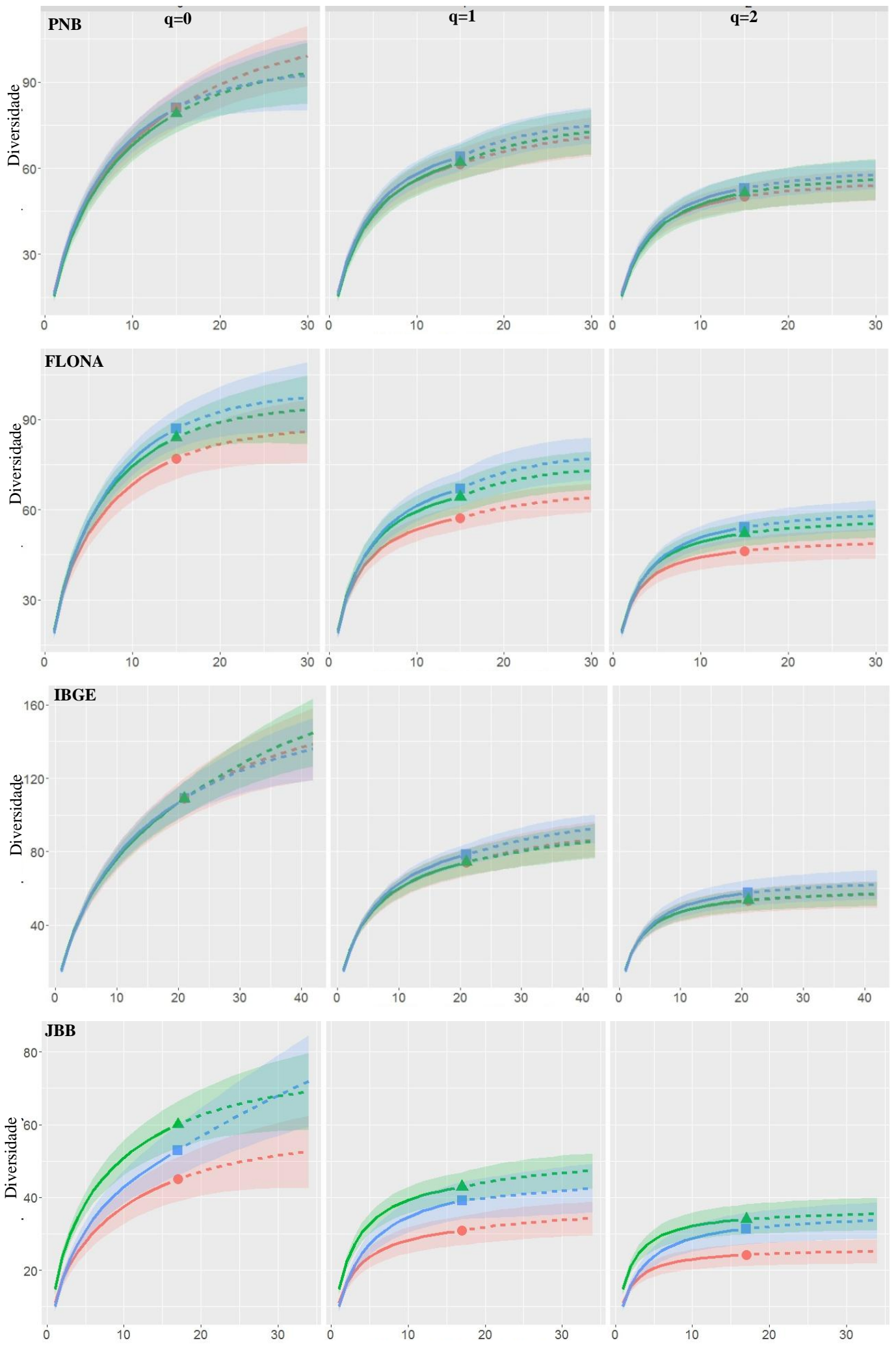

Número de unidades amostrais

Figura 5 - Rarefação e extrapolação estimadas pelo número de Hill adaptado por Chao et al (2014), para as ordens de q=0 (riqueza), q=1(exponencial do índice de Shannon) e q=2 (o inverso do índice de Simpson). Áreas sombreadas correspondem aos intervalos de confiança de $95 \%$. Trinagulo ( $\mathbf{\Delta}$ ) primeiro levantamento, círculo $(\bullet)$ segundo levantamento e quadrado ( $\bullet$ ) terceiro levantamento. (JBB - Jardim Botânico de Brasília, IBGE - Reserva Ecológica do IBGE, PNB - Parque Nacional de Brasília e FLONA - Floresta Nacional de Brasília. 


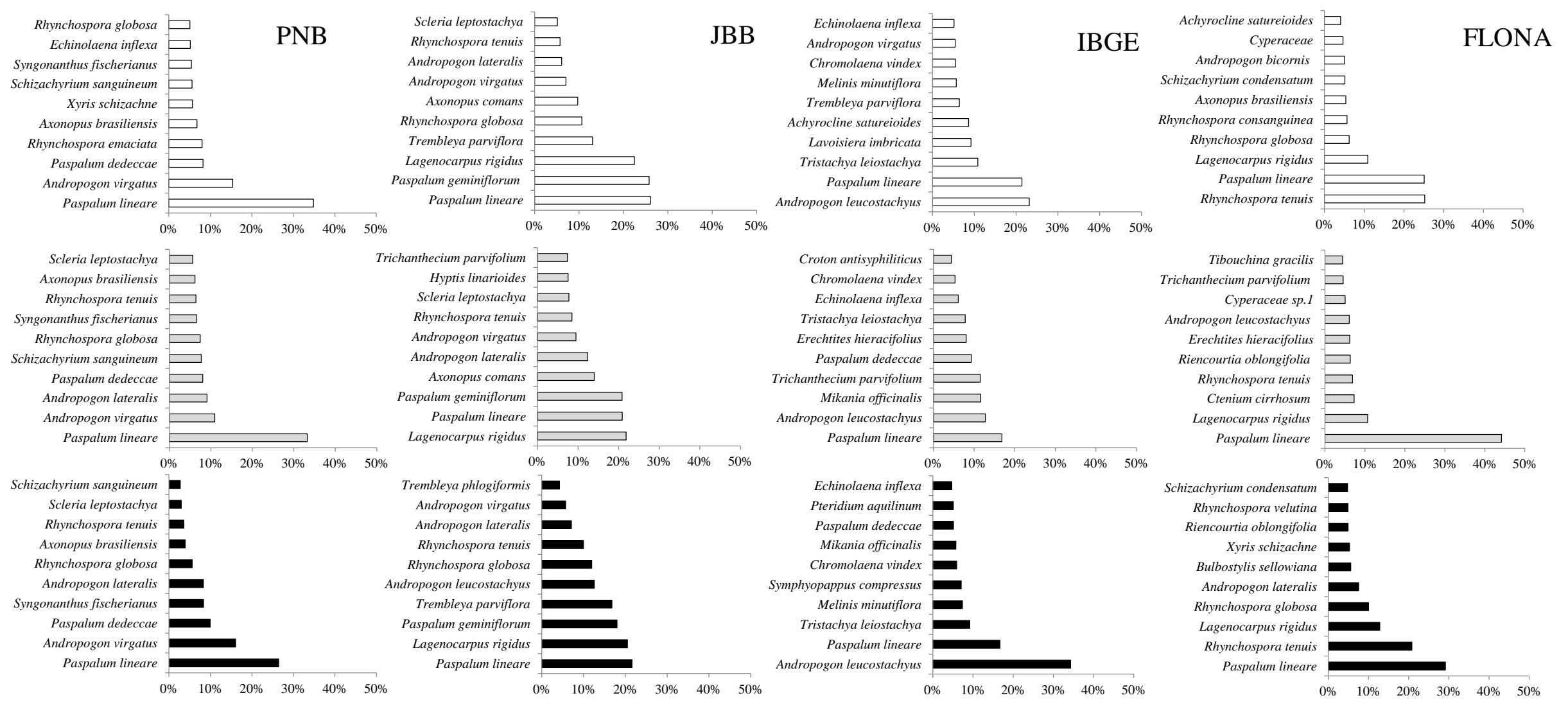

Figura 6 - Valor de Importância \% (soma da cobertura relativa e frequência relativa) das dez principais espécies nos quatro levantamentos realizados no Jardim Botânico de Brasília (JBB), Reserva Ecológica do IBGE (IBGE), Parque Nacional de Brasília (PNB) e Floresta Nacional de Brasília (FLONA). ( $\square$ ) primeiro, ( $\square$ )segundo e ( $\square$ )terceiro levantamento 
Correlações das espécies e variáveis ambientais.

Os solos apresentaram-se ácidos, com altos níveis de alumínio, e baixos níveis de cálcio, magnésio e fósforo (Tabela 3). Os solos apresentaram maiores proporção de areia e elevado teor de matéria orgânica. As variáveis edáficas mensuradas, avaliadas de forma global, diferiram entre as Veredas $(\mathrm{F}=21,79 ; \mathrm{p}<0,001)$, observando que o Fe foi a variável edáfica que mais variou entre as Veredas. Entretanto, o teor de matéria orgânica, saturação por alumínio, $\mathrm{Na}$ e $\mathrm{Zn}$ foram similares entre as Veredas.

Tabela 3 - Características edáficas (médias \pm desvio padrão) da Vereda do Parque Nacional de Brasília (PNB), da Floresta Nacional de Brasília (FLONA), da Estação Ecológica do Jardim Botânico (JBB) e da Reserva Ecológica do Instituto Brasileiro Geografia e Estatística (IBGE). Letras diferentes após os números indicam médias diferentes $(\mathrm{p}<0,05)$, pelo teste de Tukey. CTC $=$ Capacidade de Troca Catiônica, M.O.= Matéria Orgânica, S.B.= Saturação de Bases, S.Al= Saturação por Alumínio. *Váriveis utilizadas na pRDA.

\begin{tabular}{|c|c|c|c|c|}
\hline & FLONA & IBGE & JBB & $\mathrm{PNB}$ \\
\hline $\mathrm{Al}\left(\mathrm{cmolc} \cdot \mathrm{dm}^{-3}\right)^{*}$ & $1,54 \pm 0,42^{\mathrm{a}}$ & $1,13 \pm 0,87^{b}$ & $0,68 \pm 0,20^{\mathrm{c}}$ & $0,47 \pm 0,28^{\mathrm{cd}}$ \\
\hline Areia $(\%)^{*}$ & $75,8 \pm 5,74^{\mathrm{a}}$ & $65,52 \pm 9,39^{b}$ & $67,38 \pm 5,76^{\mathrm{a}}$ & $45,8 \pm 16,7^{\mathrm{c}}$ \\
\hline Argila $\left(\%^{1}\right)$ & $18,6 \pm 4,8^{\mathrm{a}}$ & $26,81 \pm 7,51^{\mathrm{b}}$ & $25,69 \pm 4,82^{\mathrm{a}}$ & $44,07 \pm 14,37^{\mathrm{c}}$ \\
\hline $\mathrm{B}\left(\mathrm{mg} \cdot \mathrm{dm}^{-3}\right) *$ & $0,22 \pm 0,02^{\mathrm{a}}$ & $0,21 \pm 0,01^{\mathrm{b}}$ & $0,22 \pm 0,02^{\mathrm{c}}$ & $0,04 \pm 0,02^{\mathrm{d}}$ \\
\hline $\mathrm{Ca}\left(\mathrm{cmolc} \cdot \mathrm{dm}^{-3}\right)^{*}$ & $0,33 \pm 0,31^{\mathrm{a}}$ & $0,12 \pm 0,05^{\mathrm{b}}$ & $0,12 \pm 0,04^{b}$ & $0,32 \pm 0,21^{\mathrm{a}}$ \\
\hline $\mathrm{Ca}+\mathrm{Mg}\left(\mathrm{cmolc} \cdot \mathrm{dm}^{-3}\right)$ & $0,49 \pm 0,42^{\mathrm{a}}$ & $0,22 \pm 0,05^{\mathrm{b}}$ & $0,22 \pm 0,04^{\mathrm{b}}$ & $0,41 \pm 0,22^{\mathrm{a}}$ \\
\hline $\mathrm{Co}\left(\mathrm{mg} \cdot \mathrm{dm}^{-3}\right)$ & $0,07 \pm 0,01^{\mathrm{a}}$ & $0,08 \pm 0,01^{\mathrm{a}}$ & $0,08 \pm 0,01^{\mathrm{a}}$ & $0,00 \pm 0,00^{\mathrm{b}}$ \\
\hline CTC (mg. $\left.\mathrm{dm}^{-3}\right)$ & $14,94 \pm 3,12^{\mathrm{a}}$ & $8,73 \pm 1,87^{b}$ & $9,18 \pm 1,46^{\mathrm{b}}$ & $9,15 \pm 2,39^{b}$ \\
\hline $\mathrm{Cu}\left(\mathrm{mg} \cdot \mathrm{dm}^{-3}\right)^{*}$ & $0,34 \pm 0,3^{\mathrm{a}}$ & $0,69 \pm 0,33^{b}$ & $0,36 \pm 0,15^{\mathrm{c}}$ & $0,99 \pm 0,4^{\mathrm{d}}$ \\
\hline $\mathrm{Fe}\left(\mathrm{mg} \cdot \mathrm{dm}^{-3}\right)^{*}$ & $165,65 \pm 178,14^{\mathrm{a}}$ & $117,0 \pm 55,68^{\mathrm{b}}$ & $191,84 \pm 86,47^{\mathrm{b}}$ & $187,37 \pm 112,51^{\mathrm{b}}$ \\
\hline 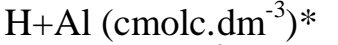 & $14,31 \pm 2,81^{\mathrm{a}}$ & $8,34 \pm 1,84^{b}$ & $8,86 \pm 1,44^{\mathrm{c}}$ & $8,61 \pm 2,3^{\mathrm{cd}}$ \\
\hline $\mathrm{K}\left(\mathrm{cmolc} \cdot \mathrm{dm}^{-3}\right)^{*}$ & $0,12 \pm 0,03^{\mathrm{a}}$ & $0,15 \pm 0,03^{b}$ & $0,08 \pm 0,01^{b}$ & $0,09 \pm 0,04^{b}$ \\
\hline M.O. $\left(\text { g.dm }{ }^{-3}\right)^{*}$ & $16,32 \pm 2,52^{\mathrm{a}}$ & $13,58 \pm 5,07^{\mathrm{a}}$ & $14,42 \pm 4,74^{\mathrm{a}}$ & $19,01 \pm 15,51^{\mathrm{a}}$ \\
\hline $\operatorname{Mg}\left(\text { cmolc. } \mathrm{dm}^{-3}\right)^{*}$ & $0,16 \pm 0,12^{\mathrm{a}}$ & $0,1 \pm 0,00^{\mathrm{b}}$ & $0,1 \pm 0,00^{\mathrm{b}}$ & $0,09 \pm 0,03^{\mathrm{b}}$ \\
\hline $\operatorname{Mn}\left(\mathrm{mg} \cdot \mathrm{dm}^{-3}\right)^{*}$ & $4,23 \pm 4,5^{\mathrm{a}}$ & $2,21 \pm 2^{\mathrm{b}}$ & $1,08 \pm 0,35^{b}$ & $2,09 \pm 1,4^{\mathrm{b}}$ \\
\hline $\operatorname{Mo}\left(\mathrm{mg} \cdot \mathrm{dm}^{-3}\right)$ & $0,06 \pm 0,01^{\mathrm{a}}$ & $0,06 \pm 0,01^{\mathrm{a}}$ & $0,06 \pm 0,01^{\mathrm{a}}$ & $0,00 \pm 0,00^{\mathrm{a}}$ \\
\hline $\mathrm{Na}\left(\mathrm{mg} \cdot \mathrm{dm}^{-3}\right)^{*}$ & $1,99 \pm 0,16^{\mathrm{a}}$ & $4,21 \pm 0,23^{\mathrm{a}}$ & $3,28 \pm 1,09^{\mathrm{a}}$ & $10,2 \pm 5,09^{\mathrm{a}}$ \\
\hline $\mathrm{P}\left(\mathrm{mg} . \mathrm{dm}^{-3}\right)^{*}$ & $5,54 \pm 1,58^{\mathrm{a}}$ & $4,36 \pm 3,8^{b}$ & $3,36 \pm 1,4^{\mathrm{c}}$ & $1,97 \pm 1,40^{\mathrm{cd}}$ \\
\hline $\mathrm{pH}\left(\mathrm{CaCl}_{2}\right)^{*}$ & $4,33 \pm 0,18^{\mathrm{a}}$ & $4,19 \pm 0,23^{\mathrm{a}}$ & $4,26 \pm 0,09^{\mathrm{a}}$ & $4,17 \pm 0,15^{b}$ \\
\hline $\mathrm{S}\left(\mathrm{mg} \cdot \mathrm{dm}^{-3}\right)^{*}$ & $5,69 \pm 0,55^{\mathrm{a}}$ & $6,33 \pm 0,46^{\mathrm{bc}}$ & $5,96 \pm 0,56^{\text {ac }}$ & $9,7 \pm 10,42^{b}$ \\
\hline S. $\mathrm{Al}(\%) *$ & $73,24 \pm 8,42^{\mathrm{a}}$ & $66,36 \pm 16,39^{a}$ & $68,76 \pm 5,43^{\mathrm{a}}$ & $49,02 \pm 14,84^{\mathrm{b}}$ \\
\hline S. B. $(\%) *$ & $3,95 \pm 1,87^{\mathrm{a}}$ & $4,65 \pm 1,10^{\mathrm{ab}}$ & $3,45 \pm 0,48^{\mathrm{ac}}$ & $6,02 \pm 2,67^{b}$ \\
\hline Silte $(\%)$ & $5,6 \pm 1,02^{\mathrm{a}}$ & $7,67 \pm 2,01^{\mathrm{b}}$ & $6,94 \pm 2,25^{\mathrm{a}}$ & $10,13 \pm 2,39^{\mathrm{c}}$ \\
\hline $\mathrm{Zn}\left(\mathrm{mg} \cdot \mathrm{dm}^{-3}\right)^{*}$ & $2,06 \pm 0,99^{\mathrm{a}}$ & $2,42 \pm 1,58^{\mathrm{a}}$ & $0,84 \pm 0,36^{\mathrm{a}}$ & $4,18 \pm 6,97^{\mathrm{a}}$ \\
\hline
\end{tabular}


Devido a multicolinearidade das variáveis ambientais, utilizou-se apenas 18 variáveis edáficas na pRDA. As variáveis ambientais e o espaço explicaram apenas $26 \%$ da variância da estrutura e composição entre as comunidades herbáceo-arbustivas das Veredas estudadas ao longo do tempo e do espaço (Figura 7), o restante da variação estaria relacionado a variáveis ambientais não mensuradas ou a eventos estocásticos. Em relação ao espaço, ocorreu estruturação tanto no sentido norte-sul $(\mathrm{F}=3,87 ; \mathrm{p}<00,1)$, como no lesteoeste $(\mathrm{F}=5,02 ; \mathrm{p}<00,1)$ principalmente para largas escalas espaciais. A variação explicada somente pelas variáveis edáficas selecionadas seria de $8 \%$, sendo que somente $\mathrm{K}, \mathrm{P}, \mathrm{S}, \mathrm{B}$, $\mathrm{Cu}, \mathrm{Fe}$ e Areia foram significativas para o modelo final $(\mathrm{F}=1,91 ; \mathrm{p}<0,01)$.

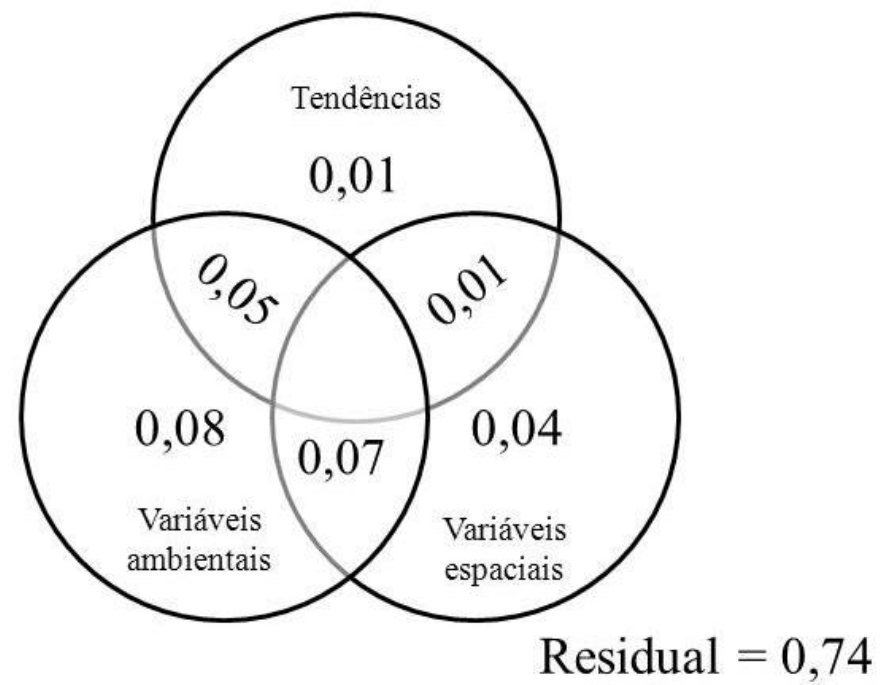

Figura 7 - Partição da variância explicada pelos dados de variáveis ambientais e espaciais na estruturação da comunidade herbáceo-arbustiva do JBB - Jardim Botânico de Brasília, IBGE - Reserva Ecológica do IBGE, PNB - Parque Nacional de Brasília e FLONA - Floresta Nacional de Brasília. 


\section{DISCUSSÃO}

O número de espécies registradas para as Veredas no Distrito Federal encontra-se dentro do esperado para essa fitofisonomia como foi registrado em Goiás (288 espécies Resende et al., 2013), Minas Gerais (101 espécies - Guimarães et al. 2002; 143 espécies Ramos et al., 2014) e Mato Grosso do Sul (67 espécies - Moreira et al.,2015). Assim como para outras áreas úmidas (45 a 98 espécies) no Cerrado com predominância do estrato herbáceo (Cianciaruso e Batalha, 2008; Munhoz e Felfili, 2008; Eugênio et al., 2011; Mendes et al., 2014) com o maior número de espécies das famílias Poaceae, Cyperaceae, Xyridaceae, Asteraceae e Melastomataceae. Em nível de espécie, foram registradas nas quatro Veredas estudadas no Distrito Federal Lagenocarpus rigidus Nees, Rhynchospora rugosa (Vahl) Gale, R. marisculus Lindl. \& Nees, Paspalum lineare Trin., Syngonanthus gracilis (Bong.) Ruhlande S. fischerianus (Bong.) Ruhland que são típicas de zonas permanentementes alagadas (Munhoz et al., 2008; Resende et al., 2013) e espécies típicas de fitosonomias secas do Cerrado como Echinolaena inflexa (Poir.) Chase e Sisyrinchium vaginatum Spreng (Silva e Nogueira, 1999; Munhoz e Felfili, 2006). A elevada riqueza para o estrato herbáceo-arbustivo a essas áreas úmidas são associadasà presença de um ambiente heterogênio com zonas permanentementes alagadas e zonas com alagamento sazonal, o que permite a coexistência de espécies restritas a solos encharcados e espécies de solos mais bem drenados (Munhoz et al., 2008; Resende et al., 2013) formando um complexo vegetacional de elevada riqueza (Araújo et al., 2002).

\section{Dinâmica temporal da comunidade}

As Veredas apresentaram comunidades herbáceo-arbustivas com estabilidade na estrutura e na composição florística. Tanto as áreas que passaram pela perturbação do fogo como a comunidade do PNB evidenciaram parâmetros de diversidade do último levantamento semelhantes aos observados no primeiro. Áreas úmidas naturalmente já apresentam distúrbios naturais devido à variação sazonal do clima e flutuação do lençol freático (Sarmiento et al., 2004; Cianciaruso e Batalha, 2008; Munhoz e Felfili, 2008). Na Vereda do PNB, por exemplo, onde não houve perturbação pelo fogo, os parâmetros de diversidade mantiveram-se constantes entre os levantamentos com variações somente no VI das 10 espécies entre os períodos de amostragem. Essa alternância na ordem de importância das espécies com maiores coberturas também foi observada em ambientes 
úmidos em estudos com dinâmica temporal superiores a três anos (Eugênio et al., 2011; Mendes et al., 2014).

A perturbação por incêndios pode alterar a comunidade herbáceo-arbustiva fortemente em intervalo menor que um ano, tendo como principais efeitos a redução temporária da riqueza e a evidência de espécies que aumentam a reprodução sexuada e/ou assexuada após a passagem do fogo. A ocorrência de incêndios intensifica as taxas de germinação, rebrota ou floração de algumas espécies do estrato herbáceo-arbustivo (San José e Farinas, 1991; Tannus et al., 2006; Munhoz e Felfili, 2007), muitas vezes associadas à maior disponibilidade de luz e menor competividade por recursos (Silva e Nogueira, 1999; Munhoz e Felfili,2006). Para as Veredas, especificamente, não só ocorre o registro de novas espécies após o fogo como se observa aumento no estímulo à floração e frutificação (Araújo et al., 2013). No presente estudo, isso foi observado com o registro de Ctenium cirrhosum (Nees) Kunth(Poaceae) somente no levantamento após o fogo, para as três Veredas que sofreram o incêndio, assim como o aumento da cobertura de Mikania officinalis Mart. (Asteraceae). Ou seja, o fogo exerce a função de garantir a presença de algumas espécies quando ocorrem incêndios de forma ocasional, visto que o fogo é comum no Cerrado, e muitas espécies evoluíram características adaptadas a ele (Simon et al., 2009).

A diferença na resposta da comunidade herbáceo-arbustiva a um distúrbio, como o fogo, encontra-se relacionada ao número de espécies e quais espécies compõem a comunidade. Por exemplo, a Vereda do IBGE mesmo passando por incêndio não apresentou grandes mudanças nos parâmetros de diversidade, principalmente no que se refere ao número de espécies, enquanto a Vereda do JBB demonstrou variação para esses parâmetros. A primeira Vereda apresentou a maior riqueza (109 espécies) enquanto a segunda apresentou a menor riqueza (53 espécies), dentre as Veredas estudadas, corroborando a ideia de que comunidades mais ricas (mais diversas) tendem a ser mais estáveis que comunidades menos ricas (Connell 1978). Santos e Munhoz (2012) assumem que a baixa riqueza no JBB estaria relacionada à grande população de $T$. parviflora, espécie que aumenta a competição no ambiente e reduz a entrada de luz, e ainda apresenta compostos aleloquímicos que altera o processo de germinação e desenvolvimento de outras espécies (Borghetti et al., 2005). Essa mesma espécie vem demonstrando aumento da população relacionada a alterações antrópicas como abertura de estradas em Unidades de Conservação e alteração no regime hídrico destas áreas, principalmente com a redução do lençol freático (Silva-Júnior e Felfili 1996; Meirelles et al. 2004). 


\section{Correlações das espécies e variáveis ambientais}

Veredas podem apresentar variação na composição físico-química do solo em função da origem e intensidade de deposição de sedimentos, variação da flutuação do lençol freático e a própria ação antrópica (Ramos et al., 2006). Apesar das quatro Veredas apresentarem características físico-químicas distintas, as variáveis edáficas mensuradas, em nível de escala regional explicaram pouco na distribuição das espécies. Entretanto, em escala local as variações da distribuição das espécies encontram-se associadas principalmente ao nível de umidade do solo e quantidade de matéria orgânica (Guimarães et al.,2002; Munhoz et al., 2008), assim como ao teor de Fe e Areia (Mendes et al., 2014). Para as quatro Veredas do Distrito Federal, o teor de Fe foi a principal variável responsável pela distinção entre as áreas, assim como a variável com maior peso na análise multivariada. Porém, associa-se a baixa explicação das variáveis edáficas mensuradas na explicação da distribuição de espécie à alta correlação espacial em pequenas distâncias devido à alta heterogeneidade do ambiente associado à flutuação do lençol freático, visto que, quando presente na análise multivariada, ela passa a ter um maior peso (Munhoz et al., 2008; Mendes et al., 2014 ). Assim como a alta correlação espacial em grandes distâncias fazendo com que as Veredas mais próximas espacialmente tenham uma composição florística e edáfica mais similar.

\section{CONCLUSÃO}

As Veredas apresentam composição florística do estrato herbáceo-arbustivo distinta entre si, o que demostra a peculiaridade de cada local independente de pertencer à mesma fitofisionomia. A composição florística desse estrato não apresentou alterações significativas localmente, dentro do intervalo de tempo estudado, mesmo com o distúrbio pelo fogo, formando comunidade persistente. As variáveis ambientais e o espaço explicaram apenas $26 \%$ da variação das comunidades herbáceo-arbustivas das Veredas estudadas ao longo do tempo e do espaço. 


\section{REFERÊNCIAS}

APG IV. (2016). An update of the Angiosperm Phylogeny Group classification for the orders and families of flowering plants: APG IV

Araújo, G. M., Amaral, A. F., Bruna, E. M., \& Vasconcelos, H. L. (2013). Fire drives the reproductive responses of herbaceous plants in a Neotropical swamp. Plant Ecology, 214, 1479-1484.

Araújo, G. M., Barbosa, A. A. A., Arantes, A. A., \& Amaral, A. F. (2002). Composição florística de veredas no Município de Uberlândia, MG. Revista Brasileira de Botânica, 25, 475-493.

Anderson, M. J., \& Willis, T. J. (2003). Canonical analysis of principal coordinates: a useful method of constrained ordination for ecology. Ecology, 84, 511-525.

Bakker, J. P., Olff, H., Willems, J. H., \& Zobel, M. (1996). Why do we need permanent plots in the study of long-term vegetation dynamics? Journal of Vegetation Science, 7, 147-155.

Bond, W. J., Woodward, F. I., \& Midgley, G. F. (2005). The global distribution of ecosystems in a world without fire. New Phytologist, 165, 525-538.

Borghetti, F., Silva, L., Pinheiro, J. D., Varella, B. B., Ferreira, A. G., Harper, J. D. I., \& Kent, J. H. (2005). Aqueous leaf extract properties of Cerrado species in Central Brazil. In: J.D.I. Harper, An M, Wu H, J.H. Kent (Eds.). Proceedings of the 4th World Congress on Allelopathy, Wagga Wagga, New South Wales, Australia, 388390.

Canfield, R. H. (1941). Application of the line interception method in sampling range vegetation. Journal of Forestry, 39, 388-394.

Canfield, R. H. (1950). Sampling range by the line interception method. Southwestern Forest and Range Experiment Station Research. Report 4.

Chao, A. (1987). Estimating the population size for capture-recapture data with unequal catchability. Biometrics 43, 783-791. 
Chao, A., Chazdon, R. L., Colwell, R. K., \& Shen, T. J. (2005). A new statistical approach for assessing similarity of species composition with incidence and abundance data. Ecology Letters, 8, 148-159.

Chao, A., Chazdon, R. L., Colwell, R. K., \& Shen, T. J. (2006). Abundance-based similarity indices and their estimation when there are unseen species in samples. Biometrics, 62, 361-371.

Chao, A., Gotelli, N. J., Hsieh, T. C., Sander, E. L., Ma, K. H., Colwell, R. K., \& Ellison, A. M. (2014). Rarefaction and extrapolation with Hill numbers: a framework for sampling and estimation in species diversity studies. Ecological Monographs, 84, 4567.

Cianciaruso, M. V., \& Batalha, M. A. (2008). A year in a Cerrado wet grassland: a nonseasonal island in a seasonal savanna environment. Brazilian Journal of Biology, 68, 495-501.

Clarke, K. R. (1993). Non-parametric multivariate analyses of changes in community structure. Australian Journal of Ecology, 18, 117-117.

Connell, J. H. (1978). Diversity in tropical rain forests and coral reefs. Science, 199, 13021310.

Colwell, R. K. (2013). Estimates: Statistical estimation of species richness e shared species from samples, Version 9.0. User's Guide e application published at: http://viceroy.eeb.uconn.edu/ estimates. Persistent URL http://purl.oclc.org/estimates.

Coutinho, L. M. (1990). Fire in the ecology of the Brazilian cerrado. 82-105. In: J. G. Goldammer (ed.). Fire in the Tropical Biota. Ecological Studies, 84. Berlin, Springer Verlag.

Diniz-Filho, J. A. F., Siqueira, T., Padial, A. A., Rangel, T. F., Landeiro, V. L., \& Bini, L. M. (2012). Spatial autocorrelation analysis allows disentangling the balance between neutral and niche processes in metacommunities. Oikos,121, 201-210.

Dormann, C. F., McPherson, M. J., Araújo, M. B., Bivand, R., Bolliger, J., Carl, G., Davies, R. G., Hirzel, A., Jetz, W. W., Kissling, D., Kühn, I., Ohlemüller, R., Peres- 
Neto, P. R., Reineking, B., Schröder, B., Schurr., F. M. \& Wilson, R. (2007). Methods to account for spatial autocorrelation in the analysis of species distributional data: a review. Ecography, 30, 609-628.

Durigan, G., \& Ratter, J. A. (2006). Successional changes in cerrado and cerrado/forest ecotonal vegetation in western Sao Paulo State, Brazil, 1962-2000. Edinburgh Journal of Botany, 63, 119-130.

Dray, S., Legendre, P., \& Peres-Neto, P. R. (2006). Spatial modelling: a comprehensive framework for principal coordinate analysis of neighbour matrices (PCNM). Ecological Modelling, 196, 483-493.

Eilts, J. A., Mittelbach, G. G., Reynolds, H. L., \& Gross, K. L. (2011). Resource heterogeneity, soil fertility, and species diversity: effects of clonal species on plant communities. The American Naturalist, 177, 574-588.

Embrapa. (1997). Manual de métodos de análise de solo. Centro Nacional de Pesquisas de Solos. Rio de Janeiro, Embrapa.

Eugênio, C. U. O., Munhoz, C. B. R., \& Felfili, J. M. (2011). Dinâmica temporal do estrato herbáceo-arbustivo de uma área de campo limpo úmido em Alto Paraíso de Goiás, Brasil. Acta Botanica Brasilica, 25, 497-507.

Fidelis, A., Muller, S. C., Pillar, V. D. P., \& Pfadenhauer, J. (2007). Efeito do fogo na ecologia de populações de herbáceas e arbustos dos campos sulinos. Revista Brasileira de Biociências, 5, 303-305.

Guimarães, A. J. M., de Araújo, G. M., \& Corrêa, G. F. (2002). Estrutura fitossociológica em área natural e antropizada de uma Vereda em Uberlândia, MG. Acta Botanica Brasilica, 16, 317-329.

Kent, M., \& Coker, P. (1992). Vegetation description and analysis: a pratical approach. Belhaven Press, London.

Legendre, P. (1993). Spatial autocorrelation: trouble or new paradigm? Ecology, 74, 16591673. 
Legendre, P., \& Gallagher, E. D. (2001). Ecologically meaningful transformations for ordination of species data. Oecologia, 129, 271-280.

Lennon J. J. (2000) Red-shifts and red herrings in geographical ecology. Ecograph 23, 101-113.

Lichstein, J. W., Simons, T. R., Shriner, S. A., \& Franzreb, K. E. (2002). Spatial autocorrelation and autoregressive models in ecology. Ecological Monographs, 72, 445-463.

Meirelles, M. L.; Guimarães, A. J. M.; Oliveira, R. C.; Araújo, G. M.; \& Ribeiro, J. F. (2004). Impactos sobre o estrato herbáceo de áreas úmidas do Cerrado. 41-68. In: Aguiar, L. M. S.; Camargo, A. J. A. (ed.). Cerrado: ecologia e caracterização. Embrapa Cerrados, Brasília.

Mendes, M. R. A., Júnior, S., Castro, A. A. J. F., Takahashi, F. S. C., \& Munhoz, C. B. R. (2014). Temporal change in species and functional plant traits in the moist grassland on the Sete Cidades National Park, Piauí, Brazil. Brazilian Journal of Biology, 74, 111-123.

Miranda, A. C., Miranda, H. S., Dias, I. F. O., \& Dias, B. F S. (1993). Soil and air temperatures during prescribed cerated fires in Central Brazil. Journal of Tropical Ecology, 9, 313-320.

Miranda, H. S., Bustamante, M. M. C., Miranda, A. C., Oliveira, P., \& Marquis, R. (2002). The fire factor. The Cerrados of Brazil. Ecology and Natural History of a Neotropical Savanna, 51-68.

Moreira, A. G. (2000). Effects of fire protection on savanna structure in Central Brazil. Journal of Biogeography, 27, 1021-1029.

Moreira, S. N., Eisenlohr, P. V., Pott, A., Pott, V. J., \& Oliveira-Filho, A. T. (2015). Similar vegetation structure in protected and non-protected wetlands in Central Brazil: conservation significance. Environmental Conservation, 42(04), 356-362.

Munhoz, C. B. R., \& Araújo, G. M. (2011). Métodos de amostragem do estrato herbáceosubarbustivo. 213-230. In: Felfili, J. M., Eisenlohr, P. E., Melo, M. M. R. F, Andrade, 
L. A., \& Meira-Neto, J. A. A. (eds). Fitossociologia no Brasil - Métodos e Estudos de caso. Universidade Federal de Viçosa, Viçosa.

Munhoz, C. B. R., \& Felfili, J. M. (2006). Floristics of the herbaceous and subshrub layer of a moist grassland in the Cerrado biosphere reserve (Alto Paraíso de Goiás), Brazil. Edinburgh Journal of Botany, 63, 343-354.

Munhoz, C. B. R., \& Felfili, J. M. (2007). Reproductive phenology of an herbaceoussubshrub layer of a Savannah (Campo Sujo) in the Cerrado Biosphere Reserve I, Brazil. Brazilian Journal of Biology, 67, 299-307.

Munhoz, C. B. R., \& Felfili, J. M. (2008). Fitossociologia do estrato herbáceo-subarbustivo em campo limpo úmido no Brasil Central. Acta Botanica Brasilica, 22, 905-913.

Munhoz, C. B. R., Felfili, J. M., \& Rodrigues, C. (2008). Species-environment relationship in the herb-subshrub layer of a moist Savanna site, Federal District, Brazil. Brazilian Journal of Biology, 68, 25-35.

Nardoto, G. B., Bustamante, M. M. C., Pinto, A. S., \& Klink, C. A. (2006). Nutrient use efficiency at ecosystem and species level in savanna areas of Central Brazil and impacts of fire. Journal of Tropical Ecology, 22, 191-201.

Oksanen, J., Kindt, R., Legendre, P., O’Hara, B., Stevens, M. H. H., Oksanen, M. J., \& Suggests, M. A. S. S. (2007). The vegan package. Community Ecology Package, 631 637.

Peres-Neto, P. R., Legendre, P., Dray, S., \& Borcard, D. (2006). Variation partitioning of species data matrices: estimation and comparison of fractions. Ecology, 87, 26142625.

Pinheiro, E. D. S., \& Durigan, G. (2009). Dinâmica espaço-temporal (1962-2006) das fitofisionomias em unidade de conservação do Cerrado no sudeste do Brasil. Revista Brasileira de Botânica, 32, 441-454.

Pivello, V. R. (2011) The use of fire in the Cerrado and Amazonian rainforests of Brazil: past and present. Fire Ecology, 7, 24-39. 
Ramos, M. V. V., Curi, N., Motta, P. D., Vitorino, A. C. T., Ferreira, M. M., \& Silva, M. L. N. (2006). Veredas do Triângulo Mineiro: solos, água e uso. Ciência Agrotécnica, 30, 283-293.

Ramos, M. V. V., Haridasan, M., \& de Araújo, G. M. (2014). Caracterização dos Solos e da Estrutura Fitossociológica da Vegetação de Veredas da Chapada no Triângulo Mineiro. Fronteiras: Sociedade, Tecnologia e Meio Ambiente, 3, 177-207.

Ramos-Neto, M. B., \& Pivello, V. R. (2000). Lightning fires in a Brazilian savanna National Park: rethinking management strategies. Environmental Management, 26, 675-684.

Resende, I. L. D. M., Chaves, L. J., \& Rizzo, J. A. (2013). Floristic and phytosociological analysis of palm swamps in the central part of the Brazilian savanna. Acta Botanica Brasilica, 27, 205-225.

Ribeiro, J. F., \& Walter, B. M. T. (2008). As principais fitofisionomias do bioma Cerrado. 151-199. In: Sano, S. M., Almeida, S. P., \& Ribeiro, J. F. (eds.). Cerrado: Ecologia e flora. Embrapa Cerrados, Brasília.

San José, J. J., \& Farinas, M. R. (1991). Temporal changes in the structure of a Trachypogon savanna protected for 25 years. Acta Ecologica, 12, 237-247.

Santos, F. F. M., \& Munhoz, C. B. R. (2012). Diversidade de espécies herbáceo-arbustivas e zonação florística em uma Vereda no Distrito Federal. Heringeriana, 6, 21-27.

Sarmiento, G., Pinillos, M., Silva, M. P. D., \& Acevedo, D. (2004). Effects of soil water regime and grazing on vegetation diversity and production in a hyperseasonal savanna in the Apure Llanos, Venezuela. Journal of Tropical Ecology, 20, 209-220.

Silva, M. A., \& Nogueira, P. E. (1999). Avaliação fitossociológica do estrato arbustivo herbáceo em cerrado stricto sensu após incêndio acidental, no Distrito Federal, Brasil. Boletim do Herbário Ezechias Paulo Heringer, 4, 65-78.

Silva-Júnior, M. C., \& Felfili, J. M. (1996). A vegetação da Estação Ecológica de Águas Emendadas. Instituto de Ecologia e Meio Ambiente do Distrito Federal, Brasília. 
Simon, M. F., Grether, R., de Queiroz, L. P., Skema, C., Pennington, R. T., \& Hughes, C. E. (2009). Recent assembly of the Cerrado, a neotropical plant diversity hotspot, by in situ evolution of adaptations to fire. Proceedings of the National Academy of Sciences, 106, 20359-20364.

Tannus, J. L., Assis, M. A., \& Morellato, L. P. C. (2006). Fenologia reprodutiva em campo sujo e campo úmido numa área de cerrado no sudeste do Brasil, Itirapina-SP. Biota Neotropica, 6, 1-27.

Zar, J.H. (2009). Biostatistical analysis. $5^{\text {th }}$. New Jersey, USA. 
Anexo 1 - Valor de importância (\%) de espécies amostradas na comunidade herbáceo-arbustiva nos anos de 2009, 2012, 2013 e 2014, registradas em área de Vereda no Parque Nacional de Brasília (PNB), na Floresta Nacional de Brasília (FLONA), Estação Ecológica do Jardim Botânico (JBB) e Reserva Ecológica do Instituto Brasileiro Geografia e Estatística (IBGE). Tabela organizada em ordem alfabética da Família Botânica. H: Hábito; S: Subarbusto; E: Erva; L: Liana; P: Palmeira; A: Arbusto.

\begin{tabular}{|c|c|c|c|c|c|c|c|c|c|c|c|c|c|}
\hline \multirow{2}{*}{ Família/Espécie } & \multirow{2}{*}{$\mathrm{H}$} & \multicolumn{3}{|c|}{ FLONA } & \multicolumn{3}{|c|}{ IBGE } & \multicolumn{3}{|c|}{ JBB } & \multicolumn{3}{|c|}{ PNB } \\
\hline & & 2009 & 2012 & 2013 & 2010 & 2012 & 2014 & 2010 & 2012 & 2014 & 2009 & 2012 & 2013 \\
\hline \multicolumn{14}{|l|}{ Acanthaceae } \\
\hline Justicia pycnophylla Lindau & $\mathrm{S}$ & 0,00 & 0,00 & 0,00 & 0,61 & 0,00 & 0,29 & 0,00 & 0,00 & 0,00 & 0,00 & 0,00 & 0,00 \\
\hline Ruellia incomta (Nees) Lindau & $S$ & 0,00 & 0,34 & 0,00 & 0,31 & 1,83 & 0,31 & 0,00 & 0,00 & 0,00 & 0,00 & 0,00 & 0,00 \\
\hline \multicolumn{14}{|l|}{ Alstroemeriaceae } \\
\hline Alstroemeria longistyla Schenk & $\mathrm{E}$ & 1,12 & 4,26 & 2,06 & 0,00 & 1,00 & 0,00 & 0,00 & 0,00 & 0,00 & 0,42 & 0,41 & 0,00 \\
\hline \multicolumn{14}{|l|}{ Apiaceae } \\
\hline Eryngium juncifolium (Urb.) Mathias \& Constance & $\mathrm{E}$ & 0,00 & 0,00 & 0,00 & 0,00 & 1,39 & 0,98 & 0,00 & 0,00 & 0,00 & 0,00 & 0,00 & 0,00 \\
\hline Eryngium sp. 1 & $\mathrm{E}$ & 0,34 & 0,00 & 0,00 & 0,00 & 0,00 & 0,00 & 0,00 & 0,00 & 0,00 & 0,00 & 0,00 & 0,00 \\
\hline Eryngium sp. 2 & $\mathrm{E}$ & 0,00 & 0,00 & 0,00 & 0,00 & 0,00 & 0,00 & 0,00 & 0,00 & 0,00 & 0,00 & 0,00 & 0,44 \\
\hline \multicolumn{14}{|l|}{ Apocynaceae } \\
\hline Minaria cordata (Turcz.) T.U.P.Konno \& Rapini & $\mathrm{S}$ & 0,00 & 0,00 & 0,00 & 0,93 & 0,00 & 0,31 & 0,00 & 0,00 & 0,00 & 0,41 & 0,46 & 0,43 \\
\hline Oxypetalum appendiculatum Mart. & $\mathrm{L}$ & 1,85 & 1,51 & 0,68 & 0,30 & 1,04 & 0,61 & 0,00 & 0,80 & 0,00 & 0,00 & 0,44 & 0,99 \\
\hline \multicolumn{14}{|l|}{ Araceae } \\
\hline Philodendron sp.1 & $\mathrm{E}$ & 0,41 & 0,00 & 0,38 & 0,00 & 0,00 & 0,00 & 0,00 & 0,00 & 0,00 & 0,00 & 0,00 & 0,00 \\
\hline Xanthosoma striatipes (Kunth) Madison & $\mathrm{E}$ & 1,33 & 1,35 & 1,30 & 0,00 & 0,00 & 0,00 & 0,00 & 0,00 & 0,00 & 0,00 & 0,00 & 0,00 \\
\hline \multicolumn{14}{|l|}{ Arecaceae } \\
\hline Mauritia flexuosa L.f. & $\mathrm{P}$ & 0,00 & 0,00 & 0,00 & 0,73 & 0,59 & 0,57 & 0,00 & 0,00 & 0,00 & 0,00 & 0,00 & 0,00 \\
\hline \multicolumn{14}{|l|}{ Asteraceae } \\
\hline Achyrocline alata (Kunth) DC. & $\mathrm{S}$ & 1,54 & 0,00 & 0,79 & 0,00 & 0,00 & 0,42 & 2,01 & 0,00 & 0,51 & 0,00 & 0,41 & 1,60 \\
\hline Achyrocline satureioides (Lam.) DC. & $\mathrm{E}$ & 4,06 & 1,34 & 1,11 & 8,62 & 0,83 & 4,39 & 2,17 & 0,00 & 1,58 & 0,00 & 0,82 & 0,48 \\
\hline Aspilia foliacea (Spreng.) Baker & $\mathrm{E}$ & 0,00 & 0,00 & 0,00 & 0,00 & 0,50 & 1,12 & 0,00 & 0,00 & 0,00 & 0,85 & 0,00 & 0,00 \\
\hline
\end{tabular}


Continuação

\begin{tabular}{|c|c|c|c|c|c|c|c|c|c|c|c|c|c|}
\hline \multirow{2}{*}{ Família/Espécie } & \multirow{2}{*}{$\mathrm{H}$} & \multicolumn{3}{|c|}{ FLONA } & \multicolumn{3}{|c|}{ IBGE } & \multicolumn{3}{|c|}{ JBB } & \multicolumn{3}{|c|}{ PNB } \\
\hline & & 2009 & 2012 & 2013 & 2010 & 2012 & 2014 & 2010 & 2012 & 2014 & 2009 & 2012 & 2013 \\
\hline Aspilia montevidensis (Spreng.) Kuntze & $\mathrm{E}$ & 0,35 & 0,59 & 0,38 & 0,00 & 0,00 & 0,00 & 0,00 & 0,00 & 0,00 & 0,00 & 0,00 & 0,00 \\
\hline Asteraceae sp.1 & $\mathrm{E}$ & 0,35 & 0,52 & 0,00 & 0,00 & 0,00 & 0,00 & 0,00 & 0,00 & 0,00 & 0,00 & 0,00 & 0,00 \\
\hline Asteraceae sp.2 & $\mathrm{E}$ & 0,00 & 0,00 & 0,00 & 0,00 & 0,96 & 0,00 & 0,00 & 0,00 & 0,00 & 0,00 & 0,00 & 0,00 \\
\hline Asteraceae sp. 3 & $\mathrm{E}$ & 0,00 & 0,00 & 0,00 & 1,06 & 0,38 & 1,28 & 0,00 & 0,00 & 0,00 & 0,00 & 0,00 & 0,00 \\
\hline Asteraceae sp.4 & $\mathrm{S}$ & 0,00 & 0,00 & 0,00 & 0,00 & 0,00 & 0,00 & 0,00 & 0,00 & 0,00 & 1,00 & 1,55 & 1,70 \\
\hline Ayapana amygdalina (Lam.) R.M.King \& H.Rob. & $\mathrm{S}$ & 0,00 & 0,00 & 0,00 & 0,32 & 0,00 & 0,00 & 0,00 & 0,00 & 0,00 & 0,46 & 0,00 & 0,00 \\
\hline Baccharis reticulata (Ruiz \& Pav.) Pers. & A & 0,00 & 0,00 & 0,00 & 0,00 & 0,00 & 0,00 & 0,00 & 0,00 & 0,00 & 1,81 & 1,36 & 0,00 \\
\hline Baccharis retusa DC. & A & 0,36 & 0,70 & 1,69 & 0,00 & 0,00 & 0,00 & 0,63 & 0,54 & 3,59 & 0,00 & 0,00 & 0,00 \\
\hline Chromolaena laevigata (Lam.) R.M. King \& H. Rob. & A & 0,00 & 0,00 & 0,00 & 0,50 & 0,00 & 0,54 & 0,00 & 0,00 & 0,00 & 0,00 & 0,00 & 0,00 \\
\hline Chromolaena vindex (DC.) R.M.King \& H.Rob. & $\mathrm{S}$ & 0,00 & 0,00 & 0,00 & 5,50 & 5,32 & 5,95 & 0,00 & 0,00 & 0,38 & 0,00 & 0,00 & 0,00 \\
\hline Elephantopus elongatus Gardner & $\mathrm{S}$ & 0,00 & 0,00 & 0,00 & 0,00 & 0,00 & 0,91 & 0,00 & 0,00 & 0,00 & 0,00 & 0,00 & 0,00 \\
\hline Erechtites hieracifolius (L.) Raf. ex DC. & $\mathrm{E}$ & 0,40 & 6,19 & 0,53 & 0,00 & 8,05 & 0,00 & 0,00 & 1,06 & 0,00 & 0,00 & 1,34 & 0,00 \\
\hline Ichthyothere latifolia Baker & $\mathrm{S}$ & 0,37 & 0,00 & 0,00 & 0,00 & 1,07 & 0,99 & 0,00 & 0,00 & 0,00 & 0,00 & 0,00 & 0,00 \\
\hline Lepidaploa aurea (Mart. ex DC.) H.Rob. & A & 0,00 & 0,00 & 0,00 & 0,00 & 0,00 & 0,00 & 0,00 & 0,00 & 0,38 & 0,00 & 0,00 & 0,00 \\
\hline Lessingianthus argyrophyllus (Less.) H.Rob. & $\mathrm{S}$ & 0,00 & 0,00 & 0,00 & 0,00 & 0,00 & 0,00 & 0,00 & 0,00 & 0,00 & 0,40 & 0,00 & 0,00 \\
\hline Lessingianthus eitenii (H.Rob.) H.Rob. & $\mathrm{S}$ & 0,00 & 0,00 & 0,00 & 0,00 & 0,00 & 0,00 & 0,62 & 0,87 & 0,42 & 0,00 & 0,00 & 0,00 \\
\hline Lessingianthus grearii (H.Rob.) H.Rob. & $\mathrm{S}$ & 0,00 & 0,00 & 0,00 & 0,32 & 0,32 & 0,00 & 0,00 & 0,00 & 0,00 & 0,00 & 0,00 & 0,00 \\
\hline Mikania microcephala DC. & $\mathrm{L}$ & 0,00 & 0,00 & 0,00 & 0,36 & 0,81 & 0,57 & 0,00 & 0,00 & 0,00 & 0,00 & 0,00 & 0,00 \\
\hline Mikania officinalis Mart. & $\mathrm{S}$ & 0,36 & 3,08 & 0,85 & 4,17 & 11,65 & 5,74 & 0,62 & 3,05 & 0,84 & 1,83 & 2,82 & 3,55 \\
\hline Raulinoreitzia leptophlebia (B.L.Rob.) R.M.King \& H.Rob. & A & 1,54 & 1,83 & 2,16 & 1,07 & 0,00 & 0,00 & 1,29 & 1,48 & 1,02 & 0,53 & 0,44 & 0,75 \\
\hline Riencourtia oblongifolia Gardner & $\mathrm{S}$ & 3,88 & 6,31 & 4,94 & 1,87 & 2,67 & 2,67 & 0,55 & 0,00 & 0,00 & 0,00 & 0,00 & 0,00 \\
\hline Senecio adamantinus Bong. & $\mathrm{E}$ & 1,22 & 1,49 & 1,69 & 0,00 & 0,00 & 0,00 & 0,00 & 0,00 & 0,00 & 0,00 & 0,00 & 0,00 \\
\hline Stevia heptachaeta DC. & $\mathrm{E}$ & 0,00 & 0,00 & 0,00 & 0,00 & 0,00 & 0,00 & 0,00 & 0,00 & 0,00 & 0,46 & 0,47 & 0,44 \\
\hline Symphyopappus compressus (Gardner) B.L.Rob. & A & 0,00 & 0,77 & 0,00 & 3,63 & 2,46 & 7,07 & 0,00 & 0,00 & 0,00 & 0,00 & 0,00 & 0,00 \\
\hline
\end{tabular}


Continuação

\begin{tabular}{|c|c|c|c|c|c|c|c|c|c|c|c|c|c|}
\hline \multirow{2}{*}{ Família/Espécie } & \multirow{2}{*}{$\mathrm{H}$} & \multicolumn{3}{|c|}{ FLONA } & \multicolumn{3}{|c|}{ IBGE } & \multicolumn{3}{|c|}{ JBB } & \multicolumn{3}{|c|}{ PNB } \\
\hline & & 2009 & 2012 & 2013 & 2010 & 2012 & 2014 & 2010 & 2012 & 2014 & 2009 & 2012 & 2013 \\
\hline Vernonanthura phosphorica (Vell.) H.Rob. & $\mathrm{S}$ & 0,00 & 0,00 & 0,00 & 0,37 & 0,00 & 0,00 & 0,00 & 0,00 & 0,00 & 0,00 & 0,00 & 0,00 \\
\hline Vernonia rubriramea Mart. ex DC. & $\mathrm{S}$ & 0,00 & 0,00 & 0,00 & 0,00 & 0,00 & 0,00 & 0,58 & 0,00 & 0,00 & 0,00 & 0,00 & 0,00 \\
\hline Wedelia cf. bishopii H.Rob. & $\mathrm{S}$ & 0,00 & 0,00 & 0,00 & 0,33 & 0,82 & 0,78 & 0,00 & 0,00 & 0,00 & 0,00 & 0,00 & 0,00 \\
\hline \multicolumn{14}{|l|}{ Bignoniaceae } \\
\hline Jacaranda ulei Bureau \& K.Schum. & A & 0,00 & 0,00 & 0,00 & 0,00 & 0,73 & 0,00 & 0,00 & 0,00 & 0,00 & 0,00 & 0,00 & 0,00 \\
\hline \multicolumn{14}{|l|}{ Campanulaceae } \\
\hline Lobelia brasiliensis A.O.S.Vieira \& G.J.Sheph. & $\mathrm{E}$ & 1,98 & 0,88 & 0,99 & 0,33 & 0,00 & 0,00 & 0,00 & 0,00 & 0,00 & 0,00 & 0,00 & 0,00 \\
\hline \multicolumn{14}{|l|}{ Celastraceae } \\
\hline Peritassa campestris (Cambess.) A.C.Sm. & $S$ & 0,00 & 0,00 & 0,00 & 0,93 & 0,79 & 0,31 & 0,00 & 0,00 & 0,00 & 0,00 & 0,00 & 0,00 \\
\hline \multicolumn{14}{|l|}{ Convolvulaceae } \\
\hline Ipomoea geophilifolia K. Afzel. & $\mathrm{E}$ & 0,00 & 0,00 & 0,00 & 0,00 & 0,00 & 0,00 & 0,64 & 1,52 & 0,40 & 0,00 & 0,00 & 0,58 \\
\hline Ipomoea procurrens Meisn. & $\mathrm{L}$ & 0,00 & 0,00 & 0,00 & 0,30 & 1,29 & 0,68 & 0,00 & 0,00 & 0,00 & 0,40 & 0,81 & 0,00 \\
\hline \multicolumn{14}{|l|}{ Cucurbitaceae } \\
\hline Cayaponia espelina (Silva Manso) Cogn. & $\mathrm{L}$ & 0,00 & 0,00 & 0,00 & 0,00 & 0,00 & 0,00 & 0,55 & 0,00 & 0,00 & 0,00 & 0,00 & 0,00 \\
\hline \multicolumn{14}{|l|}{ Cyperaceae } \\
\hline Ascolepis brasiliensis (Kunth) Benth. ex C.B.Clarke & $\mathrm{E}$ & 0,34 & 0,00 & 0,00 & 0,00 & 0,00 & 0,00 & 0,00 & 0,00 & 0,00 & 0,00 & 0,00 & 0,00 \\
\hline Bulbostylis hirtella (Schrad.) Urb. & $\mathrm{E}$ & 0,00 & 0,00 & 0,00 & 0,00 & 0,00 & 0,00 & 0,00 & 0,00 & 0,00 & 1,09 & 0,00 & 0,48 \\
\hline Bulbostylis junciformis (Kunth) C.B.Clarke & $\mathrm{E}$ & 0,00 & 0,00 & 0,00 & 1,05 & 1,18 & 0,48 & 0,00 & 0,00 & 0,00 & 0,00 & 0,00 & 0,00 \\
\hline Bulbostylis sellowiana (Kunth) Palla & $\mathrm{E}$ & 3,51 & 3,84 & 5,61 & 0,52 & 2,44 & 0,72 & 0,00 & 1,96 & 1,93 & 0,44 & 0,41 & 1,05 \\
\hline Calyptrocarya glomerulata (Brongn.) Urb. & $\mathrm{E}$ & 0,62 & 0,00 & 0,36 & 0,00 & 0,00 & 0,00 & 0,00 & 0,00 & 0,00 & 0,00 & 0,00 & 0,00 \\
\hline Cyperaceae sp.1 & $\mathrm{E}$ & 4,66 & 5,05 & 1,38 & 0,00 & 0,00 & 0,00 & 0,00 & 0,00 & 0,00 & 0,00 & 0,00 & 0,00 \\
\hline Eleocharis filiculmis Kunth & $\mathrm{E}$ & 1,02 & 1,47 & 1,61 & 0,00 & 0,00 & 0,00 & 0,00 & 0,00 & 0,00 & 0,00 & 0,40 & 1,16 \\
\hline Lagenocarpus rigidus Nees & $\mathrm{E}$ & 10,90 & 10,67 & 12,84 & 0,00 & 0,00 & 0,00 & 22,48 & 21,85 & 20,51 & 0,98 & 1,06 & 0,70 \\
\hline
\end{tabular}

Continuação 


\begin{tabular}{|c|c|c|c|c|c|c|c|c|c|c|c|c|c|}
\hline \multirow{2}{*}{ Família/Espécie } & \multirow{2}{*}{$\mathrm{H}$} & \multicolumn{3}{|c|}{ FLONA } & \multicolumn{3}{|c|}{ IBGE } & \multicolumn{3}{|c|}{ JBB } & \multicolumn{3}{|c|}{ PNB } \\
\hline & & 2009 & 2012 & 2013 & 2010 & 2012 & 2014 & 2010 & 2012 & 2014 & 2009 & 2012 & 2013 \\
\hline Lagenocarpus rigidus subsp. tenuifolius (Boeck.) T. Koyama \& Maguire & $\mathrm{E}$ & 0,00 & 0,00 & 0,00 & 0,00 & 0,00 & 0,00 & 0,61 & 0,00 & 0,00 & 0,00 & 0,00 & 0,00 \\
\hline Rhynchospora albiceps Kunth & $\mathrm{E}$ & 0,00 & 0,00 & 0,00 & 0,00 & 0,00 & 0,00 & 0,00 & 0,00 & 0,00 & 0,44 & 0,41 & 0,00 \\
\hline Rhynchospora cf. confinis (Nees) C.B.Clarke & $\mathrm{E}$ & 0,00 & 0,00 & 0,00 & 0,34 & 0,00 & 0,00 & 0,00 & 0,00 & 0,00 & 0,00 & 0,00 & 0,00 \\
\hline Rhynchospora consanguinea (Kunth) Boeckeler & $\mathrm{E}$ & 5,66 & 0,80 & 2,38 & 0,00 & 2,04 & 0,93 & 1,86 & 7,36 & 3,27 & 3,37 & 2,99 & 3,48 \\
\hline Rhynchospora emaciata (Nees) Boeckeler & $\mathrm{E}$ & 0,84 & 1,84 & 0,58 & 0,00 & 0,51 & 0,30 & 0,00 & 0,00 & 3,51 & 8,02 & 4,52 & 7,42 \\
\hline Rhynchospora globosa (Kunth) Roem. \& Schult. & $\mathrm{E}$ & 6,21 & 2,44 & 10,02 & 3,19 & 1,82 & 3,81 & 10,62 & 2,62 & 11,95 & 5,08 & 7,43 & 5,59 \\
\hline Rhynchospora holoschoenoides (Rich.) Herter & $\mathrm{E}$ & 0,00 & 0,00 & 0,00 & 0,00 & 0,00 & 0,00 & 0,00 & 0,00 & 0,00 & 1,44 & 1,31 & 1,24 \\
\hline Rhynchospora marisculus Lindl. \& Nees & $\mathrm{E}$ & 1,10 & 1,44 & 1,63 & 0,00 & 0,00 & 0,00 & 0,00 & 0,00 & 0,00 & 4,06 & 2,66 & 3,32 \\
\hline Rhynchospora robusta (Kunth) Boeckeler & $\mathrm{E}$ & 1,43 & 0,85 & 0,00 & 0,00 & 0,00 & 0,00 & 0,00 & 0,00 & 0,00 & 0,00 & 0,00 & 0,00 \\
\hline Rhynchospora rugosa (Vahl) Gale & $\mathrm{E}$ & 1,68 & 1,44 & 2,44 & 1,15 & 0,72 & 1,31 & 0,00 & 1,57 & 0,38 & 1,81 & 2,11 & 0,99 \\
\hline Rhynchospora spruceana C.B.Clarke & $\mathrm{E}$ & 0,00 & 0,00 & 0,00 & 0,71 & 0,67 & 0,30 & 0,00 & 0,00 & 0,00 & 0,00 & 0,00 & 0,00 \\
\hline Rhynchospora tenuis Link & $\mathrm{E}$ & 25,21 & 6,88 & 20,82 & 2,16 & 0,99 & 4,17 & 5,73 & 8,51 & 9,99 & 4,46 & 6,42 & 3,56 \\
\hline Rhynchospora velutina (Kunth) Boeckeler & $\mathrm{E}$ & 3,87 & 3,67 & 4,91 & 0,00 & 0,00 & 0,00 & 0,00 & 0,63 & 0,48 & 0,00 & 0,00 & 0,00 \\
\hline Scleria hirtella Sw. & $\mathrm{E}$ & 3,96 & 0,75 & 1,77 & 0,00 & 0,00 & 0,00 & 0,00 & 0,00 & 0,00 & 0,00 & 0,00 & 0,00 \\
\hline Scleria leptostachya Kunth & $\mathrm{E}$ & 0,99 & 2,01 & 2,46 & 3,03 & 2,40 & 0,31 & 5,11 & 7,73 & 2,16 & 2,83 & 5,63 & 2,96 \\
\hline Scleria secans (L.) Urb. & $\mathrm{E}$ & 0,40 & 0,00 & 0,34 & 0,00 & 0,00 & 0,00 & 0,00 & 0,00 & 0,00 & 0,00 & 0,00 & 0,00 \\
\hline \multicolumn{14}{|l|}{ Dennstaedtiaceae } \\
\hline Pteridium aquilinum (L.) Kuhn & $\mathrm{E}$ & 2,23 & 1,88 & 2,17 & 1,01 & 2,78 & 5,09 & 0,00 & 0,00 & 0,00 & 0,00 & 0,00 & 0,00 \\
\hline \multicolumn{14}{|l|}{ Droseraceae } \\
\hline Drosera montana A.St.-Hil. & $\mathrm{E}$ & 0,69 & 1,49 & 1,03 & 0,00 & 0,32 & 0,00 & 0,55 & 1,05 & 0,39 & 2,44 & 2,56 & 2,23 \\
\hline
\end{tabular}

Continuação 


\begin{tabular}{|c|c|c|c|c|c|c|c|c|c|c|c|c|c|}
\hline \multirow{2}{*}{ Família/Espécie } & \multirow{2}{*}{$\mathrm{H}$} & \multicolumn{3}{|c|}{ FLONA } & \multicolumn{3}{|c|}{ IBGE } & \multicolumn{3}{|c|}{ JBB } & \multicolumn{3}{|c|}{ PNB } \\
\hline & & 2009 & 2012 & 2013 & 2010 & 2012 & 2014 & 2010 & 2012 & 2014 & 2009 & 2012 & 2013 \\
\hline \multicolumn{14}{|l|}{ Ericaceae } \\
\hline Gaylussacia brasiliensis (Spreng.) Meisn. & A & 1,41 & 1,59 & 1,63 & 0,50 & 0,44 & 0,48 & 0,00 & 0,00 & 0,00 & 0,46 & 0,46 & 0,46 \\
\hline \multicolumn{14}{|l|}{ Eriocaulaceae } \\
\hline Comantheraxer anthemoides (Bong.) L.R.Parra \& Giul. & $\mathrm{E}$ & 0,00 & 0,00 & 0,00 & 0,00 & 0,00 & 0,00 & 0,00 & 0,00 & 0,00 & 0,00 & 0,00 & 0,47 \\
\hline Eriocaulaceae sp.1 & $\mathrm{E}$ & 0,00 & 0,00 & 0,00 & 0,00 & 0,00 & 0,00 & 0,00 & 0,00 & 0,00 & 1,87 & 1,41 & 0,92 \\
\hline Paepalanthus elongatulus Ruhland & $\mathrm{E}$ & 0,00 & 0,00 & 0,00 & 0,91 & 0,32 & 0,00 & 0,00 & 0,00 & 0,00 & 0,00 & 0,00 & 0,00 \\
\hline Paepalanthus flaccidus (Bong.) Kunth & $\mathrm{E}$ & 3,53 & 3,27 & 3,64 & 1,50 & 0,96 & 1,49 & 0,00 & 0,00 & 0,00 & 0,42 & 0,89 & 0,55 \\
\hline Paepalanthus lundii Körn. & $\mathrm{E}$ & 0,60 & 0,00 & 0,00 & 0,29 & 0,00 & 0,35 & 0,00 & 0,00 & 0,00 & 0,95 & 0,49 & 0,00 \\
\hline Syngonanthus densiflorus (Körn.) Ruhland & $\mathrm{E}$ & 1,39 & 1,10 & 1,02 & 0,00 & 0,00 & 0,00 & 0,00 & 0,00 & 0,00 & 0,00 & 0,00 & 0,00 \\
\hline Syngonanthus fischerianus (Bong.) Ruhland & $\mathrm{E}$ & 0,00 & 0,00 & 0,00 & 0,00 & 0,00 & 0,00 & 0,00 & 0,00 & 0,00 & 5,42 & 6,53 & 8,33 \\
\hline Syngonanthus gracilis (Bong.) Ruhland & $\mathrm{E}$ & 0,00 & 0,00 & 0,00 & 0,00 & 0,00 & 0,00 & 0,54 & 0,58 & 0,41 & 0,00 & 0,00 & 0,00 \\
\hline Syngonanthus nitens Ruhland & $\mathrm{E}$ & 1,10 & 0,82 & 0,45 & 0,00 & 0,00 & 0,30 & 2,27 & 2,20 & 1,23 & 0,00 & 0,00 & 0,42 \\
\hline Syngonanthus xeranthemoides (Bong.) Ruhland & $\mathrm{E}$ & 0,60 & 1,23 & 1,18 & 0,00 & 0,37 & 0,00 & 0,00 & 0,00 & 0,00 & 0,00 & 0,00 & 0,00 \\
\hline \multicolumn{14}{|l|}{ Euphorbiaceae } \\
\hline Croton antisyphiliticus Mart. & $\mathrm{E}$ & 0,00 & 0,00 & 0,00 & 2,57 & 4,41 & 2,45 & 0,56 & 0,00 & 0,00 & 0,00 & 0,00 & 0,00 \\
\hline Croton goyazensis Müll.Arg. & $\mathrm{S}$ & 0,00 & 0,00 & 0,00 & 0,38 & 0,00 & 0,39 & 0,00 & 0,00 & 0,00 & 0,00 & 0,00 & 0,00 \\
\hline Euphorbia hypericifolia L. & $\mathrm{E}$ & 0,00 & 0,00 & 0,00 & 0,31 & 1,34 & 0,30 & 0,00 & 0,00 & 0,00 & 0,00 & 0,00 & 0,00 \\
\hline Euphorbia potentilloides Boiss. & $\mathrm{E}$ & 1,94 & 0,49 & 0,44 & 0,00 & 0,00 & 0,00 & 0,00 & 0,00 & 0,00 & 0,43 & 0,88 & 0,48 \\
\hline Maproune aguianensis Aubl. & A & 0,00 & 0,00 & 0,00 & 0,00 & 0,00 & 0,00 & 0,59 & 0,00 & 0,00 & 0,00 & 0,00 & 0,00 \\
\hline Microstachys bidentata (Mart.\& Zucc.) Esser & $\mathrm{E}$ & 0,00 & 0,00 & 0,00 & 0,00 & 0,00 & 0,00 & 0,00 & 0,00 & 0,42 & 0,00 & 0,00 & 0,00 \\
\hline \multicolumn{14}{|l|}{ Fabaceae } \\
\hline Calliandra dysantha Benth. & $\mathrm{S}$ & 0,00 & 0,00 & 0,00 & 1,91 & 2,85 & 1,87 & 0,00 & 0,00 & 0,00 & 0,00 & 0,00 & 0,00 \\
\hline Calopogonium mucunoides Desv. & $\mathrm{E}$ & 0,00 & 0,00 & 0,00 & 0,00 & 0,00 & 0,00 & 0,00 & 0,00 & 0,00 & 0,94 & 0,98 & 0,95 \\
\hline
\end{tabular}

Continuação 


\begin{tabular}{|c|c|c|c|c|c|c|c|c|c|c|c|c|c|}
\hline \multirow{2}{*}{ Família/Espécie } & \multirow{2}{*}{$\mathrm{H}$} & \multicolumn{3}{|c|}{ FLONA } & \multicolumn{3}{|c|}{ IBGE } & \multicolumn{3}{|c|}{ JBB } & \multicolumn{3}{|c|}{ PNB } \\
\hline & & 2009 & 2012 & 2013 & 2010 & 2012 & 2014 & 2010 & 2012 & 2014 & 2009 & 2012 & 2013 \\
\hline Chamaecrista brachyrachis (Harms) H.S.Irwin \& Barneby & $\mathrm{S}$ & 0,00 & 0,00 & 0,00 & 0,92 & 1,14 & 0,90 & 0,00 & 0,00 & 0,00 & 0,00 & 0,00 & 0,00 \\
\hline Eriosema crinitum (Kunth) G.Don & $\mathrm{S}$ & 0,00 & 0,00 & 0,00 & 0,00 & 0,00 & 0,30 & 0,00 & 0,00 & 0,00 & 0,00 & 0,00 & 0,00 \\
\hline Galactia cf. stereophylla Harms. & $\mathrm{S}$ & 0,00 & 0,00 & 0,00 & 0,35 & 0,32 & 0,00 & 0,00 & 0,00 & 0,00 & 0,00 & 0,00 & 0,00 \\
\hline \multicolumn{14}{|l|}{ Gentianaceae } \\
\hline Curtia tenuifolia (Aubl.) Knobl. & $\mathrm{E}$ & 0,00 & 0,00 & 0,00 & 0,70 & 0,00 & 0,32 & 0,00 & 0,52 & 1,94 & 0,00 & 0,00 & 0,00 \\
\hline \multicolumn{14}{|l|}{ Gesneriaceae } \\
\hline Sinningia elatior (Kunth) Chautems & $\mathrm{E}$ & 0,70 & 1,11 & 0,72 & 0,33 & 2,63 & 1,27 & 0,00 & 0,50 & 0,85 & 0,00 & 0,00 & 0,43 \\
\hline \multicolumn{14}{|l|}{ Gleicheniaceae } \\
\hline Dicranopteris flexuosa (Schrad.) Underw. & $\mathrm{E}$ & 0,00 & 0,00 & 0,00 & 0,88 & 0,37 & 0,00 & 0,00 & 0,00 & 0,00 & 0,00 & 0,00 & 0,00 \\
\hline \multicolumn{14}{|l|}{ Iridaceae } \\
\hline Sisyrinchium restioides Spreng. & $\mathrm{E}$ & 0,00 & 0,00 & 0,00 & 0,63 & 0,68 & 0,96 & 0,00 & 0,00 & 0,38 & 0,41 & 0,41 & 0,00 \\
\hline Sisyrinchium vaginatum Spreng. & $\mathrm{E}$ & 1,56 & 2,91 & 1,82 & 2,14 & 1,51 & 1,98 & 2,28 & 5,68 & 3,59 & 2,13 & 2,96 & 3,28 \\
\hline Trimezia sp.1 & $\mathrm{E}$ & 0,00 & 3,90 & 0,77 & 0,00 & 0,72 & 0,00 & 0,00 & 0,00 & 0,39 & 0,00 & 0,00 & 0,00 \\
\hline \multicolumn{14}{|l|}{ Lamiaceae } \\
\hline Cantinoa subrotunda (Pohl ex Benth.) Harley \& J.F.B.Pastore & $\mathrm{S}$ & 3,57 & 2,93 & 3,40 & 0,00 & 0,00 & 0,00 & 0,00 & 0,00 & 0,00 & 0,00 & 0,00 & 0,00 \\
\hline Cyanocephalus tenuifolius (Epling) Harley \& J.F.B.Pastore & $\mathrm{E}$ & 0,00 & 0,00 & 0,00 & 0,68 & 0,47 & 0,34 & 0,00 & 0,00 & 0,00 & 0,00 & 0,00 & 0,00 \\
\hline Hyptis linarioides Pohl ex Benth. & A & 1,44 & 0,00 & 0,00 & 2,46 & 4,00 & 1,64 & 3,08 & 7,55 & 2,13 & 2,36 & 2,16 & 1,44 \\
\hline Hyptis nudicaulis Benth. & $\mathrm{E}$ & 0,00 & 0,00 & 0,00 & 0,68 & 0,32 & 0,00 & 0,00 & 0,00 & 0,00 & 0,00 & 0,00 & 0,00 \\
\hline \multicolumn{14}{|l|}{ Lauraceae } \\
\hline Cassytha filiformis L. & $\mathrm{L}$ & 0,45 & 0,35 & 0,98 & 1,51 & 0,00 & 1,87 & 0,54 & 1,07 & 1,67 & 1,09 & 1,31 & 1,30 \\
\hline \multicolumn{14}{|l|}{ Lentibulariaceae } \\
\hline Utricularia cf. neottioides A. St.-Hil. \& Girard & $\mathrm{E}$ & 0,00 & 0,00 & 0,00 & 0,00 & 0,31 & 0,30 & 0,00 & 0,00 & 0,00 & 1,61 & 0,00 & 0,00 \\
\hline Utricularia hispida Lam. & $\mathrm{E}$ & 0,69 & 0,00 & 0,66 & 0,00 & 0,00 & 0,00 & 0,00 & 0,00 & 0,00 & 0,00 & 0,00 & 0,00 \\
\hline
\end{tabular}

Continuação 


\begin{tabular}{|c|c|c|c|c|c|c|c|c|c|c|c|c|c|}
\hline \multirow{2}{*}{ Família/Espécie } & \multirow{2}{*}{$\mathrm{H}$} & \multicolumn{3}{|c|}{ FLONA } & \multicolumn{3}{|c|}{ IBGE } & \multicolumn{3}{|c|}{ JBB } & \multicolumn{3}{|c|}{ PNB } \\
\hline & & 2009 & 2012 & 2013 & 2010 & 2012 & 2014 & 2010 & 2012 & 2014 & 2009 & 2012 & 2013 \\
\hline Utricularia tricolor A.St.-Hil. & $\mathrm{E}$ & 0,00 & 0,34 & 0,34 & 0,00 & 0,00 & 0,00 & 0,00 & 0,00 & 0,00 & 0,00 & 0,00 & 0,00 \\
\hline \multicolumn{14}{|l|}{ Lycopodiaceae } \\
\hline Palhinhaea cernua (L.) Franco \& Vasc. & $\mathrm{E}$ & 0,71 & 0,68 & 0,33 & 0,00 & 0,00 & 0,31 & 0,00 & 0,00 & 0,00 & 0,43 & 0,41 & 0,54 \\
\hline \multicolumn{14}{|l|}{ Lythraceae } \\
\hline Cuphea linarioides Cham. \& Schltdl. & $\mathrm{S}$ & 0,00 & 0,00 & 0,00 & 0,00 & 0,39 & 0,60 & 0,00 & 0,00 & 0,00 & 0,80 & 0,44 & 0,00 \\
\hline Cuphea pohlii Lourteig & $\mathrm{S}$ & 0,82 & 0,45 & 0,77 & 0,00 & 0,00 & 0,00 & 0,00 & 0,00 & 0,00 & 0,00 & 0,00 & 0,00 \\
\hline Cupheaspermacoce A.St.-Hil. & $\mathrm{S}$ & 0,00 & 0,00 & 0,00 & 0,90 & 0,72 & 0,00 & 0,00 & 0,00 & 0,00 & 0,40 & 0,00 & 0,00 \\
\hline \multicolumn{14}{|l|}{ Malvaceae } \\
\hline Pavonia rosa-campestris A.St.-Hil. & $\mathrm{S}$ & 0,00 & 0,00 & 0,00 & 0,30 & 0,71 & 0,31 & 0,00 & 0,00 & 0,00 & 0,00 & 0,00 & 0,00 \\
\hline \multicolumn{14}{|l|}{ Melastomataceae } \\
\hline Acisanthera limnobios (Schrank \& Mart. ex DC.) Triana & $\mathrm{E}$ & 0,00 & 0,00 & 0,00 & 0,00 & 0,00 & 0,00 & 0,00 & 0,00 & 0,00 & 0,45 & 0,89 & 0,48 \\
\hline Cambessedesia espora (A.St.-Hil. ex Bonpl.) DC. & $\mathrm{E}$ & 0,00 & 0,00 & 0,00 & 0,00 & 0,00 & 0,00 & 0,00 & 0,00 & 0,00 & 0,40 & 0,00 & 0,44 \\
\hline Clidemia capitellata (Bonpl.) D.Don & A & 0,00 & 0,00 & 0,00 & 0,81 & 0,32 & 0,00 & 0,00 & 0,00 & 0,00 & 0,00 & 0,00 & 0,00 \\
\hline Comolia lanceiflora (DC.) Triana & A & 0,00 & 0,00 & 0,00 & 0,00 & 0,00 & 0,00 & 0,00 & 0,00 & 0,00 & 0,62 & 0,47 & 0,00 \\
\hline Desmoscelis villosa (Aubl.) Naudin & A & 0,75 & 0,00 & 0,68 & 0,00 & 0,31 & 0,00 & 0,00 & 0,00 & 0,78 & 1,25 & 0,40 & 0,92 \\
\hline Lavoisiera imbricata (Thunb.) DC. & $\mathrm{S}$ & 1,14 & 0,35 & 1,31 & 9,21 & 0,00 & 4,53 & 0,00 & 0,00 & 0,89 & 0,97 & 1,04 & 1,69 \\
\hline Leandra deflexa (Triana) Cogn. & A & 0,00 & 0,00 & 0,00 & 0,34 & 0,00 & 0,34 & 0,00 & 0,00 & 0,00 & 0,00 & 0,00 & 0,00 \\
\hline Leandra lacunosa Cogn. & A & 0,00 & 0,00 & 0,00 & 0,42 & 0,39 & 0,74 & 0,00 & 0,00 & 0,00 & 0,00 & 0,00 & 0,00 \\
\hline Leandra polystachya (Naudin) Cogn. & $\mathrm{S}$ & 0,38 & 0,00 & 0,00 & 0,75 & 1,24 & 1,14 & 0,00 & 0,00 & 0,00 & 0,00 & 0,00 & 0,00 \\
\hline Macairea radula (Bonpl.) DC. & $\mathrm{S}$ & 0,00 & 0,00 & 0,00 & 0,57 & 0,00 & 0,00 & 0,00 & 0,00 & 0,00 & 0,00 & 0,00 & 0,00 \\
\hline Miconia chamissois Naudin & A & 0,50 & 0,00 & 0,34 & 1,70 & 1,17 & 1,17 & 0,00 & 0,00 & 0,00 & 0,00 & 0,00 & 0,00 \\
\hline Microlicia euphorbioides Mart. & A & 0,00 & 0,00 & 0,00 & 1,07 & 0,57 & 0,36 & 0,56 & 0,00 & 0,00 & 0,00 & 0,00 & 0,00 \\
\hline Microlicia fasciculata Mart. ex Naudin & $\mathrm{S}$ & 0,00 & 0,00 & 0,00 & 0,34 & 0,00 & 0,00 & 0,00 & 0,00 & 0,00 & 0,00 & 0,00 & 0,00 \\
\hline
\end{tabular}

Continuação 


\begin{tabular}{|c|c|c|c|c|c|c|c|c|c|c|c|c|c|}
\hline \multirow{2}{*}{ Família/Espécie } & \multirow{2}{*}{$\mathrm{H}$} & \multicolumn{3}{|c|}{ FLONA } & \multicolumn{3}{|c|}{ IBGE } & \multicolumn{3}{|c|}{ JBB } & \multicolumn{3}{|c|}{ PNB } \\
\hline & & 2009 & 2012 & 2013 & 2010 & 2012 & 2014 & 2010 & 2012 & 2014 & 2009 & 2012 & 2013 \\
\hline Microlicia serpyllifolia D.Don & $\mathrm{S}$ & 0,00 & 0,00 & 0,00 & 0,00 & 0,00 & 0,00 & 2,87 & 0,00 & 2,28 & 1,32 & 1,57 & 0,52 \\
\hline Microlicia sp.1 & $S$ & 0,00 & 0,00 & 0,00 & 0,00 & 0,00 & 0,00 & 0,00 & 0,00 & 0,00 & 0,40 & 0,00 & 0,45 \\
\hline Microlicia sp.2 & $\mathrm{S}$ & 0,00 & 0,00 & 0,00 & 0,00 & 0,00 & 0,00 & 0,00 & 0,00 & 0,00 & 0,95 & 0,61 & 1,88 \\
\hline Ossaea congestiflora (Naudin) Cogn. & $\mathrm{S}$ & 0,77 & 0,00 & 0,67 & 2,14 & 2,38 & 3,26 & 0,00 & 0,00 & 0,00 & 0,00 & 0,00 & 0,00 \\
\hline Rhynchanthera grandiflora (Aubl.) DC. & $\mathrm{A}$ & 0,00 & 0,00 & 0,00 & 0,00 & 0,00 & 0,00 & 0,00 & 0,00 & 0,00 & 2,51 & 2,02 & 1,93 \\
\hline Tibouchina aegopogon (Naudin) Cogn. & $\mathrm{S}$ & 0,00 & 0,00 & 0,00 & 0,29 & 0,51 & 0,00 & 0,00 & 0,00 & 0,00 & 0,00 & 0,00 & 0,00 \\
\hline Tibouchina gracilis (Bonpl.) Cogn. & $\mathrm{E}$ & 1,90 & 4,40 & 0,73 & 0,00 & 0,72 & 0,31 & 1,70 & 2,79 & 1,68 & 1,81 & 1,86 & 0,72 \\
\hline Tibouchinastenocarpa (Schrank \& Mart. ex DC.) Cogn. & A & 0,00 & 0,00 & 0,00 & 0,00 & 0,31 & 0,00 & 0,00 & 0,00 & 0,00 & 0,00 & 0,00 & 0,00 \\
\hline Trembleya parviflora (D.Don) Cogn. & $\mathrm{S}$ & 4,04 & 0,34 & 1,38 & 6,43 & 0,31 & 0,76 & 13,05 & 3,78 & 16,79 & 0,85 & 0,42 & 0,00 \\
\hline Trembleya phlogiformis DC. & A & 0,00 & 0,00 & 0,00 & 1,82 & 0,00 & 1,70 & 2,89 & 0,00 & 4,24 & 0,00 & 0,00 & 0,98 \\
\hline \multicolumn{14}{|l|}{ Menispermaceae } \\
\hline Cissampeloso valifolia DC. & $\mathrm{S}$ & 0,00 & 0,00 & 0,37 & 0,93 & 2,00 & 0,98 & 0,00 & 0,00 & 0,00 & 0,00 & 0,00 & 0,00 \\
\hline \multicolumn{14}{|l|}{ Myrtaceae } \\
\hline Campomanesia pubescens (Mart. ex DC.) O.Berg & A & 0,00 & 0,00 & 0,00 & 1,00 & 0,84 & 0,33 & 0,00 & 0,00 & 0,00 & 0,00 & 0,00 & 0,00 \\
\hline Eugenia involucrata DC. & $\mathrm{A}$ & 0,00 & 0,00 & 0,00 & 0,32 & 0,36 & 0,36 & 0,00 & 0,00 & 0,00 & 0,00 & 0,00 & 0,00 \\
\hline Myrcia guianensis (Aubl.) DC. & $\mathrm{S}$ & 0,00 & 0,00 & 0,00 & 0,64 & 0,36 & 0,44 & 0,00 & 0,00 & 0,00 & 0,00 & 0,00 & 0,00 \\
\hline Myrcia variabilis DC. & A & 0,00 & 0,00 & 0,00 & 0,36 & 0,38 & 0,00 & 0,00 & 0,00 & 0,00 & 0,00 & 0,00 & 0,00 \\
\hline Myrtaceae sp.1 & $\mathrm{S}$ & 0,00 & 0,00 & 0,00 & 1,13 & 1,40 & 0,33 & 0,00 & 0,00 & 0,00 & 0,00 & 0,00 & 0,00 \\
\hline Psidium firmum O.Berg & $\mathrm{A}$ & 0,00 & 0,00 & 0,00 & 0,37 & 0,33 & 0,00 & 0,00 & 0,00 & 0,00 & 0,00 & 0,00 & 0,00 \\
\hline Psidium sp. 1 & $\mathrm{~S}$ & 0,00 & 0,00 & 0,00 & 0,41 & 0,45 & 0,00 & 0,00 & 0,00 & 0,00 & 0,00 & 0,00 & 0,00 \\
\hline Psidium sp.2 & $\mathrm{S}$ & 0,00 & 0,00 & 0,00 & 0,71 & 0,81 & 0,00 & 0,00 & 0,00 & 0,00 & 0,00 & 0,00 & 0,00 \\
\hline \multicolumn{14}{|l|}{ Ochnaceae } \\
\hline Sauvagesia linearifolia A.St.-Hil. & $\mathrm{E}$ & 0,00 & 0,00 & 0,00 & 0,68 & 0,00 & 0,66 & 0,00 & 0,00 & 0,39 & 0,00 & 0,00 & 0,00 \\
\hline Sauvagesia racemosa A.St.-Hil. & $\mathrm{S}$ & 1,03 & 0,49 & 0,47 & 0,32 & 0,42 & 0,89 & 0,00 & 0,00 & 0,46 & 0,00 & 0,00 & 0,00 \\
\hline
\end{tabular}

Continuação 


\begin{tabular}{|c|c|c|c|c|c|c|c|c|c|c|c|c|c|}
\hline \multirow{2}{*}{ Família/Espécie } & \multirow{2}{*}{$\mathrm{H}$} & \multicolumn{3}{|c|}{ FLONA } & \multicolumn{3}{|c|}{ IBGE } & \multicolumn{3}{|c|}{ JBB } & \multicolumn{3}{|c|}{ PNB } \\
\hline & & 2009 & 2012 & 2013 & 2010 & 2012 & 2014 & 2010 & 2012 & 2014 & 2009 & 2012 & 2013 \\
\hline \multicolumn{14}{|l|}{ Onagraceae } \\
\hline Ludwigia nervosa (Poir.) H.Hara & $\mathrm{S}$ & 0,35 & 1,23 & 0,41 & 0,00 & 0,00 & 0,00 & 0,55 & 0,00 & 0,00 & 0,82 & 0,43 & 0,90 \\
\hline \multicolumn{14}{|l|}{ Orchidaceae } \\
\hline Cleistes sp. 1 & $\mathrm{E}$ & 0,69 & 0,00 & 0,33 & 0,00 & 0,00 & 0,00 & 0,00 & 0,00 & 0,00 & 0,00 & 0,00 & 0,00 \\
\hline \multicolumn{14}{|l|}{ Oxalidaceae } \\
\hline Oxalis cordata A.St.-Hil. & $\mathrm{S}$ & 0,00 & 0,00 & 0,00 & 0,00 & 0,00 & 0,30 & 0,00 & 0,00 & 0,00 & 0,00 & 0,40 & 0,42 \\
\hline Oxalis densifolia Mart. \& Zucc. ex Zucc. & $\mathrm{S}$ & 0,00 & 0,00 & 0,00 & 0,92 & 0,69 & 0,30 & 0,00 & 0,00 & 0,00 & 0,00 & 0,00 & 0,00 \\
\hline \multicolumn{14}{|l|}{ Poaceae } \\
\hline Agenium goyazense (Hack.) Clayton & $\mathrm{E}$ & 0,00 & 0,00 & 0,00 & 0,71 & 0,00 & 1,50 & 0,00 & 0,00 & 0,00 & 0,00 & 0,00 & 0,00 \\
\hline Agenium leptocladum (Hack.) Clayton & $\mathrm{E}$ & 0,00 & 0,00 & 0,00 & 0,78 & 0,00 & 0,00 & 0,00 & 0,00 & 0,00 & 0,00 & 0,00 & 0,00 \\
\hline Andropogon bicornis $\mathrm{L}$. & $\mathrm{E}$ & 5,02 & 1,85 & 2,72 & 3,64 & 0,91 & 0,00 & 0,00 & 0,00 & 0,00 & 0,00 & 1,84 & 0,00 \\
\hline Andropogon ingratus Hack. & $\mathrm{E}$ & 0,00 & 0,00 & 0,00 & 0,00 & 0,00 & 0,00 & 0,00 & 0,00 & 0,00 & 1,66 & 0,70 & 0,00 \\
\hline Andropogon lateralis Nees & $\mathrm{E}$ & 0,42 & 0,57 & 7,55 & 1,28 & 2,95 & 3,04 & 6,07 & 12,39 & 7,09 & 3,84 & 9,10 & 8,30 \\
\hline Andropogon leucostachyus Kunth & $\mathrm{E}$ & 4,00 & 6,07 & 0,90 & 23,18 & 12,81 & 34,28 & 2,57 & 0,51 & 12,56 & 1,60 & 2,21 & 2,34 \\
\hline Andropogon virgatus Desv. & $\mathrm{E}$ & 2,34 & 4,02 & 1,66 & 5,44 & 3,29 & 3,41 & 7,04 & 9,47 & 5,71 & 15,40 & 10,95 & 16,08 \\
\hline Apochloa subtiramulosa (Renvoize \& Zuloaga) Zuloaga \& Morrone & $\mathrm{E}$ & 1,68 & 0,00 & 3,19 & 0,00 & 0,00 & 0,52 & 0,00 & 0,00 & 0,00 & 0,00 & 0,00 & 0,00 \\
\hline Aristida recurvata Kunth & $\mathrm{E}$ & 0,00 & 0,00 & 0,00 & 0,30 & 0,00 & 0,00 & 0,00 & 0,00 & 0,00 & 0,00 & 0,00 & 0,47 \\
\hline Axonopus aureus P.Beauv. & $\mathrm{E}$ & 0,00 & 0,00 & 0,00 & 0,60 & 0,60 & 2,11 & 1,41 & 1,91 & 1,67 & 3,67 & 4,33 & 4,16 \\
\hline Axonopus brasiliensis (Spreng.) Kuhlm. & $\mathrm{E}$ & 5,36 & 2,07 & 3,57 & 0,00 & 0,36 & 0,30 & 3,35 & 1,75 & 2,16 & 6,79 & 6,17 & 3,92 \\
\hline Axonopus comans (Trin. Ex Döll) Kuhlm & $\mathrm{E}$ & 0,00 & 0,00 & 1,43 & 0,00 & 0,00 & 0,00 & 9,70 & 14,00 & 0,00 & 0,00 & 0,00 & 0,00 \\
\hline Axonopus pellitus (Nees ex Trin.) Hitchc. \& Chase & $\mathrm{E}$ & 0,00 & 0,00 & 0,00 & 0,00 & 0,00 & 0,00 & 0,00 & 0,00 & 0,00 & 0,00 & 0,86 & 0,00 \\
\hline Ctenium sp.1 & $\mathrm{E}$ & 0,00 & 7,28 & 0,00 & 0,00 & 0,67 & 0,00 & 0,00 & 0,80 & 0,00 & 0,00 & 0,00 & 0,00 \\
\hline Echinolaena inflexa (Poir.) Chase & $\mathrm{E}$ & 1,50 & 0,68 & 0,78 & 5,14 & 6,11 & 4,71 & 0,59 & 0,00 & 1,18 & 5,19 & 5,19 & 4,34 \\
\hline Eriochrysis cayennensis P. Beauv. & $\mathrm{E}$ & 0,00 & 0,00 & 0,00 & 0,00 & 0,00 & 0,00 & 0,00 & 0,00 & 0,00 & 0,42 & 0,40 & 0,49 \\
\hline
\end{tabular}

Continuação 


\begin{tabular}{|c|c|c|c|c|c|c|c|c|c|c|c|c|c|}
\hline \multirow{2}{*}{ Família/Espécie } & \multirow{2}{*}{$\mathrm{H}$} & \multicolumn{3}{|c|}{ FLONA } & \multicolumn{3}{|c|}{ IBGE } & \multicolumn{3}{|c|}{ JBB } & \multicolumn{3}{|c|}{ PNB } \\
\hline & & 2009 & 2012 & 2013 & 2010 & 2012 & 2014 & 2010 & 2012 & 2014 & 2009 & 2012 & 2013 \\
\hline Hyparrhenia bracteata (Humb. \& Bonpl. ex Willd.) Stapf & $\mathrm{E}$ & 1,54 & 0,45 & 0,34 & 3,20 & 1,41 & 2,57 & 0,00 & 0,00 & 0,00 & 0,00 & 0,00 & 0,00 \\
\hline Ichnanthus procurrens (Nees ex Trin.) Swallen & $\mathrm{E}$ & 0,00 & 0,63 & 0,82 & 0,30 & 0,89 & 1,47 & 0,00 & 0,00 & 0,00 & 3,41 & 3,24 & 3,13 \\
\hline Melinis minutiflora P.Beauv. & $\mathrm{E}$ & 0,98 & 0,71 & 1,07 & 5,68 & 4,20 & 7,36 & 0,00 & 2,07 & 1,13 & 0,00 & 0,00 & 0,00 \\
\hline Otachyrium seminudum Hack. ex Send. \& Soderstr. & $\mathrm{E}$ & 1,05 & 1,76 & 1,85 & 0,00 & 0,39 & 0,30 & 0,00 & 0,00 & 0,00 & 1,61 & 0,99 & 1,16 \\
\hline Panicum olyroides Kunth & $\mathrm{E}$ & 0,00 & 0,00 & 0,00 & 0,30 & 0,00 & 0,69 & 0,00 & 0,00 & 0,00 & 0,00 & 0,00 & 0,00 \\
\hline Paspalum cordatum Hack. & $\mathrm{E}$ & 1,87 & 1,14 & 2,51 & 0,00 & 0,00 & 0,00 & 0,00 & 0,00 & 0,00 & 0,00 & 0,00 & 0,00 \\
\hline Paspalum dedeccae Quarín & $\mathrm{E}$ & 0,00 & 0,70 & 0,00 & 2,66 & 9,32 & 5,14 & 0,00 & 0,00 & 0,00 & 8,24 & 8,03 & 9,91 \\
\hline Paspalum geminiflorum Steud. & $\mathrm{E}$ & 0,00 & 0,00 & 1,56 & 0,00 & 0,00 & 0,00 & 25,79 & 20,84 & 18,02 & 0,00 & 0,00 & 0,00 \\
\hline Paspalum glaucescens Hack. & $\mathrm{E}$ & 0,88 & 1,79 & 1,56 & 0,00 & 0,00 & 0,40 & 3,92 & 1,18 & 2,92 & 0,00 & 0,00 & 0,00 \\
\hline Paspalum hyalinum Nees ex Trin. & $\mathrm{E}$ & 0,00 & 0,00 & 0,00 & 0,95 & 1,17 & 1,03 & 1,75 & 0,00 & 0,39 & 1,57 & 0,39 & 2,87 \\
\hline Paspalum imbricatum Filg. & $\mathrm{E}$ & 0,00 & 0,00 & 0,00 & 0,84 & 2,66 & 0,89 & 0,00 & 0,00 & 0,00 & 0,00 & 0,00 & 0,00 \\
\hline Paspalum lineare Trin. & $\mathrm{E}$ & 25,08 & 44,15 & 29,17 & 21,41 & 16,86 & 16,73 & 26,09 & 20,90 & 21,60 & 34,87 & 33,26 & 26,44 \\
\hline Paspalum maculosum Trin. & $\mathrm{E}$ & 0,92 & 0,87 & 0,72 & 0,00 & 0,00 & 0,34 & 0,00 & 0,00 & 0,00 & 1,67 & 1,74 & 1,39 \\
\hline Paspalum polyphyllum Nees & $\mathrm{E}$ & 0,79 & 0,00 & 0,00 & 0,00 & 0,00 & 0,00 & 0,00 & 0,00 & 0,00 & 0,00 & 0,00 & 0,00 \\
\hline Paspalum sp.1 & $\mathrm{E}$ & 0,00 & 0,00 & 0,00 & 0,49 & 0,56 & 0,61 & 0,00 & 0,00 & 0,00 & 0,00 & 0,00 & 0,00 \\
\hline Poaceae sp.1 & $\mathrm{E}$ & 0,00 & 0,00 & 0,00 & 0,00 & 0,00 & 0,00 & 0,00 & 0,00 & 0,00 & 0,00 & 0,00 & 9,53 \\
\hline Poaceae sp. 2 & $\mathrm{E}$ & 0,00 & 0,00 & 0,00 & 0,00 & 1,04 & 0,00 & 0,56 & 0,00 & 0,00 & 0,00 & 0,00 & 0,00 \\
\hline Schizachyrium condensatum (Kunth) Nees & $\mathrm{E}$ & 5,13 & 3,20 & 4,79 & 0,00 & 1,78 & 0,40 & 0,00 & 0,00 & 0,00 & 0,00 & 0,00 & 0,00 \\
\hline Schizachyrium sanguineum (Retz.) Alston & $\mathrm{E}$ & 0,00 & 0,00 & 0,00 & 0,00 & 0,00 & 0,63 & 0,56 & 0,00 & 0,00 & 5,61 & 7,70 & 2,72 \\
\hline Schizachyrium tenerum Nees & $\mathrm{E}$ & 0,00 & 0,00 & 0,00 & 0,80 & 0,47 & 0,00 & 0,00 & 0,00 & 0,00 & 0,00 & 0,00 & 0,00 \\
\hline Trachypogon spicatus (L.f.) Kuntze & $\mathrm{E}$ & 0,00 & 0,00 & 0,00 & 0,31 & 1,46 & 0,30 & 0,00 & 0,00 & 0,00 & 0,58 & 1,55 & 2,60 \\
\hline Trichanthecium parvifolium (Lam.) Zuloaga \& Morrone & $\mathrm{E}$ & 0,70 & 4,55 & 1,85 & 0,95 & 11,51 & 1,68 & 1,25 & 7,37 & 0,00 & 2,17 & 3,42 & 2,02 \\
\hline Trichanthecium wettsteinii (Hack.) Zuloaga \& Morrone & $\mathrm{E}$ & 0,00 & 0,00 & 0,00 & 0,00 & 0,00 & 0,00 & 0,00 & 0,00 & 0,00 & 3,05 & 1,25 & 1,92 \\
\hline
\end{tabular}

Continuação 


\begin{tabular}{|c|c|c|c|c|c|c|c|c|c|c|c|c|c|}
\hline \multirow{2}{*}{ Família/Espécie } & \multirow{2}{*}{$\mathrm{H}$} & \multicolumn{3}{|c|}{ FLONA } & \multicolumn{3}{|c|}{ IBGE } & \multicolumn{3}{|c|}{ JBB } & \multicolumn{3}{|c|}{ PNB } \\
\hline & & 2009 & 2012 & 2013 & 2010 & 2012 & 2014 & 2010 & 2012 & 2014 & 2009 & 2012 & 2013 \\
\hline Tristachya leiostachya Nees & $\mathrm{E}$ & 0,00 & 0,00 & 0,00 & 10,85 & 7,84 & 9,16 & 0,00 & 0,00 & 0,00 & 0,81 & 0,87 & 1,12 \\
\hline \multicolumn{14}{|l|}{ Polygalaceae } \\
\hline Polygala fendleri Chodat & $\mathrm{S}$ & 0,39 & 0,00 & 0,80 & 0,00 & 0,00 & 0,00 & 0,00 & 0,00 & 0,00 & 0,00 & 0,00 & 0,00 \\
\hline Polygala paniculata $\mathrm{L}$. & $\mathrm{E}$ & 0,69 & 1,13 & 0,72 & 0,00 & 0,00 & 0,00 & 0,00 & 0,00 & 0,00 & 0,00 & 0,00 & 0,00 \\
\hline Polygala tenuis DC. & $\mathrm{E}$ & 0,00 & 0,00 & 0,00 & 0,00 & 0,00 & 0,00 & 0,00 & 0,00 & 0,00 & 1,30 & 0,00 & 0,86 \\
\hline \multicolumn{14}{|l|}{ Primulaceae } \\
\hline Myrsine guianensis (Aubl.) Kuntze & A & 0,00 & 0,00 & 0,00 & 0,44 & 0,00 & 0,00 & 0,00 & 0,00 & 0,00 & 0,00 & 0,00 & 0,00 \\
\hline \multicolumn{14}{|l|}{ Proteaceae } \\
\hline Roupala montana Aubl. & A & 0,00 & 0,00 & 0,00 & 3,05 & 2,98 & 2,78 & 0,00 & 0,00 & 0,00 & 0,00 & 0,00 & 0,00 \\
\hline \multicolumn{14}{|l|}{ Rosaceae } \\
\hline Rubus urticifolius Poir. & A & 0,00 & 0,00 & 0,00 & 0,69 & 0,35 & 0,30 & 0,00 & 0,00 & 0,00 & 0,00 & 0,00 & 0,00 \\
\hline \multicolumn{14}{|l|}{ Rubiaceae } \\
\hline Borreria capitata (Ruiz \& Pav.) DC. & $\mathrm{E}$ & 0,00 & 0,00 & 0,00 & 0,00 & 0,00 & 0,00 & 0,00 & 0,00 & 0,00 & 0,90 & 0,44 & 0,00 \\
\hline Borreria latifolia (Aubl.) K.Schum. & $\mathrm{E}$ & 0,42 & 1,14 & 0,00 & 0,00 & 0,00 & 0,00 & 1,82 & 6,24 & 1,15 & 0,00 & 0,00 & 0,00 \\
\hline Borreria suaveolens $\mathrm{G}$. Mey. & $\mathrm{E}$ & 0,00 & 0,00 & 0,00 & 0,61 & 0,74 & 0,33 & 0,00 & 0,00 & 0,00 & 0,00 & 0,00 & 0,00 \\
\hline Coccocypselum lymansmithii Standl. & $\mathrm{E}$ & 0,35 & 1,40 & 1,80 & 0,00 & 0,36 & 0,33 & 0,56 & 1,15 & 2,24 & 1,35 & 1,55 & 0,46 \\
\hline Declieuxia fruticosa (Willd. ex Roem. \& Schult.) Kuntze & $\mathrm{S}$ & 0,00 & 0,00 & 0,00 & 0,00 & 0,31 & 0,00 & 0,00 & 0,53 & 0,87 & 0,46 & 0,50 & 1,44 \\
\hline Ferdinandusa speciosa (Pohl) Pohl & A & 0,00 & 0,00 & 0,00 & 0,33 & 0,43 & 0,76 & 0,00 & 0,00 & 0,00 & 0,00 & 0,00 & 0,00 \\
\hline Palicourea officinalis Mart. & A & 0,00 & 0,00 & 0,00 & 0,31 & 0,34 & 0,64 & 0,00 & 0,00 & 0,00 & 0,00 & 0,40 & 0,00 \\
\hline \multicolumn{14}{|l|}{ Smilacaceae } \\
\hline Smilax brasiliensis Spreng. & $\mathrm{S}$ & 0,00 & 0,00 & 0,00 & 0,00 & 0,00 & 0,00 & 0,00 & 0,00 & 0,00 & 0,00 & 0,00 & 0,43 \\
\hline \multicolumn{14}{|l|}{ Solanaceae } \\
\hline Brunfelsia obovata Benth. & A & 0,00 & 0,00 & 0,00 & 0,38 & 0,46 & 0,40 & 0,00 & 0,00 & 0,00 & 0,00 & 0,00 & 0,00 \\
\hline Solanum lycocarpum A.St.-Hil. & A & 0,00 & 0,00 & 0,00 & 0,00 & 0,36 & 0,29 & 0,00 & 0,52 & 0,00 & 0,00 & 0,00 & 0,00 \\
\hline Solanum subumbellatum Vell. & A & 0,00 & 0,00 & 0,00 & 0,00 & 0,34 & 0,00 & 0,54 & 3,28 & 1,34 & 0,00 & 0,00 & 0,00 \\
\hline
\end{tabular}




\begin{tabular}{|c|c|c|c|c|c|c|c|c|c|c|c|c|c|}
\hline \multirow{2}{*}{ Família/Espécie } & \multirow{2}{*}{$\mathrm{H}$} & \multicolumn{3}{|c|}{ FLONA } & \multicolumn{3}{|c|}{ IBGE } & \multicolumn{3}{|c|}{ JBB } & \multicolumn{3}{|c|}{ PNB } \\
\hline & & 2009 & 2012 & 2013 & 2010 & 2012 & 2014 & 2010 & 2012 & 2014 & 2009 & 2012 & 2013 \\
\hline \multicolumn{14}{|l|}{ Theaceae } \\
\hline Laplacea fructicosa (Schrad.) Kobuski & $\mathrm{A}$ & 0,00 & 0,00 & 0,00 & 0,00 & 0,00 & 0,00 & 4,58 & 1,05 & 3,50 & 0,00 & 0,00 & 0,00 \\
\hline \multicolumn{14}{|l|}{ Thelypteridaceae } \\
\hline Thelypteris cf. rivulanoides & $\mathrm{E}$ & 0,00 & 0,00 & 0,00 & 0,33 & 0,00 & 0,00 & 0,00 & 0,00 & 0,00 & 0,00 & 0,00 & 0,00 \\
\hline \multicolumn{14}{|l|}{ Turneraceae } \\
\hline Turnera oblongifolia Cambess. & $\mathrm{E}$ & 0,74 & 0,68 & 0,33 & 1,79 & 1,64 & 0,65 & 0,00 & 0,00 & 0,78 & 0,81 & 2,09 & 1,76 \\
\hline \multicolumn{14}{|l|}{ Verbenaceae } \\
\hline Lippia rotundifolia Cham. & A & 2,20 & 0,00 & 0,00 & 0,40 & 0,78 & 0,68 & 0,00 & 0,00 & 0,48 & 0,00 & 0,00 & 0,00 \\
\hline \multicolumn{14}{|l|}{ Xyridaceae } \\
\hline Abolboda pulchella Humb. & $\mathrm{E}$ & 0,00 & 0,00 & 0,34 & 0,00 & 0,00 & 0,00 & 0,00 & 0,00 & 0,00 & 0,00 & 0,00 & 0,00 \\
\hline Xyris asperula Mart. & $\mathrm{E}$ & 0,00 & 0,00 & 0,00 & 0,00 & 0,00 & 0,00 & 0,00 & 0,00 & 0,00 & 0,51 & 0,49 & 0,00 \\
\hline Xyris cf. caroliniana Walter & $\mathrm{E}$ & 0,00 & 0,00 & 0,00 & 0,00 & 0,00 & 0,00 & 0,00 & 0,00 & 0,00 & 1,54 & 1,62 & 1,03 \\
\hline Xyris diaphanobracteata Kral \& Wand. & $\mathrm{E}$ & 0,00 & 0,00 & 0,00 & 0,00 & 0,00 & 0,30 & 0,60 & 0,00 & 0,38 & 0,00 & 0,00 & 0,00 \\
\hline Xyris guaranitica Malme & $\mathrm{E}$ & 0,00 & 0,35 & 0,00 & 0,94 & 0,00 & 0,72 & 0,00 & 0,00 & 0,00 & 3,64 & 2,43 & 3,15 \\
\hline Xyris hymenachne Mart. & $\mathrm{E}$ & 1,16 & 1,15 & 2,38 & 0,69 & 0,00 & 0,46 & 0,00 & 0,00 & 0,81 & 1,30 & 1,11 & 1,59 \\
\hline Xyris macrocephala Vahl & $\mathrm{E}$ & 0,74 & 0,82 & 1,74 & 0,00 & 0,00 & 0,29 & 1,77 & 0,00 & 0,00 & 2,38 & 1,13 & 2,61 \\
\hline Xyris savanensis Miq. & $\mathrm{E}$ & 0,00 & 0,36 & 0,00 & 0,00 & 0,00 & 0,00 & 3,24 & 1,07 & 3,17 & 0,87 & 0,47 & 0,58 \\
\hline Xyris schizachne Mart. & $\mathrm{E}$ & 2,50 & 4,13 & 5,31 & 0,00 & 0,00 & 0,00 & 0,00 & 0,97 & 2,88 & 5,71 & 4,88 & 4,24 \\
\hline Xyris seubertiana A.Nils. & $\mathrm{E}$ & 0,00 & 0,00 & 0,00 & 0,00 & 0,00 & 0,00 & 3,98 & 0,00 & 1,42 & 0,00 & 0,00 & 0,00 \\
\hline Xyris sp.1 & $\mathrm{E}$ & 0,00 & 0,00 & 0,00 & 0,00 & 0,00 & 0,00 & 0,62 & 0,00 & 0,00 & 0,00 & 0,00 & 0,00 \\
\hline Xyris sp. 2 & $\mathrm{E}$ & 0,00 & 0,00 & 0,00 & 0,00 & 0,00 & 0,00 & 3,52 & 0,00 & 0,00 & 0,00 & 0,00 & 0,00 \\
\hline Xyris sp.3 & $\mathrm{E}$ & 0,00 & 0,00 & 0,00 & 0,00 & 0,00 & 0,00 & 0,00 & 4,73 & 2,35 & 0,00 & 0,00 & 0,00 \\
\hline Xyris tortula Mart. & $\mathrm{E}$ & 2,68 & 0,67 & 0,33 & 0,00 & 0,00 & 0,00 & 0,00 & 0,00 & 0,00 & 0,00 & 0,00 & 0,89 \\
\hline Xyris veruina Malme & $\mathrm{E}$ & 0,00 & 0,00 & 1,49 & 0,00 & 0,00 & 0,00 & 0,00 & 0,00 & 0,00 & 0,00 & 0,00 & 0,00 \\
\hline
\end{tabular}




\section{CAPÍTULO 2 - EFEITO DA FERTILIZAÇÃO NA COBERTURA E COMPOSIÇÃO FLORÍSTICA DO ESTRATO HERBÁCEO-ARBUSTIVO EM ECÓTONO SAVANA- FLORESTA, NO DISTRITO FEDERAL, BRASIL}

\section{RESUMO}

A composição de espécies do estrato herbáceo-arbustivo mostra-se como a mais representativa nas Savanas. Apesar da importância da vegetação desse estrato, pouco se sabe sobre a reabilitação da comunidade após a passagem de incêndio em transições savana-floresta sobre o efeito da adição de nutrientes. O objetivo do estudo foi descrever a reabilitação da cobertura vegetal do estrato herbáceo-arbustivo em ecótono savana-floresta após um incêndio assim como avaliar a influência da adição de nutrientes na dinâmica estrutural e temporal da comunidade. Foram realizados levantamentos fitossociológicos pelo método de interseção na linha em uma área de transição Cerrado sentido restrito a Mata de galeria sobre o efeito da fertilização controlada durante três anos e cinco meses, após incêndio acidental. Em cada amostragem foram determinadas a frequência e a cobertura linear das espécies e estimados os parâmetros de diversidade pelo método de rarefação e extrapolação pelo número de Hill. A adição de fertilizante aumentou a disponibilidade de nutrientes como nitrogênio, fósforo e carbono, assim como reduziu as concentrações de alumínio e ferro. O efeito dessa diferença na disponibilidade de nutrientes refletiu principalmente na estrutura e teve menor efeito na composição de espécies da comunidade herbáceo-arbustivas. No Cerrado sentido restrito observou-se maior número de táxons se comparado com a Mata de Galeria. A fertilização reduz os parâmetros de diversidade e acelera a recomposição do estrato herbáceo-arbustivo sobre o solo com o máximo da cobertura no primeiro ano, principalmente por espécies exóticas. Nas áreas sem fertilização a estabilização da recomposição ocorre somente no terceiro ano com maiores parâmetros de diversidade.

Palavras-chave: recomposição; reabilitação; Melinis minutiflora 


\section{INTRODUÇÃO}

O Cerrado, savana brasileira, se caracteriza pelo mosaico de fitofisionomias campestres, savânicas e florestais (Eiten, 1972; Ribeiro e Walter, 2008). A composição de espécies das fitofisionomias campestres e savânicas apresenta maior número de táxons do estrato herbáceo-arbustivo (Ribeiro e Walter, 2008). Nas fitofisionomias florestais o componente arbóreo apresenta o maior número de espécies, entretanto o componente herbáceo-arbustivo ainda continua presente nos sub-bosques desses ambientes (Felfili et al., 1994; Negrelle, 2006). Para esse bioma, de modo geral, o número de espécies herbáceo-arbustivas em relação às arbóreas apresenta a razão de 5,6:1 e a inclusão do estrato rasteiro em levantamento florísticos e fitossociológicos tem contribuído para o aumento da riqueza de espécies para o Cerrado (Mendonça et al., 2008).

O componente herbáceo-arbustivo possui variações na composição e na estrutura quando afetado por perturbações, como ocorrência de incêndios (Silva e Nogueira, 1999; Munhoz e Felfili, 2006; Neves e Conceição, 2010), cortes rasos (Sato et al., 2014) e sazonalidade climática, dentro do intervalo de um ano (Cianciaruso e Batalha, 2008; Munhoz e Felfili, 2008) ou em intervalos maiores (Eugênio et al., 2011). Apesar da importância da vegetação herbáceo-arbustiva, pouco se sabe sobre o efeito da adição de nutrientes nesse estrato nas diferentes fitofisionomias. Os principais resultados concentram-se nas fitofisionomias savânicas e mostraram que a alteração da fertilidade do solo causou o aumento de biomassa (Villela e Haridasan, 1994; Haridasan et al., 1997), maior presença de espécies exótica (Lannes et al., 2016) e perda de biodiversidade (Bustamante et al., 2012; Mello et al., 2014).

Pouco se sabe também sobre a composição e estrutura do estrato herbáceoarbustivo para fitofisionomias florestais no Cerrado (Negrelle, 2006; Souza, 2014) e se desconhece trabalhos que avaliaram a fertilização nesses ambientes para esse componente. Essas fitofisionomias encontram-se distribuídas na forma de mosaicos e geralmente associa-se sua distribuição às variações ambientais, principalmente de características do solo (Ratter e Dargie, 1992; Felfili et al., 1994). No entanto, a própria vegetação pode modificar o ambiente próximo e alterar diretamente o clima em escala local (Sternberg 2001; Oyama e Nobre, 2003), assim como as características intrínsecas nos perfis dos solos, como a retenção e a distribuição de nutrientes (Chapin et al., 1997). Com isso, zonas de transição entre os mosaicos presentes no Cerrado podem modificar-se ao longo do tempo, já que existe essa relação de interdependência entre ambiente e vegetação (Silva et 
al., 2008). A modificação gerada pode ser intensificada pelo aumento na quantidade de nutrientes no solo causados pela fertilização de origem antrópica (Silvertown et al., 2006; Bustamante et al., 2012) ou pela queima de biomassa (Silva e Batalha, 2008).

$\mathrm{O}$ aumento da frequência de queimadas no Cerrado resulta na redução da biomassa e na diversidade das comunidades vegetais (Ramos-Neto e Pivello, 2000; Ribeiro et al., 2012). Para o componente arbóreo, a queima constante altera a taxa de regeneração (Hoffmann, 2000; Medeiros e Miranda, 2005) e da mortalidade de plântulas (Hoffmann, 1996). Como consequência dos incêndios, ocorre ainda o aumento do entouceiramento no estrato herbáceo que dificulta o crescimento do componente arbóreo (Fiedler et al., 2004) e altera a cobertura do solo (Munhoz e Felfili, 2006; Neves e Conceição, 2010).

De acordo com o exposto, esse estudo partiu do princípio de que a diversidade de espécies tende a ser menor em áreas sobre efeito de fertilização, assim como se tende a reduzir a riqueza de espécies ao longo do gradiente savana-floresta. Para tanto, utilizou-se uma área de transição savana-floresta sobre o efeito da fertilização controlada após incêndio acidental.

\section{Objetivo geral}

Descrever a reabilitação da cobertura vegetal do estrato herbáceo-arbustivo em ecótono savana-floresta após um incêndio, assim como avaliar a influência da adição de nutrientes na dinâmica estrutural e temporal da comunidade.

\section{Objetivos específicos}

- Acompanhar a reabilitação da cobertura vegetal do estrato herbáceo-arbustivo após fogo ao longo de três anos e cinco meses (2012-2015) em ecótono savana-floresta;

- Avaliar o efeito da fertilização na dinâmica temporal da composição florística e estrutural do estrato herbáceo-arbustivo em ecótono savana-floresta;

\section{MATERIAL E MÉTODOS}

Área de estudo - O estudo foi realizado em ecótono Cerrado sentido restrito - Mata de

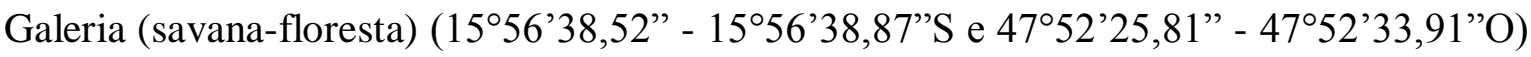
na Reserva Ecológica do Instituto Brasileiro de Geografia e Estatística (RECOR-IBGE), a aproximadamente $26 \mathrm{~km}$ ao sul do centro de Brasília, Distrito Federal, Brasil. A RECOR 
possui área de 13.000 ha que integra diferentes ambientes protegidos no Distrito Federal como a Zona de Vida Silvestre, da Área de Proteção Ambiental Distrital Gama e Cabeça de Veado, a Área de Proteção Ambiental Federal do Planalto Central e a zona nuclear da Reserva da Biosfera do Cerrado - Fase I - Programa Cobramab/UNESCO (IBGE, 2011). Na região o clima é classificado como Aw conforme Koppen, a precipitação anual variou entre 1.182 e $1.375 \mathrm{~mm}$ e a temperatura média anual foi de $22^{\circ} \mathrm{C}$ no período do estudo (Estação Meteorológica do Instituto Brasileiro de Geografia e Estatística <www.recor.org.br>). A RECOR-IBGE passou por incêndio que atingiu cerca de $95 \%$ da área total entre 8 e 9 de setembro de 2011 (RECOR, 2011). O local onde se realizou o levantamento fitossociológico teve $100 \%$ da cobertura vegetal do estrato herbáceoarbustivo queimada (Figura 1). Considerou-se como estrato herbáceo-arbustivo as plantas com diferentes formas de crescimento entre ervas, gramíneas, subarbustos e arbustos, e exclui-se as plantas com tronco definido com altura acima de $2 \mathrm{~m}$.

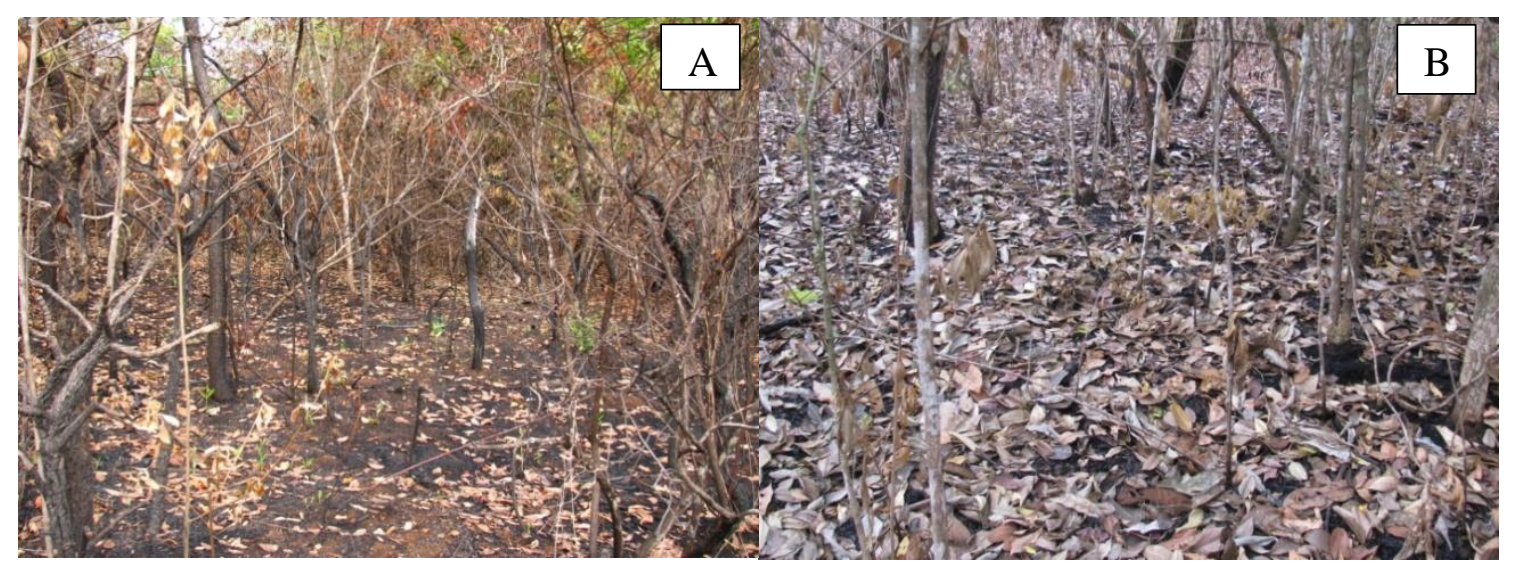

Figura 1 - Registro do local de estudo, ecótono Cerrado sentido restrito (A)-Mata de Galeria (B), em 12 de outubro de 2011 (um mês após a passagem do fogo), dentro da Reserva Ecológica do Instituto Brasileiro de Geografia e Estatística.

Amostragem da vegetação - O estrato herbáceo-arbustivo foi amostrado em fevereiro de 2012, cinco meses após a passagem do incêndio, no auge da estação chuvosa, e posteriormente em 2013, 2014 e 2015, no mesmo período. Na ausência do estrato herbáceo-arbustivo, registrou-se solo desnudo e serapilheira. Os transcetos foram alocados em 2012 no centro das parcelas instaladas para o levantamento da vegetação arbórea, realizado por Geiger et al. (2011). Em 2007, foram demarcadas 12 parcelas de 10m x 70m, perpendicular à borda da Mata de Galeria, na faixa de transição entre Mata de Galeria e 
Cerrado sentido restrito, com espaçamento de $10 \mathrm{~m}$ entre as parcelas. Cada parcela foi subdividida em sete subparcelas de $10 \mathrm{~m} \times 10 \mathrm{~m}$ para fins de amostragem (Figura 2), onde a subparcela central (ecótono) foi denominada 0m (zero), e três subparcelas adentram a Mata de Galeria, sendo denominadas -10, -20 e -30m; e, por último, as outras três parcelas adentram o Cerrado sentido restrito, sendo denominadas 10, 20 e 30m. Para definir a posição do Ecotóno (subparcela central) entre a Mata de Galeria e Cerrado sentido restrito utilizou-se da alteração da estrutura arbórea e a diminuição da cobertura do estrato herbáceo. Utilizou-se o método de inventário de interseção na linha (Canfield 1941; 1950) em transectos permanentes de $70 \mathrm{~m}$ subdividos em unidades amostrais de $10 \mathrm{~m}$. Os parâmetros fitossociológicos cobertura e frequência foram determinados segundo Munhoz e Araújo (2011).

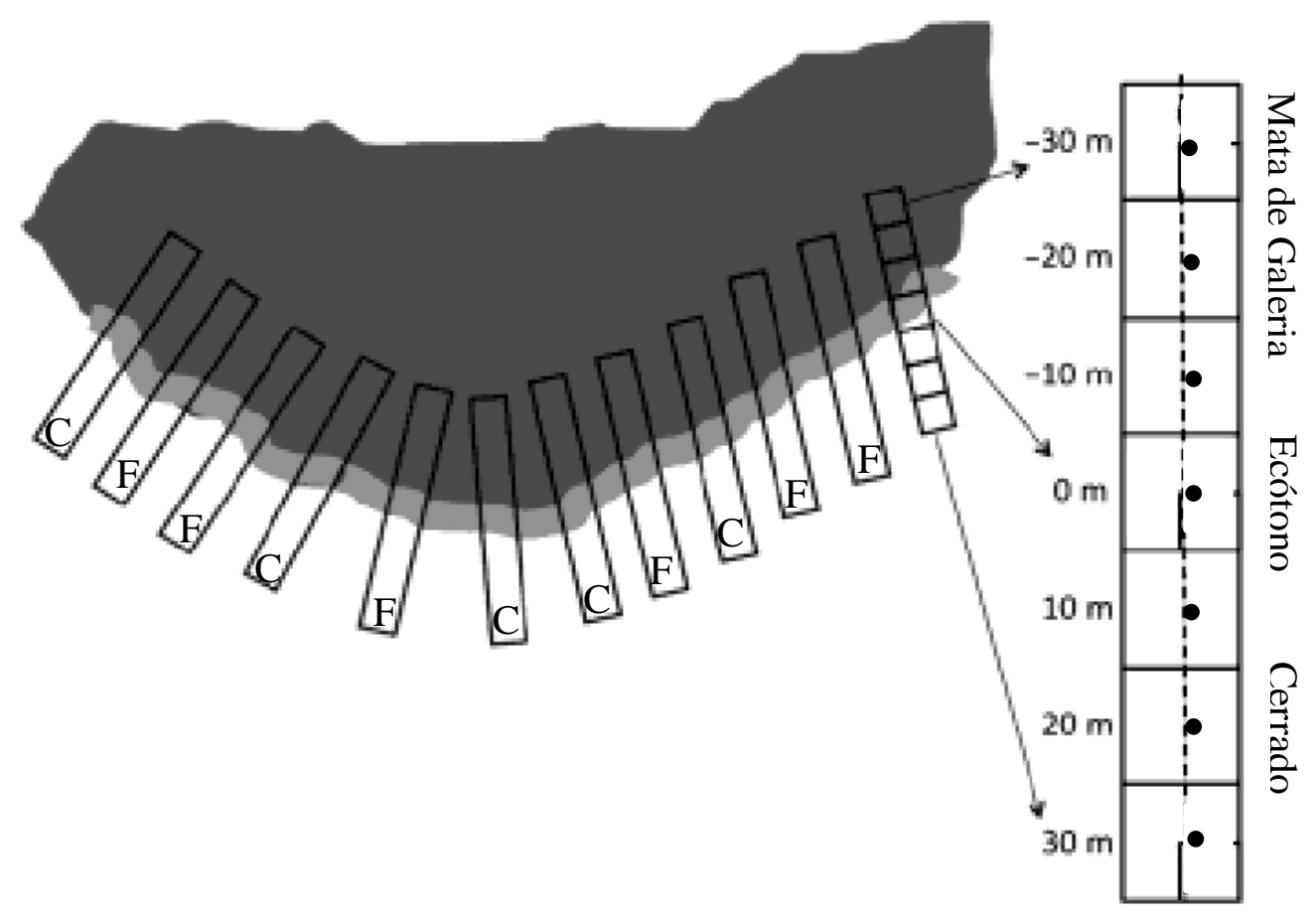

Figura 2 - Croqui do arranjo amostral do estudo do ecótono Mata de Galeria - Cerrado sentido restrito na RECOR-IBGE no Distrito Federal, adaptado de Geiger et al., (2011). Doze parcelas de $70 \mathrm{~m}$ instaladas perpendicularmente à fronteira da Mata de Galeria e subdivididas em subparcelas de $10 \mathrm{~m}$. A parcela central de $10 \mathrm{mx} 10 \mathrm{~m}$ foi considerada transição Mata de Galeria - Cerrado sentido restrito em função da mudança na estrutura do componente arbóreo e herbáceo. A amostragem do estrato herbáceo-arbustivo foi realizada em transecto de 70m localizado no centro de cada parcela (-----), sendo seis transectos em parcelas com fertilização (F) e seis sem fertilização (C). Ponto de coleta de solo 0$15 \mathrm{~cm}(\bullet)$. 
Inicialmente foram aplicados quatro tratamentos e três replicações. Os tratamentos eram controle, irrigação na época seca, adição de nutrientes (calcário, macro e micronutrientes) e irrigação com adição de nutrientes. Os nutrientes foram adicionados na quantidade de $-100 \mathrm{~kg} \mathrm{ha}^{-1}$. ano ${ }^{-1}$ de N, P e K cada e $18 \mathrm{~kg} \mathrm{ha}^{-1}$. noo $^{-1} \mathrm{de} \mathrm{Zn}, 6 \mathrm{~kg}$ ha ${ }^{1}$.ano ${ }^{-1}$ de Fe, $4 \mathrm{~kg} \mathrm{ha}^{-1}$. ano ${ }^{-1}$ de Mn, 3,6 kg ha ${ }^{-1}$. nono $^{-1}$ de B, $2 \mathrm{~kg} \mathrm{ha}^{-1}$.ano ${ }^{-1}$ de Mo e 1,6 kg $\mathrm{ha}^{-1} \cdot$ ano $^{-1}$ de $\mathrm{Cu}$, como fertilizante composto granulado; e $300 \mathrm{~kg} \mathrm{ha}^{-1}$. ano $^{-1} \mathrm{de}$ $\mathrm{CaMg}\left(\mathrm{CO}_{3}\right)_{2}$, como calcário dolomítico. A aplicação dos nutrientes foi realizada anualmente desde 2007, a lanço, para assegurar distribuição uniforme dos fertilizantes. Em função do fogo ocorrido em setembro de 2011 o tratamento de irrigação foi abandonado devido à queima da tubulação responsável pelo transporte da água e o tratamento de adição de nutrientes continuou. Análise prévia não indicou diferença significativa em relação aos fatores edáficos (Anexo 3; $p>0,05$ ) entre os tratamentos controle e irrigação na época seca, assim como entre adição de nutrientes e irrigação com adição de nutrientes. Dessa forma, o delineamento ficou com dois tratamentos: o controle e o de adição de nutrientes, onde cada um passou a apresentar seis replicações (Figura 2).

Os materiais botânicos coletados nos inventários foram identificados por meio de comparação com exemplares herborizados depositados no Herbário da Reserva Ecológica do Instituto Brasileiro de Geografia e Estatística (IBGE) e no Herbário da Universidade de Brasília (UB), com auxílio de materiais literários e consulta a especialistas. Os materiais férteis foram herborizados e depositados nos Herbários UB e IBGE. As espécies de angiospermas foram classificadas em famílias de acordo com sistema do Angiosperm Phylogeny Group IV (APG IV, 2016) e a grafia dos nomes foi confirmada no banco de dados eletrônicos do Missouri Botanical Garden (http://www.tropicos.org/).

Amostragem do solo - Paralelo à porção central de cada transecto de 10m que compõe as subparcelas de $10 \mathrm{~m} \times 10 \mathrm{~m}$, das parcelas de $10 \mathrm{~m}$ x 70m, foi coletada amostra de solo em 2007 (Geiger et al., 2011) e 2015 (Figura 2). Em ambos os momentos foram amostrados $500 \mathrm{~g}$ de solo superficial $(0-15 \mathrm{~cm})$. Análises químicas foram realizadas segundo o protocolo da EMBRAPA (1997). As variáveis de solo analisadas foram: $\mathrm{pH}$, teores de $\mathrm{Ca}$, $\mathrm{Mg}, \mathrm{Al}, \mathrm{N}, \mathrm{K}, \mathrm{P}, \mathrm{Zn}, \mathrm{B}, \mathrm{Cu}, \mathrm{Fe}, \mathrm{Mn}$ e C (matéria orgânica). As diferenças entre os pontos de coletas foram avaliadas por meio de MANOVA, utilizando como fatores a presença ou ausência da fertilização e a distância dentro do gradiente Cerrado sentido restrito - Mata de Galeria. 
Análise da vegetação - A similaridade da composição florística entre os períodos amostrados foi avaliada pelo índice de similaridade de Chao-Sørensen (Chao et al., 2005; 2006). Utilizou-se uma matriz com a cobertura de cada espécie encontrada e o ano do inventário, corrigindo, desta forma, os desvios de estimativa que podem ser produzidos em análises de similaridade baseadas somente na presença ou ausência (Chao et al., 2005; 2006). O índice Chao-Sørensen e o desvio padrão foram obtidos pelo programa EstimateS 9.0 (Colwell, 2013).

Para a comparação entre os índices de similaridades entre os inventários utilizou-se Análise de Variância de Similaridade (ANOSIM) que consiste na diferença entre os valores médios dos índices de similaridade das espécies entre as amostras $\left(\mathrm{r}_{\mathrm{B}}\right)$ e dentro de amostras $\left(\mathrm{r}_{\mathrm{W}}\right)$, por meio de teste estatístico não-paramétrico (Clarke, 1993), onde:

$$
R=\left\{\frac{8-r_{w}-}{\left[n \times \frac{4-1}{4}\right]}\right\}
$$

sendo: $\mathrm{n}$, o número total de repetições somados para as duas amostras. $\mathrm{R}$ pode variar entre -1 e +1 , sendo que se $\mathrm{R}$ for igual a zero se aceita a hipótese nula, o que significa que as amostras são semelhantes.

As relações florísticas e a cobertura entre os períodos e a posição dentro da transição Cerrado sentido restrito - Mata de Galeria foram analisadas por procedimento de escala não-métrica multidimensional (NMDS) (Clarke, 1993), a partir de matriz da cobertura das espécies, onde a significância dos eixos foram geradas por 999 permutação. Gerou-se o coeficiente de determinação $\left(\mathrm{R}^{2}\right)$ das distâncias florísticas das ordenações pelas distâncias florísticas originais entre as linhas, utilizando o software R 3.2.3 (R Core Team, 2015) com o pacote vegan 2.0 (Oksanen, 2007). Foram calculadas as diferenças entre todos os pares de amostras usando a medida de dissimilaridade de Bray-Curtis, por ser uma medida robusta para ordenação de dados ecológicos (Anderson e Willis, 2003). Para confirmação dos grupos observados na NMDS e para comparar o efeito da fertilização, da posição na transição Cerrado sentido restrito - Mata de Galeria e do ano do levantamento na composição florística realizou-se uma PerMANOVA (Permutation-based nonparametric MANOVA).

Para a comparação da riqueza e diversidade de espécies entre os períodos, locais e tratamento com fertilização, utilizou-se o método de rarefação e extrapolação pelo número de Hill, permitindo estimar as ordens de $\mathrm{q}=0$ (riqueza), $\mathrm{q}=1$ (exponencial do índice de 
Shannon) e q=2 (o inverso do índice de Simpson), possibilitando a caracterização das comunidades (Chao et al., 2014). Com base nas medidas de variâncias estimadas durante a randomização por Bootstrap, foram gerados intervalos de confianças de 95\%, para inferir diferenças estatísticas. O número total de espécies estimado para cada comunidade foi calculado pelo estimador de riqueza Chao 2 (Chao, 1987). A extrapolação e a rarefação do número de Hill foram realizadas no programa R 3.2.3 (R Core Team 2015) com a instalação dos pacotes iNEXT 2.0.5 (Hsieh et al., 2015) e devtools 1.8.0 (Wickham et al., 2015).

\section{RESULTADOS}

Solos

Para análise do solo (Figura 3) coletado em 2015, as parcelas fertilizadas apresentaram de forma global maiores teores dos parâmetros analisados (MANOVA F= $18,38 ; p<0.001)$, assim como a concentração de alguns nutrientes variou significativamente (MANOVA $\mathrm{F}=1,89 ; p<0,001$ ) ao longo do gradiente savana-floresta (Anexo2). As concentrações de C, N, Ca e Mg foram maiores na Mata de Galeria do que no Cerrado sentido restrito, o Ecótono só apresentou menores teores desses elementos quando comparado com as parcelas da Mata de Galeria. Já P e Cu e os valores foram maiores para as parcelas no Cerrado sentido restrito do que na Mata de Galeria e no Ecótono. Para o Fe e Al observou-se uma redução nas concentrações nas parcelas fertilizadas.

\section{Vegetação}

A comunidade herbáceo-arbustiva ao longo de três anos após o fogo apresentou total de 166 espécies (Anexo2), sendo 161 no Cerrado sentido restrito, 82 no Ecótono e 27 em Matas de Galeria. Dentre as 27 espécies observadas na Mata de Galeria somente dez ocorreram a $30 \mathrm{~m}$ do Ecótono e as outras 17 espécies foram levantadas principalmente nos primeiros $10 \mathrm{~m}$, entre o Ecótono e a Mata de Galeria. As famílias com maiores números de espécies foram Poaceae (25), Asteraceae (24) e Fabaceae (17). 

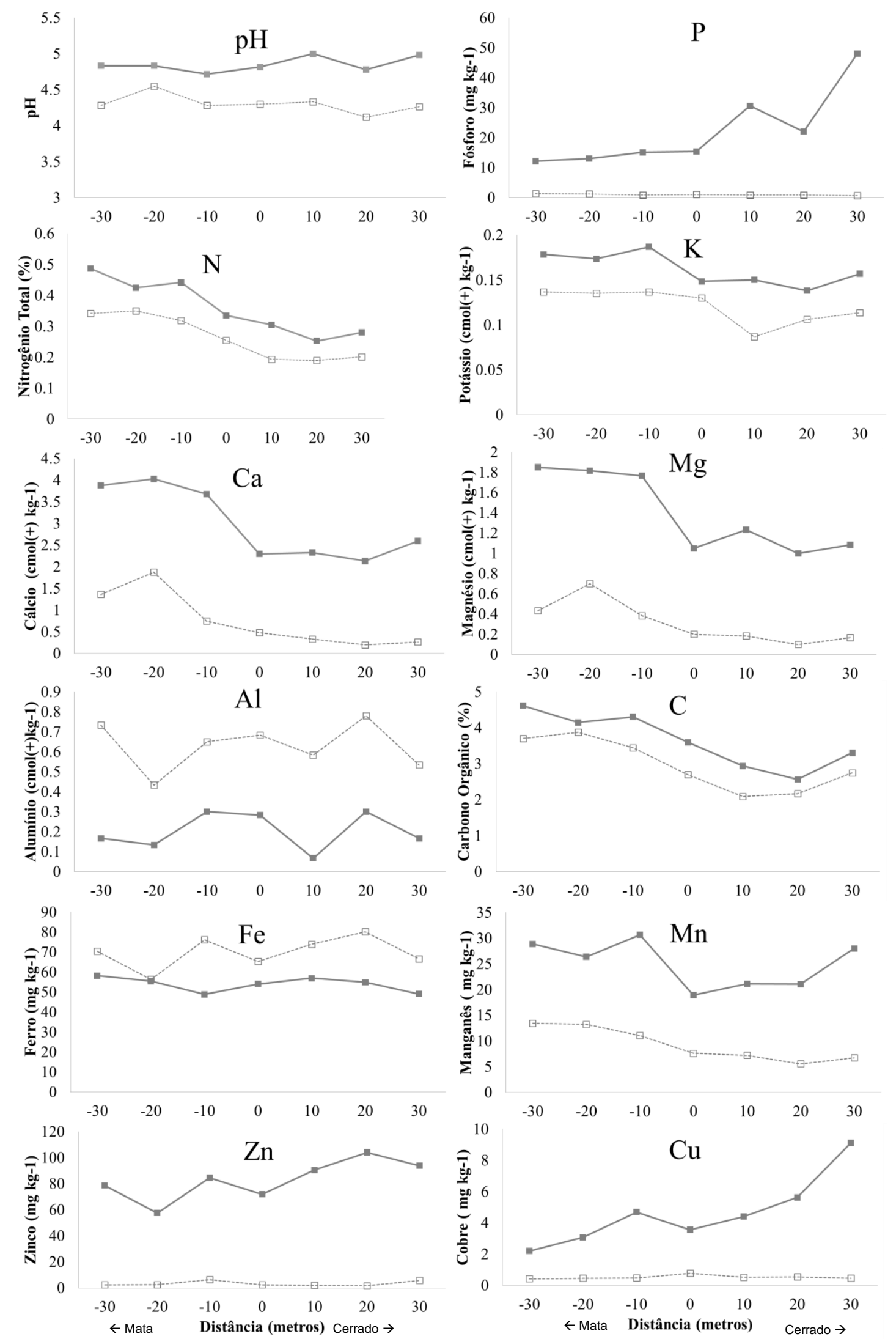

Figura 3 - Variação do pH e na concentração de nutrientes do solo em transectos 10x70m ao longo de uma transição entre o Cerrado sentido restrito e a Mata de Galeria na RECOR-IBGE. Médias após sete anos de fertilização (- $\left.{ }^{-}-\right)$e médias das parcelas controle sem fertilização (--- $\square---)$. 
Desde o primeiro levantamento (cinco meses após a passagem do fogo), dentre as dez espécies com maior cobertura (Figura 4) observa-se o predomínio de Melinis minutiflora P. Beauv. nas áreas com fertilização e de Echinolaena inflexa (Poir.) Chase nas áreas sem fertilização. Entretanto, ao longo do tempo, foi observado aumento da cobertura de Baccharis tridentata Vahl e predominância de M. minutiflora nas parcelas fertilizadas, principalmente para as parcelas de Cerrado sentido restrito. Porém, para Mata de Galeria observou-se a maior cobertura para Ichnanthus pallens (Sw.) Munro ex Benth, nas parcelas sem fertilização e para as parcelas fertilizadas observou principalmente a deposição de serapilheira. No Ecótono, novamente E. inflexa teve maior cobertura nas parcelas sem fertilização, enquanto o M. minutiflora e Pteridium aquilinum (L.) Kuhn predominaram nas parcelas fertilizadas (Figura 4).

A composição das espécies mostrou-se similar entre as épocas de amostragem pelo índice de Chao-Sørensen (Tabela 1) e a ANOSIM confirmou a semelhança entre a composição florística ao longo do tempo $(\mathrm{R}=0,004 ; p=0,58)$ e diferença entre os tratamentos com e sem fertilização $(\mathrm{R}=0,29 ; p<0,05)$.

Tabela 1 - Índice de similaridade de Chao-Sørensen \pm intervalo de confiança, entre os inventários e tratamentos com e sem fertilização em uma área de transição Savana-Floresta na Reserva Ecológica do IBGE, Brasília, Distrito Federal, Brasil.

\begin{tabular}{|c|c|c|c|c|c|c|c|}
\hline & $\begin{array}{c}\text { Fertilizada } \\
2012\end{array}$ & $\begin{array}{c}\text { Controle } \\
2012\end{array}$ & $\begin{array}{c}\text { Fertilizada } \\
\quad 2013 \\
\end{array}$ & $\begin{array}{c}\text { Controle_ } \\
2013\end{array}$ & $\begin{array}{c}\text { Fertilizada } \\
\_2014 \\
\end{array}$ & $\begin{array}{c}\text { Controle } \\
2014\end{array}$ & $\begin{array}{c}\text { Fertilizada } \\
\quad 2015 \\
\end{array}$ \\
\hline $\begin{array}{c}\text { Controle } \\
2012\end{array}$ & $0,91 \pm 0,04$ & & & & & & \\
\hline $\begin{array}{c}\text { Fertilizada } \\
\quad 2013\end{array}$ & $0,96 \pm 0,02$ & $0,85 \pm 0,05$ & & & & & \\
\hline $\begin{array}{c}\text { Controle } \\
2013\end{array}$ & $0,89 \pm 0,03$ & $0,98 \pm 0,01$ & $0,89 \pm 0,03$ & & & & \\
\hline $\begin{array}{c}\text { Fertilizada } \\
\_2014\end{array}$ & $0,95 \pm 0,03$ & $0,84 \pm 0,04$ & $0,98 \pm 0,01$ & $0,88 \pm 0,05$ & & & \\
\hline $\begin{array}{c}\text { Controle } \\
2014\end{array}$ & $0,87 \pm 0,05$ & $0,96 \pm 0,01$ & $0,86 \pm 0,06$ & $0,99 \pm 0,01$ & $0,85 \pm 0,05$ & & \\
\hline $\begin{array}{c}\text { Fertilizada } \\
\_2015\end{array}$ & $0,94 \pm 0,04$ & $0,82 \pm 0,07$ & $0,96 \pm 0,02$ & $0,84 \pm 0,06$ & $0,97 \pm 0,03$ & $0,82 \pm 0,05$ & \\
\hline $\begin{array}{c}\text { Controle } \\
2015\end{array}$ & $0,89 \pm 0,05$ & $0,95 \pm 0,02$ & $0,88 \pm 0,06$ & $0,99 \pm 0,01$ & $0,87 \pm 0,04$ & $0,99 \pm 0,00$ & $0,86 \pm 0,05$ \\
\hline
\end{tabular}




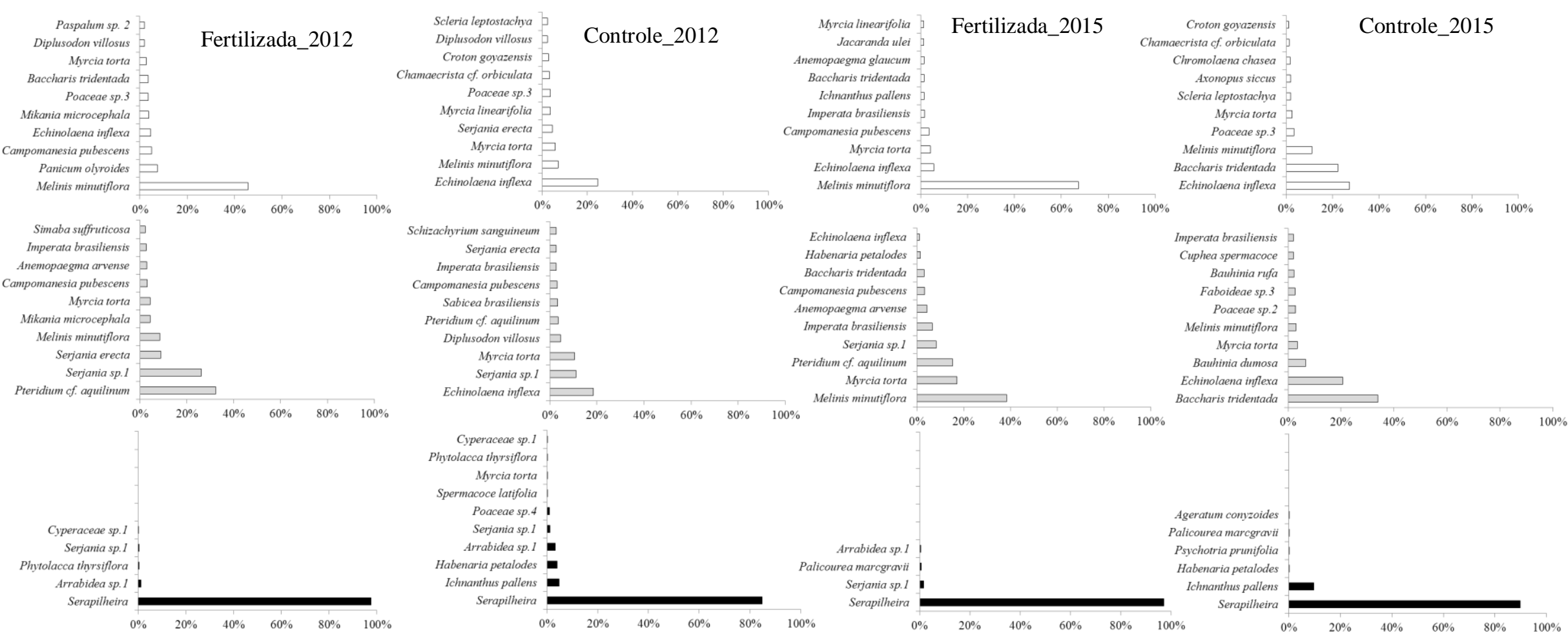

Figura 4 - Cobertura relativa das dez principais espécies nos quatro levantamentos sob tratamentos com e sem fertilização em uma área de transição Savana-Floresta na Reserva Ecológica do IBGE, Brasília, Distrito Federal, Brasil. ( $\square$ ) Cerrado, ( $\square$ ) Ecótono e (匹) Mata. 
A estimativa de diversidade pelo método de rarefação e extrapolação de Hill demonstrou que entre os anos, para as parcelas na Mata de Galeria, não houve diferença no tratamento com (Figura 5) e sem (Figura 6) fertilização para as três ordens de q. Não se observou, portanto, variação significativa para o número de táxons, a riqueza da comunidade $(\mathrm{q}=0)$, como para as medidas de diversidade pelo exponencial do índice de Shannon $(\mathrm{q}=1)$ e pelo inverso do índice de Simpson $(\mathrm{q}=2)$. Entretanto para parcelas no Cerrado sentido restrito evidenciou uma redução de cerca de $50 \%$ da riqueza de espécies (Figura 5 e 6). Onde verificou-se menores valores para os parâmetros de diversidade nas parcelas fertilizadas (Figura 5) quando comparadas com as sem fertilização (Figura 6). Sendo evidente que com o passar dos anos a riqueza de espécies $(\mathrm{q}=0)$ para parcelas com fertilização tendeu a reduzir. Observou-se ainda um gradiente de diversidade entre Cerrado sentido restrito e a Mata de Galeria, onde ao longo do período de observação a vegetação savânica manteve-se mais diversa.

A fertilização formou grupos consistentes (PerMANOVA, $\mathrm{F}=24,89 ; p<0,001$ ) como observado na análise de ordenação (Figura 7), assim como em função da distância do ecótono (PerMANOVA, $\mathrm{F}=23,60 ; p=0,001$ ). Entretanto, o tempo não afetou a composição (PerMANOVA, $F=1,65 ; p=0,08)$, A correlação entre a distância florística e a distância $n$ dimensional original apresentou coeficiente de determinação alto de 0,93.

O aumento da cobertura do solo pelo estrato herbáceo-arbustivo após o fogo foi mais rápido nas parcelas adubadas (Figura 8), com tendência a estabilizar a cobertura já na primeira amostragem, cinco meses após a passagem do fogo. Enquanto na cobertura do solo para as parcelas controle houve aumento até o terceiro ano especialmente para parcelas do Cerrado sentido restrito. 


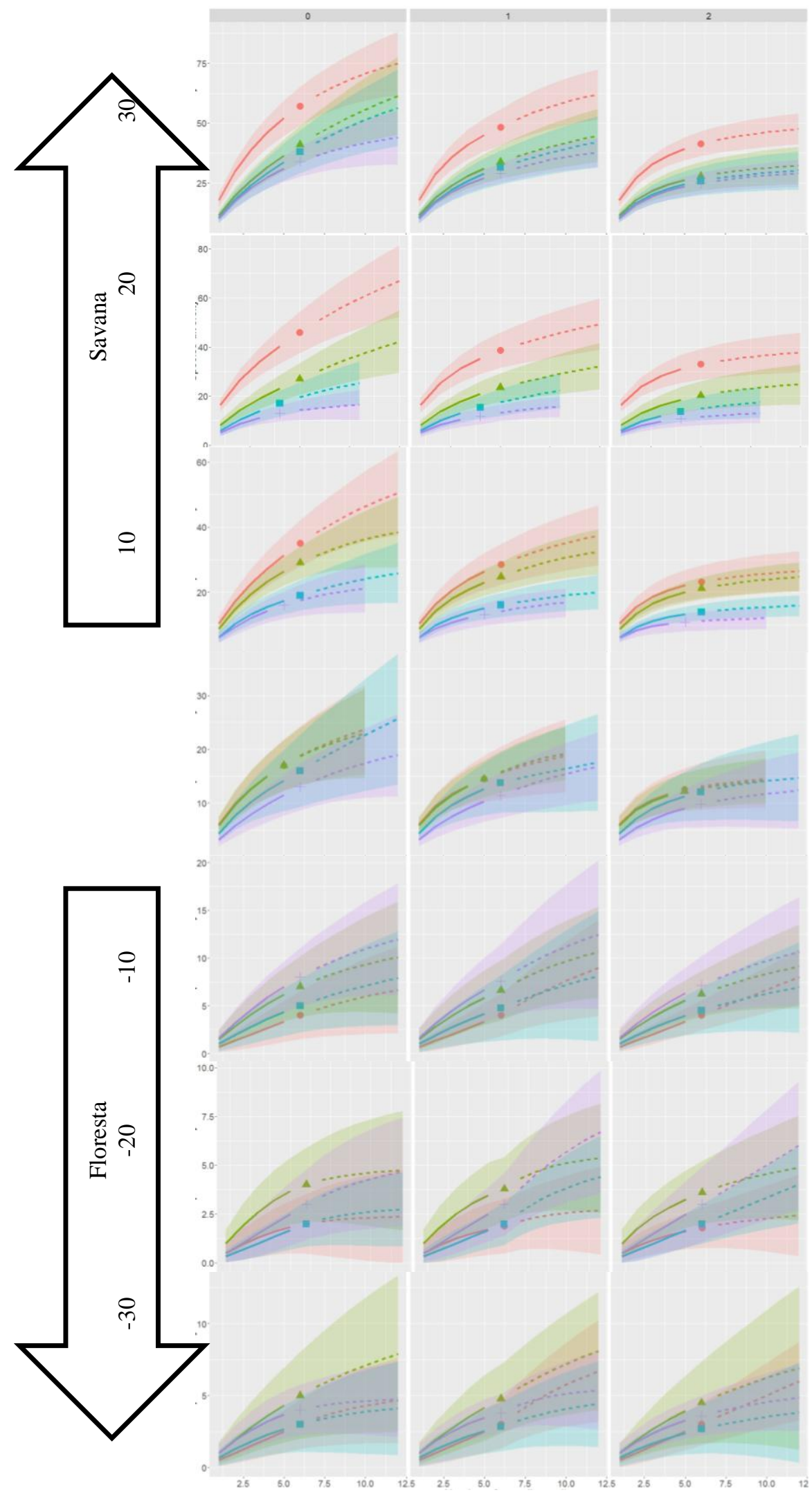

Figura 5 - Rarefação e extrapolação estimado pelo número de Hill adaptado por Chao et al., (2014), para as ordens de q=0 (riqueza), q=1(exponencial do índice de Shannon) e q=2 (o inverso do índice de Simpson). Áreas sombreadas correspondem aos intervalos de confiança de $95 \%,(\bullet)$ primeiro levantamento, $(\boldsymbol{\Delta})$ segundo levantamento, (घ) terceiro levantamento e $(+)$ quarto levantamento para as parcelas sobre efeito da fertilização. 


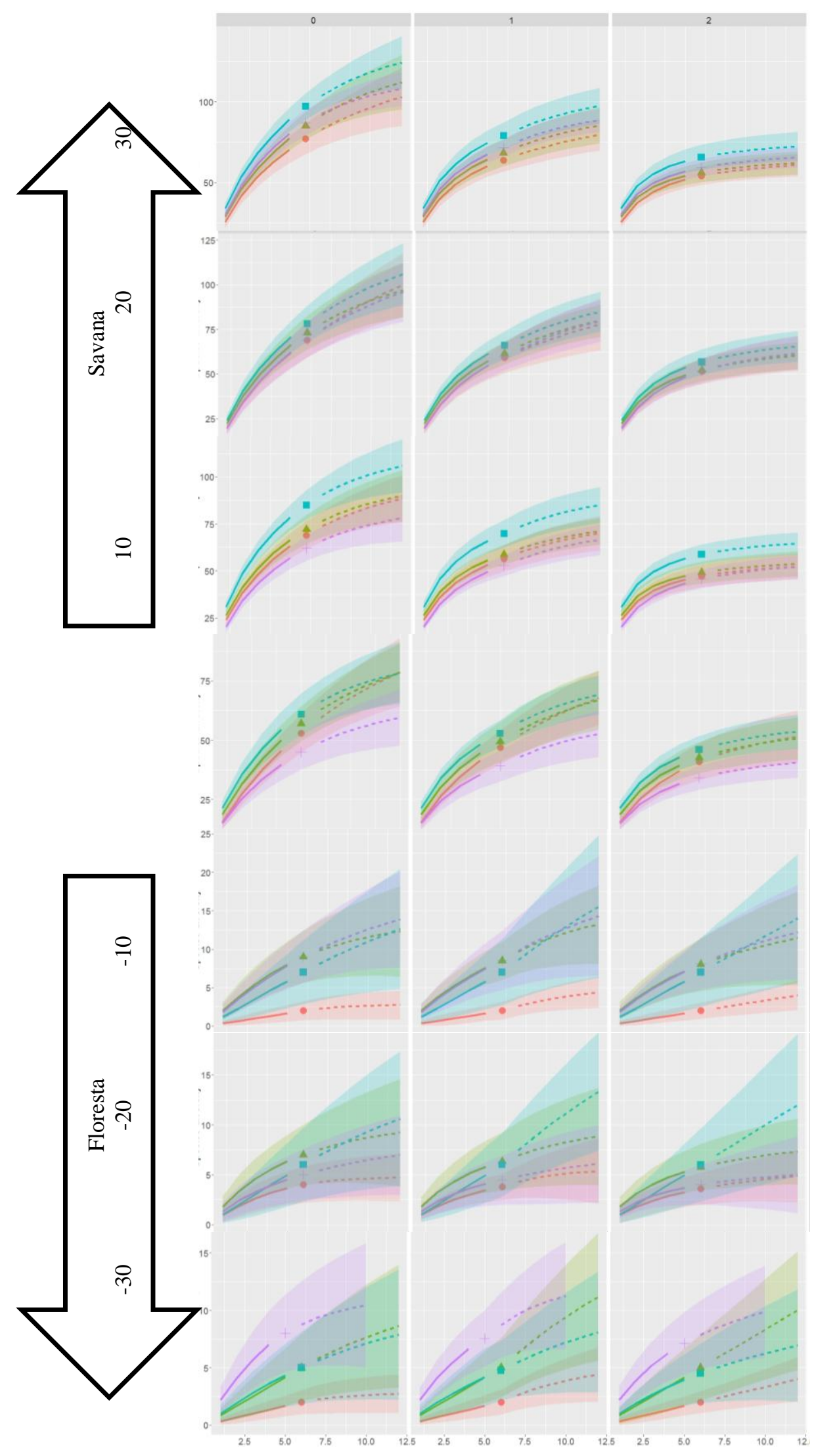

Figura 6 - Rarefação e extrapolação estimado pelo número de Hill adaptado por Chao et al., (2014), para as ordens de q=0 (riqueza), q=1(exponencial do índice de Shannon) e q=2 (o inverso do índice de Simpson).

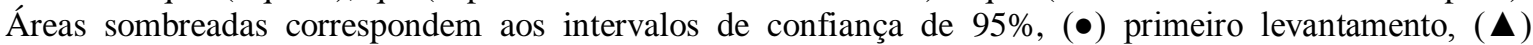
segundo levantamento, ( $\mathbf{\square})$ terceiro levantamento e $(+)$ quarto levantamento para as parcelas sem fertilização. 




Figura 7 - Ordenações quantitativas da composição de espécies herbáceo-arbustivas entre ecótono Mata de galeria - Cerrado sentido restrito em áreas sobre fertilização e áreas sem fertilização na Reserva Ecológica do IBGE, Distrito Federal, Brasil. 


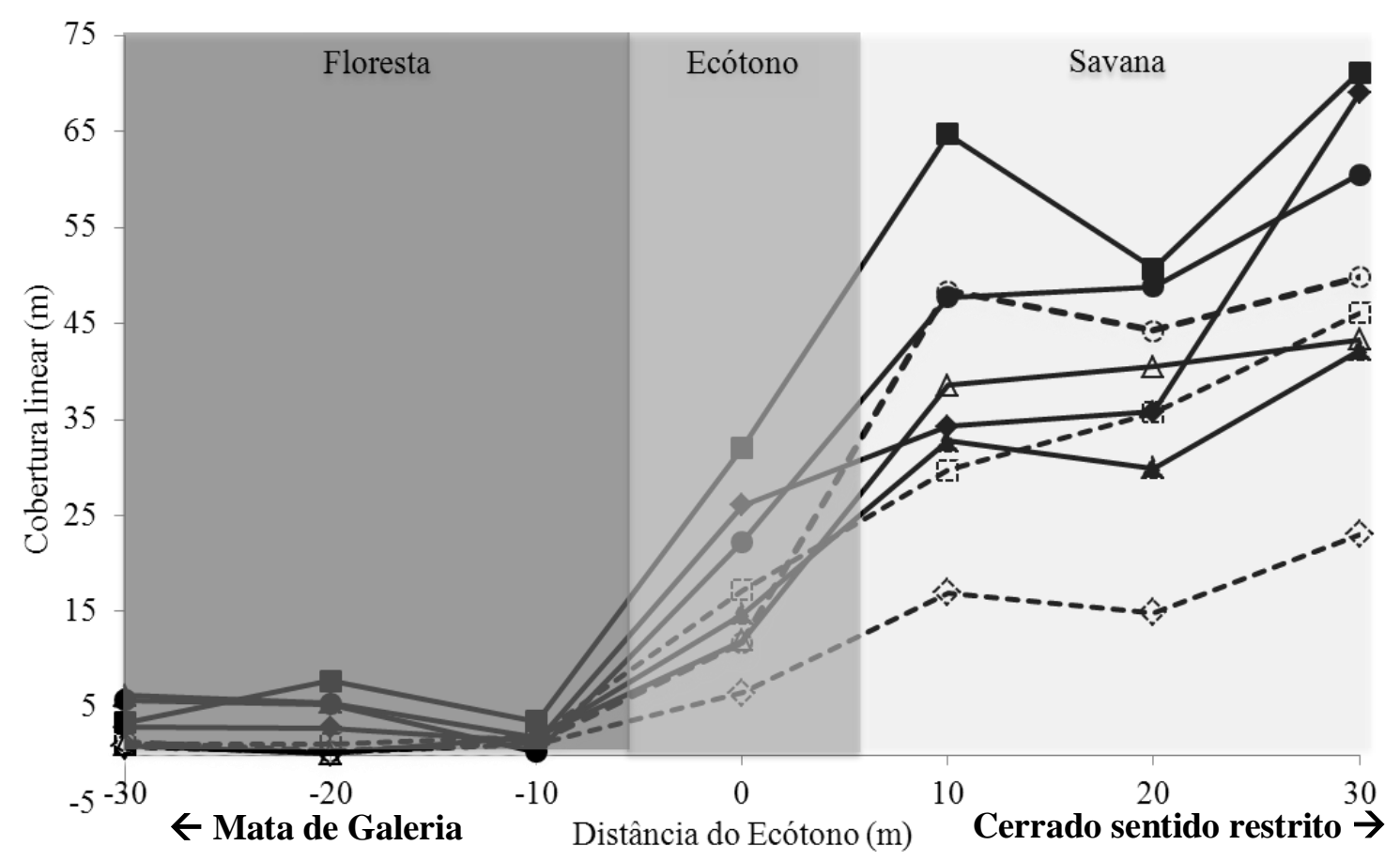

Figura 8 - Variação da cobertura absoluta média (m) do estrato herbáceo-arbustivo entre os anos de 2012, 2013 e 2014 em uma transição Mata de Galeria - Cerrado sentido restrito (-30m a 30m) na Reserva Ecológica do IBGE, Distrito Federal, Brasil. Fertilizada 2012 ( $\Delta-$ ), Fertilizada 2013 (o-

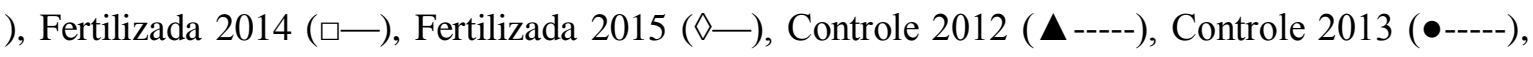
Controle 2014 (ロ-----) e Controle 2015 (

\section{DISCUSSÃO}

A composição florística herbáceo-arbustiva para as áreas de Cerrado sentido restrito apresentou características similares aos levantamentos realizados em áreas campestres (Munhoz e Felfili, 2006; Neves e Conceição, 2010; Sato et al., 2014), como para áreas savânicas (Silva e Nogueira, 1999; Mello et al., 2014) com maior cobertura para espécies pertencentes às famílias Poaceae, Asteraceae e Fabaceae. Para as áreas de florestas, observou-se a família Poaceae como a mais importante na cobertura do solo, porém essa cobertura manteve-se abaixo de 10\%. Sendo que a principal dinâmica observada foi a deposição de serapilheira no solo que inicialmente (em setembro de 2011) encontrava-se exposto. A composição de espécies para o sub-bosque de ambientes florestais refere-se principalmente a plântulas do componente arbóreo e poucos indivíduos 
do componente herbáceo (Negrelle, 2006). O raleamento do componente herbáceo de áreas savânicas para áreas florestais é previsto pela classificação fitofisionômica para o Cerrado (Ribeiro e Walter, 2008), da mesma forma que a diminuição da importância do estrato herbáceo-arbustivo na composição florística de fitofisionomias florestais (Mendonça et al., 2008). A composição e a diversidade apresentaram gradiente entre a savana e a floresta em estudo, com maiores valores para as áreas savânicas, independente da adição de fertilizantes.

O componente herbáceo-arbustivo manteve menor riqueza para áreas fertilizadas se comparadas com as áreas sem fertilização, o que corroborou a ideia de que a diversidade tende a ser menor em áreas sob efeito de fertilização (Bustamante et al., 2012; Lannes et al., 2016). A fertilização muitas vezes leva à dominância de espécies que apresentam ampla distribuição, assim como para aquelas que apresentam crescimento clonal horizontal via rizomas e estolões (Reynolds et al., 2007; Eilts et al., 2011), essa estratégia de desenvolvimento é característica das espécies com maior cobertura nas parcelas fertilizadas, por exemplo Melinis minutiflora. Essa espécie invasora elevou a cobertura em áreas de savanas onde havia aumento da disponibilidade de fósforo (Mello et al., 2014; Lannes et al., 2016). O aumento da concentração do fósforo com a fertilização na área de Cerrado sentido restrito resultou na entrada e na dominância local de M. minutiflora. A junção das estratégias descritas imprime maior capacidade da espécie se tornar dominante, pois limita o crescimento de plantas que produzem rizomas ou estolões curtos ou não apresentam esse tipo de desenvolvimento (Schoolmaster Jr et al., 2014).

O sucesso de colonização de $M$. minutiflora encontra-se dependente da luminosidade, visto que nesse estudo a cobertura dessa espécie restringe-se às áreas de savana, não conseguindo colonizar as áreas de floresta mesmo sob fertilização. A luminosidade tem se mostrado como fator limitante para o aumento da biomassa dessa espécie, apresentando alta correlação entre a redução de luminosidade e a menor importância de biomassa de M. minutiflora em ambientes florestais (Hoffmann et al., 2004). Da mesma forma, observa-se que a cobertura do componente herbáceo-arbustivo, de modo geral, reduz em ambientes savânicos mais fechados, com menores níveis de luminosidade (Braga, 2010). A alteração na cobertura não se restringiu somente as espécies exóticas observou-se o aumento de espécies nativas, por exemplo, a liana Serjania erecta Radlk. As trepadeiras são descritas como espécies que se favorecem com o aumento da fertilidade do solo (Haridasan, 2000) e indicadoras de ambientes florestais sobre interferência antrópica (Laurence, 2001; Phillips et al., 2005) 
A composição florística da área não foi alterada dentro do intervalo do estudo. Entretanto, pouco se sabe sobre a dinâmica temporal para o estrato herbáceo-arbustivo em savana. Em intervalo de um ano a composição de espécies não se alterou mesmo sobre a passagem de incêndio acidental (Silva e Nogueira, 1999). Em outros ambientes, observa-se que esse componente pode não apresentar mudança na composição florística, mas alternância na dominância ao longo do tempo (Luis et al., 2006) ou apresentar variação na composição e na dinâmica espacial em intervalos de dois anos (Reis et al., 2006). A espécie Baccharis tridentada aumentou a cobertura no último período de amostragem, o que pode evidenciar a alternância da dominância de espécies na savana estudada.

\section{CONCLUSÃO}

$\mathrm{Na}$ transição savana-floresta, observou-se maior riqueza de espécies herbáceoarbustivas na savana e demonstrou-se que a fertilização reduz a diversidade de espécies e acelera a recomposição da cobertura vegetal do solo pelo estrato herbáceo-arbustivo, principalmente por espécies exóticas. A reabilitação da cobertura vegetal do estrato herbáceo-arbustivo após um incêndio em ecótono savana-floresta mostrou-se mais rápida na savana, onde as parcelas fertilizadas atingem o máximo de cobertura no primeiro ano e as parcelas controles estabilizam somente no terceiro ano. 


\section{REFERÊNCIAS}

Anderson, M. J., \& Willis, T. J. (2003). Canonical analysis of principal coordinates: a useful method of constrained ordination for ecology. Ecology, 84, 511-525.

APG - The Angiosperm Phylogeny Group. 2016. An Update of the Angiosperm Phylogeny Group Classification for the Orders and Families of Flowering Plants: APG IV. Botanical Journal of the Linnean Society. DOI: 10.1111/boj.12385.

Braga, E. P. (2010). Relação entre parâmetros de radiação solar e espécies herbáceosubarbustivas de cerrado sentido restrito no Jardim Botânico de Brasília. Dissertação de Mestrado. Departamento de Ecologia. Universidade de Brasília.

Bustamante, M. M., de Brito, D. Q., Kozovits, A. R., Luedemann, G., de Mello, T. R., de Siqueira Pinto, A., Munhoz, C. B. R., \& Takahashi, F. S. (2012). Effects of nutrient additions on plant biomass and diversity of the herbaceous-subshrub layer of a Brazilian savanna (Cerrado). Plant Ecology, 213, 795-808.

Canfield, R. H. (1941). Application of the line interception method in sampling range vegetation. Journal of Forestry, 39, 388-394.

Canfield, R. H. (1950). Sampling range by the line interception method. Southwestern Forest and Range Experiment Station Research. Report 4.

Chao, A. (1987). Estimating the population size for capture-recapture data with unequal catchability. Biometrics 43, 783-791.

Chao, A., Chazdon, R. L., Colwell, R. K., \& Shen, T. J. (2005). A new statistical approach for assessing similarity of species composition with incidence and abundance data. Ecology Letters, 8, 148-159.

Chao, A., Chazdon, R. L., Colwell, R. K., \& Shen, T. J. (2006). Abundance-based similarity indices and their estimation when there are unseen species in samples. Biometrics, 62, 361-371.

Chao, A., Gotelli, N. J., Hsieh, T. C., Sander, E. L., Ma, K. H., Colwell, R. K., \& Ellison, A. M. (2014). Rarefaction and extrapolation with Hill numbers: a framework for 
sampling and estimation in species diversity studies. Ecological Monographs, 84, 4567.

Chapin, F. S., Walker, B. H., Hobbs, R. J., Hooper, D. U., Lawton, J. H., Sala, O. E., \& Tilman, D. (1997). Biotic control over the functioning of ecosystems. Science, 277, 500-504.

Cianciaruso, M. V., \& Batalha, M. A. (2008). A year in a Cerrado wet grassland: a nonseasonal island in a seasonal savanna environment. Brazilian Journal of Biology, 68, 495-501.

Clarke, K. R. (1993). Non-parametric multivariate analyses of changes in community structure. Australian Journal of Ecology, 18, 117-117.

Colwell, R. K. (2013). Estimates: Statistical estimation of species richness e shared species from samples, Version 9.0. User's Guide $\mathrm{e}$ application published at: http://viceroy.eeb.uconn.edu/ estimates. Persistent URL http://purl.oclc.org/estimates.

Eilts, J. A., Mittelbach, G. G., Reynolds, H. L., \& Gross, K. L. (2011). Resource heterogeneity, soil fertility, and species diversity: effects of clonal species on plant communities. The American Naturalist, 177, 574-588.

Eiten, G. (1972). The cerrado vegetation of Brazil. The Botanical Review, 38, 201-341.

Eugênio, C. U. O., Munhoz, C. B. R., \& Felfili, J. M. (2011). Dinâmica temporal do estrato herbáceo-arbustivo de uma área de campo limpo úmido em Alto Paraíso de Goiás, Brasil. Acta Botanica Brasilica, 25, 497-507.

Felfili, J.M.; Filgueiras, T.S.; Haridasan, M.; Silva Junior, M.C.; Mendonça, R.C. \& Resende, A.V. (1994). Projeto Biogeografia do Bioma Cerrado: Vegetação \& Solos. Caderno de Geociências, 12, 75-166.

Fiedler, N.C.; Azevedo, I.N.C.; Resende, A.V.; Medeiros, M.B. \& Venturoli, F. (2004). Efeito de incêndios florestais na estrutura e composição florística de uma área de cerrado sensu stricto na Fazenda Água Limpa - DF. Revista Árvore, 28, 129-138. 
Geiger, E. L., Gotsch, S. G., Damasco, G., Haridasan, M., Franco, A. C., \& Hoffmann, W. A. (2011). Distinct roles of savanna and forest tree species in regeneration under fire suppression in a Brazilian savanna. Journal of Vegetation Science, 22, 312-321.

Haridasan, M. (2000). Nutrição mineral de plantas nativas do cerrado. Revista Brasileira de Fisiologia Vegetal, 12, 54-64.

Haridasan, M., Pinheiro, A. A. M. C., \& Torres, F. R. R. (1997). Resposta de algumas espécies do estrato rasteiro de um cerrado à calagem e à adubação. 87-91. In: Leite, L. L. e Saito, C. H. (Eds). Contribuição ao conhecimento ecológico do cerrado. Brasília, Universidade de Brasília.

Hoffmann, W. A. (1996). The effects of fire and cover on seedling establishment in a neotropical savanna. Journal of Ecology, 84, 383-393.

Hoffmann, W. A. (2000). Post-Establishment Seedling Success in the Brazilian Cerrado: A Comparison of Savanna and Forest Species.Biotropica, 32, 62-69.

Hoffmann, W. A., Lucatelli, V. M., Silva, F. J., Azeuedo, I. N., Marinho, M. D. S., Albuquerque, A. M. S., Lopes, A.O., \& Moreira, S. P. (2004). Impact of the invasive alien grass Melinis minutiflora at the savanna-forest ecotone in the Brazilian Cerrado. Diversity and Distributions, 10, 99-103.

Lannes, L. S., Bustamante, M. M., Edwards, P. J., \& Venterink, H. O. (2016). Native and alien herbaceous plants in the Brazilian Cerrado are (co-) limited by different nutrients. Plant and Soil, 400, 231-243.

Laurence, W. F. (2001). Rain forest fragmentation and the structure of Amazonian liana communities. Journal of Ecology, 82, 105-116.

Luis, M., Raventós, J., \& González-Hidalgo, J. C. (2006). Post-fire vegetation succession in Mediterranean gorse shrublands. Acta Oecologica, 30, 54-61.

Medeiros, M. D., \& Miranda, H. S. (2005). Mortalidade pós-fogo em espécies lenhosas de campo sujo submetido a três queimadas prescritas anuais. Acta Botanica Brasilica, 19, 493-500. 
Mello, T. R., Munhoz, C. B., \& Bustamante, M. M. C. (2014). Effects of Nutrient Additions on the Diversity of the Herbaceous-Subshrub Layer of a Brazilian Savanna (Cerrado). 147-154. In: Sutton, M. A., Mason, K. E., Sheppard, L. J., Sverdrup, H. Haeuber, R., Hicks, W. K. (eds.). Nitrogen Deposition, Critical Loads and Biodiversity. Springer Netherlands.

Mendonça, R. C., Felfili, J. M., Walter, B. M. T., Silva Júnior, M. C., Rezende, A. V., Filgueiras, T. S., Nogueira, P. E. N., \& Fagg, C. W. (2008). Flora vascular do Cerrado. Checklist com 12.356 espécies. In: Sano, S. M., Almeida, S. P. e Ribeiro, J. F. (eds.). Cerrado: Ambiente e Flora. Embrapa Cerrados, Brasília.

Munhoz, C. B. R., \& Araújo, G. M. (2011). Métodos de amostragem do estrato herbáceosubarbustivo. 213-230. In: Felfili, J. M., Eisenlohr, P. E., Melo, M. M. R. F, Andrade, L. A., \& Meira-Neto, J. A. A. (eds). Fitossociologia no Brasil - Métodos e Estudos de caso. Universidade Federal de Viçosa, Viçosa.

Munhoz, C. B. R., \& Felfili, J. M. (2006). Floristics of the herbaceous and subshrub layer of a moist grassland in the Cerrado biosphere reserve (Alto Paraíso de Goiás), Brazil. Edinburgh Journal of Botany, 63, 343-354.

Munhoz, C. B. R., \& Felfili, J. M. (2008). Fitossociologia do estrato herbáceo-subarbustivo em campo limpo úmido no Brasil Central. Acta Botanica Brasilica, 22, 905-913.

Negrelle, R. R. B. (2006). Composição florística e estrutura vertical de um trecho de Floresta Ombrófila Densa de Planície Quaternária. Hoehnea, 33, 261-289.

Neves, S. P. S., \& Conceição, A. A. (2010). Campo rupestre recém-queimado na Chapada Diamantina, Bahia, Brasil: plantas de rebrota e sementes, com espécies endêmicas na rocha. Acta Botanica Brasilica, 24, 697-707.

Oksanen, J., Kindt, R., Legendre, P., O’Hara, B., Stevens, M. H. H., Oksanen, M. J., \& Suggests, M. A. S. S. (2007). The vegan package. Community Ecology Package, 631637.

Oyama, M. D., \& Nobre, C. A. (2003). A new climate-vegetation equilibrium state for tropical South America. Geophysical Research Letters, 30, 2199-2203. 
Phillips, O. L., Vásquez Martínez, R., Monteagudo Mendoza, A., Baker, T. R., \& Núñez Vargas, P. (2005). Large lianas as hyperdynamic elements of the tropical forest canopy. Ecology, 86, 1250-1258.

Ramos-Neto, M. B., \& Pivello, V. R. (2000). Lightning fires in a Brazilian savanna National Park: rethinking management strategies. Environmental management, 26, 675-684.

Ratter, J. A., \& Dargie, T. C. D. (1992). An analysis of the floristic composition of 26 cerrado ares in Brazil. Edinburgh Journal of Botany, 49, 235-250.

Reis, A. M. S., Araújo, E. L., Ferraz, E. M. N., \& Moura, A. N. (2006). Inter-annual variations in the floristic and population structure of an herbaceous community of "caatinga" vegetation in Pernambuco, Brazil. Brazilian Journal of Botany, 29, 497508.

Reynolds, H. L., Mittelbach, G. G., Darcy-Hall, T. L., Houseman, G. R., \& Gross, K. L. (2007). No effect of varying soil resource heterogeneity on plant species richness in a low fertility grassland. Journal of Ecology, 95, 723-733.

Ribeiro, J. F., \& Walter, B. M. T. (2008). As principais fitofisionomias do bioma Cerrado. 151-199. In: Sano, S. M., Almeida, S. P., \& Ribeiro, J. F. (eds.). Cerrado: Ecologia e flora. Embrapa Cerrados, Brasília.

Ribeiro, M. N., Sanchez, M., Pedroni, F., \& Peixoto, K. S. (2012). Fogo e dinâmica da comunidade lenhosa em cerrado sentido restrito, Barra do Garças, Mato Grosso. Acta Botanica Brasilica, 26, 203-217.

Sato, M. N., Miranda, H. S., Aires, S. S., \& Aires, F. S. (2014). Alterações na fitossociologia do estrato rasteiro de uma área de campo sujo, invadida por Melinis minutiflora P. Beauv., submetida a corte anual. Biodiversidade Brasileira, 2, 137-148.

Schoolmaster Jr, D. R., Mittelbach, G. G., \& Gross, K. L. (2014). Resource competition and community response to fertilization: the outcome depends on spatial strategies. Theoretical ecology, 7, 127-135. 
Silva, D. M., \& Batalha M.A. (2008). Soil-vegetation relationships in cerrados under different fire frequencies. Plant and Soil, 311, 87-96.

Silva, L. C. R., Sternberg, L., Haridasan, M., Hoffmann, W. A., Miralles-Wilhelm, F., \& Franco, A. C. (2008). Expansion of gallery forests into central Brazilian savannas. Global Change Biology, 14, 2108-2118.

Silva, M. A., \& Nogueira, P. E. (1999). Avaliação fitossociológica do estrato arbustivo herbáceo em cerrado stricto sensu após incêndio acidental, no Distrito Federal, Brasil. Boletim do Herbário Ezechias Paulo Heringer, 4, 65-78.

Silvertown, J., Poulton, P., Johnston, E., Edwards, G., Heard, M., \& Biss, P. M. (2006). The Park Grass Experiment 1856-2006: its contribution to ecology. Journal of Ecology, 94, 801-814.

Souza, A. C. M. (2014). Comunidade de monocotiledôneas herbáceas e pteridófitas terrestres e suas relações com o ambiente em Mata de Galeria no Parque Nacional de Brasília. 2014. Dissertação de Mestrado Departamento de Botânica. Universidade de Brasília.

Sternberg, L. S. L. (2001) Savanna-forest hysteresis in the tropics. Global Ecology and Biogeography, 10, 369-378.

Villela, D. M., \& Haridasan, M. (1994). Response of the ground layer community of a cerrado vegetation in central Brazil to liming and irrigation. Plant and Soil, 163, 2531. 
Anexo 1 - Cobertura relativa (\%) de espécies amostradas na comunidade herbáceo-arbustiva nos anos de 2012, 2013, 2015, registradas em uma área de transição entre Savana-Floresta (Cerrado sentido restrito a Mata de Galeria) da Reserva Ecológica do IBGE, Distrito Federal, Brasil, F Áreas Fertilizadas, $\mathbf{C}$ - áreas sem Fertilização (controle), $\mathbf{H}$ - hábito; $\mathbf{S}$ - subarbusto; $\mathbf{A}$ - arbusto; $\mathbf{E}$ - erva, L - liana.

\begin{tabular}{|c|c|c|c|c|c|c|c|c|c|}
\hline \multirow[b]{2}{*}{ Família/Espécie } & \multirow[b]{2}{*}{$\mathbf{H}$} & \multicolumn{2}{|c|}{2012} & \multicolumn{2}{|c|}{2013} & \multicolumn{2}{|c|}{2014} & \multicolumn{2}{|c|}{2015} \\
\hline & & $\mathbf{F}$ & $\mathbf{C}$ & $\mathbf{F}$ & $\mathbf{C}$ & $\mathbf{F}$ & $\mathbf{C}$ & $\mathbf{F}$ & $\mathbf{C}$ \\
\hline \multicolumn{10}{|l|}{ Acanthaceae } \\
\hline Justicia pycnophylla Lindau & $\mathrm{S}$ & 0,03 & 0,00 & 0,00 & 0,00 & 0,00 & 0,05 & 0,02 & 0,02 \\
\hline \multicolumn{10}{|l|}{ Anacardiaceae } \\
\hline Anacardium humile A. St.-Hil. & $\mathrm{S}$ & 0,00 & 0,00 & 0,00 & 0,02 & 0,00 & 0,00 & 0,00 & 0,00 \\
\hline \multicolumn{10}{|l|}{ Annonaceae } \\
\hline Barjonia cf. cymosa E. Fourn. & $\mathrm{S}$ & 0,00 & 0,00 & 0,00 & 0,03 & 0,00 & 0,01 & 0,00 & 0,02 \\
\hline Barjonia cf. erecta (Vell.) K. Schum & $\mathrm{S}$ & 0,00 & 0,10 & 0,00 & 0,00 & 0,00 & 0,01 & 0,00 & 0,00 \\
\hline \multicolumn{10}{|l|}{ Aristolochiaceae } \\
\hline Aristolochia cf. galeata Mart. & $\mathrm{L}$ & 0,00 & 0,03 & 0,00 & 0,00 & 0,00 & 0,00 & 0,00 & 0,00 \\
\hline \multicolumn{10}{|l|}{ Asteraceae } \\
\hline Achyrocline satureioides (Lam.) DC. & $\mathrm{E}$ & 0,00 & 0,00 & 0,03 & 0,08 & 0,00 & 0,32 & 0,00 & 0,81 \\
\hline Asteraceae sp. 1 & $\mathrm{~S}$ & 0,00 & 0,00 & 0,00 & 0,16 & 0,00 & 0,08 & 0,00 & 0,14 \\
\hline Asteraceae sp. 2 & $\mathrm{~S}$ & 0,17 & 0,23 & 0,08 & 0,58 & 0,03 & 0,78 & 0,00 & 0,17 \\
\hline Baccharis tridentada Vahl & $\mathrm{S}$ & 2,01 & 1,67 & 4,99 & 11,74 & 3,20 & 16,78 & 1,27 & 24,44 \\
\hline Bidens graveolens Mart. & $\mathrm{S}$ & 0,00 & 0,47 & 0,00 & 0,14 & 0,00 & 0,73 & 0,00 & 0,17 \\
\hline Campuloclinium megacephalum (Mart. ex Baker) R.M. King \& H. Rob. & $\mathrm{S}$ & 0,00 & 0,20 & 0,00 & 0,06 & 0,00 & 0,03 & 0,00 & 0,00 \\
\hline Chromolaena chasea (B. L. Rob.) R. M. King. \& H. Rob. & $\mathrm{S}$ & 0,00 & 1,12 & 0,00 & 1,36 & 0,00 & 1,36 & 0,00 & 1,27 \\
\hline
\end{tabular}




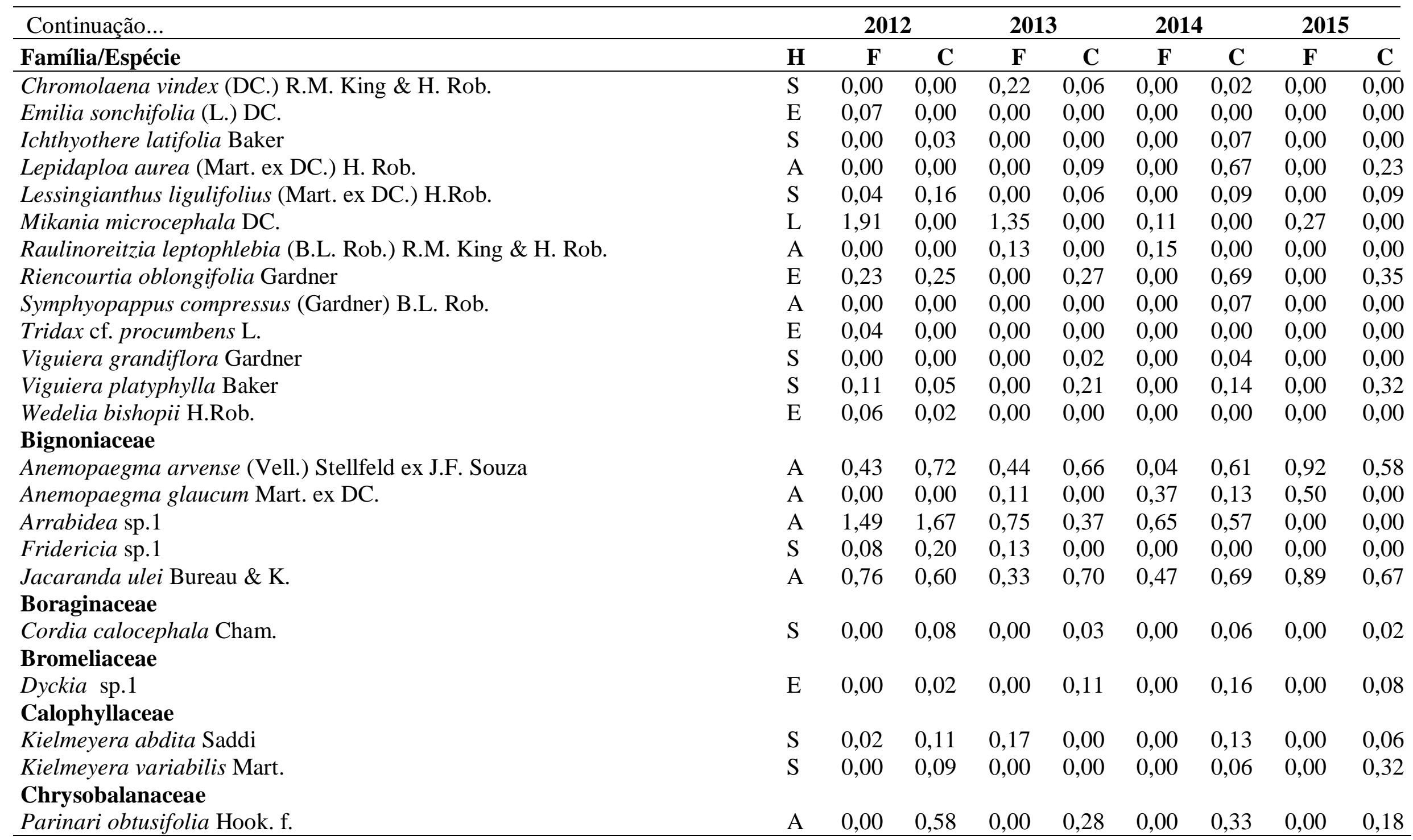




\begin{tabular}{|c|c|c|c|c|c|c|c|c|c|}
\hline \multirow{2}{*}{$\begin{array}{l}\text { Continuação... } \\
\text { Família/Espécie }\end{array}$} & \multirow[b]{2}{*}{$\mathbf{H}$} & \multicolumn{2}{|r|}{2012} & \multicolumn{2}{|r|}{2013} & \multicolumn{2}{|c|}{2014} & \multicolumn{2}{|c|}{2015} \\
\hline & & $\mathbf{F}$ & $\mathbf{C}$ & $\mathbf{F}$ & $\mathbf{C}$ & $\mathbf{F}$ & $\mathbf{C}$ & $\mathbf{F}$ & $\mathbf{C}$ \\
\hline Ipomoea procurrens Meisn. & $\mathrm{L}$ & 0,00 & 0,02 & 0,00 & 0,00 & 0,00 & 0,01 & 0,00 & 0,00 \\
\hline \multirow{2}{*}{\multicolumn{10}{|c|}{ Curcubitaceae }} \\
\hline & & & & & & & & & \\
\hline Curcubitaceae sp.1 & $\mathrm{L}$ & 0,16 & 0,00 & 0,00 & 0,00 & 0,00 & 0,00 & 0,00 & 0,00 \\
\hline Curcubitaceae sp.2 & $\mathrm{L}$ & 0,02 & 0,00 & 0,00 & 0,00 & 0,74 & 0,00 & 0,00 & 0,00 \\
\hline Bulbostylis edwalliana (Boeckeler) A. Prata & $\mathrm{E}$ & 0,00 & 0,00 & 0,00 & 0,02 & 0,00 & 0,00 & 0,00 & 0,00 \\
\hline Bulbostylis sphaerocephala (Boeckeler) C.B. Clarke & $\mathrm{E}$ & 0,00 & 0,33 & 0,00 & 0,34 & 0,00 & 0,51 & 0,00 & 0,08 \\
\hline Cyperaceae sp. 1 & $\mathrm{E}$ & 0,07 & 0,97 & 0,00 & 0,56 & 0,00 & 1,03 & 0,00 & 0,77 \\
\hline Rhynchospora albiceps Kunth & $\mathrm{E}$ & 0,00 & 0,05 & 0,00 & 0,08 & 0,00 & 0,08 & 0,00 & 0,01 \\
\hline Scleria leptostachya Kunth & $\mathrm{E}$ & 0,07 & 1,08 & 0,04 & 0,76 & 0,00 & 0,84 & 0,23 & 1,05 \\
\hline Scleria panicoides Kunth & $\mathrm{E}$ & 0,00 & 0,00 & 0,22 & 0,07 & 0,02 & 0,20 & 0,00 & 0,02 \\
\hline \multicolumn{10}{|l|}{ Erythroxylaceae } \\
\hline Erythroxylum cf. campestre A. St.-Hil. & $\mathrm{S}$ & 0,17 & 0,86 & 0,00 & 0,53 & 0,00 & 0,65 & 0,22 & 0,56 \\
\hline \multicolumn{10}{|l|}{ Euphorbiaceae } \\
\hline Croton antisyphiliticus Mart. & $\mathrm{S}$ & 0,12 & 0,74 & 0,09 & 0,78 & 0,11 & 0,73 & 0,31 & 0,80 \\
\hline Croton campestris A. St.-Hil & $\mathrm{S}$ & 0,00 & 0,11 & 0,00 & 0,06 & 0,00 & 0,01 & 0,00 & 0,02 \\
\hline Croton cf. longinervius Müll. Arg. & $\mathrm{E}$ & 0,00 & 0,20 & 0,07 & 0,14 & 0,07 & 0,11 & 0,00 & 0,16 \\
\hline Croton goyazensis Müll. Arg. & $\mathrm{S}$ & 0,39 & 3,03 & 0,28 & 1,49 & 0,04 & 1,12 & 0,20 & 0,96 \\
\hline Dalechampia caperonioides Baill. & $\mathrm{E}$ & 0,02 & 0,50 & 0,01 & 0,27 & 0,00 & 0,32 & 0,00 & 0,95 \\
\hline Euphorbia sp.1 & $\mathrm{E}$ & 0,07 & 0,00 & 0,00 & 0,00 & 0,26 & 0,02 & 0,00 & 0,05 \\
\hline
\end{tabular}




\begin{tabular}{|c|c|c|c|c|c|c|c|c|c|}
\hline \multirow{2}{*}{$\begin{array}{l}\text { Continuação... } \\
\text { Família/Espécie }\end{array}$} & \multirow[b]{2}{*}{$\mathbf{H}$} & \multicolumn{2}{|r|}{2012} & \multicolumn{2}{|r|}{2013} & \multicolumn{2}{|r|}{2014} & \multicolumn{2}{|c|}{2015} \\
\hline & & $\mathbf{F}$ & $\mathbf{C}$ & $\mathbf{F}$ & $\mathbf{C}$ & $\mathbf{F}$ & $\mathbf{C}$ & $\mathbf{F}$ & $\mathbf{C}$ \\
\hline Manihot gracilis Pohl & $\mathrm{S}$ & 0,00 & 0,25 & 0,00 & 0,11 & 0,00 & 0,03 & 0,00 & 0,16 \\
\hline $\begin{array}{l}\text { Sebastiania ditassoides (Didr.) Müll. Arg. } \\
\text { Fabaceae }\end{array}$ & $\mathrm{E}$ & 0,00 & 0,14 & 0,00 & 0,02 & 0,00 & 0,03 & 0,00 & 0,04 \\
\hline Bauhinia dumosa Benth. & $\mathrm{S}$ & 0,57 & 1,74 & 0,26 & 2,10 & 0,20 & 2,18 & 1,93 & 2,07 \\
\hline Bauhinia rufa (Bong.) Steud & $\mathrm{S}$ & 0,28 & 0,92 & 0,03 & 0,72 & 0,30 & 0,74 & 0,81 & 0,39 \\
\hline Caesalpinioideae sp.1 & $\mathrm{S}$ & 0,00 & 0,00 & 0,00 & 0,09 & 0,00 & 0,21 & 0,00 & 0,16 \\
\hline Calliandra dysantha Benth. & $\mathrm{S}$ & 0,20 & 1,34 & 0,22 & 1,04 & 0,07 & 0,75 & 0,50 & 1,14 \\
\hline Centrosema bracteosum Benth. & $\mathrm{L}$ & 0,06 & 0,03 & 0,00 & 0,57 & 0,00 & 0,52 & 0,00 & 0,12 \\
\hline Chamaecrista cf. orbiculata (Benth.) H.S. Irwin \& Barneby & $\mathrm{S}$ & 0,14 & 1,07 & 0,00 & 0,59 & 0,00 & 0,20 & 0,00 & 0,56 \\
\hline Chamaecrista decrescens (Benth.) H.S. Irwin \& Barneby & $\mathrm{S}$ & 0,00 & 0,17 & 0,00 & 0,05 & 0,02 & 0,14 & 0,00 & 0,08 \\
\hline Fabaceae sp.1 & $\mathrm{S}$ & 0,11 & 0,44 & 0,00 & 0,14 & 0,00 & 0,09 & 0,27 & 0,14 \\
\hline Faboideae sp.1 & $\mathrm{S}$ & 0,29 & 0,85 & 0,03 & 0,74 & 0,08 & 0,49 & 0,00 & 0,83 \\
\hline Faboideae sp. 2 & $\mathrm{~S}$ & 0,00 & 0,05 & 0,00 & 0,05 & 0,00 & 0,01 & 0,00 & 0,00 \\
\hline Faboideae sp.3 & $\mathrm{S}$ & 0,00 & 0,00 & 1,76 & 1,30 & 1,07 & 1,16 & 0,00 & 0,41 \\
\hline Galactia grewiifolia (Benth.) Taub. & $\mathrm{E}$ & 0,00 & 0,26 & 0,00 & 0,22 & 0,00 & 0,24 & 0,00 & 0,28 \\
\hline Mimosa cf. nuda Benth. & $\mathrm{S}$ & 0,04 & 0,21 & 0,00 & 0,08 & 0,00 & 0,05 & 0,00 & 0,31 \\
\hline Mimosa claussenii Benth. & $\mathrm{S}$ & 0,00 & 0,00 & 0,00 & 0,00 & 0,00 & 0,14 & 0,00 & 0,02 \\
\hline Mimosa gracilis Benth. & $\mathrm{S}$ & 0,06 & 0,08 & 0,00 & 0,00 & 0,00 & 0,00 & 0,00 & 0,06 \\
\hline Periandra mediterranea (Vell.) Taub. & $\mathrm{S}$ & 0,00 & 0,00 & 0,00 & 0,06 & 0,00 & 0,12 & 0,00 & 0,09 \\
\hline Stylosanthes guianensis (Aubl.) Sw. & $\mathrm{S}$ & 0,12 & 0,08 & 0,09 & 0,29 & 0,00 & 0,47 & 0,00 & 0,08 \\
\hline Indeterminada & & & & & & & & & \\
\hline Indeterminada 1 & $\mathrm{~S}$ & 0,00 & 0,06 & 0,00 & 0,10 & 0,00 & 0,12 & 0,00 & 0,05 \\
\hline Iridaceae & & & & & & & & & \\
\hline Cipura xanthomelas Mart. ex Klatt & $\mathrm{E}$ & 0,00 & 0,05 & 0,00 & 0,01 & 0,00 & 0,05 & 0,00 & 0,06 \\
\hline Sisyrinchium restioides Spreng. & $\mathrm{E}$ & 0,00 & 0,00 & 0,00 & 0,03 & 0,00 & 0,04 & 0,00 & 0,01 \\
\hline Sisyrinchium vaginatum Spreng. & $\mathrm{E}$ & 0,00 & 0,00 & 0,00 & 0,00 & 0,00 & 0,00 & 0,00 & 0,03 \\
\hline Lamiaceae & & & & & & & & & \\
\hline Amasonia hirta Benth. & $\mathrm{E}$ & 0,00 & 0,02 & 0,00 & 0,00 & 0,00 & 0,00 & 0,00 & 0,00 \\
\hline
\end{tabular}




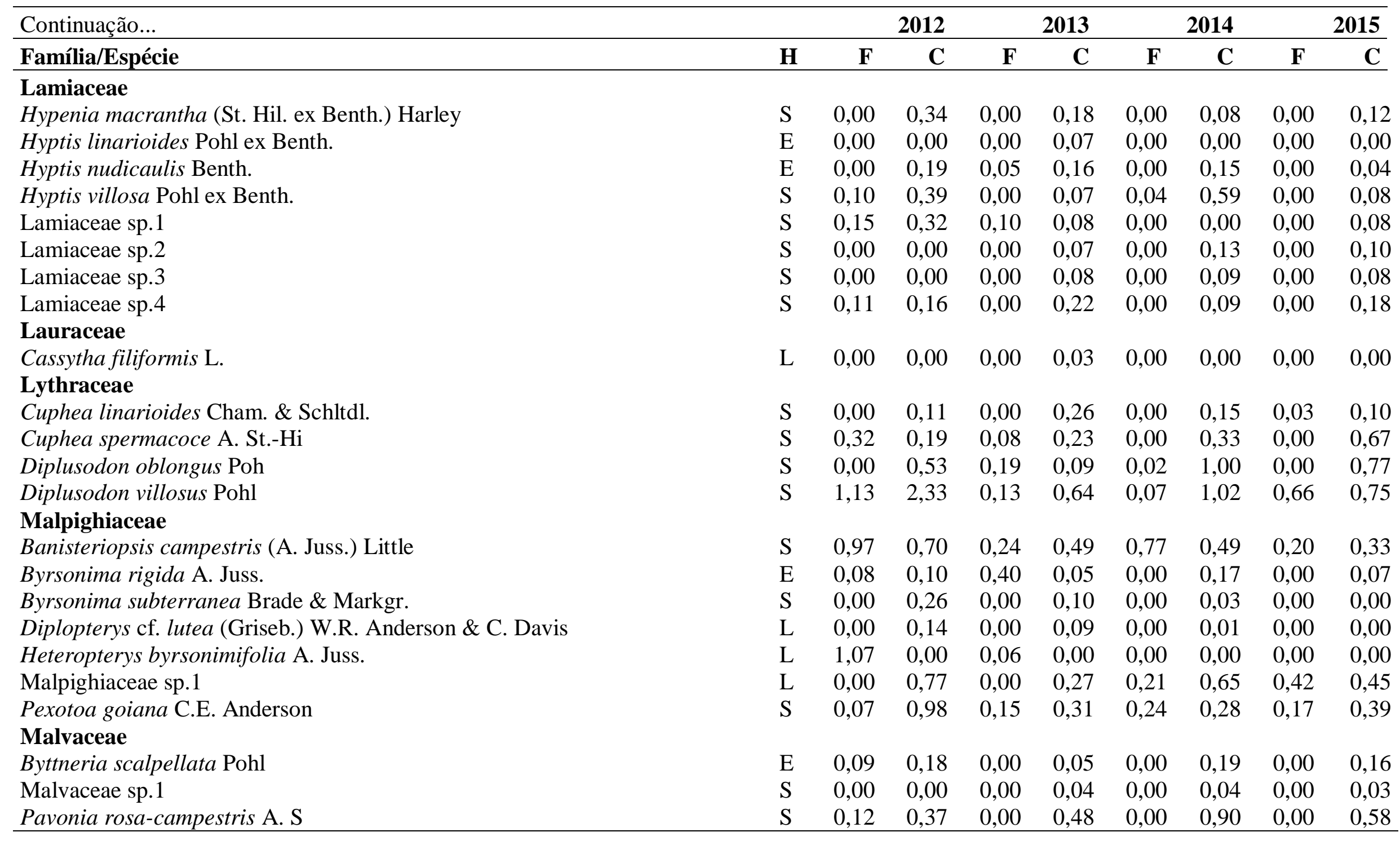




\begin{tabular}{|c|c|c|c|c|c|c|c|c|c|}
\hline \multirow{2}{*}{$\begin{array}{l}\text { Continuação... } \\
\text { Família/Espécie }\end{array}$} & \multirow[b]{2}{*}{$\mathbf{H}$} & \multicolumn{2}{|r|}{2012} & \multicolumn{2}{|r|}{2013} & \multicolumn{2}{|c|}{2014} & \multicolumn{2}{|c|}{2015} \\
\hline & & $\mathbf{F}$ & $\mathbf{C}$ & $\mathbf{F}$ & $\mathbf{C}$ & $\mathbf{F}$ & $\mathbf{C}$ & $\mathbf{F}$ & $\mathbf{C}$ \\
\hline $\begin{array}{l}\text { Sida linifolia } \text { Cav. } \\
\text { Melastomataceae }\end{array}$ & $\mathrm{E}$ & 0,23 & 0,00 & 0,03 & 0,09 & 0,08 & 0,16 & 0,00 & 0,00 \\
\hline $\begin{array}{l}\text { Leandra lacunosa Cogn. } \\
\text { Menispermaceae }\end{array}$ & $\mathrm{S}$ & 0,16 & 0,54 & 0,33 & 0,76 & 0,08 & 1,04 & 0,00 & 0,35 \\
\hline $\begin{array}{l}\text { Cissampelos ovalifolia DC. } \\
\text { Myrtaceae }\end{array}$ & $\mathrm{S}$ & 0,00 & 0,00 & 0,00 & 0,03 & 0,00 & 0,00 & 0,00 & 0,05 \\
\hline Campomanesia pubescens (DC.) O. Berg & A & 3,01 & 2,57 & 1,73 & 2,14 & 2,00 & 1,19 & 2,93 & 0,99 \\
\hline Eugenia involucrata DC. & $\mathrm{S}$ & 0,00 & 0,00 & 0,00 & 0,00 & 0,00 & 0,29 & 0,00 & 0,13 \\
\hline Myrcia guianensis (Aubl.) DC. & $\mathrm{S}$ & 0,46 & 0,11 & 0,42 & 0,22 & 0,38 & 0,19 & 0,45 & 0,16 \\
\hline Myrcia linearifolia Cambess & $\mathrm{S}$ & 0,61 & 1,77 & 0,31 & 1,06 & 0,67 & 0,85 & 0,66 & 1,02 \\
\hline $\begin{array}{l}\text { Myrcia torta DC. } \\
\text { Ochnaceae }\end{array}$ & $\mathrm{S}$ & 2,08 & 5,51 & 1,47 & 3,89 & 1,64 & 3,41 & 5,28 & 3,00 \\
\hline $\begin{array}{l}\text { Ouratea floribunda Engl. } \\
\text { Orchidaceae }\end{array}$ & $\mathrm{S}$ & 0,00 & 0,62 & 0,00 & 0,65 & 0,00 & 0,49 & 0,00 & 0,38 \\
\hline Cyrtopodium cf. eugenii Rchb. f. \& Warm. & $\mathrm{E}$ & 0,04 & 0,00 & 0,03 & 0,00 & 0,05 & 0,00 & 0,08 & 0,00 \\
\hline $\begin{array}{l}\text { Habenaria petalodes Lindl. } \\
\text { Oxalidaceae }\end{array}$ & $\mathrm{E}$ & 0,40 & 1,58 & 0,00 & 0,08 & 0,47 & 0,79 & 0,25 & 0,58 \\
\hline Oxalis cordata A. St.-Hil. & $\mathrm{S}$ & 0,09 & 0,19 & 0,00 & 0,20 & 0,00 & 0,26 & 0,00 & 0,29 \\
\hline $\begin{array}{l}\text { Oxalis densifolia Mart. ex Zucc. } \\
\text { Phytolaccaceae }\end{array}$ & $\mathrm{S}$ & 0,01 & 0,05 & 0,00 & 0,44 & 0,00 & 0,07 & 0,00 & 0,11 \\
\hline $\begin{array}{l}\text { Phytolacca thyrsiflora Fenzl ex J.A. Schmidt } \\
\text { Poaceae }\end{array}$ & $\mathrm{E}$ & 1,20 & 0,03 & 0,00 & 0,00 & 0,00 & 0,00 & 0,00 & 0,00 \\
\hline Agenium leptocladum (Hack.) Clayton & $\mathrm{E}$ & 0,00 & 0,00 & 0,00 & 0,00 & 0,00 & 0,00 & 0,00 & 0,01 \\
\hline Andropogon leucostachyus Kunth & $\mathrm{E}$ & 0,00 & 0,00 & 0,00 & 0,00 & 0,00 & 0,17 & 0,00 & 0,00 \\
\hline Aristida setifolia Kunth & $\mathrm{E}$ & 0,00 & 0,00 & 0,26 & 0,03 & 0,06 & 0,05 & 0,11 & 0,04 \\
\hline Aristida sp.1 & $\mathrm{E}$ & 0,00 & 0,00 & 0,00 & 0,00 & 0,03 & 0,03 & 0,00 & 0,00 \\
\hline Axonopus aureus P. Beauv. & $\mathrm{E}$ & 0,00 & 0,00 & 0,00 & 0,00 & 0,00 & 0,01 & 0,00 & 0,00 \\
\hline Axonopus siccus (Nees) Kuhlm. & $\mathrm{E}$ & 0,20 & 0,21 & 0,00 & 0,24 & 0,00 & 0,59 & 0,00 & 0,81 \\
\hline
\end{tabular}




\begin{tabular}{|c|c|c|c|c|c|c|c|c|c|}
\hline \multirow{2}{*}{$\begin{array}{l}\text { Continuação... } \\
\text { Família/Espécie }\end{array}$} & \multirow[b]{2}{*}{$\mathbf{H}$} & \multicolumn{2}{|r|}{2012} & \multicolumn{2}{|r|}{2013} & \multicolumn{2}{|r|}{2014} & \multicolumn{2}{|r|}{2015} \\
\hline & & $\mathbf{F}$ & $\mathbf{C}$ & $\mathbf{F}$ & $\mathbf{C}$ & $\mathbf{F}$ & $\mathbf{C}$ & $\mathbf{F}$ & $\mathbf{C}$ \\
\hline Hyparrhenia bracteata (Humb. \& Bonpl. ex Willd.) Stapf & $\mathrm{E}$ & 0,00 & 0,11 & 0,00 & 0,07 & 0,00 & 0,00 & 0,00 & 0,01 \\
\hline Ichnanthus pallens (Sw.) Munro ex Benth. & $\mathrm{E}$ & 0,00 & 3,41 & 0,24 & 5,08 & 0,44 & 1,80 & 0,53 & 1,32 \\
\hline Imperata brasiliensis Trin. & $\mathrm{E}$ & 16,92 & 1,88 & 22,84 & 2,24 & 20,70 & 2,08 & 15,51 & 0,85 \\
\hline Leptocoryphium lanatum (Kunth) Nees & $\mathrm{E}$ & 0,00 & 1,08 & 0,00 & 0,97 & 0,00 & 0,50 & 0,00 & 0,34 \\
\hline Panicum olyroides Kunth & $\mathrm{E}$ & 2,48 & 3,35 & 1,05 & 3,24 & 0,67 & 1,77 & 0,00 & 1,14 \\
\hline Paspalum pectinatum Nees ex Trin. & $\mathrm{E}$ & 0,12 & 1,37 & 0,00 & 0,47 & 0,00 & 0,14 & 0,00 & 0,19 \\
\hline Paspalum geminiflorum Steud. & $\mathrm{E}$ & 0,00 & 0,00 & 0,00 & 0,02 & 0,00 & 0,02 & 0,00 & 0,00 \\
\hline Paspalum sp.1 & $\mathrm{E}$ & 0,07 & 0,23 & 0,04 & 0,13 & 0,00 & 0,05 & 0,00 & 0,03 \\
\hline Paspalum sp.2 & $\mathrm{E}$ & 1,99 & 0,54 & 1,10 & 1,25 & 0,48 & 0,81 & 0,23 & 0,27 \\
\hline Poaceae sp. 1 & $\mathrm{E}$ & 0,00 & 0,31 & 0,00 & 0,88 & 0,00 & 0,79 & 0,00 & 0,20 \\
\hline \multicolumn{10}{|l|}{ Polygalaceae } \\
\hline Polygala sp. 1 & $\mathrm{~S}$ & 0,00 & 0,21 & 0,00 & 0,07 & 0,00 & 0,03 & 0,00 & 0,04 \\
\hline \multicolumn{10}{|l|}{ Rubiaceae } \\
\hline Coccocypselum cf. aureum (Spreng.) Cham. \& Schltdl. & $\mathrm{E}$ & 0,00 & 0,00 & 0,00 & 0,08 & 0,35 & 0,23 & 0,00 & 0,78 \\
\hline Palicourea marcgravii A.St.-Hil. & A & 0,00 & 0,00 & 0,00 & 0,00 & 0,00 & 0,00 & 0,14 & 0,03 \\
\hline Palicourea officinalis Mart. & $\mathrm{S}$ & 0,00 & 0,28 & 0,00 & 0,41 & 0,02 & 0,68 & 0,11 & 0,49 \\
\hline Psychotria prunifolia (Kunth) Steyerm. & $\mathrm{A}$ & 0,00 & 0,00 & 0,07 & 0,00 & 0,40 & 0,42 & 1,39 & 0,51 \\
\hline Sabicea brasiliensis Wernham & $\mathrm{S}$ & 0,10 & 1,10 & 0,45 & 1,43 & 0,08 & 0,77 & 0,09 & 0,80 \\
\hline Spermacoce latifolia Aubl. & $\mathrm{E}$ & 0,41 & 0,78 & 0,00 & 0,56 & 0,00 & 0,42 & 0,00 & 0,52 \\
\hline
\end{tabular}




\begin{tabular}{|c|c|c|c|c|c|c|c|c|c|}
\hline \multirow{2}{*}{$\begin{array}{l}\text { Continuação... } \\
\text { Família/Espécie }\end{array}$} & \multicolumn{3}{|c|}{2012} & \multicolumn{2}{|c|}{2013} & \multicolumn{2}{|c|}{2014} & \multicolumn{2}{|c|}{2015} \\
\hline & $\mathbf{H}$ & $\mathbf{F}$ & $\mathbf{C}$ & $\mathbf{F}$ & $\mathbf{C}$ & $\mathbf{F}$ & $\mathbf{C}$ & $\mathbf{F}$ & $\mathbf{C}$ \\
\hline Rutaceae & & & & & & & & & \\
\hline $\begin{array}{l}\text { Esembeckia grandiflora Mart. } \\
\text { Sapindaceae }\end{array}$ & A & 0,00 & 0,62 & 0,00 & 0,34 & 0,00 & 0,44 & 0,00 & 0,41 \\
\hline Serjania erecta Radlk. & $\mathrm{L}$ & 3,61 & 2,49 & 0,88 & 0,59 & 1,00 & 0,38 & 0,02 & 0,28 \\
\hline Serjania sp.1 & $\mathrm{L}$ & 4,02 & 2,24 & 1,93 & 0,37 & 6,25 & 1,46 & 4,37 & 0,10 \\
\hline Simaroubaceae & & & & & & & & & \\
\hline $\begin{array}{l}\text { Simaba suffruticosa Engl. } \\
\text { Smilacaceae }\end{array}$ & $\mathrm{S}$ & 0,26 & 0,19 & 0,13 & 0,03 & 1,22 & 0,00 & 0,00 & 0,06 \\
\hline $\begin{array}{l}\text { Smilax brasiliensis } \text { Spreng. } \\
\text { Solanaceae }\end{array}$ & $\mathrm{S}$ & 0,00 & 0,16 & 0,00 & 0,06 & 0,11 & 0,08 & 0,33 & 0,05 \\
\hline $\begin{array}{l}\text { Nicandra physalodes (L.) Gaertn. } \\
\text { Turneraceae }\end{array}$ & A & 0,00 & 0,00 & 0,22 & 0,00 & 0,00 & 0,00 & 0,25 & 0,00 \\
\hline $\begin{array}{l}\text { Piriqueta sidifolia (Cambess.) Urb. } \\
\text { Verbenaceae }\end{array}$ & A & 0,00 & 0,02 & 0,00 & 0,00 & 0,00 & 0,00 & 0,00 & 0,00 \\
\hline Lippia lupulina Cham. & $\mathrm{S}$ & 0,00 & 0,08 & 0,06 & 0,04 & 0,00 & 0,02 & 0,00 & 0,00 \\
\hline Lippia sp.1 & $\mathrm{S}$ & 0,04 & 0,05 & 0,00 & 0,10 & 0,00 & 0,21 & 0,00 & 0,03 \\
\hline $\begin{array}{l}\text { Stachytarpheta longispicata (Pohl) S.Atkins } \\
\text { Violaceae }\end{array}$ & $\mathrm{E}$ & 0,03 & 0,42 & 0,00 & 0,00 & 0,00 & 0,00 & 0,00 & 0,00 \\
\hline $\begin{array}{l}\text { Hybanthus lanatus (A. St.-Hil.) Baill. } \\
\text { Vitaceae }\end{array}$ & $\mathrm{S}$ & 0,00 & 0,06 & 0,00 & 0,06 & 0,00 & 0,04 & 0,00 & 0,13 \\
\hline Cissus erosa Rich. & $\mathrm{L}$ & 0,20 & 0,32 & 0,17 & 0,06 & 0,00 & 0,06 & 0,00 & 0,00 \\
\hline
\end{tabular}


Anexo 2 - Resultado da análise química dos solos coletados nas sub-parcelas. Para cada ponto de amostragem, a primeira linha corresponde aos dados coletados em 2007 e a segunda linha, entre parênteses, aos dados coletados em 2015. Média \pm Desvio Padrão.

\begin{tabular}{|c|c|c|c|c|c|c|}
\hline Distância(m) & pH & Al & $\mathbf{C}$ & $\mathbf{N}$ & $\mathbf{P}$ & $\mathbf{K}$ \\
\hline \multicolumn{7}{|c|}{ Mata de Galeria (Sem fertilização) } \\
\hline-30 & $\begin{array}{c}4,39 \pm 0,30 \\
(4,28 \pm 0,33)\end{array}$ & $\begin{array}{c}1,12 \pm 1,33 \\
(0,73 \pm 0,76)\end{array}$ & $\begin{array}{l}3,63 \pm 0,78 \\
(3,7 \pm 0,84)\end{array}$ & $\begin{array}{c}0,33 \pm 0,09 \\
(0,34 \pm 0,05)\end{array}$ & $\begin{array}{c}2,50 \pm 1,68 \\
(2,62 \pm 1,17)\end{array}$ & $\begin{array}{c}0,20 \pm 0,08 \\
(0,14 \pm 0,02)\end{array}$ \\
\hline-20 & $\begin{array}{c}4,69 \pm 0,37 \\
(4,55 \pm 0,35)\end{array}$ & $\begin{array}{c}0,66 \pm 1,02 \\
(0,43 \pm 0,67)\end{array}$ & $\begin{array}{c}3,69 \pm 0,71 \\
(3,88 \pm 0,36)\end{array}$ & $\begin{array}{c}0,35 \pm 0,06 \\
(0,35 \pm 0,04)\end{array}$ & $\begin{array}{c}2,38 \pm 1,33 \\
(2,14 \pm 0,64)\end{array}$ & $\begin{array}{c}0,22 \pm 0,07 \\
(0,14 \pm 0,03)\end{array}$ \\
\hline-10 & $\begin{array}{c}4,54 \pm 0,16 \\
(4,28 \pm 0,20)\end{array}$ & $\begin{array}{c}0,52 \pm 0,44 \\
(0,65 \pm 0,65)\end{array}$ & $\begin{array}{c}2,86 \pm 0,36 \\
(3,44 \pm 0,52)\end{array}$ & $\begin{array}{c}0,25 \pm 0,03 \\
(0,32 \pm 0,07)\end{array}$ & $\begin{array}{l}2,38 \pm 0,87 \\
(1,9 \pm 1,17)\end{array}$ & $\begin{array}{c}0,20 \pm 0,03 \\
(0,14 \pm 0,03)\end{array}$ \\
\hline \multicolumn{7}{|c|}{ Transição (Sem fertilização) } \\
\hline 0 & $\begin{array}{c}4,44 \pm 0,10 \\
(4,30 \pm 0,11)\end{array}$ & $\begin{array}{c}0,61 \pm 0,20 \\
(0,68 \pm 0,57)\end{array}$ & $\begin{array}{c}2,44 \pm 0,26 \\
(2,70 \pm 0,69)\end{array}$ & $\begin{array}{c}0,21 \pm 0,03 \\
(0,26 \pm 0,03)\end{array}$ & $\begin{array}{c}2,02 \pm 0,54 \\
(2,26 \pm 0,84)\end{array}$ & $\begin{array}{c}0,16 \pm 0,03 \\
(0,13 \pm 0,03)\end{array}$ \\
\hline \multicolumn{7}{|c|}{ Cerrado sentido restrito (Sem fertilização) } \\
\hline 10 & $\begin{array}{c}4,44 \pm 0,06 \\
(4,33 \pm 0,10)\end{array}$ & $\begin{array}{c}0,59 \pm 0,23 \\
(0,58 \pm 0,27)\end{array}$ & $\begin{array}{c}2,18 \pm 0,33 \\
(2,09 \pm 0,51)\end{array}$ & $\begin{array}{c}0,18 \pm 0,05 \\
(0,19 \pm 0,06)\end{array}$ & $\begin{array}{c}1,9 \pm 0,87 \\
(2,14 \pm 0,64)\end{array}$ & $\begin{array}{c}0,10 \pm 0,03 \\
(0,09 \pm 0,02)\end{array}$ \\
\hline 20 & $\begin{array}{c}4,39 \pm 0,14 \\
(4,12 \pm 0,08)\end{array}$ & $\begin{array}{c}0,75 \pm 0,45 \\
(0,78 \pm 0,24)\end{array}$ & $\begin{array}{c}2,20 \pm 0,30 \\
(2,17 \pm 0,56)\end{array}$ & $\begin{array}{c}0,18 \pm 0,04 \\
(0,19 \pm 0,02)\end{array}$ & $\begin{array}{c}1,71 \pm 0,39 \\
(1,86 \pm 0,64)\end{array}$ & $\begin{array}{c}0,12 \pm 0,03 \\
(0,11 \pm 0,04)\end{array}$ \\
\hline 30 & $\begin{array}{c}4,41 \pm 0,10 \\
(4,27 \pm 0,05)\end{array}$ & $\begin{array}{c}0,63 \pm 0,23 \\
(0,53 \pm 0,29)\end{array}$ & $\begin{array}{c}2,07 \pm 0,24 \\
(2,75 \pm 0,76)\end{array}$ & $\begin{array}{c}0,19 \pm 0,03 \\
(0,20 \pm 0,06)\end{array}$ & $\begin{array}{c}1,79 \pm 0,39 \\
(1,43 \pm 0,45)\end{array}$ & $\begin{array}{c}0,12 \pm 0,03 \\
(0,11 \pm 0,05)\end{array}$ \\
\hline \multicolumn{7}{|c|}{ Mata de Galeria (Com fertilização) } \\
\hline-30 & $\begin{array}{c}4,60 \pm 0,29 \\
(4,83 \pm 0,32)\end{array}$ & $\begin{array}{c}0,63 \pm 0,60 \\
(0,17 \pm 0,16)\end{array}$ & $\begin{array}{c}3,54 \pm 0,72 \\
(4,61 \pm 0,47)\end{array}$ & $\begin{array}{c}0,33 \pm 0,08 \\
(0,49 \pm 0,12)\end{array}$ & $\begin{array}{c}1,32 \pm 0,60 \\
(12,22 \pm 7,28)\end{array}$ & $\begin{array}{c}0,20 \pm 0,03 \\
(0,18 \pm 0,03)\end{array}$ \\
\hline-20 & $\begin{array}{c}4,53 \pm 0,22 \\
(4,83 \pm 0,23)\end{array}$ & $\begin{array}{c}0,61 \pm 0,62 \\
(0,13 \pm 0,10)\end{array}$ & $\begin{array}{c}3,39 \pm 0,45 \\
(4,15 \pm 0,30)\end{array}$ & $\begin{array}{c}0,32 \pm 0,04 \\
(0,42 \pm 0,11)\end{array}$ & $\begin{array}{c}1,25 \pm 0,63 \\
(13,08 \pm 8,03)\end{array}$ & $\begin{array}{c}0,18 \pm 0,05 \\
(0,17 \pm 0,04)\end{array}$ \\
\hline-10 & $\begin{array}{c}4,75 \pm 0,40 \\
(4,72 \pm 0,36)\end{array}$ & $\begin{array}{l}0,44 \pm 0,56 \\
(0,3 \pm 0,41)\end{array}$ & $\begin{array}{c}3,55 \pm 0,81 \\
(4,30 \pm 0,59)\end{array}$ & $\begin{array}{c}0,32 \pm 0,08 \\
(0,44 \pm 0,09)\end{array}$ & $\begin{array}{c}0,88 \pm 0,27 \\
(15,13 \pm 2,67)\end{array}$ & $\begin{array}{c}0,20 \pm 0,06 \\
(0,19 \pm 0,04)\end{array}$ \\
\hline \multicolumn{7}{|c|}{ Transição (Com fertilização) } \\
\hline 0 & $\begin{array}{c}4,44 \pm 0,21 \\
(4,82 \pm 0,40)\end{array}$ & $\begin{array}{c}0,72 \pm 0,52 \\
(0,28 \pm 0,37)\end{array}$ & $\begin{array}{c}2,83 \pm 0,60 \\
(3,60 \pm 0,22)\end{array}$ & $\begin{array}{c}0,25 \pm 0,06 \\
(0,33 \pm 0,04)\end{array}$ & $\begin{array}{c}1,05 \pm 0,45 \\
(15,43 \pm 13,40)\end{array}$ & $\begin{array}{c}0,20 \pm 0,05 \\
(0,15 \pm 0,04)\end{array}$ \\
\hline \multicolumn{7}{|c|}{ Cerrado sentido restrito (Com fertilização) } \\
\hline 10 & $\begin{array}{c}4,42 \pm 0,07 \\
(5,00 \pm 0,26)\end{array}$ & $\begin{array}{c}0,63 \pm 0,14 \\
(0,07 \pm 0,10)\end{array}$ & $\begin{array}{c}2,23 \pm 0,15 \\
(2,94 \pm 0,85)\end{array}$ & $\begin{array}{c}0,19 \pm 0,02 \\
(0,30 \pm 0,03)\end{array}$ & $\begin{array}{c}0,93 \pm 0,36 \\
(30,68 \pm 26,43)\end{array}$ & $\begin{array}{c}0,14 \pm 0,04 \\
(0,15 \pm 0,03)\end{array}$ \\
\hline 20 & $\begin{array}{c}4,41 \pm 0,09 \\
(4,78 \pm 0,42)\end{array}$ & $\begin{array}{l}0,63 \pm 0,28 \\
(0,3 \pm 0,34)\end{array}$ & $\begin{array}{c}2,20 \pm 0,35 \\
(2,56 \pm 0,61)\end{array}$ & $\begin{array}{c}0,18 \pm 0,04 \\
(0,25 \pm 0,03)\end{array}$ & $\begin{array}{c}0,88 \pm 0,37 \\
(22,06 \pm 27,93)\end{array}$ & $\begin{array}{c}0,15 \pm 0,05 \\
(0,14 \pm 0,02)\end{array}$ \\
\hline 30 & $\begin{array}{c}4,44 \pm 0,03 \\
(4,98 \pm 0,53) \\
\end{array}$ & $\begin{array}{c}0,51 \pm 0,08 \\
(0,17 \pm 0,23)\end{array}$ & $\begin{array}{c}1,87 \pm 0,25 \\
(3,31 \pm 0,49) \\
\end{array}$ & $\begin{array}{c}0,16 \pm 0,02 \\
(0,28 \pm 0,02)\end{array}$ & $\begin{array}{c}0,73 \pm 0,42 \\
(48,07 \pm 37,14) \\
\end{array}$ & $\begin{array}{c}0,09 \pm 0,02 \\
(0,16 \pm 0,06)\end{array}$ \\
\hline
\end{tabular}


Continuação Anexo 2 - Resultado da análise química dos solos coletados nas sub-parcelas. Para cada ponto de amostragem, a primeira linha corresponde aos dados coletados em 2007 e a segunda linha, entre parênteses, aos dados coletados em 2015. Média \pm Desvio Padrão.

\begin{tabular}{|c|c|c|c|c|c|c|}
\hline Distância(m) & $\mathbf{C a}$ & Mg & $\mathbf{F e}$ & Mn & $\mathbf{Z n}$ & $\mathbf{C u}$ \\
\hline \multicolumn{7}{|c|}{ Mata de Galeria(Sem fertilização) } \\
\hline-30 & $\begin{array}{c}1,10 \pm 1,00 \\
(1,37 \pm 1,38)\end{array}$ & $\begin{array}{c}0,65 \pm 0,33 \\
(0,43 \pm 0,33)\end{array}$ & $\begin{array}{c}80,41 \pm 59,49 \\
(70,42 \pm 27,85)\end{array}$ & $\begin{array}{l}33,83 \pm 16,99 \\
(13,43 \pm 7,08)\end{array}$ & $\begin{array}{c}17,20 \pm 10,47 \\
(2,52 \pm 1,23)\end{array}$ & $\begin{array}{c}2,87 \pm 1,64 \\
(0,42 \pm 0,27)\end{array}$ \\
\hline-20 & $\begin{array}{c}3,68 \pm 3,33 \\
(2,07 \pm 2,02)\end{array}$ & $\begin{array}{c}1,07 \pm 0,67 \\
(0,79 \pm 0,36)\end{array}$ & $\begin{array}{l}49,82 \pm 15,76 \\
(56,4 \pm 12,28)\end{array}$ & $\begin{array}{c}38,82 \pm 14,17 \\
(13,23 \pm 4,59)\end{array}$ & $\begin{array}{c}16,9 \pm 7,11 \\
(2,60 \pm 0,77)\end{array}$ & $\begin{array}{c}2,02 \pm 0,99 \\
(0,45 \pm 0,21)\end{array}$ \\
\hline-10 & $\begin{array}{c}1,02 \pm 0,87 \\
(4,37 \pm 4,90)\end{array}$ & $\begin{array}{c}0,66 \pm 0,45 \\
(1,27 \pm 0,64)\end{array}$ & $\begin{array}{c}58,69 \pm 15,16 \\
(76,22 \pm 12,45)\end{array}$ & $\begin{array}{c}21,78 \pm 8,58 \\
(11,07 \pm 2,37)\end{array}$ & $\begin{array}{c}13,45 \pm 1,97 \\
(6,47 \pm 10,12)\end{array}$ & $\begin{array}{c}2,93 \pm 1,12 \\
(0,47 \pm 0,23)\end{array}$ \\
\hline \multicolumn{7}{|c|}{ Transição (Sem fertilização) } \\
\hline 0 & $\begin{array}{c}0,36 \pm 0,59 \\
(0,59 \pm 0,64)\end{array}$ & $\begin{array}{c}0,26 \pm 0,21 \\
(0,41 \pm 0,25)\end{array}$ & $\begin{array}{c}74,68 \pm 29,54 \\
(65,33 \pm 11,55)\end{array}$ & $\begin{array}{l}11,71 \pm 2,51 \\
(7,62 \pm 2,31)\end{array}$ & $\begin{array}{l}10,23 \pm 1,29 \\
(2,45 \pm 1,62)\end{array}$ & $\begin{array}{r}3,38 \pm 0,98 \\
(0,77 \pm 0,47)\end{array}$ \\
\hline \multicolumn{7}{|c|}{ Cerrado sentido restrito (Sem fertilização) } \\
\hline 10 & $\begin{array}{c}0,12 \pm 0,06 \\
(0,33 \pm 0,10)\end{array}$ & $\begin{array}{c}0,13 \pm 0,09 \\
(0,18 \pm 0,04)\end{array}$ & $\begin{array}{c}63,32 \pm 6,41 \\
(73,93 \pm 17,93)\end{array}$ & $\begin{array}{c}9,17 \pm 2,26 \\
(7,20 \pm 1,34)\end{array}$ & $\begin{array}{l}12,27 \pm 2,08 \\
(2,10 \pm 1,17)\end{array}$ & $\begin{array}{r}4,35 \pm 1,10 \\
(0,52 \pm 0,31)\end{array}$ \\
\hline 20 & $\begin{array}{c}0,08 \pm 0,06 \\
(0,06 \pm 0,02)\end{array}$ & $\begin{array}{c}0,11 \pm 0,04 \\
(0,14 \pm 0,11)\end{array}$ & $\begin{array}{c}83,51 \pm 64,22 \\
(80,20 \pm 23,35)\end{array}$ & $\begin{array}{c}7,51 \pm 3,48 \\
(5,54 \pm 0,67)\end{array}$ & $\begin{array}{l}10,86 \pm 4,36 \\
(1,76 \pm 0,69)\end{array}$ & $\begin{array}{r}4,12 \pm 1,76 \\
(0,54 \pm 0,26)\end{array}$ \\
\hline 30 & $\begin{array}{c}0,06 \pm 0,03 \\
(0,06 \pm 0,03)\end{array}$ & $\begin{array}{c}0,09 \pm 0,03 \\
(0,09 \pm 0,03)\end{array}$ & $\begin{array}{c}70,16 \pm 12,54 \\
(66,67 \pm 23,30)\end{array}$ & $\begin{array}{c}6,09 \pm 1,81 \\
(6,73 \pm 1,27)\end{array}$ & $\begin{array}{c}8,82 \pm 2,63 \\
(5,9 \pm 10,84)\end{array}$ & $\begin{array}{r}3,70 \pm 0,91 \\
(0,45 \pm 0,16)\end{array}$ \\
\hline \multicolumn{7}{|c|}{ Mata de Galeria (Com fertilização) } \\
\hline-30 & $\begin{array}{c}2,74 \pm 3,26 \\
(3,88 \pm 1,49)\end{array}$ & $\begin{array}{c}0,95 \pm 0,58 \\
(1,85 \pm 0,59)\end{array}$ & $\begin{array}{c}55,12 \pm 46,93 \\
(58,25 \pm 21,74)\end{array}$ & $\begin{array}{l}33,59 \pm 11,29 \\
(28,87 \pm 6,48)\end{array}$ & $\begin{array}{c}14,05 \pm 4,22 \\
(78,75 \pm 57,92)\end{array}$ & $\begin{array}{c}1,85 \pm 0,47 \\
(2,20 \pm 1,29)\end{array}$ \\
\hline-20 & $\begin{array}{c}2,07 \pm 2,02 \\
(4,03 \pm 1,06)\end{array}$ & $\begin{array}{c}0,79 \pm 0,36 \\
(1,82 \pm 0,52)\end{array}$ & $\begin{array}{c}60,71 \pm 41,41 \\
(55,53 \pm 16,69)\end{array}$ & $\begin{array}{c}31,68 \pm 8,53 \\
(26,37 \pm 4,04)\end{array}$ & $\begin{array}{c}14,55 \pm 4,05 \\
(57,68 \pm 23,53)\end{array}$ & $\begin{array}{r}1,75 \pm 0,63 \\
(3,07 \pm 2,22)\end{array}$ \\
\hline-10 & $\begin{array}{c}4,37 \pm 4,90 \\
(3,68 \pm 1,56)\end{array}$ & $\begin{array}{c}1,27 \pm 0,64 \\
(1,77 \pm 0,89)\end{array}$ & $\begin{array}{c}49,47 \pm 14,08 \\
(48,92 \pm 15,27)\end{array}$ & $\begin{array}{c}44,21 \pm 27,06 \\
(30,67 \pm 12,93)\end{array}$ & $\begin{array}{c}14,62 \pm 4,93 \\
(84,67 \pm 34,56)\end{array}$ & $\begin{array}{r}1,70 \pm 0,79 \\
(4,68 \pm 3,61)\end{array}$ \\
\hline \multicolumn{7}{|c|}{ Transição (Com fertilização) } \\
\hline 0 & $\begin{array}{c}0,59 \pm 0,64 \\
(2,30 \pm 1,07)\end{array}$ & $\begin{array}{c}0,41 \pm 0,25 \\
(1,05 \pm 0,90)\end{array}$ & $\begin{array}{c}79,81 \pm 42,76 \\
(54,07 \pm 15,51)\end{array}$ & $\begin{array}{c}18,66 \pm 6,95 \\
(18,90 \pm 5,70)\end{array}$ & $\begin{array}{c}10,13 \pm 2,26 \\
(72,02 \pm 40,22)\end{array}$ & $\begin{array}{r}3,55 \pm 1,49 \\
(3,55 \pm 2,75)\end{array}$ \\
\hline \multicolumn{7}{|c|}{ Cerrado sentido restrito (Com fertilização) } \\
\hline 10 & $\begin{array}{c}0,07 \pm 0,03 \\
(2,33 \pm 0,71)\end{array}$ & $\begin{array}{c}0,12 \pm 0,02 \\
(1,23 \pm 0,62)\end{array}$ & $\begin{array}{c}89,91 \pm 55,05 \\
(57,03 \pm 10,19)\end{array}$ & $\begin{array}{l}10,24 \pm 2,44 \\
(21,1 \pm 5,11)\end{array}$ & $\begin{array}{c}9,55 \pm 2,13 \\
(90,75 \pm 38,96)\end{array}$ & $\begin{array}{l}4,15 \pm 1,63 \\
(4,4 \pm 1,44)\end{array}$ \\
\hline 20 & $\begin{array}{c}0,06 \pm 0,02 \\
(2,14 \pm 1,07)\end{array}$ & $\begin{array}{c}0,14 \pm 0,11 \\
(1,00 \pm 0,78)\end{array}$ & $\begin{array}{l}102,38 \pm 74,75 \\
(54,98 \pm 10,51)\end{array}$ & $\begin{array}{c}8,37 \pm 2,59 \\
(21,04 \pm 7,26)\end{array}$ & $\begin{array}{c}9,98 \pm 2,23 \\
(104,14 \pm 61,89)\end{array}$ & $\begin{array}{r}3,84 \pm 0,61 \\
(5,62 \pm 3,54)\end{array}$ \\
\hline 30 & $\begin{array}{c}0,06 \pm 0,03 \\
(2,60 \pm 1,01)\end{array}$ & $\begin{array}{c}0,09 \pm 0,03 \\
(1,08 \pm 0,74)\end{array}$ & $\begin{array}{c}53,74 \pm 16,93 \\
(49,07 \pm 18,06)\end{array}$ & $\begin{array}{c}5,94 \pm 1,92 \\
(28,00 \pm 14,68)\end{array}$ & $\begin{array}{c}7,70 \pm 1,61 \\
(94,00 \pm 61,04)\end{array}$ & $\begin{array}{r}4,95 \pm 4,00 \\
(9,12 \pm 5,79)\end{array}$ \\
\hline
\end{tabular}


Anexo 3 - Análise Multivariada de Variância (MANOVA) da comparação dos fatores edáficos entre as parcelas sobre efeito de fertilização e irrigação registrados em uma área de transição entre Savana-Floresta (Cerrado sentido restrito a Mata de Galeria) da Reserva Ecológica do IBGE, Distrito Federal, Brasil.

\begin{tabular}{ccccccc}
\hline & Df & Pillai & approx F & num Df & den Df & $\operatorname{Pr}(>\mathrm{F})$ \\
\hline Fertilização & 13 & 3,049 & 1,59 & 156 & 732 & $3,54 \mathrm{E}-05$ \\
Irrigação & 7 & 1,226 & 0,991 & 84 & 392 & 0,506 \\
Residuos & 61 & & & & & \\
\hline
\end{tabular}

Anexo 4 - Resultado da Análise Multivariada de Variância da comparação dos fatores edáficos entre as parcelas sobre efeito de fertilização em uma área de transição entre Savana-Floresta (Cerrado sentido restrito a Mata de Galeria) da Reserva Ecológica do IBGE, Distrito Federal, Brasil.

\begin{tabular}{ccccccc}
\hline & Df & Pillai & approx F & num Df & den Df & $\operatorname{Pr}(>\mathrm{F})$ \\
\hline Fertilização & 1 & 0,794 & 18,380 & 12 & 57 & $2,17 \mathrm{E}-15$ \\
Savana-Floresta & 6 & 1,605 & 1,887 & 72 & 372 & $8,17 \mathrm{E}-05$ \\
Interação & 6 & 1,074 & 1,127 & 72 & 372 & 0.239 \\
Residuos & 68 & & & & & \\
\hline
\end{tabular}




\section{CAPÍTULO 3 - UTILIZAÇÃO DE ESPECTROSCOPIA DE REFLECTÂNCIA NO INFRAVERMELHO PRÓXIMO NA DISCRIMINAÇÃO DE ESPÉCIES HERBÁCEO-ARBUSTIVAS E A RELAÇÃO COM A CONCENTRAÇÃO FOLIAR DE CARBONO, NITROGÊNIO E ENXOFRE}

\section{RESUMO}

Nas últimas décadas, o interesse em utilizar a espectroscopia de reflectância no infravermelho próximo cresceu permitindo a discriminação e mapeamento de espécies, o acompanhamento da expansão de espécie invasora, levantamento da riqueza florística e relações filogenéticas. No Brasil, os trabalhos que utilizam a espectroscopia ainda são focados no mapeamento e monitoramento de áreas, como meio de indicar a estrutura do ambiente, auxiliar no planejamento da paisagem, tomar decisões sobre estratégias de conservação e restauração; entretanto, para as fitofisionomias savânicas e campestres do Cerrado, os trabalhos são ainda incipientes. Para isso, este estudo teve como objetivo averiguar se existe diferença nas curvas espectrais das folhas entre as espécies comuns em áreas de Vereda, assim como se o espectro se mantém em diferentes localidades e se são relacionadas às concentrações de nutrientes foliares. Dessa forma, amostraram-se indivíduos de Trembleya parviflora e Lavoisiera imbricata, espécies arbustivas que se encontram em expansão em áreas úmidas no Distrito Federal, e indivíduos de Paspalum lineare, Andropogon bicornis e A. leucostachyus, espécies de gramíneas comuns e abundantes, encontrando-se entre as dez espécies com maior cobertura. As espécies apresentam curvas espectrais distintas e independentes do local de ocorrência e podem ser utilizadas para estimar a concentração foliar de carbono, nitrogênio e enxofre

Palavras-chave: curvas espectrais; Vereda; Trembleya parviflora. 


\section{INTRODUÇÃO}

A região do espectro eletromagnético entre 750 a $2500 \mathrm{~nm}$ correspondente à faixa do infravermelho próximo (NIR - do inglês Near Infrared) tem se demostrado importante tanto para espectroscopia de laboratório (Vance et al., 2016), como para espectroscopia de imageamento (Adam et al., 2010). A espectroscopia de laboratório permite diferenciar e identificar compostos químicos, especialmente com os grupos funcionais $\mathrm{O}-\mathrm{H}, \mathrm{N}-\mathrm{H}$ e C=O (Barbosa, 2007), isso se deve à variação do momento dipolar das ligações com o estiramento ou deformações dos ângulos da molécula, devido à variação do nível de energia dos átomos ou das moléculas (Pasquini, 2003; Barbosa, 2007). Por meio da espectroscopia de imageamento, denominada também como sensoriamento remoto hiperespectral, a faixa do NIR auxilia na caracterização da biodiversidade (Serbin et al., 2014) e do ambiente (Adam et al., 2010), isso porque se trata de uma região que responde bem às variações bióticas e abióticas dos ecossistemas (Asner, 1998). Nas duas escalas, os sensores trabalham com a medida de reflectância e/ou transmitância emitida pelo material alvo que sofreu a incidência do espectro eletromagnético na região do NIR (Adam et al., 2010, Vance et al., 2016), o que gera uma curva espectral para cada tipo de material, tanto em termos de molécula, quanto em termos de paisagem.

Nas últimas décadas, o interesse em utilizar a curva espectral cresceu permitindo a discriminação e mapeamento de espécies (Rosso et al., 2005; Vaiphasa et al., 2005; Belluco et al., 2006; Pengra et al., 2007), o acompanhamento da expansão de espécies invasoras (Asner et al., 2008; Hestir et al., 2008), levantamento da riqueza florística (Castro-Esaú et al., 2006, Carlson et al., 2007), contaminação de ecossistemas (Zomer et al., 2009), diversidade bioquímica (Asner et al., 2009) e relações filogenéticas (Asner e Martins, 2011). Isso porque algumas técnicas permitem mensurar variações nas propriedades biofísicas e bioquímicas das plantas, tais como, índice de área foliar, biomassa, teor de água da vegetação e concentração de nutrientes (Kovacs et al., 2005; Proisy et al., 2007; Ramoelo et al., 2011).

As propriedades bioquímicas e biofísicas das folhas ou do dossel são os principais fatores da vegetação que interagem com a radiação solar. A folha é o principal componente da planta a contribuir para o sinal detectado pelos sensores óticos (Guyot, 1990; Kumar et al., 2001; Zarco-Tejada et al., 2004). Além disso, a folha mostra-se como o principal representante do dossel, sobretudo quando esse apresenta copas altamente foliadas que amplificam o sinal (Asner, 1998; Castro-Esaú, et al., 2006) e também representa 
componente fundamental para estudos de ciclagem de nutrientes nos ecossistemas (Bustamante et al., 2012).

A determinação dos teores de $\mathrm{C}$ e $\mathrm{N}$ foliar por meio de técnicas de espectroscopia torna-se interessante, visto que esses são fortes preditores de capacidade fotossintética e dos ciclos biogeoquímicos nos ecossistemas. Compostos químicos interagem com diferentes intensidades em distintos pontos do espectro de radiação eletromagnética (Curran, 1989). Por exemplo, observa-se variação na região 1200-2400 nm em função do teor de fibras, lignina e celulose (Asner, 1998). Já o teor de C e $\mathrm{N}$ responde a uma região mais curta, 1500-2400 nm (Elvidge 1990; Castro-Esaú et al., 2006).

No Brasil, os trabalhos que utilizam a espectroscopia ainda são focados no mapeamento e monitoramento de áreas, como meio de indicar a estrutura do ambiente, auxiliar no planejamento da paisagem, tomar decisões sobre estratégias de conservação e restauração (Freitas et al., 2005; Couto Júnior et al., 2010). Alguns trabalhos recentemente vêm utilizando a espectroscopia para auxiliar na identificação taxonômica de espécies principalmente na Amazônia (Durgante et al., 2013; Lang et al., 2015), entretanto, para as fitofisionomias savânicas e campestres do Cerrado, os trabalhos são ainda incipientes (Silva-França e Sano, 2011; Amaral et al., 2015).

A Vereda está entre as fitofísionomias savânicas do Cerrado que apresentam grande riqueza de espécies (Araújo et al., 2002; Resende et al., 2013; Moreira et al., 2015). Essas áreas úmidas ocorrem normalmente próximas às nascentes, em áreas com lençóis freáticos superficiais (Araújo et al., 2002; Ribeiro e Walter, 2008; Resende et al., 2013). A Vereda apresenta na paisagem a presença de Mauritia flexuosa L. (Buriti) (Araújo et al., 2002; Guimarães et al., 2002) e próximo a essa palmeira encontra-se componente arbustivoarbóreo, representando entre 5\% a 10\% da cobertura das espécies (Ribeiro e Walter, 2008). Assim como apresenta ampla extensão composta por espécies herbáceo-subarbustivas, componente com maior riqueza florística para essa fitofisionomia e de maior cobertura (Araújo et al., 2002; Resende et al., 2013).

Apesar da elevada riqueza do componente herbáceo-arbustivo apenas dez espécies desse estrato compõem $50 \%$ da cobertura do solo nas áreas mais abertas das fitofisionomias alagadas do Cerrado (Munhoz et al., 2008; Munhoz e Felfili, 2008; Eugênio et al., 2011; Moreira et al 2015). Dentre as dez espécies, encontram-se componentes do estrato arbustivo, subarbustivo e herbáceo, sendo o último representado principalmente por espécies da família Poaceae dentro dos gênerosPaspalum e Andropogon (Eugênio 2011; Santos e Munhoz, 2012). Nessas fitofisionomias observa-se 
dinâmica na composição florística que altera a proporção dos estratos (Amaral et al., 2013) e que aumenta de forma considerável a cobertura de algumas espécies, dentre elas: Trembleya parviflora (D.Don) Cogn., Lavoisiera imbricata (Thunb.) DC., Leandra polystachya (Naudin) Cogn., Erythroxylum deciduumA.St.-Hil.e Roupala montanaAubl. (Eugênio, 2011). Particularmente T. parviflora e L. imbricata formam dossel arbustivo homogêneo em Campo Limpo Úmido e em Vereda (Silva-Júnior e Felfili, 1996; Meirelles et al., 2004; Munhoz e Ribeiro, 2008), alterando a paisagem local e possivelmente os dados hiperespectrais da vegetação.

Portanto mostra-se importante realizar estudos espectrais com espécies de maior cobertura nessas fitofisionomias, assim como com espécies com potencial para alterar a paisagem. Este trabalho procurou testar a hipótese de que espécies comuns em comunidades de Vereda do Distrito Federal apresentam curvas espectrais distintas e independentes do local de ocorrência, e que estas podem ser utilizadas para estimar a concentração foliar de carbono, nitrogênio e enxofre.

\section{Objetivo geral}

- Averiguar se existe diferença nas curvas espectrais das folhas entre as espécies frequentes em áreas de Vereda, assim como se o espectro se mantém em diferentes localidades e se são relacionadas às concentrações foliares de carbono, nitrogênio e enxofre.

\section{Objetivos específicos:}

- Diferenciar a curva espectral de espécies herbáceo-arbustivas comuns em áreas de Vereda, assim como se essa curva se mantém constante em diferentes localidades;

- Associar as refletâncias descritas nas curvas espectrais com as concentrações foliares de carbono, nitrogênio e enxofre.

- Quantificar o teor de carbono, nitrogênio e enxofre foliar das espécies herbáceoarbustivas comuns em áreas de Vereda, assim como se esses teores se mantêm constante em diferentes localidades; 


\section{MATERIAL E MÉTODOS}

Seleção de espécies e das áreas de estudo

Indivíduos de Trembleya parviflora (D.Don) Cogn. e Lavoisiera imbricata (Thunb.) DC., pertencente a Melastomataceae, foram amostrados. As duas espécies arbustivas que se encontram em expansão em áreas úmidas no Distrito Federal (Silva-Júnior e Felfili, 1996; Meirelles et al., 2004; Munhoz e Ribeiro, 2008; Eugênio, 2011). Também foram selecionados indivíduos de Paspalum lineare Trin., Andropogon bicornis L. e A. leucostachyus Kunth, espécies de gramíneas frequentes e com ampla cobertura em áreas úmidas nessa região que se encontram entre as dez espécies com maior cobertura do solo nessas áreas(Eugênio, 2011; Eugênio et al., 2011; Santos e Munhoz, 2012).

A coleta das espécies foi realizada em cinco Unidades de Conservação no Distrito Federal (Figura 1), buscando espacializar a amostragem em áreas preservadas em que se realiza o acompanhamento da dinâmica do estrato herbáceo-arbustivo. Todos os locais são Veredas sobre solo hidromórfico, com áreas permanentemente alagadas, assim como áreas que apresentam alagamento somente no período chuvoso. O clima da região é do tipo Aw, segundo a classificação de Koppen (1948), com dois períodos definidos; um seco, de abril a setembro, e outro úmido, de outubro a abril.

\section{Coletas e processamento de amostras de folhas}

Em cada local foram marcados de três a cinco indivíduos de cada espécie para amostragem e coleta de folhas totalmente expandidas durante o mês de outubro de 2013, na estação chuvosa. Para as gramíneas, realizou-se o corte na altura a $5 \mathrm{~cm}$ do solo e posteriormente, em laboratório, realizou-se a seleção das folhas sem injúrias. As folhas das espécies arbustivas foram selecionadas em campo, coletando principalmente folhas mais externas da copa. As amostras foram imediatamente seladas em sacos plásticos, que foram acondicionados em caixas de isopor com gelo. O transporte para o laboratório ocorreu em intervalo de 1-3 horas para processamento adicional. Posteriormente, realizou-se a triagem do material e colocou-se para secar em estufa a $70^{\circ} \mathrm{C}$ durante $72 \mathrm{~h}$ (adaptado de Zhaiet al., 2013). Após esse período as amostras foram trituradas em moinho de martelo e a amostra final passou por uma peneira de 20 mesh $(0,841 \mathrm{~mm})$. 
Medições da reflectância na faixa do infravermelho próximo (NIRS- Near Infrared Reflectance Spectroscopy)

As medidas de reflectância foliar foram mensuradas no NIRS 5500 (NIR Systems Foss, Silver Spring, MD), na faixa espectral de 1100-2498nm, com resolução espectral de $2 \mathrm{~nm}$. As regiões do espectro foram selecionadas por meio de revisão de estudos anteriores (adaptado de Serbin et al., 2014) que demonstram melhor correlação com os teores de nitrogênio e carbono foliar (Elvidge, 1990). As amostras de folhas trituradas e peneiradas foram colocadas tão uniformemente quanto possível em ring cell (mini tubos - células padrões do equipamento) de amostras com profundidade de $1 \mathrm{~cm}$ e diâmetro de $3,9 \mathrm{~cm}$. Cada amostra foi medida duas vezes e o espectro de cada amostra foi à média das duas leituras. As saídas de dados espectrais foram armazenadas no programa WinISI (3.2.3, Foss and Infrasoft International LLC, State College, PA, USA) e posteriormente foram importadas e analisadas no programa estatístico Rversão 3.2.3 (R Development Core Team 2015), assim como no programa The Unscrambler® versão 10.2.0.80 (CAMO AS, Norway).

\section{Concentração de Carbono, Nitrogênio e Enxofre}

Após a aquisição do espectro, cada amostra foi seca novamente em estufa por 12 horas a $70^{\circ} \mathrm{C}$ antes de se mensurar o teor de carbono, nitrogênio e enxofre, para garantir medição correta de massa seca do material e melhor precisão do equipamento. Determinou-se pelo método de combustão a concentração de nitrogênio foliar (Nmass\%) e carbono foliar (Cmass\%) com 100mg de cada amostra que foram queimadas a $950^{\circ} \mathrm{C} \mathrm{em}$ um analisador elementar LECO CHN 628 (Leco Corporation, St. Joseph, MI). Para o teor de enxofre foliar (Smass\%) 200mg da amostra foram queimadas a $1.350^{\circ} \mathrm{C}$ no módulo LECO S 628 (Leco Corporation, St. Joseph, MI). 




Figura 1 - Localização das cinco Unidades de Conservação (áreas de amostragem) em que se realizou a coleta das espécies herbáceo-arbustivas comuns às Veredas no Distrito Federal, Brasil. 
As variações nos teores de nutrientes entre os hábitos (arbustivos e herbáceos) foram avaliadas pelo teste $t$ para amostras independentes. Enquanto que para avaliar a influência do local de coleta sobre a variação dos teores de nutrientes foliares utilizou-se ANOVA e, posteriormente, o teste de Tukey para comparação de médias. Para tanto, testou-se as premissas de normalidade e homocedasticidade (Zar, 2010). As análises foram realizadas no programa estatístico Rversão 3.2.3 (R Development Core Team 2015).

A avaliação e exploração das relações dos valores de reflectância, entre as espécies e o local de coleta, foram visualizadas pela Análise de Componentes Principais (ACP ou PCA - Principal Component Analysis). Essa análise permite reduzir a dimensionalidade de dados multivariados (nesse caso refletância de cada amostra na faixa espectral de 1100$2498 \mathrm{~nm}$, com resolução espectral de $2 \mathrm{~nm}$ ) em componente principal, que caracteriza o máximo possível da variação em um conjunto de dados multivariado (Wehrens, 2011) e facilitar a interpretação de dados multivariados.

A separação das espécies pela variação global dos teores de nutriente e posteriormente pela variação global dos espectros foram realizadas por meio de uma Análise Discriminante Linear (ADL ou LDA - Linear Discriminant Analysis). A LDA é uma técnica estatística que permite avaliar se distinção entre dois ou mais grupos por um conjunto de variáveis independentes (Wehrens, 2011). Isso porque se calcula o centróide de cada grupo através da média dos escores discriminantes para todas as amostras em um grupo particular, dessa forma os centróides de cada grupo indicam o local mais típico de qualquer indivíduo de um grupo particular, e uma comparação dos centróides de grupos mostra os quão afastados estão os grupos em termo da função discriminante. A análise foi realizada no programa The Unscrambler ${ }^{\circledR}$ versão 10.2.0.80 (CAMO AS, Norway). Testouse a aplicação de algumas transformações como correção multiplicativa do sinal (MSC), variação normal padrão (SNV) e segunda derivada como pré-tratamento para melhorar a eficiência da LDA (Chen et al., 2013); entretanto, não houve aumento significativo da LDA, optando-se, assim, por trabalhar com a média dos espectros brutos.

Utilizou-se modelagem PLSR (Partial Least-Squares Regression) (Geladi e Kowalski, 1986; Serbin et al., 2012), usando o pacote pls (Mevik e Wehrens, 2007) no programa Rversão 3.2.3 (R Development Core Team 2015) para prever as características foliares nos espectros. A PLSR trata-se de uma estatística padrão utilizada em análises quimiométricas (Serbinet al., 2014), pois consegue lidar com a alta colinearidade das 
variáveis preditoras, assim como em delineamentos onde o número de variáveis preditoras é igual ou maior do que o número de observações, características que poderiam gerar erros em regressões lineares do tipo stepwise (Grossman et al., 1996). A PLSR ainda reduz a matriz grande de variáveis preditoras para um número relativamente pequeno de componentes não correlacionados (Serbin et al., 2014).

Para calibração do modelo, utilizou-se $80 \%$ das amostras $(n=84)$, sendo que $20 \%$ $(n=22)$ foram utilizadas para validação independente, assegurando que ambos os conjuntos de dados abrangessem o intervalo de variação das medidas para cada característica foliar estudada. Os dados da calibração foram divididos adicionalmente de $70 \%(n=59)$ a $30 \%$ $(n=25)$ via 1000 permutações, para realizar a análise de incerteza. Segundo Serbin et al. (2014), para qualquer permutação (dentre as 1.000), 56\% dos dados seriam aleatórios para o desenvolvimento de modelos e $24 \%$ para a avaliação e a análise da incerteza do modelo, enquanto $20 \%$ dos dados seriam retidos totalmente até o fim do processo de avaliação dos modelos finais. Utilizou-se também Prediction Residual Sum of Squares (PRESS - Chen et al., 2004) para minimizar o número de componentes da PLSR e evitar excesso de ajustes (over-fit) na calibração dos modelos. Utilizou-se leave-one-out cross-validation para estimar a PRESS devido ao número de amostras. Finalmente, o número ideal de componentes para cada modelo foi determinado pelo menor valor de Root Mean Square Error (RMSE) das estatísticas da PRESS (Wold et al., 2001), e os sucessivos componentes da PLSR não melhoraram a RMSE significativamente pelo teste $t$ (Serbin et al., 2014). Por último, foi calculada a Variable Importance of Projections métrica (VIP- variable importance of projections; Wold et al., 1994) sobre os modelos finais para identificar as regiões do espectro que foram significativas para prever as três características foliares.

Avaliação de desempenho do modelo PLSR e análise de incerteza

No desempenho de cada modelo de PLSR, utilizou-se de três medidas principais: o coeficiente de determinação $\left(\mathrm{R}^{2}\right)$, RMSE e o viés do modelo (model bias). Para cada modelo de PLSR, utilizou-se 1000 permutações para caracterizar o desempenho da calibração do modelo. Calculou-se a média do coeficiente do modelo em todas as permutações para gerar o modelo final. A etapa final da análise envolveu a aplicação dos modelos de 1000 permutações para os 20\% (n=22) dos dados que foram originalmente separados do conjunto de dados total (e nunca utilizados) para criação do modelo. 


\section{RESULTADOS}

\section{Refletância foliar}

As curvas de refletância espectral apresentaram variação ao longo do espectro de 8 a 26\%, com maior variação nos comprimentos de ondas maiores do que 1700nm (Figura 2). O gênero Andropogon apresentou menor variação no espectro, enquanto T. parviflora foi a espécie que apresentou maior variação nos espectros.

O primeiro componente principal da PCA explicou $70 \%$ da variação das amostras em relação aos valores de reflectância gerados nos espectros. Essa variação gerou dispersão das amostras de forma a visualizar a formação de um grupo das espécies arbustivas e outro grupo formado pelas espécies herbáceas (Figura 3A). Com a soma dos $14 \%$ da variação explicada pelo segundo componente principal, observou-se a formação do grupo formado pelas amostras de T. parviflora e outro grupo formado pelas amostras de L.imbricata. Os grupos formados pelas amostras das três espécies de Poaceae tornaram-se mais nítidos com a presença do terceiro componente principal (que explicou $4 \%$ da variação), o qual juntamente com os dois componentes anteriores explicaram $86 \%$ da variação das amostras em relação aos espectros mensurados (Figura 3B). Os espectros apresentaram maior variação entre as espécies estudadas do que entre os locais de amostragem (Figura 4), ou seja, a dispersão das amostras se agrupou principalmente em função da espécie, não apresentado grande variação nos valores de reflectância gerados nos espectros, mesmo que estes tenham sido coletados em diferentes Veredas. 

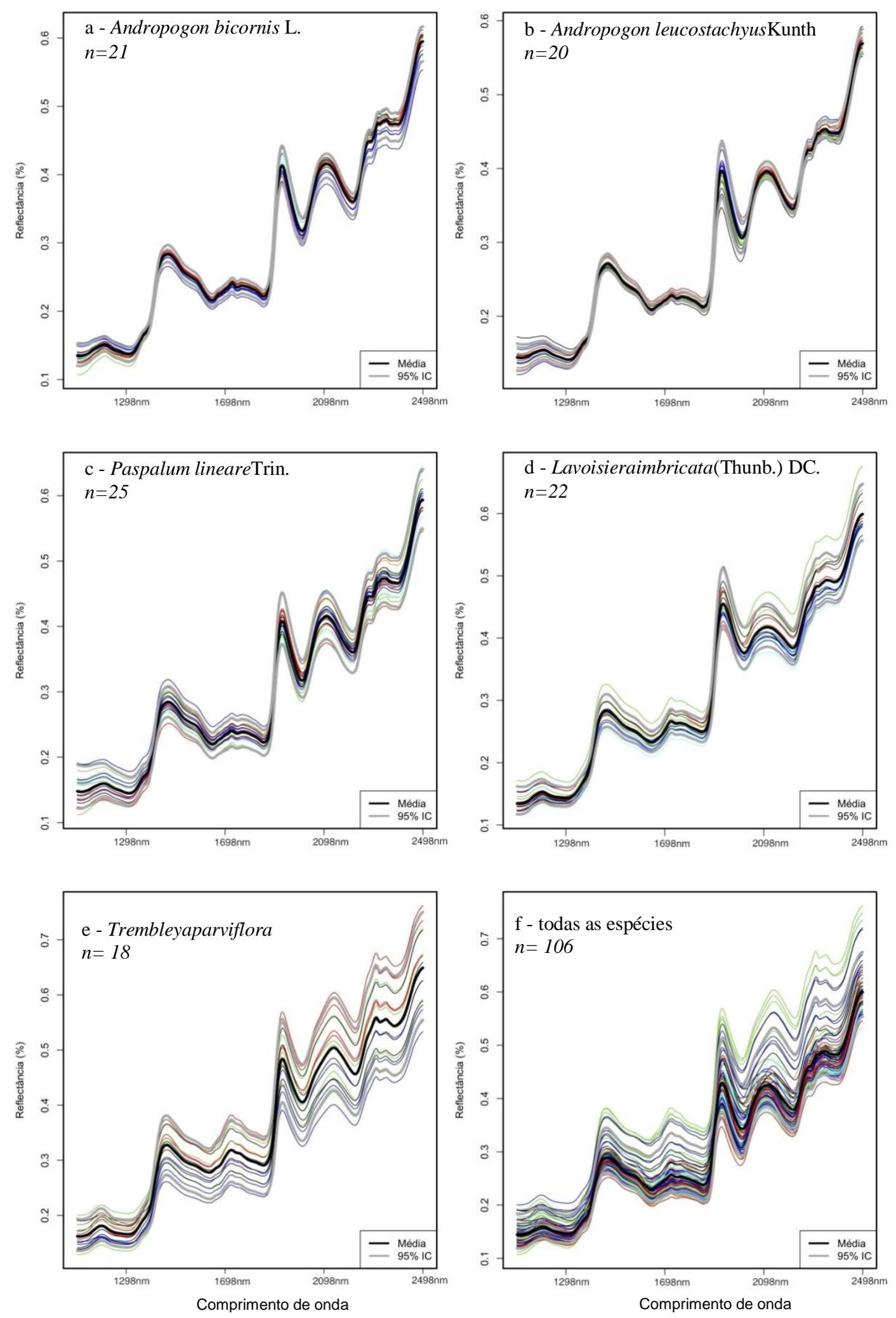

Figura 2 - Curvas espectrais das reflectâncias de folhas (a) de Andropogon bicornis, (b) de A. leucostachyus, (c) de Paspalum lineare, (d) de Lavoisiera imbricata, (e) de Trembleya parviflora e (f) do total de 106 folhas das cinco as espécies estudadas. 
A matriz de confusão gerada pela LDA mostrou 97,17\% de classificação correta (Tabela 1). A LDA confirmou os grupos observados na PCA, ou seja, a nítida separação entre as plantas herbáceas em relação às arbustivas, nesse caso sem nenhum erro da descriminação dos grupos. Também sem erro na discriminação foi possível separar as duas espécies arbustivas (T. parviflora e L. imbricata). Observou-se a mistura na classificação, levando a uma margem de erro na determinação, somente entre as Poaceae, tanto entre os gêneros Andropogon e Paspalum, quanto entre as espécies A. bicornise A. leucostachyus.

Tabela 1. Matriz de confusão gerada pelos valores de reflectância das curvas espectrais para todas as amostras coletadas para as cinco espécies do estrato herbáceo-arbustivo em cinco Veredas no Distrito Federal, Brasil.

\begin{tabular}{|c|c|c|c|c|c|c|}
\hline \multirow[b]{2}{*}{ Espécies } & \multicolumn{3}{|c|}{ Poaceae } & \multicolumn{2}{|c|}{ Melastomataceae } & \multirow[b]{2}{*}{$\begin{array}{c}\text { Total } \\
\text { amostras }\end{array}$} \\
\hline & A. bicornis & A.leucostachyus & P. lineare & L. imbricata & T. parviflora & \\
\hline A. bicornis & 20 & 0 & 1 & 0 & 0 & 21 \\
\hline A. leucostachyus & 1 & 19 & 0 & 0 & 0 & 20 \\
\hline P. lineare & 0 & 1 & 24 & 0 & 0 & 25 \\
\hline L. imbricata & 0 & 0 & 0 & 22 & 0 & 22 \\
\hline T. parviflora & 0 & 0 & 0 & 0 & 18 & 18 \\
\hline Total amostras & 21 & 20 & 25 & 22 & 18 & 106 \\
\hline
\end{tabular}



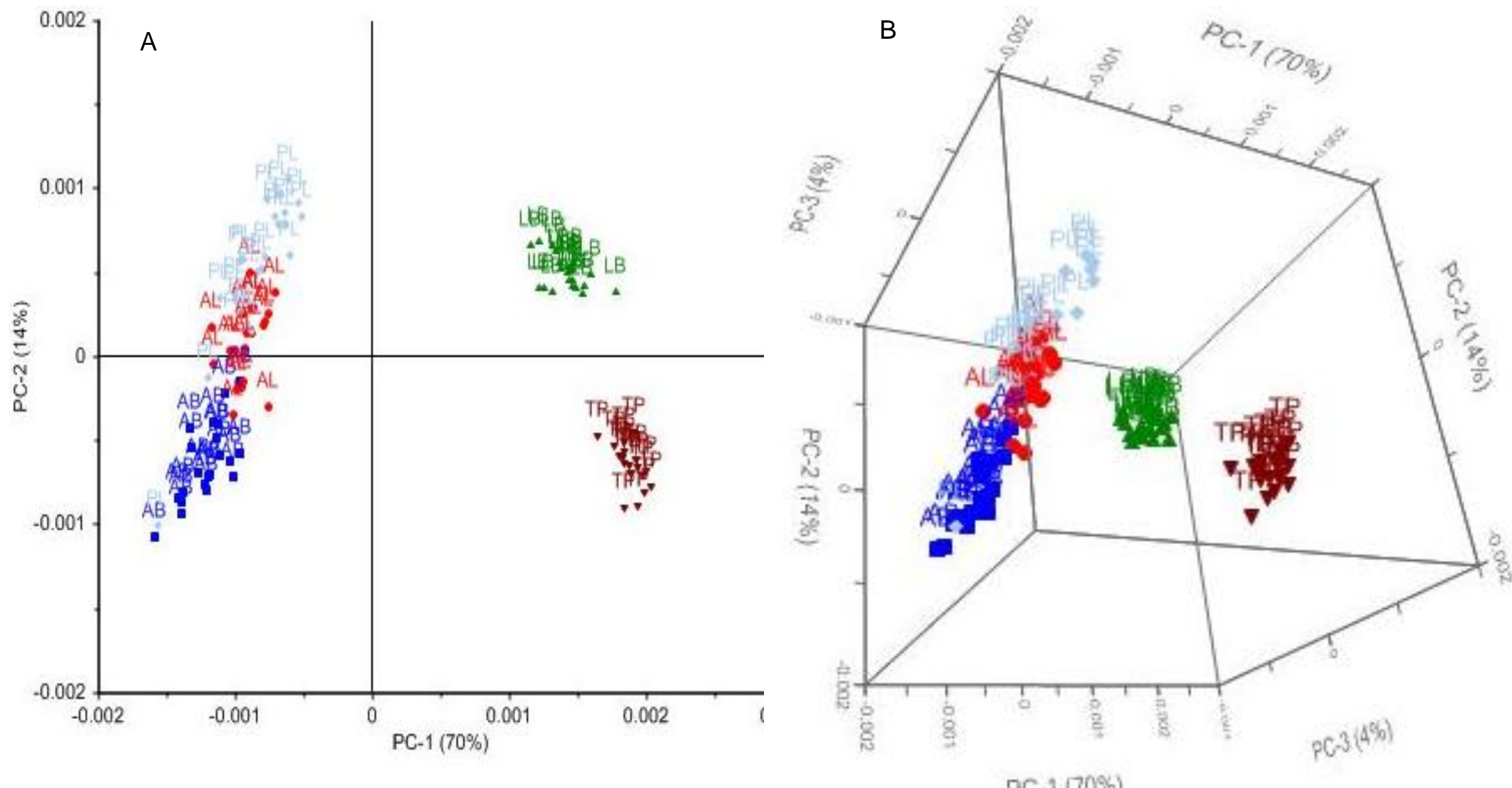

Figura 3 - Separação de cinco espécies do estrato herbáceo-arbustivo (A) pelo primeiro e segundo componente principal (PC) explicando 84\% da variância e (B) pelo primeiro, segundo e terceiro componente principal explicando $88 \%$ da variância, gerados pelos valores de reflectância da curva espectral (1100-2500 nm) das espécies amostradas em cinco Veredas no Distrito Federal, Brasil.ロ Andropogon bicornis, $\bullet$ A. leucostachyus, $\gg$ Paspalum lineare, $\mathbf{\Delta}$ Lavoisiera imbricata, $\mathbf{\nabla}$ Trembleya parviflora. 


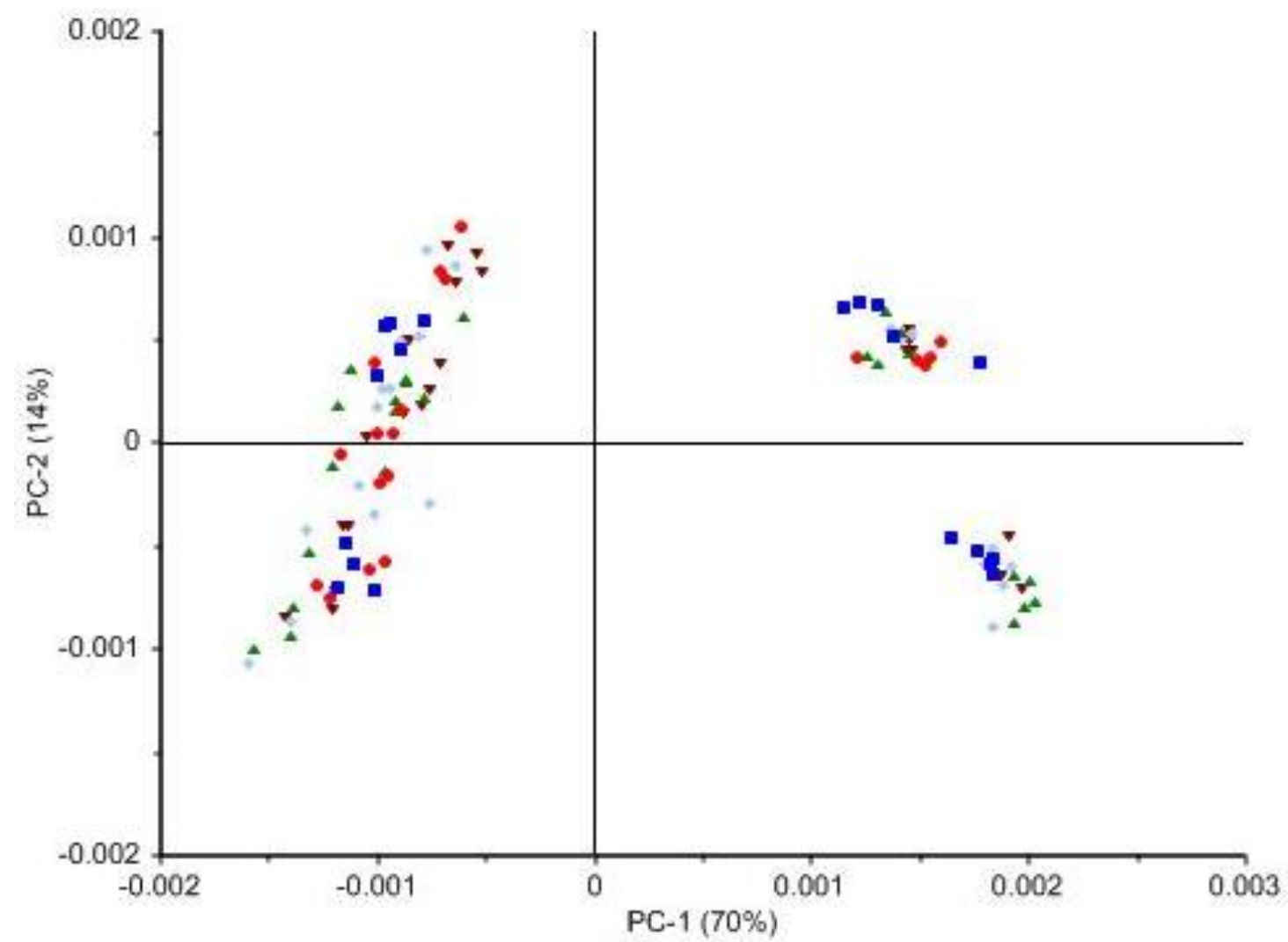

Figura 4 - Separação de cinco espécies do estrato herbáceo-arbustivo pelos componentes principais (PC) gerados pelos valores de reflectância da curva espectral (1100-2500 nm) das espécies amostradas em cinco Veredas no Distrito Federal, Brasil. — ESECAE Estação Ecológica de Águas Emendadas; - FLONA - Floresta Nacional de Brasília; $\triangle \mathrm{IBGE}$ - Reserva Ecológica do IBGE; $\gg$ JBB - Jardim Botânico de Brasília, $\nabla$ PNB Parque Nacional de Brasília. 
O local de coleta interferiu de forma variada para cada espécie e elemento analisado (Tabela 2). $\mathrm{O}$ local de coleta não influenciou no teor de enxofre para T. parviflora $\left(\mathrm{F}_{3,14}=\right.$ $2,63 ; p=0,09)$, P. lineare $\left(\mathrm{F}_{4,20}=2,75 ; p=0,06\right)$ e A. leucostachyus $\left(\mathrm{F}_{3,16}=2,42 ; p=0,10\right)$; no teor de carbono para A. bicornis $\left(\mathrm{F}_{4,16}=1,82 ; p=0,17\right)$ e $P$. lineare $\left(\mathrm{F}_{4,20}=2,37 ; p=0,09\right)$ e no teor de nitrogênio para A. bicornis $\left(\mathrm{F}_{4,16}=1,07 ; p=0,40\right)$ e A. leucostachyus $\left(\mathrm{F}_{4,16}=\right.$ $1,72 ; p=0,20)$.

As espécies arbustivas apresentaram maiores concentrações de nitrogênio $\left(1,26 \pm 0,24 \% ; t_{65,49}=-11,90 ; p<0,01\right)$ e enxofre $\left(0,08 \pm 0,01 \% ; t_{61,39}=-8,50 ; p<0,01\right)$, enquanto o teor de carbono não apresentou variação entre os hábitos estudados $\left(t_{65,49}=1,17\right.$; $p=0,24)$.

Quando se avaliou os teores de nutrientes em conjunto pela LDA, observou-se, entretanto, que o local de coleta apresentou menor influência, podendo-se distinguir parte das espécies, principalmente as duas arbustivas que se separaram entre si e em relação as gramíneas (Figura 5). Pela análise discriminante linear, observou-se que $74 \%$ da variação foram explicados pelo primeiro eixo, separando as espécies, sobretudo pelo teor de carbono, enquanto o segundo eixo explicou $24 \%$ da variação, separando as espécies especialmente pelo teor de nitrogênio. 
Tabela 2 - Teor de carbono (C), nitrogênio (N) e enxofre (S) foliar para cinco espécies herbáceo-arbustivas amostradas em cinco Veredas no Distrito Federal, Brasil. Média \pm desvio padrão.

\begin{tabular}{|c|c|c|c|c|c|c|}
\hline & & Teor & & $\begin{array}{c}\text { Poaceae } \\
\text { (herbáceas) }\end{array}$ & \multicolumn{2}{|c|}{ Melastomataceae (arbustivas) } \\
\hline & & $\mathrm{C}(\%)$ & & $46,10 \pm 1,55^{\mathrm{a}}$ & \multicolumn{2}{|c|}{$45,10 \pm 5,34^{\mathrm{a}}$} \\
\hline & & $\mathrm{N}(\%)$ & & $0,76 \pm 0,14^{a}$ & \multicolumn{2}{|c|}{$1,26 \pm 0,24^{b}$} \\
\hline & & $\mathrm{S}(\%)$ & & $0,06 \pm 0,02^{\mathrm{A}}$ & \multicolumn{2}{|c|}{$0,08 \pm 0,01^{\mathrm{B}}$} \\
\hline $\begin{array}{l}\text { Unidade de } \\
\text { Conservação }\end{array}$ & & ESECAE & FLONA & IBGE & JBB & PNB \\
\hline \multirow{3}{*}{ A. bicornis } & $\mathrm{C}(\%)$ & $46,76 \pm 0,26^{\mathrm{a}}$ & $46,97 \pm 0,50^{\mathrm{a}}$ & $47,53 \pm 0,33^{\mathrm{a}}$ & $47,11 \pm 0,53^{\mathrm{a}}$ & $47,33 \pm 0,28^{a}$ \\
\hline & $\mathrm{N}(\%)$ & $0,64 \pm 0,06^{a}$ & $0,61 \pm 0,07^{a}$ & $0,60 \pm 0,03^{a}$ & $0,69 \pm 0,05^{a}$ & $0,64 \pm 0,07^{a}$ \\
\hline & $\mathrm{S}(\%)$ & $0,05 \pm 0,01^{\mathrm{AB}}$ & $0,04 \pm 0,00^{\mathrm{B}}$ & $0,05 \pm 0,00^{\mathrm{AB}}$ & - & $0,08 \pm 0,02^{\mathrm{A}}$ \\
\hline \multirow{3}{*}{ A.leucostachyus } & $\mathrm{C}(\%)$ & - & $45,83 \pm 0,40^{\mathrm{c}}$ & $47,45 \pm 0,39^{\mathrm{a}}$ & $46,42 \pm 0,30^{\mathrm{bc}}$ & $46,82 \pm 0,44^{\mathrm{ab}}$ \\
\hline & $\mathrm{N}(\%)$ & - & $0,82 \pm 0,12^{a}$ & $0,88 \pm 0,06^{a}$ & $0,81 \pm 0,09^{a}$ & $0,96 \pm 0,14^{a}$ \\
\hline & $\mathrm{S}(\%)$ & - & $0,06 \pm 0,00^{\mathrm{A}}$ & $0,05 \pm 0,00^{\mathrm{A}}$ & $0,05 \pm 0,01^{\mathrm{A}}$ & $0,06 \pm 0,01^{\mathrm{A}}$ \\
\hline \multirow{3}{*}{ P. lineare } & $\mathrm{C}(\%)$ & $43,49 \pm 1,59^{\mathrm{a}}$ & $44,48 \pm 2,30^{\mathrm{a}}$ & $46,24 \pm 1,35^{\mathrm{a}}$ & $44,4 \pm 0,66^{\mathrm{a}}$ & $45,78 \pm 0,70^{\mathrm{a}}$ \\
\hline & $\mathrm{N}(\%)$ & $0,88 \pm 0,07^{a}$ & $0,69 \pm 0,06^{b}$ & $0,75 \pm 0,10^{a b}$ & $0,73 \pm 0,05^{a b}$ & $0,86 \pm 0,09^{a}$ \\
\hline & $\mathrm{S}(\%)$ & $0,06 \pm 0,01^{\mathrm{A}}$ & $0,04 \pm 0,00^{\mathrm{A}}$ & $0,07 \pm 0,01^{\mathrm{A}}$ & $0,06 \pm 0,02^{\mathrm{A}}$ & $0,08 \pm 0,03^{\mathrm{A}}$ \\
\hline \multirow{3}{*}{ L. imbricata } & $\mathrm{C}(\%)$ & $42,11 \pm 0,75^{\mathrm{a}}$ & $39,15 \pm 0,39^{c}$ & $40,88 \pm 0,58^{\mathrm{ab}}$ & $39,75 \pm 1,05^{\mathrm{bc}}$ & $39,61 \pm 0,60^{b c}$ \\
\hline & $\mathrm{N}(\%)$ & $01,23 \pm 0,07^{a}$ & $01,16 \pm 0,10^{a b}$ & $1,12 \pm 0,10^{a b}$ & $1,05 \pm 0,06^{a b}$ & $1,04 \pm 0,03^{b}$ \\
\hline & $\mathrm{S}(\%)$ & $0,08 \pm 0,00^{\mathrm{ABC}}$ & $0,09 \pm 0,01^{\mathrm{A}}$ & $0,09 \pm 0,01^{\mathrm{AB}}$ & $0,07 \pm 0,00^{\mathrm{C}}$ & $0,07 \pm 0,01^{\mathrm{BC}}$ \\
\hline \multirow{3}{*}{ T. parviflora } & $\mathrm{C}(\%)$ & $51,8 \pm 0,80^{\mathrm{a}}$ & - & $49,91 \pm 0,76^{\mathrm{b}}$ & $51,13 \pm 0,33^{\mathrm{ab}}$ & $50,44 \pm 0,57^{\mathrm{ab}}$ \\
\hline & $\mathrm{N}(\%)$ & $1,29 \pm 0,05^{b}$ & - & $1,75 \pm 0,14^{a}$ & $1,28 \pm 0,24^{b}$ & $1,33 \pm 0,12^{b}$ \\
\hline & $\mathrm{S}(\%)$ & $0,08 \pm 0,01^{\mathrm{A}}$ & - & $0,10 \pm 0,00^{\mathrm{A}}$ & $0,09 \pm 0,02^{\mathrm{A}}$ & $0,09 \pm 0,01^{\mathrm{A}}$ \\
\hline
\end{tabular}




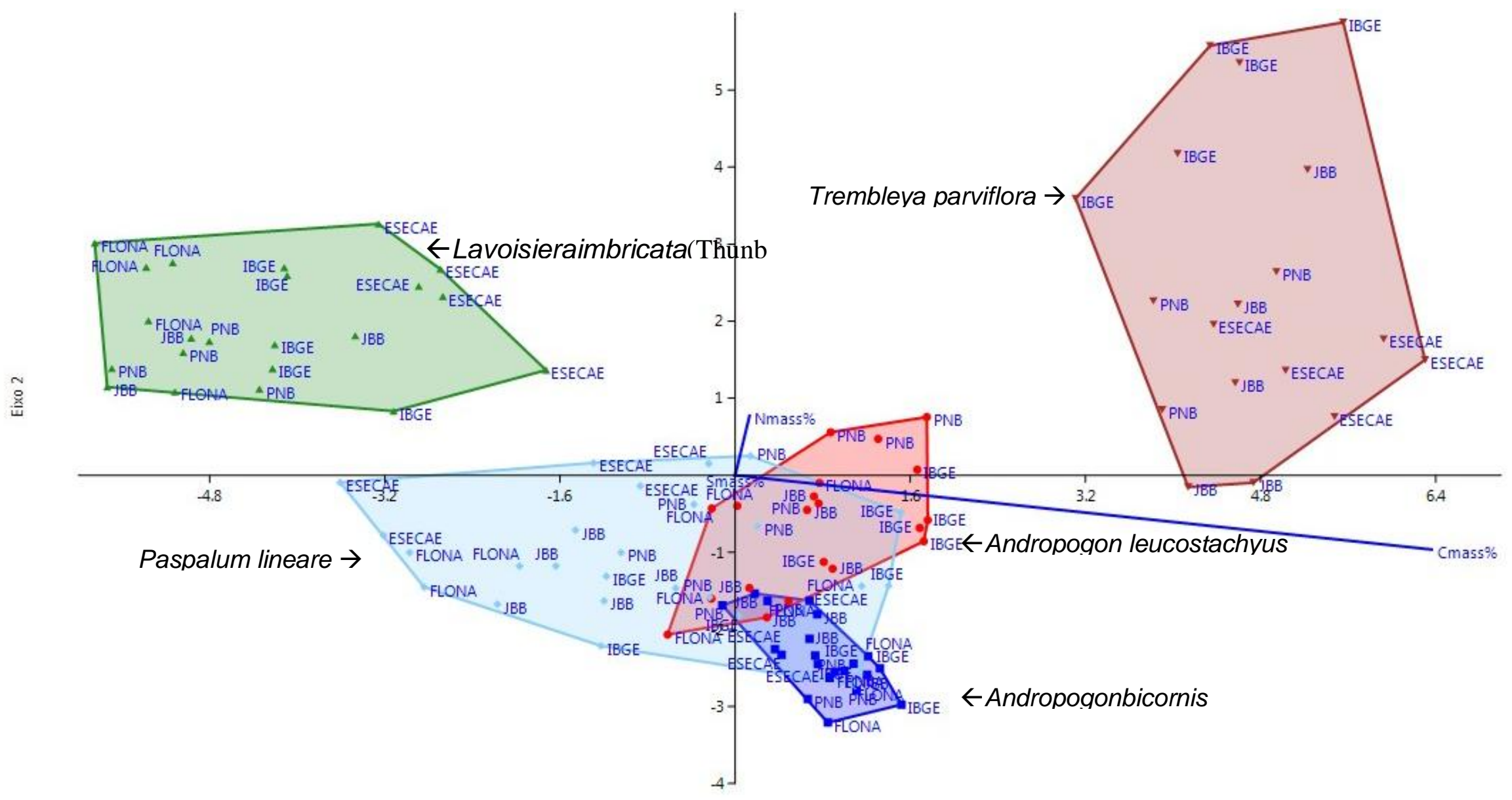

Eixo 1

Figura 5 - Análise discriminante linear (LDA) de cinco espécies herbáceo-arbustivas pelo teor de Carbono (Cmass\%), Nitrogenio (Nmass\%) e Enxofre (Smass\%) coletadas em cinco Veredas no Distrito Federal, Brasil. @ Andropogon bicornis, $\bullet$ A. leucostachyus, $\bullet$ Paspalum lineare, $\boldsymbol{\Lambda}$ Lavoisiera imbricata, $\boldsymbol{\nabla}$ Trembleya parviflora. JBB - Jardim Botânico de Brasília, FLONA - Floresta Nacional de Brasília, PNB - Parque Nacional de Brasília, ESECAE - Estação Ecológica de Águas Emendadas e IBGE - Reserva Ecológica do IBGE. 
Relação entre reflectância foliar e teor de carbono, nitrogênio e enxofre

A reflectância de cada espécie apresentou relação com os teores de carbono, nitrogênio e enxofre. Podendo esses parâmetros ser previstos por meio da PLSR (Tabela 3). O modelo PLSR para concentração de carbono (Figura 6, calibração $R^{2}=0,84$, calibração $\mathrm{RMSE}=1,07 \%$ ) apresentou melhores resultados no modelo global e de validação, seguido pelo nitrogênio na folha (Figura 6 , calibração $R^{2}=0,76$, calibração RMSE $=0,12 \%$ ) e enxofre (Figura 6 , calibração $\mathrm{R}^{2}=0,55$, calibração $\mathrm{RMSE}=0,01 \%$ ). Os três modelos de previsão pela PLSR apresentaram-se adequados para prever as características foliares, porém com maior precisão e menor incerteza para o Nmass e menor precisão e maior incerteza para Smass.

Tabela 3 - Resultadosda modelagem e cross-validation PLSR para os teores de carbono (Cmass\%), nitrogênio (Nmass\%) e enxofre (Smass\%) foliar para cinco espécies herbáceoarbustivas amostradas em cinco Veredas no Distrito Federal, Brasil. Calibração (Cal). Validação (Val). Coeficiente de Determinação $\left(\mathrm{R}^{2}\right)$, Root Mean Square Error (RMSE)

\begin{tabular}{ccccccc}
\hline & & \multicolumn{2}{c}{$\mathbf{R}^{2}$} & \multicolumn{2}{c}{ RMSE } & RMSE \% \\
& \multirow{2}{*}{$N^{\text {o componentes }}$} & Cal. & Val. & Cal. & Val. & Cal. \\
\hline $\mathrm{C}_{\text {mass }}(\%)$ & 15 & 0,84 & 0,83 & 0,92 & 1,4 & 6,54 \\
$\mathrm{~N}_{\text {mass }}(\%)$ & 9 & 0,76 & 0,84 & 0,12 & 0,13 & 8,21 \\
$\mathrm{~S}_{\text {mass }}(\%)$ & 5 & 0,34 & 0,55 & 0,02 & 0,01 & 16,21 \\
\hline
\end{tabular}



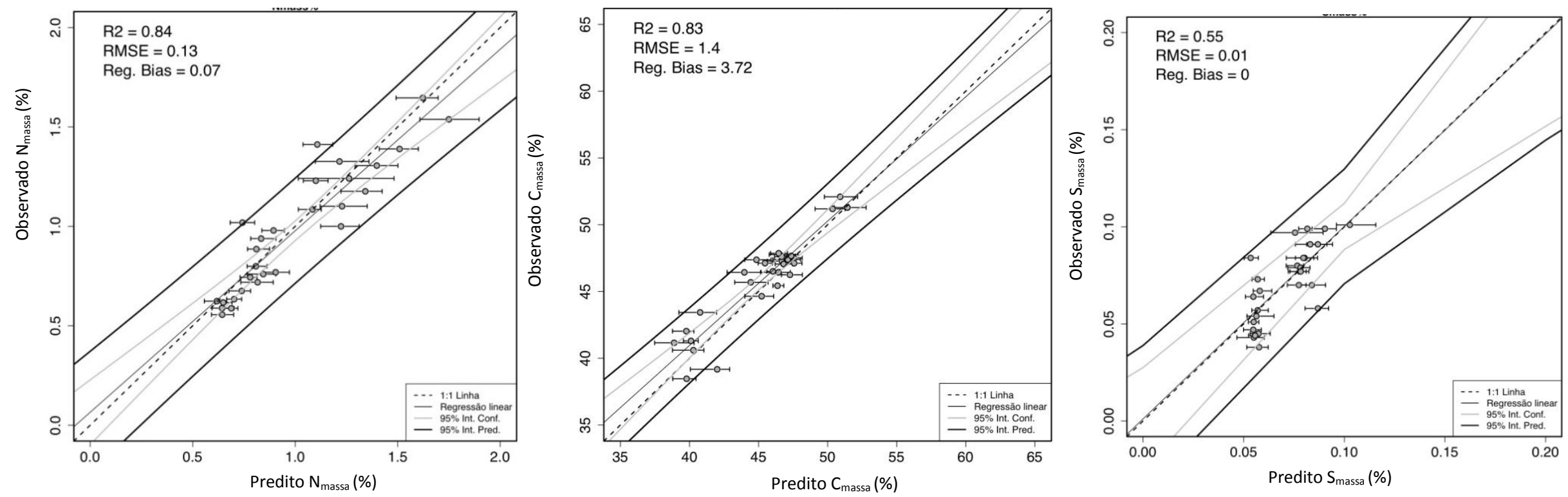

Figura 6 - Resultados da validação de dados independente para a modelagem PLSR (Partial Least-Squares Regression); teor de nitrogênio $\left(\mathrm{N}_{\text {massa }}\right)$, teor de carbono $\left(\mathrm{C}_{\text {massa }}\right)$ e teor de enxofre $\left(\mathrm{S}_{\text {massa }}\right)$. As barras de erro indicam os intervalos de confiança de $95 \%$ para cada valor previsto, enquanto que as linhas pretas denotam os intervalos de predição com $95 \%$ de confiança e linhas cinzentas mostram o intervalo de confiança de 95\% dos modelos. As linhas tracejadas mostram a 1:1, com a linha de regressão mostrado a cinzento claro. PRESS - Prediction Residual Sum of Squares; RMSE - Root Mean Square Error e Coeficiente de Determinação $\left(\mathrm{R}^{2}\right)$. 


\section{DISCUSSÃO}

Apesar da semelhança no comportamento das curvas de refletância espectral de espécies vegetais a combinação da variação em determinados pontos do espectro foi suficiente para separação das espécies. Esses pontos normalmente encontram-se na região superior a $1700 \mathrm{~nm}$, parte onde tem se demonstrado melhor predição entre as espécies (Manevski et al., 2011; Ullah et al., 2012; Durgante et al., 2013; Lang et al. 2015). Isso ocorre porque nessa região do espectro observa-se maior associação da reflectância com a presença de carboidratos, como celuloses, lignina e polissacarídeos. Estes compostos estão relacionados com as estruturas físicas e químicas das folhas e assim respondem melhor ao NIR (Vance et al., 2016).

Associa-se a maior similaridade nos espectros das amostras das Poaceae devido a menor variação morfológica, pois as três espécies apresentam folhas simples lineares concentradas na base das plantas (Munhoz et al., 2011). Enquanto as espécies arbustivas apresentam folhas ao longo de uma copa, ou seja, não se concentram em um único ponto da planta, e apresentam folhas com morfologia de ovada a ovado-oblonga (Munhoz et al., 2011). Essas variações morfológicas e na disposição das folhas na planta refletem de forma indireta no espectro, mesmo em amostras de folhas trituradas e peneiradas. Visto que é possível separar folhas maduras de folhas novas em material triturado (Li et al., 2012;) de modo tão eficiente quanto nas análises feitas em folhas inteiras (Krajsek et al., 2008; Lang et al., 2015), isto porque as características tanto físicas quanto químicas das amostras tornam-se indiretamente presentes nos materiais analisados pelo NIR. A disposição das folhas no ambiente e na copa também afeta a reflectância do material devido à quantidade de incidência solar que atinge a folha e consequentemente nas proporções de pigmentos e nutrientes (Asner, 1998; Castro-Esaú et al., 2006; Manevski et al., 2011).

A menor variação das curvas espectrais dentro da espécie do que entre as áreas de amostragem reforça a ideia de que cada espécie pode ser representada por uma curva espectral, ou seja, por uma assinatura espectral.As assinaturas espectrais têm ajudado a ampliar o monitoramento e manejo de ecossistemas, visto que tem sido utilizadas para acompanhamento da dinâmica de espécies invasoras (Asner et al., 2008; Barbosa et al., 
2016) e para mapear a riqueza de espécies (Clark et al., 2005; Carlson et al., 2007). A separação de espécies pela espectroscopia pode ser utilizada para o monitoramento da expansão das espécies nativas T. parviflora e L. imbricata, pois essas têm reduzido a riqueza de espécies de áreas úmidas (Eugênio, 2011; Santos e Munhoz, 2012).

A estratégia de monitoramento pela espectroscopia já vem sendo empregada para espécies com comportamento invasivo em ilhas havaianas (Asner et al., 2008) e na Califórnia (Hestir et al., 2008). O monitoramento por imagens hiperespectrais com comprimentos de ondas entre 2 a $10 \mathrm{~nm}$ mostra-se promissor para o acompanhamento da dinâmica de áreas de Vereda. Isso porque o componente arbóreo-arbustivo encontrase distribuído de forma concentrada em manchas nessas fitofisionomias (Araújo et al., 2002; Ribeiro e Walter 2008). Dessa forma, as alterações das curvas espectrais em Veredas seriam facilmente reconhecidas com a expansão de espécies arbustivas como $T$. parviflora e L. imbricata sobre áreas predominantemente cobertas por Poaceae.

A expansão do componente arbustivo nas Veredas levaria a uma alteração na paisagem e na composição química desses ambientes, principalmente em relação ao nitrogênio e enxofre que apresentaram maiores teores nas folhas das espécies arbustivas. A predição do teor de $\mathrm{N}$ e $\mathrm{C}$ tem sido bem representada em diversos ecossistemas (Serbin et al., 2014), observando que os modelos de calibração podem ser sugeridos como abordagem rápida e eficaz para a quantificação da variação espacial desses e outros traços foliares. A utilização desses modelos de calibração permite averiguar e caracterizar a diversidade química das folhas e do ecossistema (Asner e Martin, 2008; Asner et al., 2014), permitindo o monitoramento dos preditores de capacidade fotossintética e dos ciclos biogeoquímicos nos ecossistemas. Para o teor de enxofre houve menor precisão e maior incerteza, associa-se a isso o fato do NIR responder melhor aos grupos funcionais $\mathrm{O}-\mathrm{H}, \mathrm{N}-\mathrm{H}$ e $\mathrm{C}=\mathrm{O}$ (Barbosa, 2007). Modelos de predição para o enxofre são pouco explorados (Serbin et al., 2014), necessitando de mais trabalhos para auxiliar na comparação dos teores desse elemento e gerar melhores modelos.

As características químicas e espectrais foliares para as espécies estudadas demonstraram variação espacial, ou seja, pelo local de coleta. As variações no espectro e nas características biofísicas ou bioquímicas dentro da espécie são influenciadas pela pluviosidade (Asner et al., 2009), pela fertilidade do solo (Asner e Martin, 2008) ou 
pela posição da copa (Castro-Esaú et al., 2006). Entretanto, a variação observada nas propriedades químicas e espectrais das folhas de diferentes locais não superou a variação entre as espécies estudadas, assim como foi observado para espécies arbóreas (Castro-Esaú et al., 2006; Asner e Martin, 2008; Asner et al., 2009). Portanto, dentro de uma localidade e de um período é possível diferenciar as principais espécies de um ecossistema pela sua curva espectral. O comportamento espectral em termos de espécie ou paisagem permite estimar padrões de diversidade e conservação da comunidade (Cabacinha e Castro, 2009; Heumann et al., 2015).

\section{CONCLUSÃO}

As espécies comuns em comunidades de Vereda do Distrito Federal apresentam curvas espectrais distintas e independentes do local de ocorrência e estas podem ser utilizadas para estimar o teor foliar de carbono, nitrogênio e enxofre. A diversidade espectral pode servir como subsídio fundamental para compreensão e determinação da diversidade química, abrindo novas portas para o uso de dados hiperespectrais, permitindo futuramente o uso de métodos de modelagens de diversidade e ciclos biogeoquímicos. 


\section{REFERÊNCIAS}

Adam, E., Mutanga, O., \& Rugege, D. (2010). Multispectral and hyperspectral remote sensing for identification and mapping of wetland vegetation: a review. Wetlands Ecology and Management, 18, 281-296.

Amaral, A. G., Munhoz, C. B. R., Eugênio, C. U. O., \& Felfili, J. M. (2013). Vascular flora in dry-shrub and wet grassland Cerrado seven years after a fire, Federal District, Brasil. Check List, 9, 487-503.

Amaral, C. H., Roberts, D. A., Almeida, T. I., \& Souza Filho, C. R. (2015). Mapping invasive species and spectral mixture relationships with neotropical woody formations in southeastern Brazil. ISPRS Journal of Photogrammetry and Remote Sensing, 108, 80-93.

Araújo, G. M., Barbosa, A. A. A., Arantes, A. A., \& Amaral, A. F. (2002). Composição florística de Veredas no Município de Uberlândia, MG. Revista Brasileira de Botânica, 25, 475-493.

Asner, G. P. (1998). Biophysical and biochemical sources of variability in canopy reflectance. Remote Sensing of Environment, 64, 234-253.

Asner, G. P., \& Martin, R. E. (2008). Airborne spectranomics: mapping canopy chemical and taxonomic diversity in tropical forests. Frontiers in Ecology and the Environment, 7, 269-276.

Asner, G. P., \& Martin, R. E. (2011). Canopy phylogenetic, chemical and spectral assembly in a lowland Amazonian forest. New Phytologist, 189, 999-1012.

Asner, G. P., Jones, M. O., Martin, R. E., Knapp, D. E., \& Hughes, R. F. (2008). Remote sensing of native and invasive species in Hawaiian forests. Remote Sensing of Environment, 112, 1912-1926. 
Asner, G. P., Martin, R. E., Ford, A. J., Metcalfe, D. J., \& Liddell, M. J. (2009). Leaf chemical and spectral diversity in Australian tropical forests. Ecological Applications, 19, 236-253.

Asner, G. P., Martin, R. E., Tupayachi, R., Anderson, C. B., Sinca, F., CarranzaJiménez, L., \& Martinez, P. (2014). Amazonian functional diversity from forest canopy chemical assembly. Proceedings of the National Academy of Sciences, $111,5604-5609$.

Barbosa LC (2007) Espectroscopia no infravermelho: na caracterização de compostos orgânicos. Viçosa: Ed. UFV.

Barbosa, J. M., Asner, G. P., Martin, R. E., Baldeck, C. A., Hughes, F., \& Johnson, T. (2016). Determining Subcanopy Psidium cattleianum Invasion in Hawaiian Forests Using Imaging Spectroscopy. Remote Sensing, 8, 1-17.

Belluco, E., Camuffo, M., Ferrari, S., Modenese, L., Silvestri, S., Marani, A., \& Marani, M. (2006). Mapping salt-marsh vegetation by multispectral and hyperspectral remote sensing. Remote Sensing of Environment, 105, 54-67.

Bustamante, M. M. C., Nardoto, G. B., Pinto, A. S., Resende, J. C. F., Takahashi, F. S. C., \& Vieira, L. C. G. (2012). Potential impacts of climate change on biogeochemical functioning of Cerrado ecosystems. Brazilian Journal of Biology, $72,655-671$.

Cabacinha, C. D., \& de Castro, S. S. (2009). Relationships between floristic diversity and vegetation indices, forest structure and landscape metrics of fragments in Brazilian Cerrado. Forest Ecology and Management, 257, 2157-2165.

Carlson, K. M., Asner, G. P., Hughes, R. F., Ostertag, R., \& Martin, R. E. (2007). Hyperspectral remote sensing of canopy biodiversity in Hawaiian lowland rainforests. Ecosystems, 10, 536-549. 
Castro-Esaú, K. L., Sánchez-Azofeifa, G. A., Rivard, B., Wright, S. J., \& Quesada, M. (2006). Variability in leaf optical properties of Mesoamerican trees and the potential for species classification. American Journal of Botany, 93, 517-530.

Chen, S., X. Hong, C. J. Harris, \& P. M. Sharkey. (2004). Spare modeling using orthogonal forest regression with PRESS statistic and regularization. IEEE Transaction on Systems, Man and Cybernetics 34, 898-911.

Chen, H., Song, Q., Tang, G., Feng, Q., \& Lin, L. (2013). The combined optimization of Savitzky-Golay smoothing and multiplicative scatter correction for FT-NIR PLS models. ISRN Spectroscopy, 2013.

Clark, M. L., Roberts, D. A., \& Clark, D. B. (2005). Hyperspectral discrimination of tropical rain forest tree species at leaf to crown scales. Remote Sensing of Environment, 96, 375-398.

Couto Júnior, A. F., Souza, V. V. D., Carvalho Júnior, O. A. D., Martins, É. D. S., Santana, O. A., Freitas, L. F., \& Gomes, R. A. T. (2010). Integração de parâmetros morfométricos e imagem ASTER para a delimitação das fitofisionomias da Serra da Canastra, Parque Nacional da Serra da Canastra, MG. Revista Brasileira de Geomorfologia, 11, 57-68.

Curran, P. J. (1989). Remote sensing of foliar chemistry. Remote Sensing of Environment, 30, 271-278.

Durgante, F. M., Higuchi, N., Almeida, A., \& Vicentini, A. (2013). Species spectral signature: discriminating closely related plant species in the Amazon with nearinfrared leaf-spectroscopy. Forest Ecology and Management, 291, 240-248.

Elvidge, C. D. (1990). Visible and near infrared reflectance characteristics of dry plant materials. Remote Sensing, 11, 1775-1795.

Eugênio, C. U. O. (2011). Dinâmica temporal do estrato herbáceo-arbustivo em comunidades campestres no Brasil Central. Dissertação de Mestrado. Departamento de Engenharia Florestal. Universidade de Brasília. 
Eugênio, C. U. O., Munhoz, C. B. R., \& Felfili, J. M. (2011). Dinâmica temporal do estrato herbáceo-arbustivo de uma área de campo limpo úmido em Alto Paraíso de Goiás, Brasil. Acta Botanica Brasilica, 25, 497-507.

Freitas, S. R., Mello, M. C., \& Cruz, C. B. (2005). Relationships between forest structure and vegetation indices in Atlantic Rainforest. Forest Ecology and Management, 218, 353-362.

Geladi, P., \& B. R. Kowalski. 1986. Partial least-squares regression-a tutorial. Analytica Chimica Acta, 185, 1-17.

Grossman, Y. L., S. L. Ustin, S. Jacquemoud, E. W. Sanderson, G. Schmuck, \& J. Verdebout. (1996). Critique of stepwise multiple linear regression for the extraction of leaf biochemistry information from leaf reflectance data. Remote Sensing of Environment, 56, 182-193.

Guimarães, A. J. M., de Araújo, G. M., \& Corrêa, G. F. (2002). Estrutura fitossociológica em área natural e antropizada de uma Vereda em Uberlândia, MG. Acta Botanica Brasilica, 16, 317-329.

Guyot, G. (1990). Optical properties of vegetation canopies. 19-43. In: Steven, M. D., Clark, J. A. (Eds). Application of Remote Sensing in Agriculture. London, Butterworths.

Hestir, E. L., Khanna, S., Andrew, M. E., Santos, M. J., Viers, J. H., Greenberg, J. A., Rajapakse, S. S. \& Ustin, S. L. (2008). Identification of invasive vegetation using hyperspectral remote sensing in the California Delta ecosystem. Remote Sensing of Environment, 112, 4034-4047.

Heumann, B. W., Hackett, R. A., \& Monfils, A. K. (2015). Testing the spectral diversity hypothesis using spectroscopy data in a simulated wetland community. Ecological Informatics, 25, 29-34.

Kovacs, J. M., Wang, J., \& Flores-Verdugo, F. (2005). Mapping mangrove leaf area index at the species level using IKONOS and LAI-2000 sensors for the Agua 
Brava Lagoon, Mexican Pacific. Estuarine, Coastal and Shelf Science, 62, 377384.

Kumar, L., Schmidt, K. S., Dury, S., \& Skidmore, A. K. (2001). Review of hyperspectral remote sensing and vegetation science. Imaging spectrometry: Basic Principles and Prospective Applications, 111-155.

Krajsek, S., Buh, P., Zega, A., \& Kreft, S. (2008). Identification of herbarium wholeleaf samples of Epilobium species by ATR-IR spectroscopy. Chemistry \& Biodiversity, 5, 310-317.

Lang, C., Costa, F. R. C., Camargo, J. L. C., Durgante, F. M., \& Vicentini, A. (2015). Near infrared spectroscopy facilitates rapid identification of both young and mature Amazonian tree species. PloS One, 10, 1-15.

Li, B., Wei, Y., Duan, H., Xi, L., \& Wu, X. (2012). Discrimination of the geographical origin of Codonopsis pilosula using near infrared diffuse reflection spectroscopy coupled with random forests and k-nearest neighbor methods. Vibrational Spectroscopy, 62, 17-22.

Manevski, K., Manakos, I., Petropoulos, G. P., \& Kalaitzidis, C. (2011). Discrimination of common Mediterranean plant species using field spectroradiometry. International Journal of Applied Earth Observation and Geoinformation, 13, 922933.

Meirelles, M. L.; Guimarães, A. J. M.; Oliveira, R. C.; Araújo, G. M.; \& Ribeiro, J. F. (2004). Impactos sobre o estrato herbáceo de áreas úmidas do Cerrado. 41-68. In: Aguiar, L. M. S.; Camargo, A. J. A. (ed.). Cerrado: ecologia e caracterização. Embrapa Cerrados, Brasília.

Mevik, B. H., \& Wehrens, R. (2007). The pls package: principal component and partial least squares regression in R. Journal of Statistical Software, 18, 1-24. 
Moreira, S. N., Eisenlohr, P. V., Pott, A., Pott, V. J., \& Oliveira-Filho, A. T. (2015). Similar vegetation structure in protected and non-protected wetlands in Central Brazil: conservation significance. Environmental Conservation, 42, 356-362.

Munhoz, C. B. R., Eugênio, C. U. O., \& Oliveira, R. C. (2011). Vereda: guia de campo. Rede de Sementes do Cerrado, Brasília.

Munhoz, C. B. R., \& Felfili, J. M. (2008). Fitossociologia do estrato herbáceosubarbustivo em campo limpo úmido no Brasil Central. Acta Botanica Brasilica, 22, 905-913.

Munhoz, C. B. R., Felfili, J. M., \& Rodrigues, C. (2008). Species-environment relationship in the herb-subshrub layer of a moist Savanna site, Federal District, Brazil. Brazilian Journal of Biology, 68, 25-35.

Munhoz, C. B. R., \& Ribeiro, J. F. (2008) Veredas. 156-162. In: Fonseca, F. O. (org.) Águas Emendadas. Secretaria de Desenvolvimento Urbano e Meio Ambiente, Brasília.

Pasquini C (2003) Near infrared spectroscopy: fundamentals practical aspects and analytical applications. Journal of the Brazilian Chemical Society, 14, 138-219.

Pengra, B. W., Johnston, C. A., \& Loveland, T. R. (2007). Mapping an invasive plant, Phragmites australis, in coastal wetlands using the EO-1 Hyperion hyperspectral sensor. Remote Sensing of Environment, 108, 74-81.

Proisy, C., Couteron, P., \& Fromard, F. (2007). Predicting and mapping mangrove biomass from canopy grain analysis using Fourier-based textural ordination of IKONOS images. Remote Sensing of Environment, 109, 379-392.

R Core Team (2015). R: A language and environment for statistical computing. R Foundation for Statistical Computing, Vienna, Austria. URL https:/www.Rproject.org/. 
Ramoelo, A., Skidmore, A. K., Schlerf, M., Mathieu, R., \& Heitkönig, I. M. (2011). Water-removed spectra increase the retrieval accuracy when estimating savanna grass nitrogen and phosphorus concentrations. ISPRS Journal of Photogrammetry and Remote Sensing, 66, 408-417.

Resende, I. L. D. M., Chaves, L. J., \& Rizzo, J. A. (2013). Floristic and phytosociological analysis of palm swamps in the central part of the Brazilian savanna. Acta Botanica Brasilica, 27, 205-225.

Ribeiro, J. F., \& Walter, B. M. T. (2008). As principais fitofisionomias do bioma Cerrado. 151-199. In: Sano, S. M., Almeida, S. P., \& Ribeiro, J. F. (eds.). Cerrado: Ecologia e flora. Embrapa Cerrados, Brasília.

Rosso, P. H., Ustin, S. L., \& Hastings, A. (2005). Mapping marshland vegetation of San Francisco Bay, California, using hyperspectral data. International Journal of Remote Sensing, 26, 5169-5191.

Santos, F. F. M., \& Munhoz, C. B. R. (2012). Diversidade de espécies herbáceoarbustivas e zonação florística em uma Vereda no Distrito Federal. Heringeriana, 6, 21-27.

Serbin, S. P., D. N. Dillaway, E. L. Kruger, \& P. A. Townsend. 2012. Leaf optical properties reflect variation in photosynthetic metabolism and its sensitivity to temperature. Journal of Experimental Botany, 63, 489-502.

Serbin, S. P., Singh, A., McNeil, B. E., Kingdon, C. C., \& Townsend, P. A. (2014). Spectroscopic determination of leaf morphological and biochemical traits for northern temperate and boreal tree species. Ecological Applications, 24, 16511669.

Silva-França, A. M., \& Sano, E. E. (2011). Mapeamento de áreas de campo limpo úmido no Distrito Federal a partir de fusão de imagens multiespectrais. Sociedade \& Natureza, 23, 197-209. 
Silva-Júnior, M. C., \& Felfili, J. M. (1996). A vegetação da Estação Ecológica de Águas Emendadas. Instituto de Ecologia e Meio Ambiente do Distrito Federal, Brasília.

Ullah, S., Schlerf, M., Skidmore, A. K., \& Hecker, C. (2012). Identifying plant species using mid-wave infrared $(2.5-6 \mu \mathrm{m})$ and thermal infrared $(8-14 \mu \mathrm{m})$ emissivity spectra. Remote Sensing of Environment, 118, 95-102.

Vance, C. K., Tolleson, D. R., Kinoshita, K., Rodriguez, J., \& Foley, J. W. (2016). Near infrared spectroscopy in wildlife and biodiversity. Journal of Nears Infrared Spectroscopy, 24, 01-25.

Vaiphasa, C., Ongsomwang, S., Vaiphasa, T., \& Skidmore, A. K. (2005). Tropical mangrove species discrimination using hyperspectral data: A laboratory study. Estuarine, Coastal and Shelf Science, 65, 371-379.

Wehrens, R. (2011). Chemometrics with R: multivariate data analysis in the natural sciences and life sciences. Springer Science \& Business Media.

Wold, S., Sjöström, M., \& Eriksson, L. (2001). PLS-regression: a basic tool of chemometrics. Chemometrics and Intelligent Laboratory Systems, 58, 109-130.

Zhai, Y., Cui, L., Zhou, X., Gao, Y., Fei, T., \& Gao, W. (2013). Estimation of nitrogen, phosphorus, and potassium contents in the leaves of different plants using laboratory-based visible and near-infrared reflectance spectroscopy: comparison of partial least-square regression and support vector machine regression methods. International Journal of Remote Sensing, 34, 2502-2518.

Zar, J. H. (2010). Biostatistical analysis. $5^{\text {th }}$ Ed. New Jersey, USA.

Zarco-Tejada, P. J., Miller, J. R., Morales, A., Berjón, A., \& Agüera, J. (2004). Hyperspectral indices and model simulation for chlorophyll estimation in opencanopy tree crops. Remote Sensing of Environment, 90, 463-476. 
Zomer, R. J., Trabucco, A., \& Ustin, S. L. (2009). Building spectral libraries for wetlands land cover classification and hyperspectral remote sensing. Journal of Environmental Management, 90, 2170-2177. 